PNL-7830 Vol. 2

UC-245

Subcontractor Report

Development of an Extruder-Feeder Biomass Direct Liquefaction Process

Final Report, Volume 2: Parts 4 - 8

October 1991

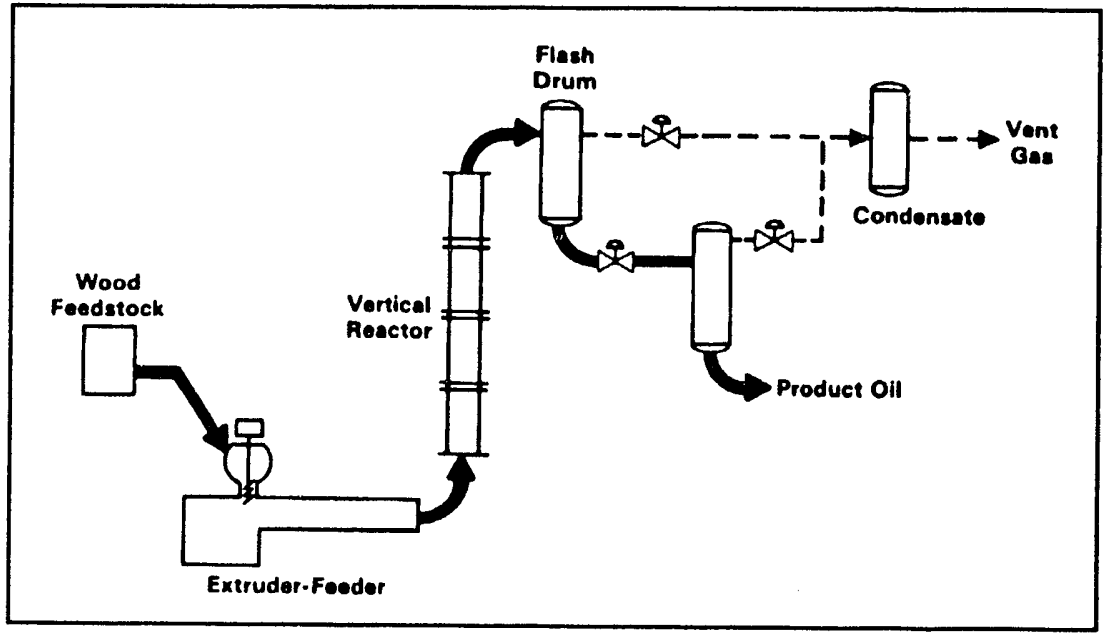

Prepared for the U.S. Department of Energy under Contract DE-AC06-76RLO 1830

Pacific Northwest Laboratory

Operated for the U.S. Department of Energy by Battelle Memorial Institute 


\title{
DISCLAIMER
}

This report was prepared as an account of work sponsored by an agency of the United States Government. Neither the United States Government nor any agency thereof, nor Battelle Memorial Institute, nor any of their employees, makes any warranty, expressed or implied, or assumes any legal liability or responsibility for the accuracy, completeness, or usefulness of any information, apparatus, product, or process disclosed, or represents that its use would not infringe privately owned rights. Reference herein to any specific commercial product, process, or service by trade name, trademark, manufacturer, or otherwise does not necessarily constitute or imply its endorsement, recommendation, or favoring by the United States Government or any agency thereof, or Battelle Memorial Institute. The views and opinions of authors expressed herein do not necessarily state' $r$ reflect those of the United States Government or any agency thereof.

\author{
PACIFIC NORTHWEST LABORATORY \\ operated by \\ BATTELLE MEMORIAL INSTITUTE \\ for the \\ UNITED STATES DEPARTMENT OF ENERGY \\ under Contract DE-ACO6-76RLO 1830
}

Printed in the United States of America

Available to DOE and DOE contractors from the

Office of Scientific and Technical Information, P.O. Box 62, Oak Ridge, IN 37831;

prices available from (615) 576-8401. FTS 626-8401.

Available to the public from the National Technical Information Service,

U.S. Department of Commerce, 5285 Port Royal Rd., Springfield, VA 22161. 
PNL- $7830-$ Vol. 2

DE92 003844

\section{DEVELOPMENT OF AN EXTRUDER-FEEDER BIOMASS DIRECT LIQUEFACTION PROCESS}

Final Report; Volume 2: Parts 4-8

Work Period: 1978 - 1988

D. H. White and D. Wolf

Department of Chemical Engineering

University of Arizona

Tucson, Arizona 85721

G. F. Schiefelbein, PNL Project Manager

October 1991

Prepared by the University of Arizona for

Pacific Northwest Laboratory Under Contract DE-AC06-76RLO 1830 with the U.S. Department of Energy under Agreement 006249-A-Q

Pacific Northwest Laboratory

Richland, Washingt' . 99352 


\title{
DEVELOPMENT OF AN EXTRUDER-FEEDER BIOMASS DIRECT LIQUEFACTION PROCESS
}

\begin{abstract}
As an abundant, renewable, doinestic energy resource, biomass could help the United States reduce its dependence on imported oil. Biomass is the only renewable energy technology capable of addressing the national need for liquid transportation fuels. Thus, there is an incentive to develop economic conversion processes for converting biomass, including wood, into liquid fuels. Through research sponsored by the U.S. Department of Energy's Biomass Thermochemical Conversion Program, managed by Pacific Northwest Laboratory $(\mathrm{PNL})^{(a)}$, the University of Arizona has developed a unique biomass direct liquefaction system. The system features a modified single-screw extruder capable of pumping solid slurries containing as high as $60 \mathrm{wt} \%$ wood flour in wood oil derived vacuum bottoms at pressures up to 3,000 psi. By comparison, conventional pumping systems are capable of pumping slurries containing only $10-20 \mathrm{wt} \%$ wood flour in wood oil under similar conditions.
\end{abstract}

The extruder-feeder has been integrated with a unique reactor by the University of Arizona to form a system which offers potential for improving high pressure biomass direct liquefaction technology. The extruder-feeder acts simultaneously as both a feed preheater and a pumping device for injecting wood slurries into a 3,000 psi pressure reactor in the biomass liquefaction process.

An experimental facility was constructed at the University during 1983-84. Following shakedown operations, wood crude oil was produced by mid-1985. During the period January 1985 through July 1988, a total of 57 experimental continuous biomass liquefaction runs were made using White Birch wood feedstock. Good operability was achieved at slurry feed rates up to $30 \mathrm{lb} / \mathrm{hr}$, reactor pressures from 800 to 3,000 psi and temperatures from $350^{\circ} \mathrm{C}$ to $430^{\circ} \mathrm{C}$ under conditions covering a range of carbon monoxide feed rates and

(a) Operated for the U.S. Department of Energy by Battelle Memorial Institute under Contract DE-AC06-76RLO 1830 
sodium carbonate catalyst addition. Crude wood oils containing as little as 6-10 wt\% residual oxygen were produced.

The work is reported in two volumes. Volume 1 contains the Executive Summary, Parts 1 through 3 which cover development and scale-up of the extruder-feeder, and Appendices A through C. Volume 2 contains Parts 4 through 8 covering the design, construction and operation of the continuous liquefaction unit, characterization of the wood oils produced, and conclusions and recommendations. Volume 2 also contains Appendix D, which presents experimental data on the test runs conducted in the experimental liquefaction facility. 


\section{ACKNOWLEDGEMENTS}

This research project and final report was produced by a research team in the Department of Chemical Engineering, University of Arizona, Tucson, Arizona, supplemented by subcontract research at the University of Lowell and special tests by other organizations. The material in this report is the result of efforts by many team members and we wish to express our gratitude. We wish to thank the sponsors for their wholehearted support over the 11-year period, especially Simon Friedrich of the U.S. Department of Energy and Gary Schiefelbein and Don Stevens of Pacific Northwest Laboratory.

\section{PART 1}

Major Investigators: Dr.. Don H. White, Dr. David Wolf, Dr. Nick R. Schott, A. Homaidan, I. Iregbulem.

Other Contributors: M. Ghoddoussi, A. Haddad, J. Hagen, L. Hampel, V. Joshi, D. Kaufman, D. Schott, S. Gonzales.

\section{PART 2}

Major Investigators: Dr. Don H. White, Dr. David Wolf, Dr. Nick R. Schott, M. Chehab, A. Haddad, A. Lezzar, L. Yang.

Other Contributors: L. Hampel, D. Schott, S. Gonzales.

\section{PART 3}

Major Investigators: Dr. Don H. White, Dr. David Wolf, Dr. Nick R. Schott.

Other Contributors: A. Homaiden, M. Chehab, A. Lezzar.

\section{PART 4}

Major Investigators: Dr. Don H. White, Dr. David Wolf, Dr. Nick R. Schott, M. Moghaddan, M. Khan, N. Andrews, D. Joshi, B. Reyes, J. Wong.

Other Contributors: H. Elliott (Construction Supervisor), J. Southwell (Plant Supervisor), D. Arbo, J. Arrizon, B. Benard, R. Robles, P. Wood. 


\section{PART 5}

Major Investigators: Dr. Don H. White, Dr. David Wolf, D. Joshi, B. Reyes, J. Wong, G. Davenport, S. Mathews, Y. Zhao.

Other Contributors: P. Wood (Plant Supervisor), D. Arbo, J. Arrizon, B. Benard, T. Bingham, F. Holmes, J. Southwell, M. Porter, L. York, M. Folkerts, G. Hopper, J. Risser, K. Stuffle.

\section{PART 6}

Major Investigators: Dr. Don H. White, Dr. David Wolf, J. Wong, B. Reyes, D. Joshi, G. Davenport, S. Mathews, Y. Zhao.

Other Contributors: M. Porter (Plant Supervisor), S. Risser, K. Stuffle, L. York, R. Felty, W. Clemons, C. Chen, R. Felty, A. Maya, T. Kuhl, J. Hawkins, D. Sabalesky.

\section{PART 7}

Major Investigators: Dr. Don H. White, Dr. David Wolf, Y. Zhao, R. Cranford.

Other Contributors: Dr. Don H. White, Dr. David Wolf.

\section{CONTRIBUTING ORGANIZATIONS}

1. University of Lowell

Scale-up data and calculations, experimental data upon Plasticorder work, viscous dissipation and Instron capillary rheology for model PE fluids and wood flour slurries.

2. Pacific Northwest Laboratory

Analysis and properties of Albany TR-9 and TR-12 crude wood oils, analytical assistance.

3. Rensselaer Polytechnic Institute

Surface friction coefficients for wood flour slurries and related materials.

4. HPM Corporation

Experimental scale-up data on a larger single screw extruder for wood flour slurries, operating and cost data on large single sçrew extruders. 
5. Werner \& Pfleiderer Corporation

Evaluation of wood flour slurry extrusion in a twin screw extruder.

6. Solar Energy Research Institute

Pyrolysis mass spectroscopy upon University of Arizona wood oils and Albany vacuum bottoms.

7. Berstorff Corporation

Operating and cost data on large single screw extruders.

8. Davis-Standard Division, Crompton \& Knowles Corporation

Operating and cost data on single screw extruders.

9. Farrel Corporation

Operating and cost data on large single screw extruders.

10. Midland Ross Company

Operating and cost data on large single screw extruders.

11. Welex, Inc.

Operating and cost data on large single screw extruders.

12. Exxon Chemical Company

Sharing information on high-pressure liquefaction equipment.

13. Hydrocarbon Research, Inc.

Sharing information on high-pressure liquefaction equipment.

14. Sandia Laboratories

Supported Dr. White as a visiting professor for two summers to assist and exchange technology on laboratory pilot plant scale for coal liquefaction.

15. U.S. DOE North Dakota Laboratory

Sharing information on high-pressure liquefaction equipment. 
16. Colorado School of Mines

Sharing information on high-pressure liquefaction equipment.

17. Laramie Bureau of Mines

Sharing information on high-pressure liquefaction processes.

18. University of Utah

Sharing information on high-pressure liquefaction equipment.

19. University of California LBL Laboratories

Sharing information on biomass liquefaction processes.

20. Rust Engineering

Sharing information on biomass liquefaction processes.

21. Autoclave Engineers, Inc.

Sharing information on high-pressure liquefaction equipment, especially autoclaves, valves and seals.

22. Fluor Corporation

Review of extruder-feeder biomass liquefaction unit design.

23. Union Oil Company

Sharing information on vacuum distillation of heavy oils to produce vacuum bottoms.

24. Chevron Oil Company

Sharing information on vacuum distillation of heavy oils to produce vacuum bottoms.

25. National Institute for Petroleum and Energy Research

Sharing information on vacuum distillation of heavy oils in Pope Vacuum Stills. 


\section{DISCLAIMER}

The contents of this report are offered as information. The University of Arizona and all technical sources referenced in this report do not (a) make any warranty or representation, expressed or implied, with respect to the accuracy, completeness, or usefulness of the information contained in this report, or that the use of any information, apparatus, muisiod, or process disclosed in this report may not infringe on privately owned rights; (b) assume any liabilities with respect to the use of, or for damages resulting from the use of, any information, apparatus, method, or process disclosed in this report. This report does not reflect official views or policy of the above-mentioned institution. Mention of trade names or commercial products does not constitute endorsement or recommendation for use. 


\section{CONTENTS}

$\underline{\text { Volume } 1}$

EXECUTIVE SUMMARY $\ldots \ldots \ldots \ldots \ldots \ldots \ldots \ldots \ldots \ldots \ldots \ldots \ldots$ ES-1

PART 1 DEVELOPMENT OF A BIOMASS EXTRUDER-FEEDER $\ldots \ldots$ 1-1

PART 2 RHEOLOGY OF WOOD FLOUR SLURRIES $\ldots \ldots \ldots \ldots \ldots .2-1$

PART 3 SCALE-UP OF THE EXTRUDER-FEEDER AND

PRELIMINARY ECONOIMIC EVALUATION $\ldots \ldots \ldots \ldots \ldots$. $3-1$

APPENDIX A EXPERIMENTAL DATA FOR WOOD FLOUR

SLURRIES USING PRODEX EXTRUDER-FEEDER ..... A A-1

APPENDIX B CALCULATIONS OF THE MODIFIED BRINKMAN NUMBER $\ldots \ldots \ldots \ldots \ldots \ldots \ldots \ldots \ldots \ldots \ldots \ldots$ B- 1

APPENDIX C CALCULATIONS FOR SCALE-UP FOR EXTRUDER-FEEDER $\ldots \ldots \ldots \ldots \ldots \ldots \ldots \ldots$

Volume 2

PART 4 DESIGN AND CONSTRUCTION OF AN ADVANCED BIOMASS EXTRUDER-FEEDER DIRECT LIQUEFACTION FACILITY . . . .

PART 5 SHAKE-DOWN OPERATIONS AND INITIAL EXPERIMENTAL RUNS $\ldots \ldots \ldots \ldots \ldots \ldots \ldots \ldots \ldots \ldots$

PART 6 EXPERIMENTAL OPERATION OF CONTINUOUS BIOMASS LIQUEFACTION UNIT $\ldots \ldots \ldots \ldots \ldots \ldots \ldots \ldots .6 . \ldots \ldots$

PART 7 CHARACTERIZATION OF THE WOOD OILS $\ldots \ldots \ldots \ldots \ldots$ 7-1

PART 8 CONCLUSIONS AND RECOMMENDATIONS ............ 8-1

APPENDIX D EXPERIMENTAL DATA ON THE CONTINUOUS EXTRUDER-FEEDER LIQUEFACTION RUNS 


\section{PART 4}

Design and Construction of an Advarced Biomass

Extruder-Feeder Direct Liquefaction Facililty 


\section{PART 4}

\section{DESIGN AND CONSTRUCTION OF AN ADVANCED BIOMA.SS EXTRUDER-FEEDER DIRECT LIQUEFACTION FACILITY}

4.1 INTRODUCTION ......................... 4 4-1

4.2 PHYSICAL FACILITIES $\ldots \ldots \ldots \ldots \ldots \ldots \ldots \ldots \ldots \ldots$ 4-1

4.3 PROCESS DESIGN $\ldots \ldots \ldots \ldots \ldots \ldots \ldots \ldots \ldots \ldots \ldots \ldots \ldots$. . . . . . . . . .

4.3.1. Design Basis . . . . . . . . . . . . . . . . . . . . . 4-2

4.3.2. Process Equipment . . . . . . . . . . . . . . . . . . 4-4

4.3.3. Summary Process Description . . . . . . . . . . . . . . 4-11

4.3.4. Extruder-Feeder System .................... 4-11

4.3.5. Carbon Monoxide System ... . . . . . . . . . . . . . 4 4-12

4.3.6. Superhsated Steam System ... . . . . . . . . . . . . . 4-12

4.3.7. Sodium Carbonate Catalyst System . . . . . . . . . . . . . . . . 4-12

4.3.8. Solvent Flush System . . . . . . . . . . . . . . . . . 4-12

4.3.9. Gas Dispersion System . . . . . . . . . . . . . . . . . 4 4-12

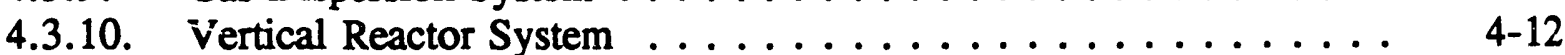

4.3.11. Pressure Let-down System ... . . . . . . . . . . . . . 4 4-13

4.3.12. Product and Process Sampling ... . . . . . . . . . . . . . 4 4-13

4.3.13. Real-Time Microprocessor Control System . . . . . . . . . . . . 4 4-13

4.3.14. Mass Balance Model for Experimental Unit . . . . . . . . . . . . 4- 43

4.3.15. Detailed Design of Superheated Steam System . . . . . . . . . . . . 4-18

4.3.15. Design of Real-time Computer Process Control System . . . . . . . 4-31

4.4 IMPLEMENTATION OF THE REAL-TIME COMPUTER PROCESS CONTROL SYSTEM . . . . . . . . . . . . . . . 4-43

4.4.1. Extruder-Feeder Control System . . . . . . . . . . . . . . 4-43

4.4.2. Carbon Monoxide Control System . . . . . . . . . . . . . . . . 4 4-43

4.4.3. Superheated Steam Control System . . . . . . . . . . . . . . . . 4 4-43

4.4.4. Vertical Reactor Control System ... . . . . . . . . . . . . . 4 4-44

4.4.5. Off-Gas Pressure Let-down Vessel Control System . . . . . . . . . . 4-44

6.4.6. Liquid-Product Pressure Let-Down Vessel Control System . . . . . 4-44

4.4.7. Extruder-Feeder Sensors . . . . . . . . . . . . . . . . . 4 4-45

4.4.8. Superheated Steam Sensors System . . . . . . . . . . . . . 4-45

4.4.9. Vertical Reactor Control Sensors . . . . . . . . . . . . . . . 4-50

4.4.10. Off-Gas Pressure Let-Down Vessel Control Sensors . . . . . . . . 4-52

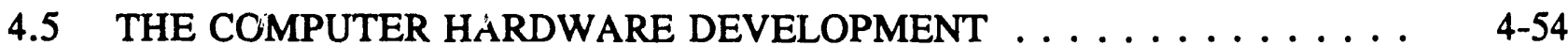

4.5.1. Interface Control Hardware . . . . . . . . . . . . . . 4-54 
4.5.2. Process Control Hardware . . . . . . . . . . . . . . 4-55

4.5.3. The Software Design ... . . . . . . . . . . . . . . 4-57

4.5.4. Data Acquisition Strategy .................. 4-61

4.6. CONSTRUCTION OF LIQUEFACTION PLANT $\ldots \ldots \ldots \ldots \ldots \ldots$. . . . . .

4.6.1. Process Structure and Concrete Pads . . . . . . . . . . . . . . 4-61

4.6.2. Major Process Equipment ................... 4 4-61

4.6.3. Disruption of Construction . . . . . . . . . . . . . . 4-64

4.6.4. Completion of Construction ................. 4-64

5.0 NOMENCLATURE $\ldots \ldots \ldots \ldots \ldots \ldots \ldots \ldots \ldots \ldots \ldots \ldots$ 4.70

6.0 REFERENCES FOR PART $4 \ldots \ldots \ldots \ldots \ldots \ldots \ldots \ldots \ldots \ldots$ 4-71

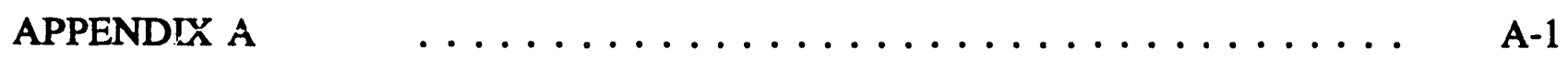

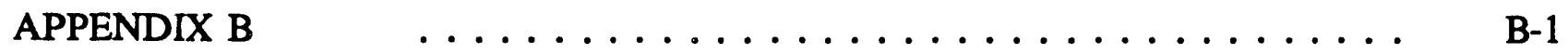

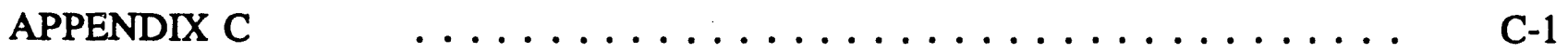




\section{LIST OF TABLES}

Table

Page

4.1. Biomass Liquefaction Reactor Effluent Composition (Basis: $1 \mathrm{hr}$ ). . . . . . 4-19

\section{LIST OF FIGURES}

\section{Figure}

$\underline{\text { Page }}$

4.1. The Overall Flow Diagram of the Extruder-Feeder-

Reactor Biomass Liquefaction Unit . . . . . . . . . . . . . . . .

4.2. Detailed Drawing of Extruder-Feeder . . . . . . . . . . . . . . . . . . 4-6

4.3. Detailed Drawing of Extruder-Feeder/Reactor Interconnection Section ................... 4. . . . . . . . . . . .

4.4. Detailed Drawing of Reactor (Section A) . . . . . . . . . . . . . . . 4-8

4.5. Detailed Drawing of Reactor (Section B) . . . . . . . . . . . . . . . . . 4-9

4.6. Detailed Drawing of Pressure Let-Down Vessel . . . . . . . . . . . . . . . 4-10

4.7. Process Schematic for Overall Mass Balance . . . . . . . . . . . . . . . . . 4-14

4.8. Composition of Streams from the Flash Drum as Calculated by the Mass Balance Equation . . . . . . . . . . . 4-15

4.9. Detailed Schematic Diagram of Water Treatment System . . . . . . . . . . . . 4-21

4.10. Detailed Vaporizer Process Diagram . . . . . . . . . . . . . . . . . . . . 4-22

4.11. Vaporizer Schematic for Dynamic Modeling . . . . . . . . . . . . . . . . . 4-23

4.12. Effect of Liquid Level on Temperature Development

in Vaporizer for a Heating Rate of $42,000 \mathrm{BTU} / \mathrm{h} \ldots$. . . . . . . 4-25

4.13. Schematic of Superheater Internals.

(All Dimensions are in Inches) . . . . . . . . . . . . . 4 4-26

4.14. Detailed Superheater Process Diagram . . . . . . . . . . . . . . . . . . . 4-28

4.15. Steam Temperature Profiles in Superheater . . . . . . . . . . . . . . . . . 4 4-29

4.16. Extruder Barrel for Vaporizer, As Received.

(All Dimensions are in Inches) . . . . . . . . . . . . . 4-30 4 4.

4.17. Short-time Tensile and Allowable Stresses for 316 SS and Inconel $625 \ldots \ldots \ldots$ 4. . . . . . . . . . . . . . . . . . . .

4.18. Stresses to Produce Rupture after $1,000 \mathrm{~h}$ of Operation . . . . . . . . . . 4-33

4.19. Real-Time Program Structure . . . . . . . . . . . . . . . . . . 4-35

4.20. KIM Microcomputer System . . . . . . . . . . . . . . . . . . . . . . 4-36

4.21. Biomass Liquefaction Process Control Schematic . . . . . . . . . . . . . . 4-37

4.22. Multi-variable Block Diagram for Biomass

Process Control . . . . . . . . . . . . . . . . . . . 4-38

4.23. Franklin Microcomputer Control Hardware . . . . . . . . . . . . . . . . . 4-39

4.24. Schematic Instrumentation Layout for the Extruder-Feeder System . . . . . . . . . . . . . . . . . 4-46 
4.25. Schematic of Detail Mounting of Instrumentation

on the Extruder-Feeder Barrel . . . . . . . . . . . . . . . . 4 4-47

4.26. Tubing Length to Isolate Transducer

from Temperature Source . . . . . . . . . . . . . . . . . 4-48

4.27. Schematic Instrumentation Layout for

the Superheated Steam System . . . . . . . . . . . . . . . . . 4-49

4.28. Schematic Instrumentation for the Vertical Reactor System . . . . . . . . . 4-51

4.29. Schematic Instrumentation Layout for the

Off-Gas Let-Down Vessel System ... . . . . . . . . . . 4-53

4.30. Franklin ACE-1200 Microcomputer System

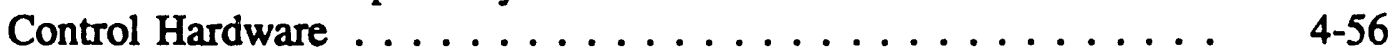

4.31. Op-Amps Circuit for the Thermocouples . . . . . . . . . . . . . . . 4-58

4.32. N-Number of Thermocouples Interfacing with

Electronic Cold Junction . . . . . . . . . . . . . . . . . 4-59

4.33. Op-Amps Circuit for the Voltage-to-Current

conversion for the DAC ............... 4-60

4.34. Schematic Diagram of the Multiplexer Circuit for

the 16 Channel to 128 Channels ... . . . . . . . . . . . 4-62

4.35. Site of Extruder-Feeder Biomass Liquefaction Facility . . . . . . . . . . . 4-65

4.36. Major Equipment Components of Extruder-Feeder 66

Liquefaction Facility . . . . . . . . . . . . . . 4-66 . . . . . . . . .

4.37. Details of Extruder-Feeder . . . . . . . . . . . . . . . . . . . . . . . . . . . . . . . . . . . . . . . . . .

4.38. Typical Commercial Single Screw Extruder . . . . . . . . . . . . . . . . . 4-68

4.39. Technical Operator Showing Viscosity of

Hot Crude Wood Oil . . . . . . . . . . . . . . . 4-69 


\section{PART 4}

\section{DESIGN AND CONSTRUCTION OF AN ADVANCED BIOMASS EXTRUDER-FEEDER DIRECT LIQUEFACTION FACILITY}

\subsection{INTRODUCTION}

A preliminary design and cost estimate was prepared in early 1982 for the construction of a continuous direct liquefaction experimental unit (White 1982). This Phase II would integrate the extruder pumping system with a unique vertical reactor which offered potential for further improving direct biomass liquefaction technology. The cost estimate projected a 15-month period (a) 10 months of mechanical design, purchasing and construction of an experimental unit, followed by (b) five months of shake-down and initial experimental runs.

A delay in work was experienced at this point in time, awaiting review and approval of the funding for the proposed experimental facility. All DOE-funded work on this project was stopped for the period February 1, 1982 - April 20, 1983. The process design was initiated on April 20, 1983 and was completed by about mid-October, 1983. In the meantime, construction began in June, 1983 upon a $27 \mathrm{ft}$. x $80 \mathrm{ft}$. process area, pouring four footings for a vertical steel process structure and concrete slabs for the process and storage areas. A reinforced concrete block wall was constructed around the process area.

\subsection{PHYSICAL FACILITIES}

The University of Arizona provided space in three existing small buildings at its Campbell Farm, College of Agriculture, about four miles north of the main Campus for this project, and land next to one of these buildings for the biomass liquefaction process area. These buildings were utilized as follows:

\section{Building 2097}

This $20 \mathrm{ft}$. $\mathrm{x} 20 \mathrm{ft}$. building was utilized as a remote microprocessor control room. This did not interfere with its other function as a high-pressure autoclave facility, utilizing its outside autoclave bunker area.

\section{Building 2096}

One office, one large wet chemistry laboratory and a rest room were assigned to this project, with the remainder of the building assigned to Agricultural Engineering.

\section{Building 2098}

This $20 \mathrm{ft}$. $\mathrm{x} 30 \mathrm{ft}$. building served as a storage building for spare equipment, spare parts and miscellaneous storage. 


\subsection{PROCESS DESIGN}

\subsubsection{Design Basis}

A small continuous process unit was sized on the basis of the smallest plasticating single-screw extruder that would give meaningful engineering and operability data. It is generally accepted that this size is 1.75 -inch diameter extruder (laboratory size) compared with the smallest commercial extruder of 2.5 -inch diameter. In order to provide good operability in the handling of solids, the same inside diameter of 1.75 inches was maintained in the vertical reactor.

The experimental unit was designed for day-long runs on a continuous basis, so that some six hours of lined-out operating data could be obtained. Two to four hours of startup time were necessary to reach steady-state operating conditions. This allows the processing of about 150 to 200 pounds of feedstock in a one-day run, or double that amount by running on two successive days. Process operations are controlled remotely by utilizing a real-time computer control system.

A simplified process flow diagram for the biomass liquefaction unit is shown in Figure 4.1. Biomass feedstock enters the cold end of the extruder-feeder, sometimes continuously and sometimes by plastic "cupfuls," but in all cases the extruder-feeder output is at steadystate. The extruder-feeder serves three main purposes, namely, (a) the generation of output pressure, which can be controlled at any desired pressure in the range of 100 psi up to 3,500 psi, (24 MPa) (b) the preheating and the melting of the heavy carrier oil in the feedstock, usually from $80^{\circ} \mathrm{C}$ on up to $150^{\circ} \mathrm{C}$, and (c) the plasticising and mixing of the heavy carrier oil with the wood flour or wood sawdust.

The first reactor configuration chosen for experimentation was a vertical reactor, consisting of two sections with headroom space for additional sections, so that a range of residence times could be studied. Saturated or superheated steam is injected at the spool just prior to the reactor inlet, but band heaters area also utilized along the vertical reactor. Temperatures and pressures can be controlled by the remote real-time computer control systems. Temperatures can be held at any desired point, and to date have been held at $330^{\circ} \mathrm{C}$ up to a maximum temperature of $410^{\circ} \mathrm{C}$. Pressures up to a maximum of 3,000 psi $(20.7 \mathrm{MPa})$, and possibly holding pressures up to $3,500 \mathrm{psi}(24 \mathrm{MPa})$ when operating above the critical temperature were provided for in the design. Provisions with and without the catalyst sodium carbonate. It should be noted that reactive molecular hydrogen was not utilized, but "in-situ" hydrogen was formed by the water gas shift reaction. It is believed that sodium carbonate (and its derivatives in recycle streams) acts as a catalyst both for the liquefaction reactions and for the water gas shift reaction (5). Radioactive tracers (neutronactivated manganese oxide with a 2.46 hour half-life) were to be used in some runs to study residence time, flow patterns and the degree of mixing. Provisions were made to install static mixers, but certain designs were tested only in laboratory flow systems.

A two-stage pressure let-down system was designed originally, but only one stage was constructed and used. In other words, the overhead vapor stream was reduced in pressure 


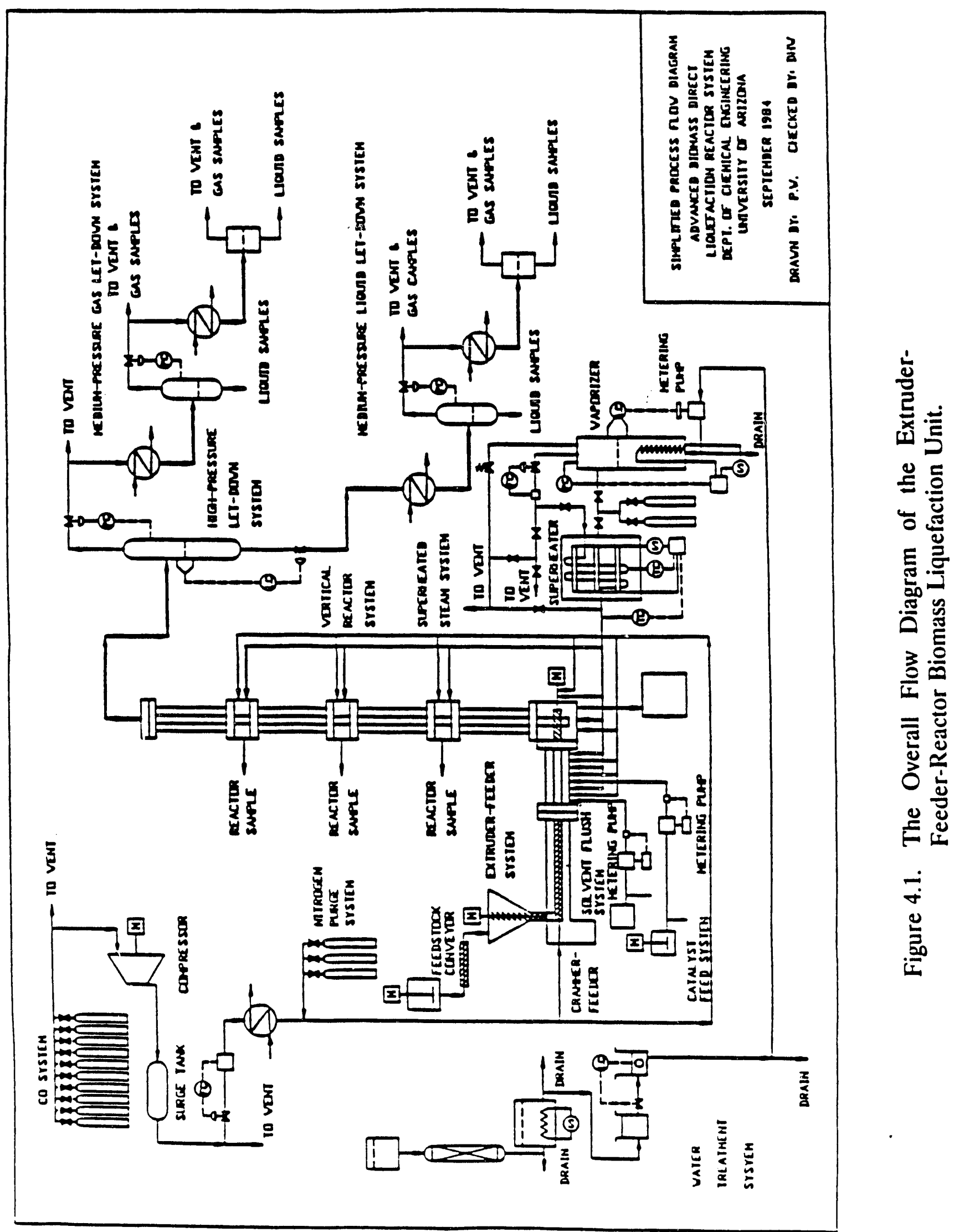


from operating pressure to atmospheric pressure by means of a control valve on the vapor line from the pressure let-down vessel. This is the key control valve for maintaining the desired pressure on the let-down vessel and the vertical reactor, operated remotely by the real-time computer control system. Similarly, the rector effluent liquid product was removed from the bottom of the pressure let-down vessel through one valve to atmospheric pressure.

Carbon monoxide was provided from a bank of cylinders, and compressed to 4,500 psi (31 MPa) by a two-stage reciprocating compressor. The sodium carbonate and some moisture was usually added to the feedstock; however, in many passes simulating recycle streams no additional sodium carbonate is added. A sophisticated steam superheater was designed, constructed and successfully operated. The unit was designed for flow rates of 5 to 40 pounds per hour at up to $3,100 \mathrm{psi}(21.4 \mathrm{MPa})$ and temperatures ranging from the saturation point (about $370^{\circ} \mathrm{C}$ ) to about $800^{\circ} \mathrm{C}$.

The overhead vapors normally contained 5 to 10 percent of the crude wood oil product. Suitable process equipment was installed to handle these light product oils. It is condensed with chilled water and separated into water and oil layers for analyses. The noncondensable gases are passed through a scrubber, normally using a dilute sodium carbonate solution, then passed through a wet gas meter and then vented to the stack. The major portion of the crude wood oil is recovered by batch vacuum distillation from the reactor effluent at two $\mathrm{mm}$ abs. pressure and distillation terminated at $260^{\circ} \mathrm{C}$.

\subsubsection{Process Equipment}

Some of the more significant specifications of the equipment that were installed in the experimental liquefaction unit are as follows:

Crammer-Feeder. Hopper, $3.4 \mathrm{Ft}^{3}$ with $2.6 \mathrm{Ft}^{3}$ working volume, 2-5 rpm screw of Prodex design, 5 Hp DC drive.

Extruder-Feeder. Single-screw, 1.75-inch diameter, 24 L/D Ratio, variable speed 10-10 rpm screw, $15 \mathrm{hp}, 3$-phase, $220 \mathrm{~V}$, chilled water-cooling at feed throat, five heater bands, five pressure transducers and five thermocouples along the barrel.

Vertical Reactor. Two flanged reactor sections, 1.75-inch I.D., Xalloy-lined steel, bottom section 49 inches in length, top section 46 inches in length with steel spools of 1.75-inch I.D. below and above the bottom reactor section, and both sections complete with thermocouples, pressure transducers and inorganic insulation.

Reactor Piping. Extruder-feeder connected to spool below reactor by "a cross" consisting of 26 inches horizontal pipe section, a cross and 26 inches of vertical pipe section, all 1.90inch I.D. Top of reactor connected to pressure let-down vessel by 29 -inch vertical flanged pipe section, $90^{\circ}$ flanged el, 11 -inches of horizontal flanged pipe section and a second $90^{\circ}$ flanged el, all about 1.9-inch I.D., steel construction. 
Pressure Let-Down Vessel. Vertical Flanged Vessel, 3.5-inch I.D. $x 47$ inches height, Xalloylined steel, $3,000 \mathrm{psi}, 350^{\circ} \mathrm{C}$.

Carbon Monoxide Compressor. Aminco 2-stage, 5,250 psig (36.2 MPa) maximum discharge pressure, compressor, $9 \mathrm{scfm}$ maximum flowrate, $10 \mathrm{Hp}, 3$-phase, $220 \mathrm{~V}$.

Flow Valves. Masoneilan Micropack 29000 series control valve, $C_{v}=0.002$ at 3,200 psi $(22.1 \mathrm{MPa}), 360^{\circ} \mathrm{C}$ with electropneumatic transducer.

Pressure Let-Down Valve. Masoneilan Model Wee Willie 6051, $C_{v} 0.00001$ to 0.01 at 3,200 psi $(22.1 \mathrm{MPa}), 370^{\circ} \mathrm{C}$, driven by Amiflow turbine flow meter and controller.

Steam Vaporizer. Vertical flanged vessel, 3.5-inch I.D., 3.5 gal., 3,10 psi (21.4 MPa), 370 ${ }^{\circ} \mathrm{C}$, Xalloy-lined steel, $15 \mathrm{KW}$ electrical heaters, 3-phase $240 \mathrm{~V}$.

Steam Superheater. Tubular hairpin, 0.25-inch I.D., 96-inch length, 316 stainless steel, Inconel 625, 3,100 psi (21.4 MPa), SiC electrical heaters, $7 \mathrm{KW}, 240 \mathrm{~V}$, 3-phase and 120V 1-phase.

Overhead Condenser. Heat exchanger, $5.0 \mathrm{Ft}^{2}$ double-pipe both sides high pressure, $316 \mathrm{SS}$.

Vacuum Distillation Still. Vertical flanged vessel, 4-inch I.D. x 10-feet height, Schedule 40, $316 \mathrm{~S}$, complete with vacuum pump, condenser and auxiliaries for operation at $2 \mathrm{~mm} / \mathrm{Hg}$ abs. pressure up to $360^{\circ} \mathrm{C}$.

Real-Time Computer Control System. Sensors for temperature pressure flowmeters, off-on solenoid valves and alarms controlled remotely by real-time process control software in a remote location. The detailed dimensions of the extruder-feeder, the vertical reactor and the piping/cross connecting the two units are shown in Figures 4.2-4.6.

Other major equipment components are as follows:

1. Feedstock drum with mixer.

2. Screw conveyer, 2-in Dia. x 12' long, steel, $100 \mathrm{rpm}$.

3. Battery rack and manifold for 10 cylinders, $17 \mathrm{SCF} /$ cylinder; 1650 psig at $70^{\circ} \mathrm{F}$.

4. Over-pressure relief valve, 2,000 psig.

5. Surge tank, $600 \mathrm{ft}^{3}$.

6. Over-pressure relief valve, 5,000 psig.

7. Two distilled water holding drums, 55 gal. and 16 gal., steel.

8. Ion exchange column.

9. De-aerator, 18.5 gal. tank, $1.6 \mathrm{kw}$ heater, 110 volt, 7 phase.

10. Treated water holding tanks, 10 gal. and 30 gal., SS.

11. Metering pump, $1 \mathrm{hp}, 6.6 \mathrm{GPH}$ at $4450 \mathrm{psi}, 240 \mathrm{~V}, 3$-phase.

12. Argon purge system, 2 cylinders, $285 \mathrm{SCF} / \mathrm{cylinder}, 270^{\circ} \mathrm{F}$, with rack and regulator.

13. Catalyst holding tank with mixer.

14. Metering pump, $3 \mathrm{hp}, 3000 \mathrm{psig}$ delivery pressure. 


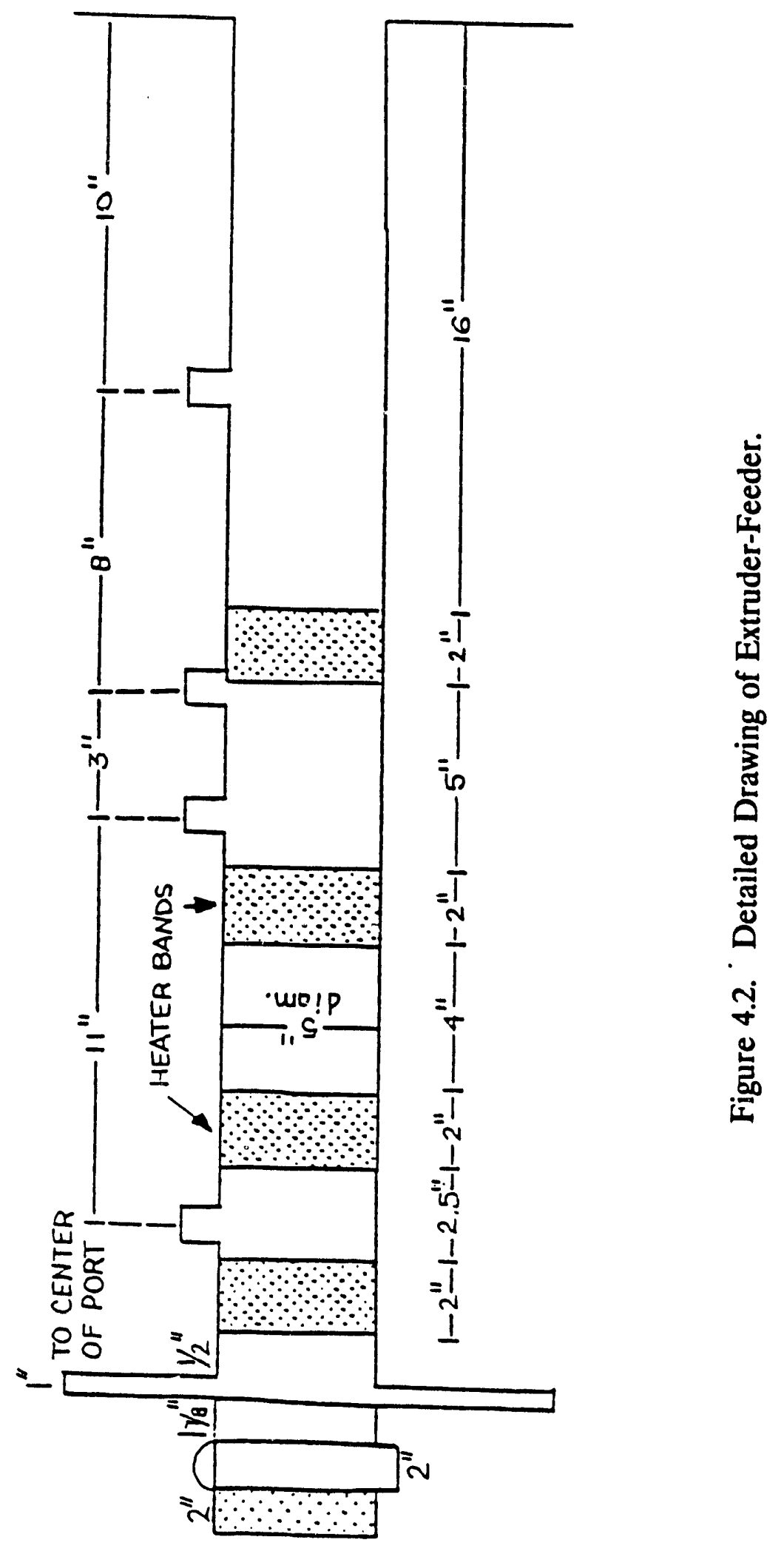




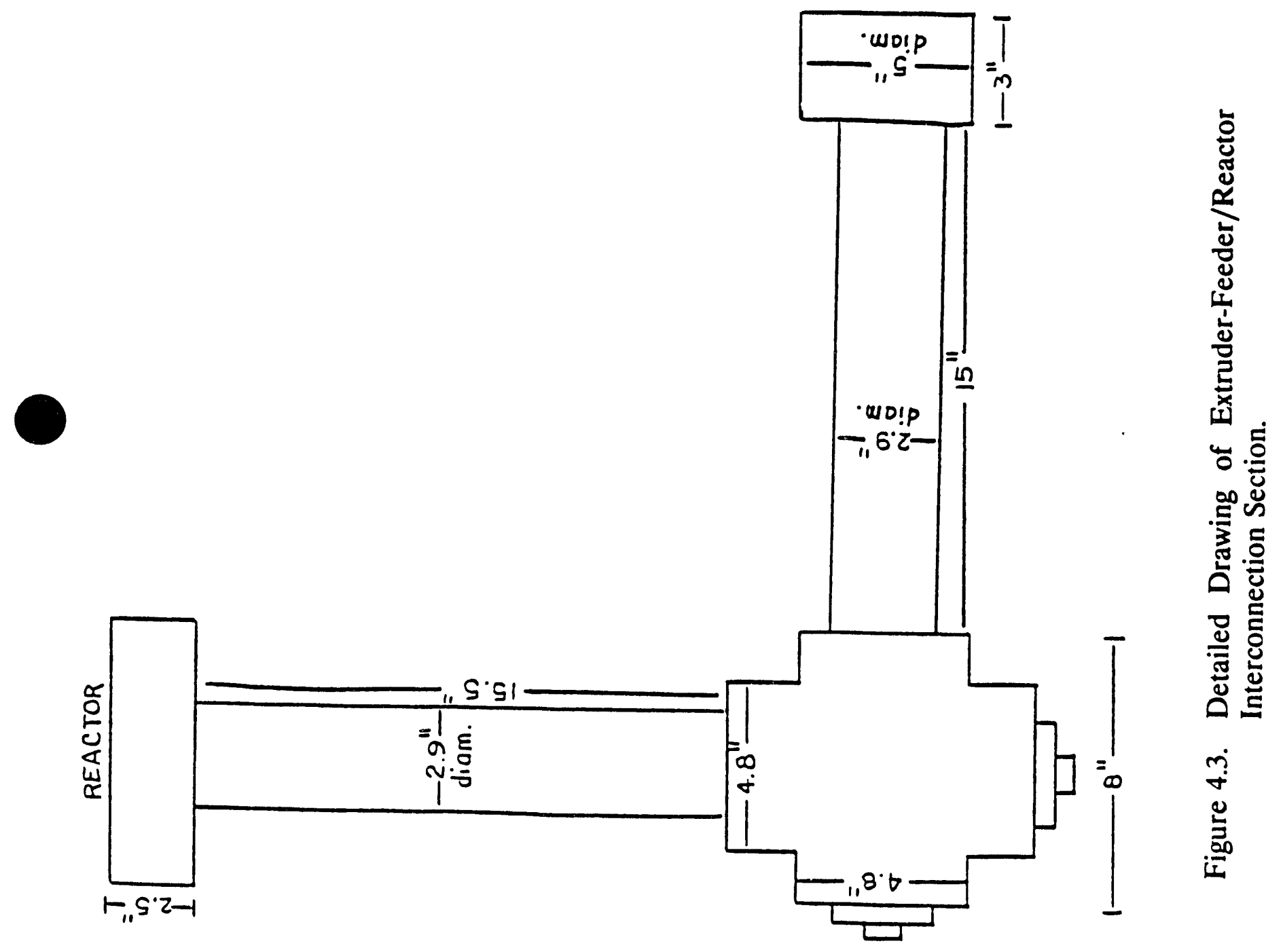




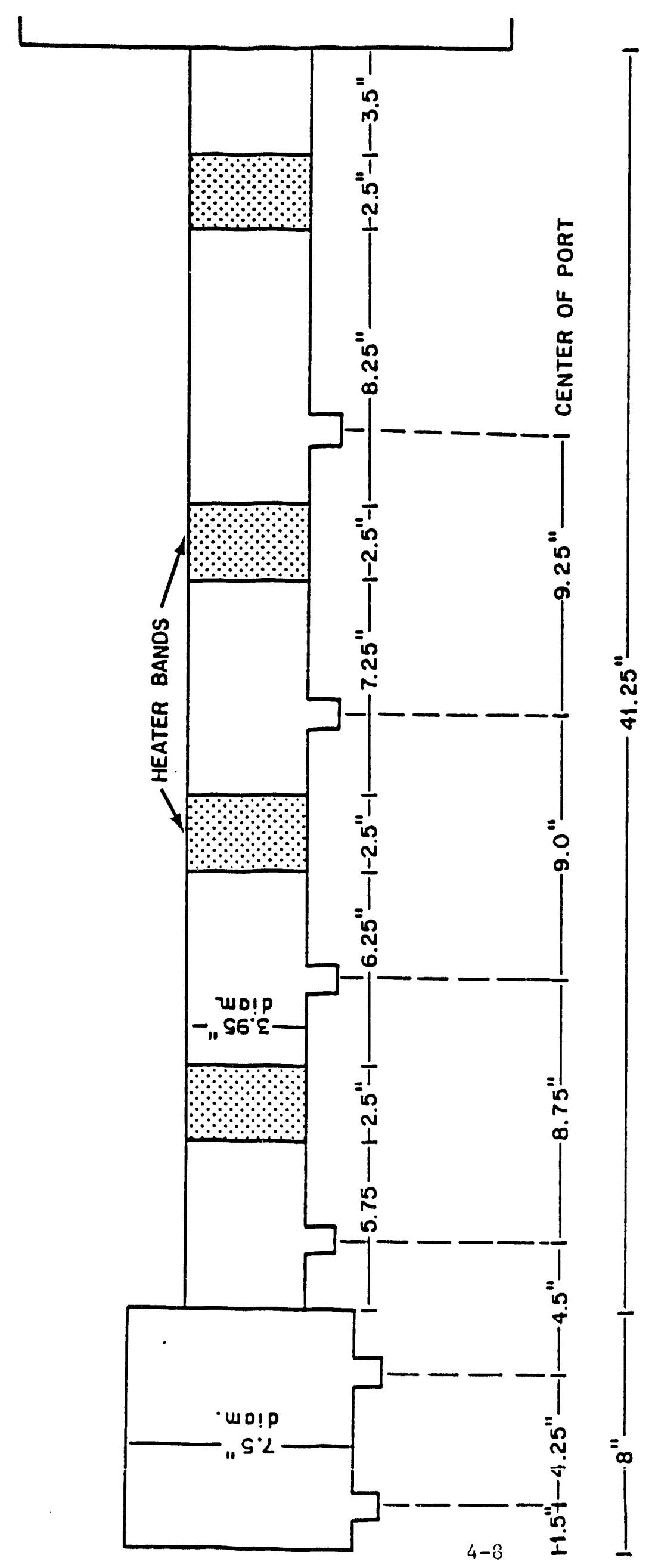

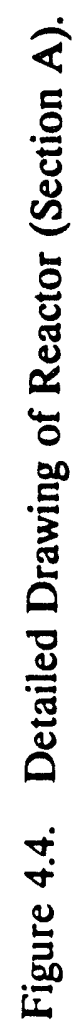




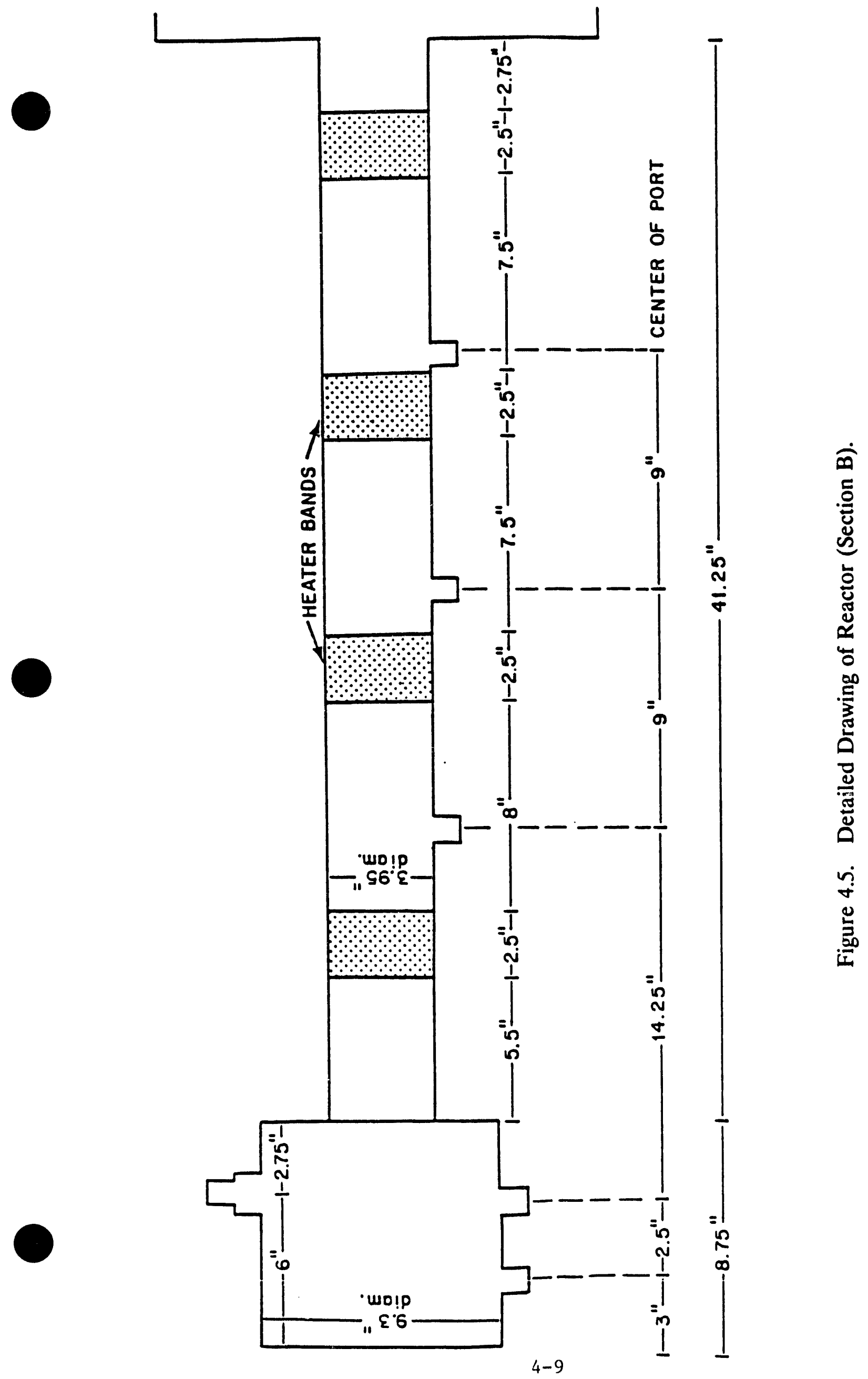




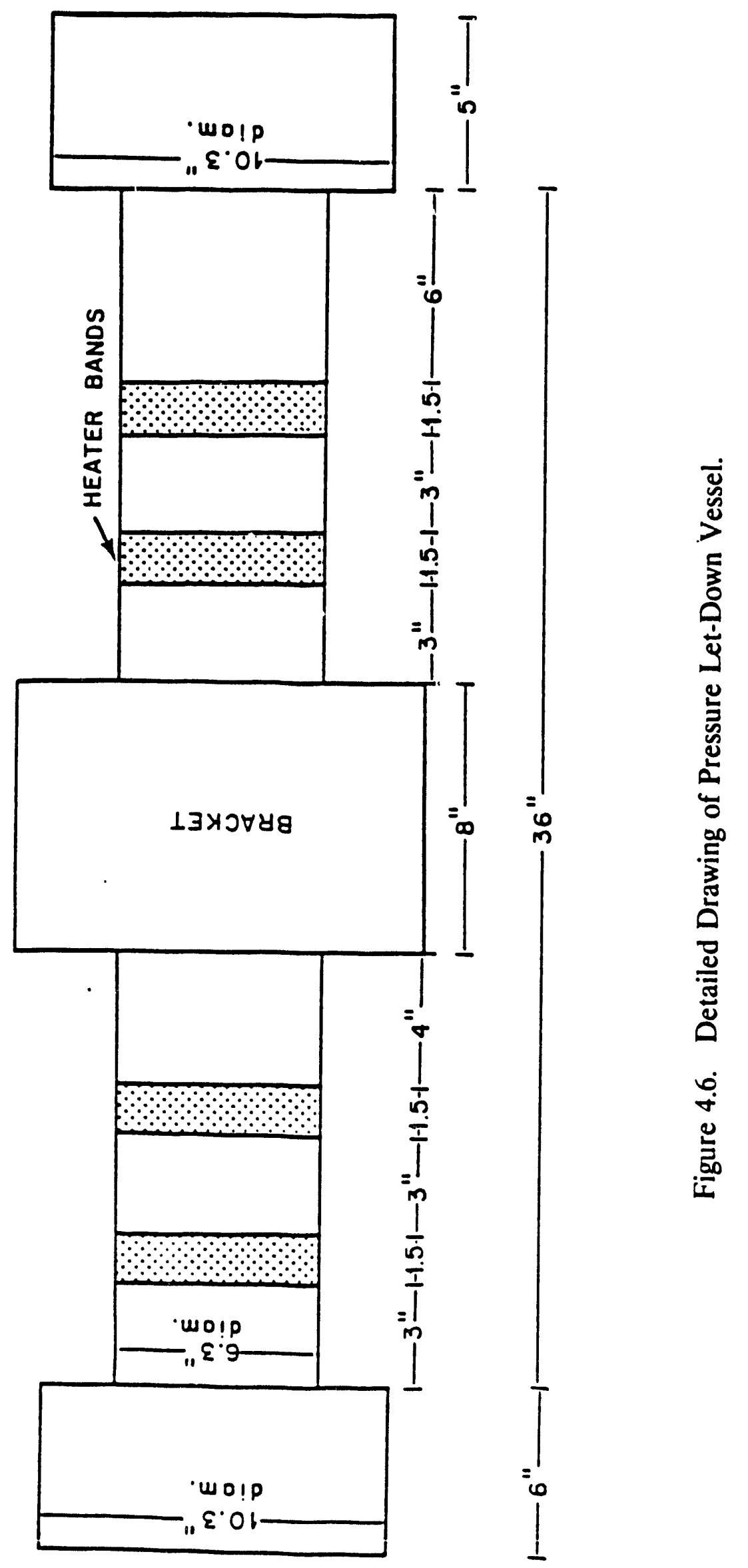


15. Solvent holding tank.

16. Metering pump, $3 \mathrm{hp}, 3000$ psig.

17. Flanged tee with static mixer elements, 1.75" ID with sparge-, 316 stainless steel, 28" length, $18^{\prime \prime}$ offshoot, $3000 \mathrm{psig}, 550^{\circ} \mathrm{C}$.

18. Vapor condenser, double-pipe coiled type, $1.5 \mathrm{ft}^{2}$, inlet $350^{\circ} \mathrm{C}$ outlet $40^{\circ} \mathrm{C}$.

19. Low pressure overhead flash drum, 6.5 gal. stainless steel class 150 flanged connections.

20. Control valve, 300 psi inlet, atmospheric pressure outlet.

21. Cold trap.

22. Product tank.

23. Low pressure flash drum, 100 gal., carbon steel, (Vessel $1100^{\circ} \mathrm{F}, 875 \mathrm{psig}$ ) or at 200 C, $\left(750^{\circ} \mathrm{F}, 495 \mathrm{psig}\right) 400 \mathrm{psi}$.

24. Product tank.

25. Sampling system, dual in-line off/on solenoid valves, downstream normally closed, upstream normally open, stainless steai sample cylinders.

26. Flanged reactor spools, 6" long, 1.175" ID 7" OD with sampling and injector ports.

The liquefaction process was designed so that it could be operated experimentally on a continuous basis as described below.

\subsubsection{Summary Process Description}

The advanced extruder-feeder biomass liquefaction reactor system was designed to experimentally convert wood flour to liquid wood oil fuels by direct liquefaction. The extruder-feeder system was incorporated into the system to develop 3,000 psig pressure at its discharge and preheat the slurry prior to entering the vertical reactor, as shown in $\mathrm{Fi}_{5}$ ure 4.1. As the wood flour slurry enters the reactor it is mixed with superheated steam and carbon monoxide. The superheated steam is used to heat the wood flour slurry to the reaction temperature of 350 to $400^{\circ} \mathrm{C}$ almost instantaneously, which is then maintained by the use of electrical band heaters surrounding the recitor. Steam and carbon monoxide also react via the water-gas shift reaction to provide hydrogen for the liquefaction. The liquefaction products are split into the vapor and liquid fractions, condensed, cooled down and reduced to atmospheric pressure by mean: of the pressure let-down system. Computer control and real-time data acquisition were implemented as an integral part of the unit.

\subsubsection{Extruder-Feeder System}

The extruder-feeder section of the system consists of a mixing drum, a conveyer, a crammer-feeder and an extruder-feeder. A feedstock dium mixes the wood flour and the brittle granular vacuum bottoms into a solid mixture, which is then transported tot he crammer-feeder by a screw conveyer. The crammer-feeder, with an operating capacity of $2.6 \mathrm{ft}^{3}$, feeds the extruder-feeder at a continuous rate. The 1.75-inch diameter single screw extruder-feeder is designed to generate 3,000 psi with flow rates over a range of about 5 to $60 \mathrm{lb}$./h. The extruder-feeder also acts as a preheater, normally to $150^{\circ} \mathrm{C}$, but if desired up to about $250^{\circ} \mathrm{C}$. 


\subsubsection{Carbon Monoxide System}

The carbon monoxide section is a bank of $\mathrm{CO}$ cylinders with a booster compressor to obtain the derived pressure. Carbon monoxide from a 10-cylinder battery was fed to a two-stage, $10 \mathrm{hp}$ compressor which provided up to $40 \mathrm{lb}$./h. of CO at 5,000 psig. Highpressure $\mathrm{CO}$ is accumulated in a surge tank and then fed to the reactor after heating to the reaction temperature. A control valve regulates the $\mathrm{CO}$ flow rate.

\subsubsection{Superheated Steam System}

The steam superheater section provides high-purity water, a vaporizer and a superheater. The steam superheater is designed to deliver $40 \mathrm{lb} . / \mathrm{h}$. of superheated steam at $816^{\circ} \mathrm{C}$ and 3,100 psia. Distilled water is purified by ion-exchange and degassed before feeding it to the vaporizer operating at 3,100 psia and $372^{\circ} \mathrm{C}$. Steam flows through a control valve to the superheater where it is heated to $816^{\circ} \mathrm{C}$. High-temperature corrosion is minimized by keeping an argon atmosphere in the superheater "furnace" chamber.

\subsubsection{Sodium Carbonate Catalyst System}

The sodium carbonate catalyst injection system provides flexibility for experimental purposes. Three systems for introduction of $\mathrm{Na}_{2} \mathrm{CO}_{3}$ are provided: (1) One is soaking the wood flour with a $\mathrm{Na}_{2} \mathrm{CO}_{3}$ solution; (2) introduction of solid $\mathrm{Na}_{2} \mathrm{CO}_{3}$ with the solid feedstock; (3) direct injection system of an aqueous solution of $\mathrm{Na}_{2} \mathrm{CO}_{3}$ using a highpressure metering pump.

\subsubsection{Solvent Flush System}

A solvent flush system has been designed for use during shutdown to flush the reactor with solvent in order to clean it for the next run. Alternatively, hold-up of the reactor can be emptied just by heating the reactor and blowing out the contents.

\subsubsection{Gas Dispersion System}

A series of gas dispersion elements have been designed to disperse superheated steam and carbon monoxide into the viscous wood flour slurry. The initial design is a mixing tee, connecting the vertical reactor with the extruder-feeder. The various ports in the spools between reactor sections can also be used. Some steam and $\mathrm{CO}$ are premixed so the water gas shift reaction will proceed to some extent, even before entering the reactor. Other designs will be incorporated into the system for evaluation purposes.

\subsubsection{Vertical Reactor System}

A vertical reactor system of about 20 feet in height was provided. Initially, two reactor sections to give about $11 \mathrm{ft}$. height were installed. These are steel flanged sections with Xalloy-linings. The flanged sections are connected by spools which allow gas injection and reactor sampling. Electrical heater bands are utilized first for heat-up purposes during 
start-up and second to maintain the outer reactor walls as close as possible to the reaction temperature. In order to increase the reactor throughput and to study a wider range of residence times, two more flanged sections can be added in the existing steel structure.

\subsubsection{Pressure Let-down System}

The pressure let-down system is designed for two stages of lowering the pressure. Only one stage was constructed and utilized in these work pressure let-down system has two purposes: (a) to regulate the reactor pressure at 3,000 psig, and (b) to split the product into its vapor and liquid fractions to be collected at atmospheric pressure. The high-pressure letdown vessel is designed to maintain a liquid level. The pressure of the reactor and the letdown vessel is controlled at 3,000 psi by the rate of release of gases. The latter are coiled, filtered for mists and metered, prior to venting to the stack. The liquid level is maintained by the withdrawal of liquid products through a control valve.

\subsubsection{Product and Process Sampling}

Product sampling is carried out at the reactor spools of the reactor and from the vent lines of the pressure let-down system. The sampling ports consist of dual in-line on/off solenoid valves, and sample cylinders.

\subsubsection{Real-Time Microprocessor Control System}

A real-time digital microprocessor control system was designed and installed, so that the experimental unit could be operated remotely. Initially, the pressure let-down system control valves, the steam superheater flow control valve, the $C O$ flow control valve and the reactor temperature control heaters are controlled by this real-time control system. The latter was specially developed at the University of Arizona for a 6502 microprocessor based upon the experience gained in Chemical Engineering. The input signals fed the computer from various pressure, temperature and flow transducers. Provision was made for eventual flow control of feed by adjustment of the extruder-feeder screw rpm. The system was configured for 16 PID controllers and for real-time data acquisition.

\subsubsection{Mass Balance Model for Experimental Unit}

The niaterial balance model first used in this development considers mostly the "heart" of the process shown in Figure 4.7 and 4.8. Due to the lack of experimental information some simplifications were introduced into this first material balance model, based on good engineering judgement and some experiences from the Albany plant. A computer massbalanced program was written in completely general terms so that simplifying assumptions could be revised as soon as the required experimental data became availabie. For more details, refer to the DOE Quarterly report of August-October 1984 submitted to the DOE. 


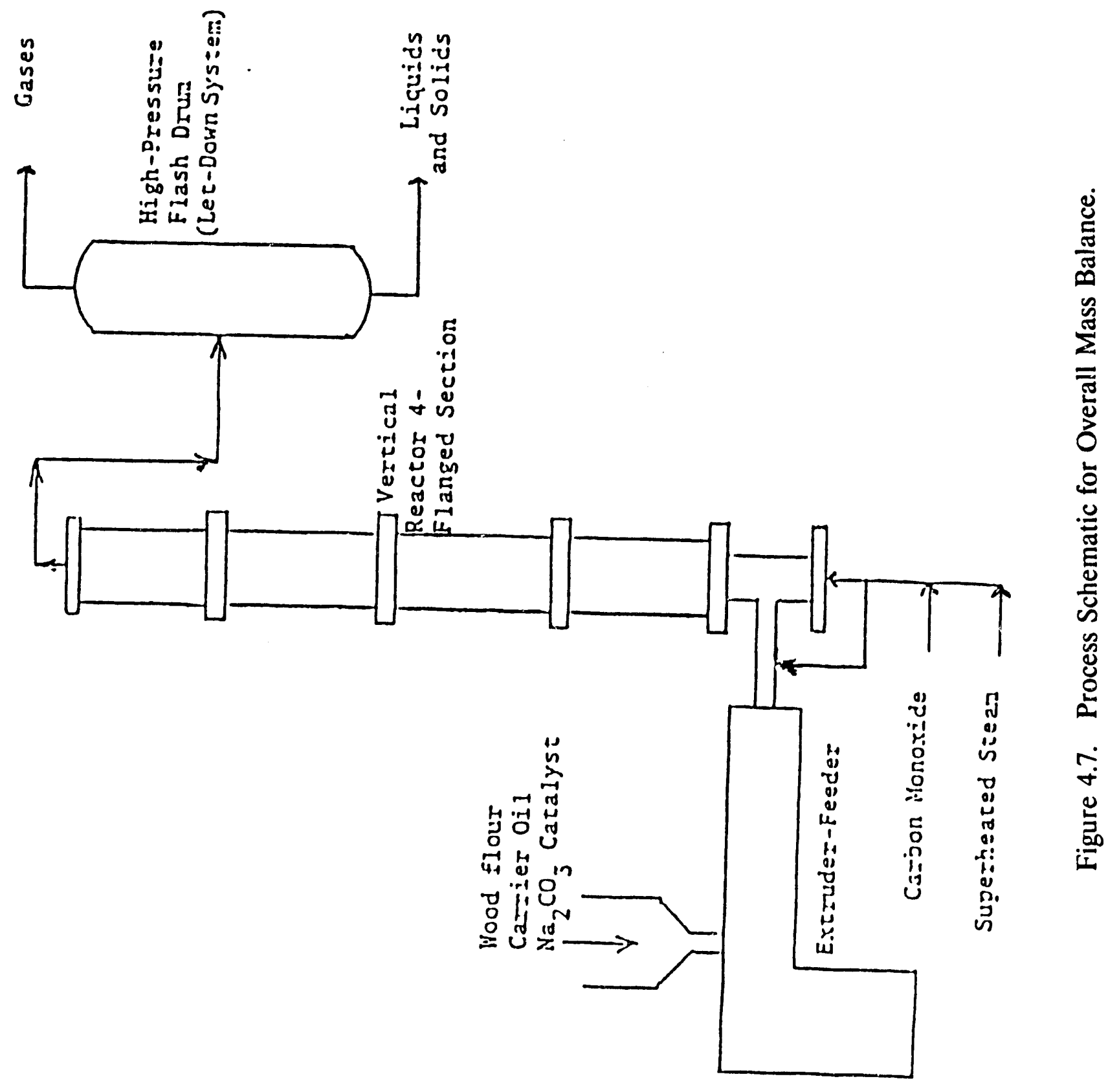




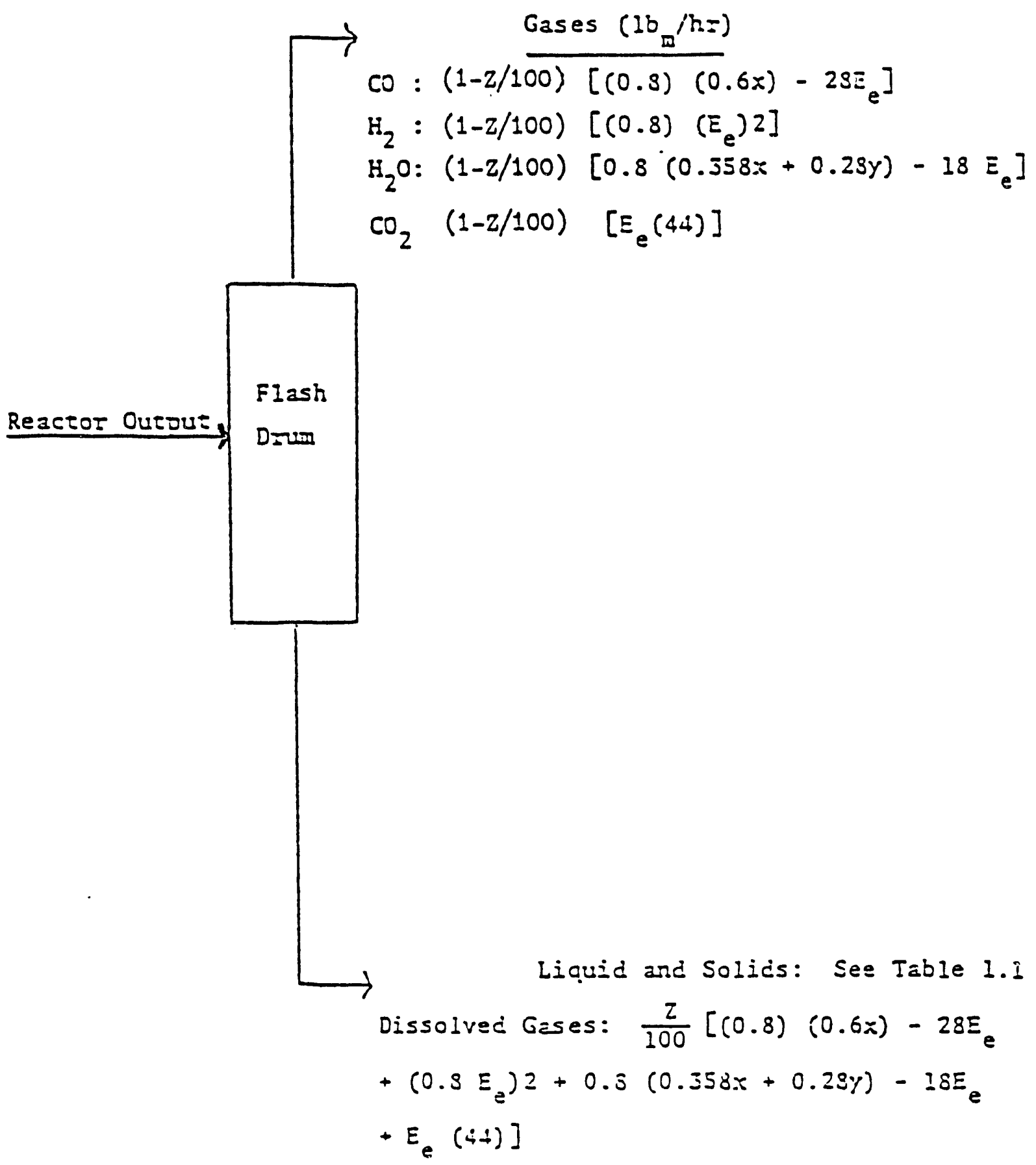

Figure 4.8. Composition of Streams from the Flash Drum as Calculated by the Mass Balance Equation. 


\section{Feed to Reactor}

It is assumed that this stream contains $\mathrm{X}$ and $\mathrm{Y} \mathrm{lb}_{\mathrm{m}}$ of wood flour and carrier oil, respectively. The amount of $\mathrm{Na}_{2} \mathrm{CO}_{3}$ then required corresponds to $0.05 \mathrm{X} \mathrm{lb}_{\mathrm{m}}$ and the amount of $\mathrm{CO}$ needed is about $0.6 \mathrm{X} \mathrm{lb}_{\mathrm{m}}$. The wood flour in the feed would have been dried to about $5 \mathrm{wt}$. \% moisture after substantial soaking with the catalyst solution. The required amount of superheated steam is such that it raises the temperature of the extrudate to about $670^{\circ} \mathrm{F}\left(350^{\circ} \mathrm{C}\right)$. Carbon monoxide will be preheated independently to this temperature. Hence, a heat balance gives:

$$
S=0.23(1.1 X+Y)
$$

where:

$\mathrm{S}=\quad$ the amount of steam, and $\mathrm{X}$ and $\mathrm{Y}$ were defined above.

The feed rate to the reactor is then:

$$
Q-X+Y+0.6 X+0.05 X+0.05 X+0.23(1.1 X+Y)-1.95 X+1.23 Y
$$

where:

$\mathrm{Q}=$ The total extrudate flow rate.

\section{Reactor Outlet}

The conversion is assumed to be 0.30 for an extrudate flow rate of $40 \mathrm{lb} / \mathrm{h}$ and 0.50 for $10 \mathrm{lb}_{\mathrm{m}} / \mathrm{h}$. The conversion per pass can therefore be assumed to depend linearly on the extrudate flow rate:

$$
h=a+b Q
$$

where:

$\mathrm{h}=$ conversion per pass, $\mathrm{Q}=$ Extrudate flow rate, $\mathrm{a}=-0.0067, \mathrm{~b}=0.5667$.

The total solid to non-solid conversion is assumed to be about $98 \mathrm{wt}$. \% so the unreacted wood flour outlet will be around $0.02 \mathrm{X} \mathrm{b}_{\mathrm{m}} / \mathrm{h}$.

The water gas shift reaction can be considered to be at equilibrium giving the equilibrium expression 


$$
K-\frac{(f P)_{\mathrm{H}_{2}}(f I P)_{\mathrm{CO}_{2}}}{(f I P)_{C O}(f I) \mathrm{H}_{2} \mathrm{O}} \cdot \frac{N_{\mathrm{H}_{2}} N_{C \mathrm{O}_{2}}}{N_{C O} N_{\mathrm{H}_{2} \mathrm{O}}}
$$

where:

$\mathrm{K}=$ equilibrium constant, $\mathrm{P}=$ pressure, $\mathrm{f}=$ fugicity, and $\mathrm{N}=$ molar concentration.

which reduces to:

$$
\frac{N_{\mathrm{H}_{2}} N_{C O_{2}}}{N_{C O} N_{H_{2}} \mathrm{O}}=12.0
$$

The amount of $\mathrm{CO}$ initially present is $0.6 \mathrm{X} / 28 \mathrm{lb}$. mols while that of $\mathrm{H}_{2} \mathrm{O}$ is $(0.30 \mathrm{X}$ $+0.23 \mathrm{Y}) / 18$. Assuming that about $20 \mathrm{~mol} \%$ of the $\mathrm{CO}$ and $\mathrm{H}_{2} \mathrm{O}$ initially present react directly with the wood to form the oil, one is left with $0.8(0.6 \mathrm{X} / 28) \mathrm{lb}$. mol of $\mathrm{CO}=$ $0.48 \mathrm{X} / 28 \mathrm{lb}$. mol of $\mathrm{CO}$ and $0.24 \mathrm{X}+0.18 \mathrm{Y} / 18 \mathrm{~mol}$ of $\mathrm{H}_{2} \mathrm{O}$.

Now, also assuming that about $20 \mathrm{~mol} \%$ of the generated hydrogen reactions directly with the wood particles to generate the wood oil, the gaseous phase equilibrium composition is then such that

$$
-d N_{C O}=-d N_{\mathrm{H}_{2} \mathrm{O}}=d N_{C O_{2}}=d N_{\mathrm{H}_{2}} / 0.8=d E
$$

Integration from $\mathrm{E}=0$ to $\mathrm{E}=\mathrm{Ee}=$ Equilibrimm gives

$$
\begin{aligned}
& N_{C O}-0.48 X / 28-E_{e} \\
& N_{\mathrm{H}_{2} \mathrm{O}}-(0.24 X+0.18 Y) / 18-E_{e} \\
& N_{\mathrm{CO}_{2}}-E_{e} \\
& N_{\mathrm{H}_{2}}=0.8 E_{e}
\end{aligned}
$$

The equilibrium constant relaticnship can now be written as:

$$
\frac{0.8 E_{e}^{\prime 2}}{\left(\frac{0.48 X}{28}-E_{e}\right)\left[\frac{0.24 X+0.18 Y}{18}-E_{e}\right]}-12.0
$$


The general reactor outlet composition is then as shown in Table 4.1. If one assumes that $7 \mathrm{wt} . \%$ of the gases leaving the reactor are dissolved in the liquid phase and remain so in the first flash drum, then the final composition (on a mass basis) of the streams leaving the flash drum.

\subsubsection{Detailed Design of Superheated Steam System}

The use of high-pressure, high-temperature, superheated steam was one of several options for the design of the extruder-reactor biomass liquefaction unit at the University of Arizona. The use of superheated steam in biomass liquefaction eliminated the need of a gas-fired preheater with its associated coking and plugging problems. Direct steam heating can bring the feedstock to the reaction temperature almost instantaneously, and can also provide the water for the water-gas shift reaction that generates hydrogen, which is believed to help liquefaction reactions.

According to design specifications, the biornass liquefaction unit of the University of Arizona requires steam flow rates in the range of $5-40 \mathrm{lb} / \mathrm{h}$ at up to $3100 \mathrm{psi}$ and temperatures ranging from the saturation point (approx. $700^{\circ} \mathrm{F}$ ) to about $1500^{\circ} \mathrm{F}$. Because of the combination of extreme operating conditions and low capacities, the required steam superheating system was not available from industrial suppliers of steam-generating units. Therefore, the whole system had to be designed and nost of it constructed at the University of Arizonia (Reyes, 1985).

High-pressure steam generation requires high-purity feed water in order to minimize corrosion and fouling levels of heat transfer equipment, instruments, and steam lines (Sculthore 1972). At high pressures and temperatures, dissolved solids in the feed water will not only deposit on vaporizer surfaces, but will also be carried over with the steam to the superheater and into the process. For example, it is well-known that silica concentrations in boiler waters should be less than $3 \mathrm{ppm}$ for pressures of $2500 \mathrm{psi}$ and that less than 1 ppm is recommended for even higher pressures; this accounts for the fact that solubility of silica in steam increases rapidly with the operating pressure.

Low oxygen content is absolutely necessary for both low- and high-pressure systems, since oxygen is the prime factor in boiler corrosion. However, while $1 \mathrm{ppm}$ of oxygen residual may be acceptable for a low-pressure boiler, modern high-pressure boilers require less than $0.005 \mathrm{ppm}$ of dissolved oxygen.

Certainly, carbon dioxide will also have to be "completely" removed from the feed water and even normally inert gases such as nitrogen need to be eliminated. This is necessary not only because it will decrease the heat transfer efficiency of steam, but also 
Table 4.1. Biomass Liquefaction Reactor Emuent Composition (Basis: 1 hr)

\begin{tabular}{|c|c|c|c|}
\hline Component & $\begin{array}{l}\text { Amount in Feed to } \\
\text { the reactor }\left(1 b_{m}\right)\end{array}$ & $\begin{array}{l}\text { Amount in Gaseous } \\
\text { stream from the } \\
\text { reactor }\left(1 b_{m}\right)\end{array}$ & $\begin{array}{l}\text { Amount in solid or } \\
\text { liquid stream from } \\
\text { the reactor }\left(\mathrm{lb}_{\mathrm{m}}\right)\end{array}$ \\
\hline $\mathrm{CO}$ & $0.6 x$ & $(0.8)(0.6 \mathrm{x})-28 \mathrm{E}_{\mathrm{e}}$ & \\
\hline $\mathrm{H}_{2}$ & & $(0.8)\left(E_{e}\right) 2$ & \\
\hline $\mathrm{H}_{2} \mathrm{O}$ & $(0.30 x+0.23 y)$ & $\begin{array}{l}(0.8)(0.30 x+0.23 y)- \\
18 E_{e}\end{array}$ & \\
\hline $\mathrm{CO}_{2}$ & & $44 \mathrm{E}_{\mathrm{e}}$ & \\
\hline $\mathrm{Na}_{2} \mathrm{CO}_{3}$ & $0.05 x$ & & $0.05 x$ \\
\hline Carrier & $\mathrm{y}$ & & $\mathbf{y}$ \\
\hline Wood Oil & & & $\begin{array}{l}\text { (Conversion per } \\
\text { pass) } X+0.2[0.6 x \\
+2 E_{c}+0.30 x+ \\
0.23 y]\end{array}$ \\
\hline Wood Flour & $\mathbf{x}$ & & $0.02 x$ \\
\hline Residue & & $\begin{array}{l}\mathrm{Z} \% \text { of these gases will } \\
\text { be dissolved in the } \\
\text { liquid. }\end{array}$ & (Balance) \\
\hline Total & $1.95 x+1.23 y$ & $0.72 x+0.18 y-0.4 E_{e}$ & $\begin{array}{l}1.23 x+1.05 y+0.4 \\
E_{e}\end{array}$ \\
\hline
\end{tabular}


because at temperatures as high as $1500^{\circ} \mathrm{F}$ in the superheater some nitration of carbon in steel and alloys can be expected.

Therefore, a very good water treatment was required for the biomass liquefaction experimental unit and, to obtain better results, it was decided to use commercially available distilled or demineralized water which would be additionally treated using an ion exchange column and a degassing tank.

A schematic diagram of the water treatment system is shown in Figure 4.9. The three main components are: Ion exchange column, degassing unit, and storage tanks. The expected operating conditions are also shown in the figure.

\section{Ion Exchange Column}

In order to be able to remove practically all the dissolved solids of the water, a deionizer consisting of cation and anion resins must be used.

To simplify the process, disposable, laboratory-size resin cartridges were selected. Replacement instead of regeneration was preferred. Two cartridges in series (Ultrapure, Barnstead $d^{\text {m}}$ ) are able to produce water with specific resistance up to $10 \mathrm{Mohm}-\mathrm{cm}$, which compares favorably with the recommended value of $3.3 \mathrm{Mohm}-\mathrm{cm}$ for high-pressure boilers. It is interesting to note that the theoretical maximum for the water resistance is $20 \mathrm{Monm}$ $\mathrm{cm}$ at $25^{\circ} \mathrm{C}$ due solely to its dissociation products.

\section{Degassing Unit}

The need for very low concentrations of oxygen in the feed water is conventionally satisfied by the used of heater de-aerators operating around the corresponding boiling point of water at operating pressures between 1-10 a.m. In addition to the temperature effect, the process is mass-transfer-aided since steam, with very low oxygen content, is passed countercurrently with respect to the water being treated.

\section{Steam Vaporizer Design}

A high-pressure extruder barrel, 3.5" ID and $7 \mathrm{ft}$. long, became available and was utilized for the main body of the steam vaporizer. The barrel is made of high-alloy steel with an inner X-alloy lining giving a total wall thickness of 1.5". Preliminary calculations showed that the pressure rating of the barrel was compatible with the design requirements.

The process diagram for the vaporizer process and the detailed vaporization unit are shown in Figures 4.10 and 4.11. A high-pressure metering pump feeds treated water into the vaporizer, driven by a $12 \mathrm{Mohm}-\mathrm{cm}$ conductivity level controller. A safety relief valve prevents over-pressurization of pump ad feed-water lines, and a pulsation dampener smooths out the flow to protect the pump and prevent fitting failure. 


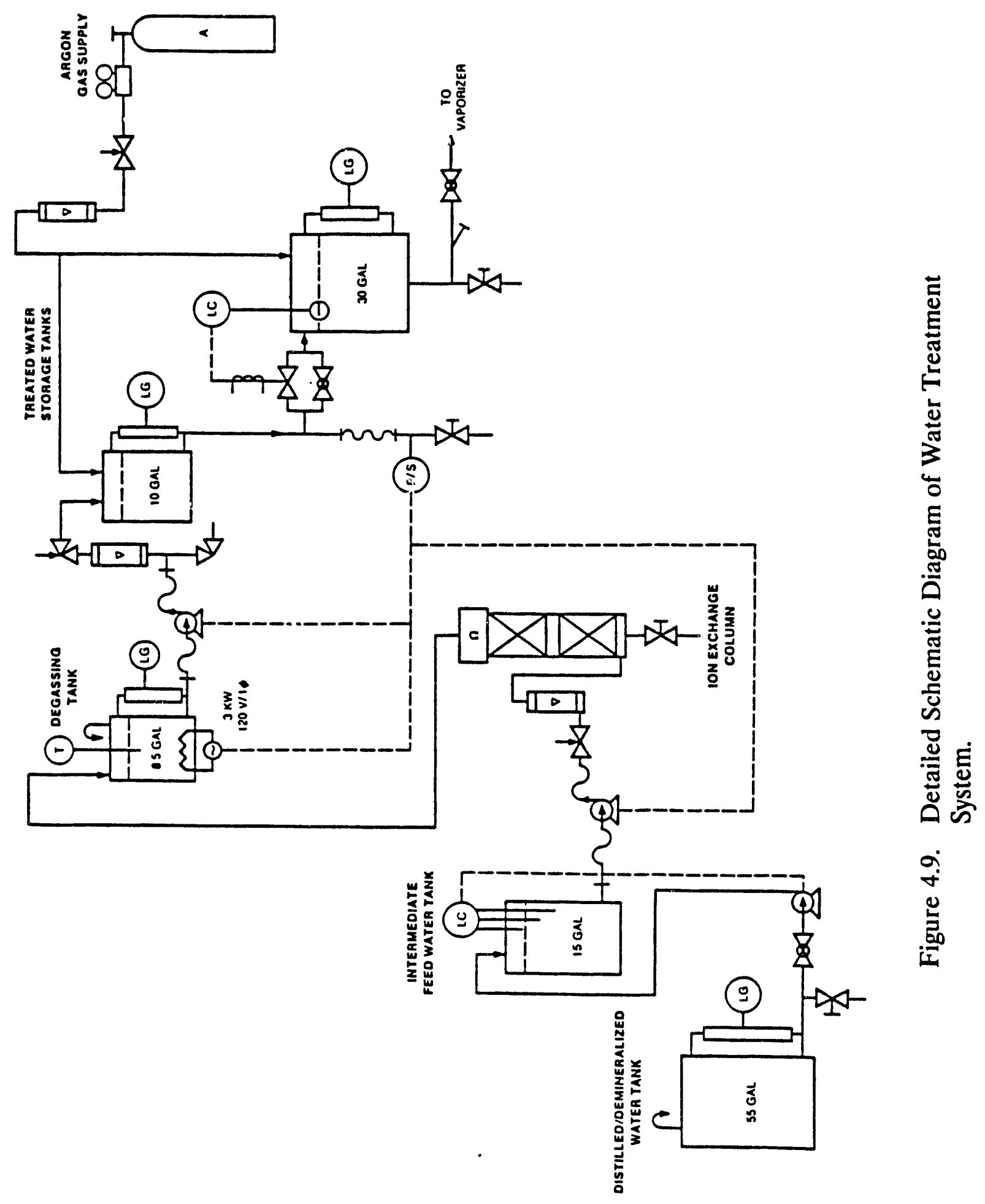




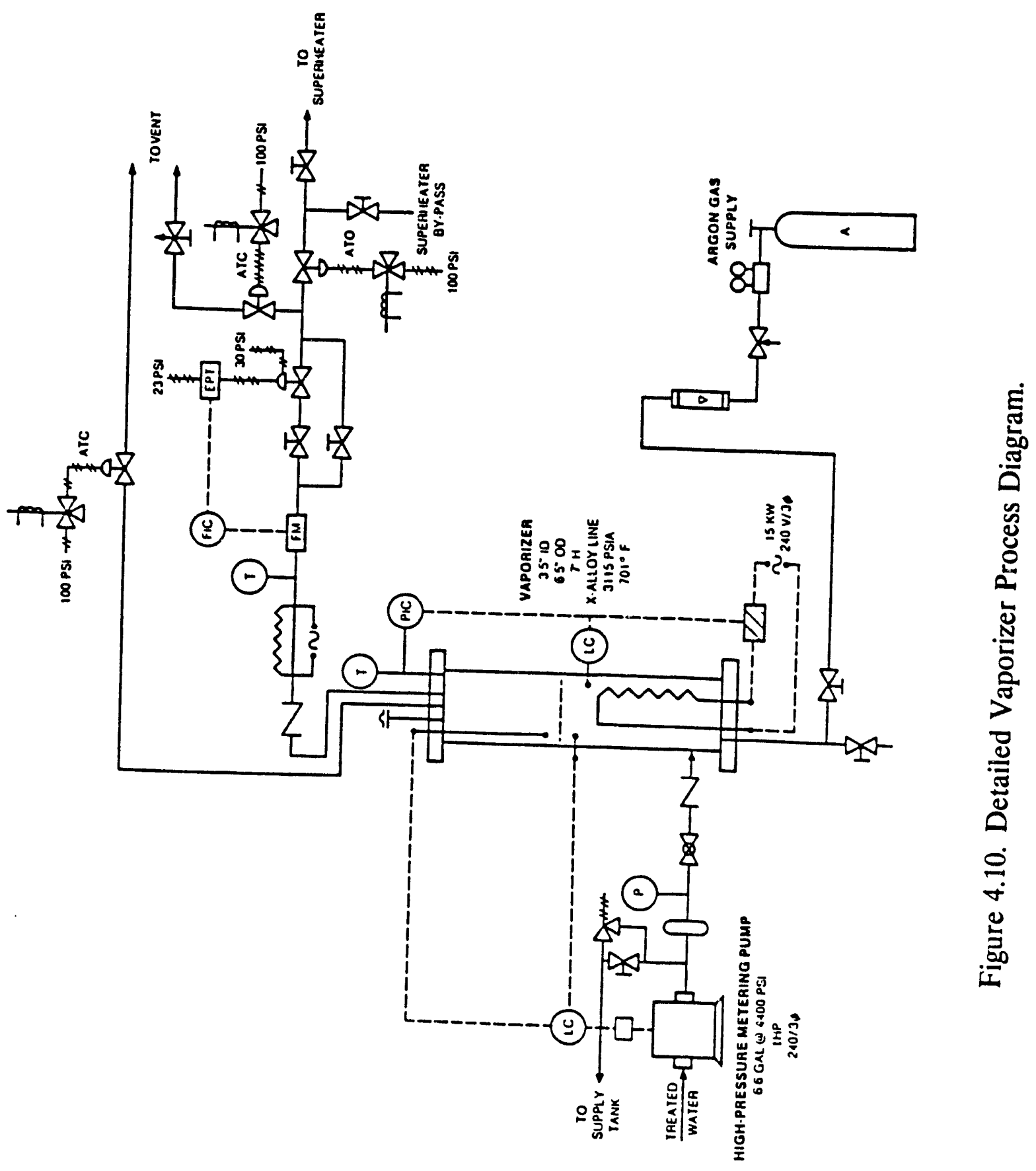




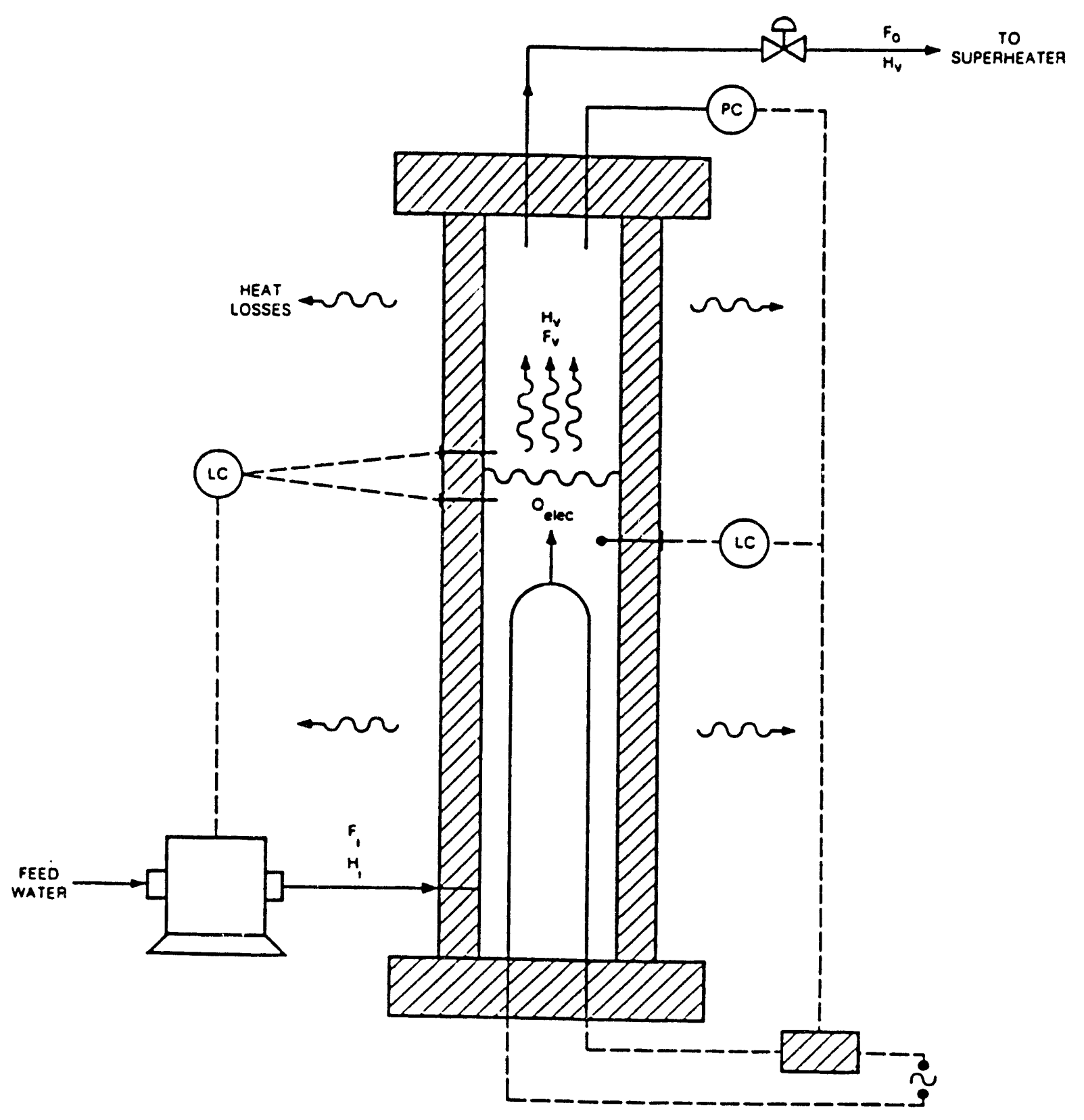

Figure 4.11. Vaporizer Schematic for Dynamic Modeling. 
Over-pressurization of the vaporizer is prevented by an inconel bursting disc rated for $4170 \mathrm{psi}$ at $72^{\circ} \mathrm{F}$ or about $3600 \mathrm{psi}$ at $700^{\circ} \mathrm{F}$; additionally, direct venting of the vaporizer is possible thrcugh an on/off air-operated valve. A high-pressure, low-flow control valve, together with a turbine volumetric flowmeter, is used to provide accurate PID flow control of the steam going into the superheater. This is important as the design calls for operating the steam superheater near the critical temperature of water.

\section{Vaporizer Modeling and Computer Simulation}

Dynamic modeling of boilers has received considerable theoretical and practical attention because of its importance in efficient operation and for safety considerations. The dynamics of conventional and nuclear plant boilers can be analyzed considering in-depth refinements such as bubble dynamics and steam wetness effects, natural convection in twophase flows, influence of solid content in water and non-uniform oulk temperatures. A simplified thermodynamic and heat transfer approach for the modeling of the vaporizer was utilized.

The effect of the heating rate on the maximum pressure attained in the vaporizer for average liquid levels of 1.8 and $4.0 \mathrm{ft}$ were calculated for one hour after start-up. There is an optimum point since too low values of heating rate do not develop enough vaporization rates, while too high heat inputs reduce the liquid level in such a way that the level controller will turn off the heating elements more frequently and a somewhat unstable liquid level and pressure development are obtained.

For the optimum heating rate $(\approx 42,000 \mathrm{BTU} / \mathrm{h})$, the effect of liquid level was checked (see Figure 4.12, lower curve). For liquid levels above $4 \mathrm{ft}$, the system is unstable because critical conditions are attained during start-up. The optimum operational liquid level was found to be around 3.7-4.0 it.

The effect of heating rate on pressure development suggests that the liquid level has a small effect on vaporizer behavior. Silicon carbide heating elements were selected over the more usual nickel/chromium resistors because they can operate at higher temperatures, have a higher emissivity, and are less affected by oxidation. Initially, 316 SS tubing was specified for the steam coil, although a nickel-based alloy will be used in the near future. In any case, an argon inert atmosphere will be maintained inside the superheater to protect the tubing from excessive high-temperature corrosion. Information on materials for high temperatures were found in Clauss (1969) and in publications by the American Society for Metals $(1976,1984)$.

\section{Steam Superheater Design}

The steam superheater schematic diagram of the internals is shown in Figure 4.13. The superheater was insulated with Kaowool ceramic fiber boards and low-density refractory bricks. 


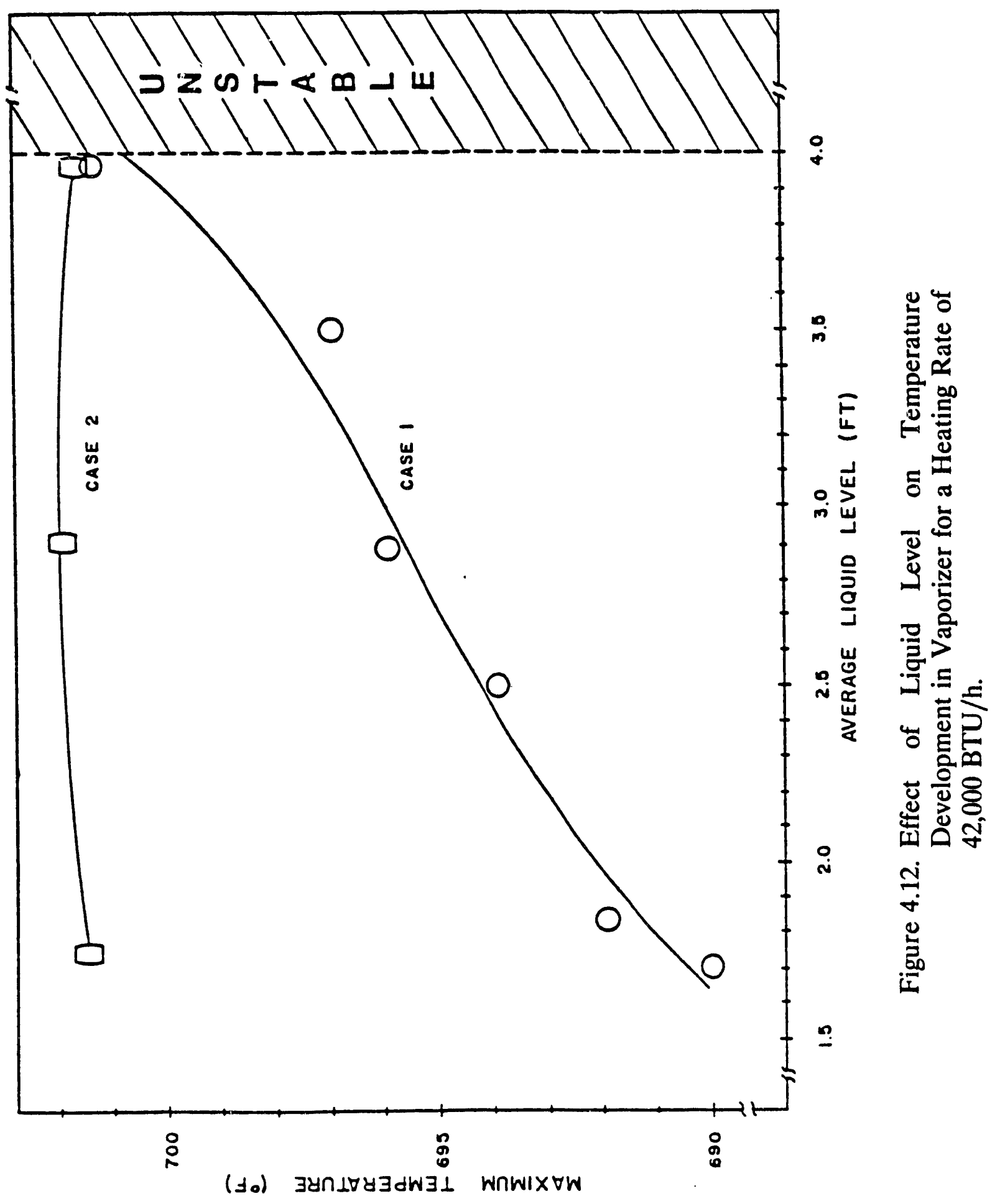




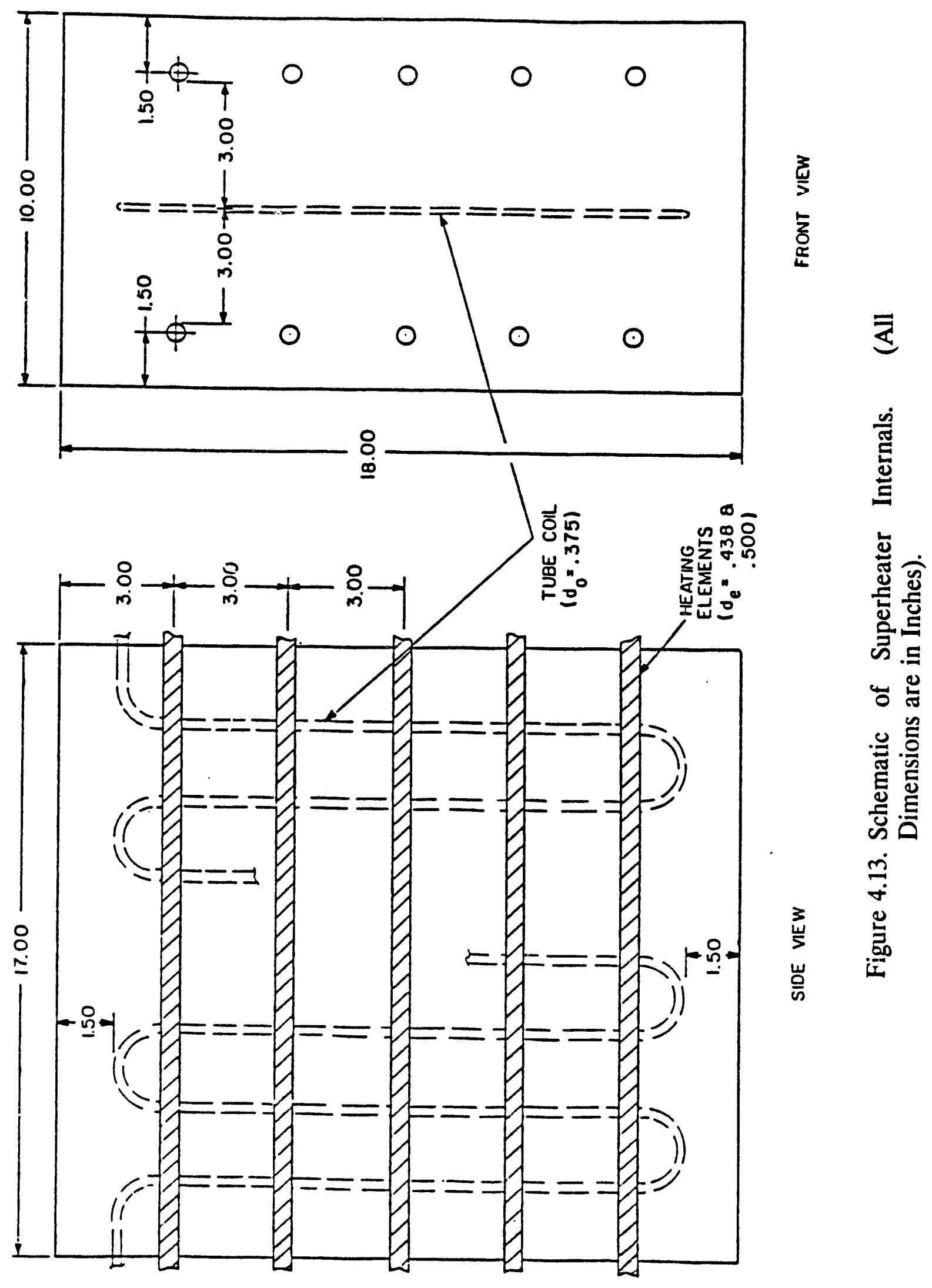


According to manufacturer's information, silicon carbide heating elements in air or inert atmospheres can be used with a specific load of around $0.07 \mathrm{Kw} / \mathrm{in}^{2}$; then

$$
(0.07)\left(\mathrm{n}_{\mathrm{he}}\right)\left(\mathrm{s}_{\mathrm{r}}\right)=10 \mathrm{Kw}
$$

where $n_{h e}$ is the number of heating elements and $s_{r}$ their radiating surface in square inches. Six heating elements were specified, three on each side wall. From manufacturer's data, at $1960^{\circ} \mathrm{F}$, the resistance of each heating element is $3.68 \mathrm{ohm}$; then the required voltage drop is $78.3 \mathrm{~V}$ with a current of 21.3 amps.

The choice of size and number of heating elements influenced the inside dimensions of the furnace. Minimum clearances and spacings depend on greater diameter and are required to produce uniform heat distribution and avoid overheated spots. Relatively large spacings were selected in order to have enough room for possible addition of heating elements and modifications of tube coil design. It was finally decided to add four secondary heating elements, $7 / 16$ in. diameter with a somewhat lower rating, which provided an extra safety factor and flexibility for operation at low flow rates.

The final arrangement of the steam superheater is presented in Figure 4.14. There are two temperature control loops, a three-phase PID power controller set-up which monitors the outlet temperature of the steam through the primary silicon carbide heaters, and a single-phase proportional controller which drives the secondary heaters according to the heaters or chamber temperature. As an experimental trial, 316 SS was initially used for lines and fittings and Inconel 625 for main valves.

Computer calculations generated the development of the steam temperature profile in the superheater as shown in Figure 4.15. An abnormal behavior is observed during initial time increments which is more likely an erroneous numerical result due to inaccuracies in the initial conditions combined with the non-linearity of the system of differential equations. The assumed initial conditions are approximate since they involve the initial steady-state temperature distribution through the insulation, the tube temperature, and the heating element temperature. In reality, an initially slow temperature development is expected which will become faster as the heating elements warm up.

A high-pressure extruder barrel is used as the vaporization unit. The barrel had an inside diameter of 3.5 inches and a total wall thickness of 1.5 inches. Other dimensions are shown in Figure 4.16, which shows the extruder barrel as received. A corrosion-resistant, nickel-based lining constitutes one-third of the wall thickness, while the other two-thirds are apparently made up of a low-alloy steel.

In order to check the adequacy of the barrel for operation at $3100 \mathrm{psi}$ and $700^{\circ} \mathrm{F}$, the maximum allowable working pressure was calculated using a very conservative design stress, $\mathrm{s}=10,000 \mathrm{psi}$, and without taking the lining into account.

Materials and mechanical considerations play an important role in the design and specification of tube coil and fittings for the steam superheater. Although corrosion 


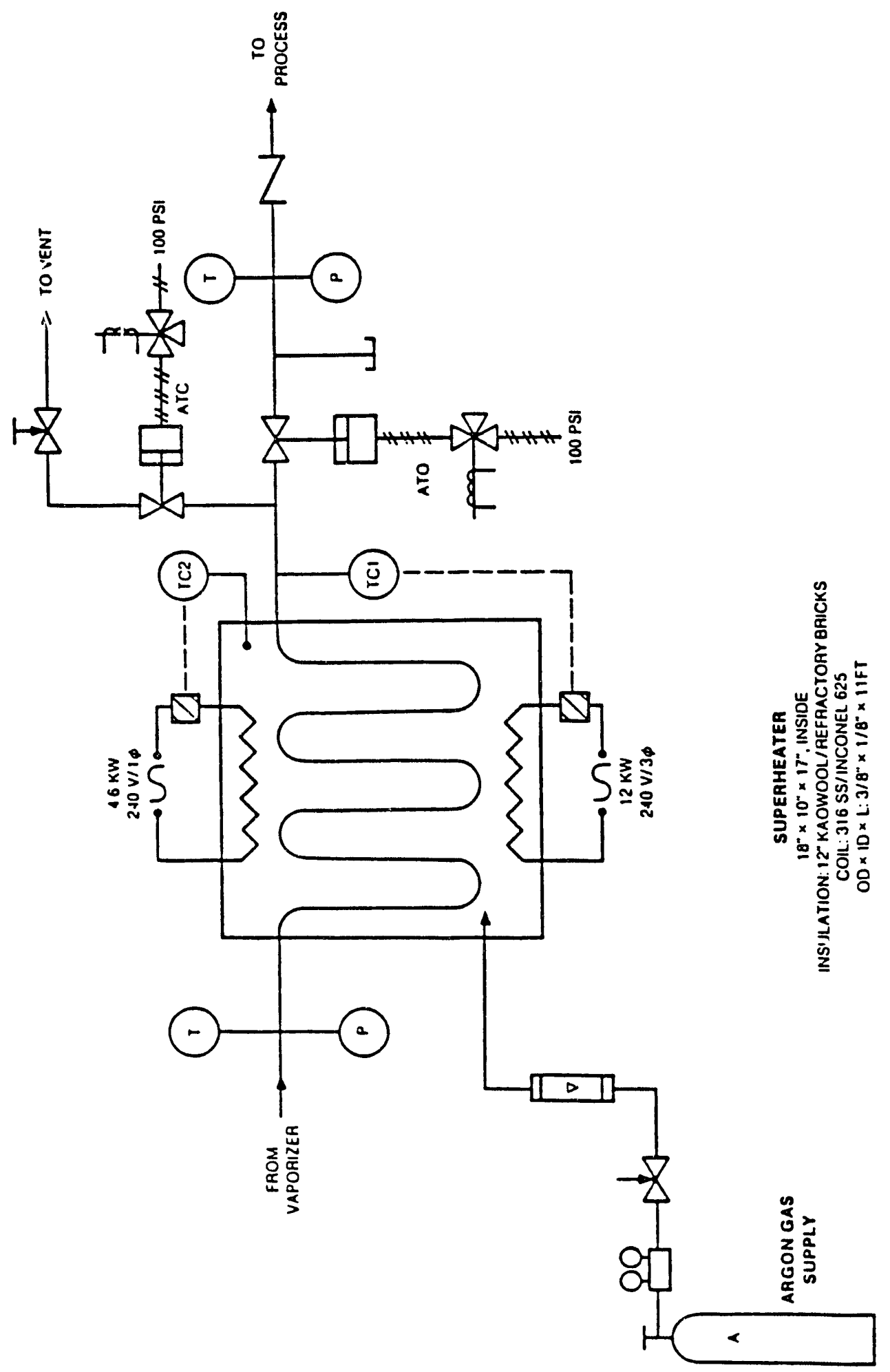

है 


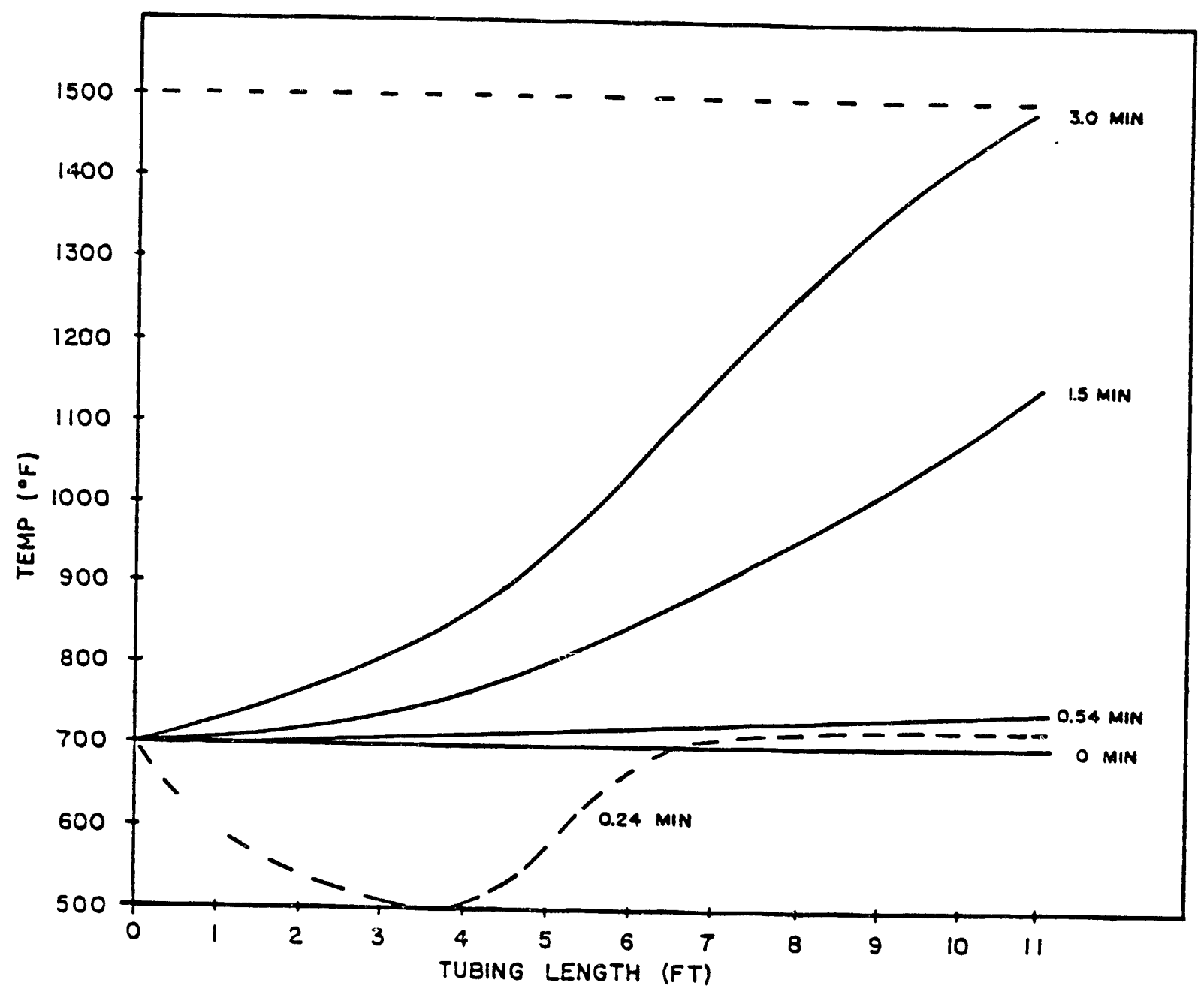

Figure 4.15. Steam Temperature Profiles in Superheater. 


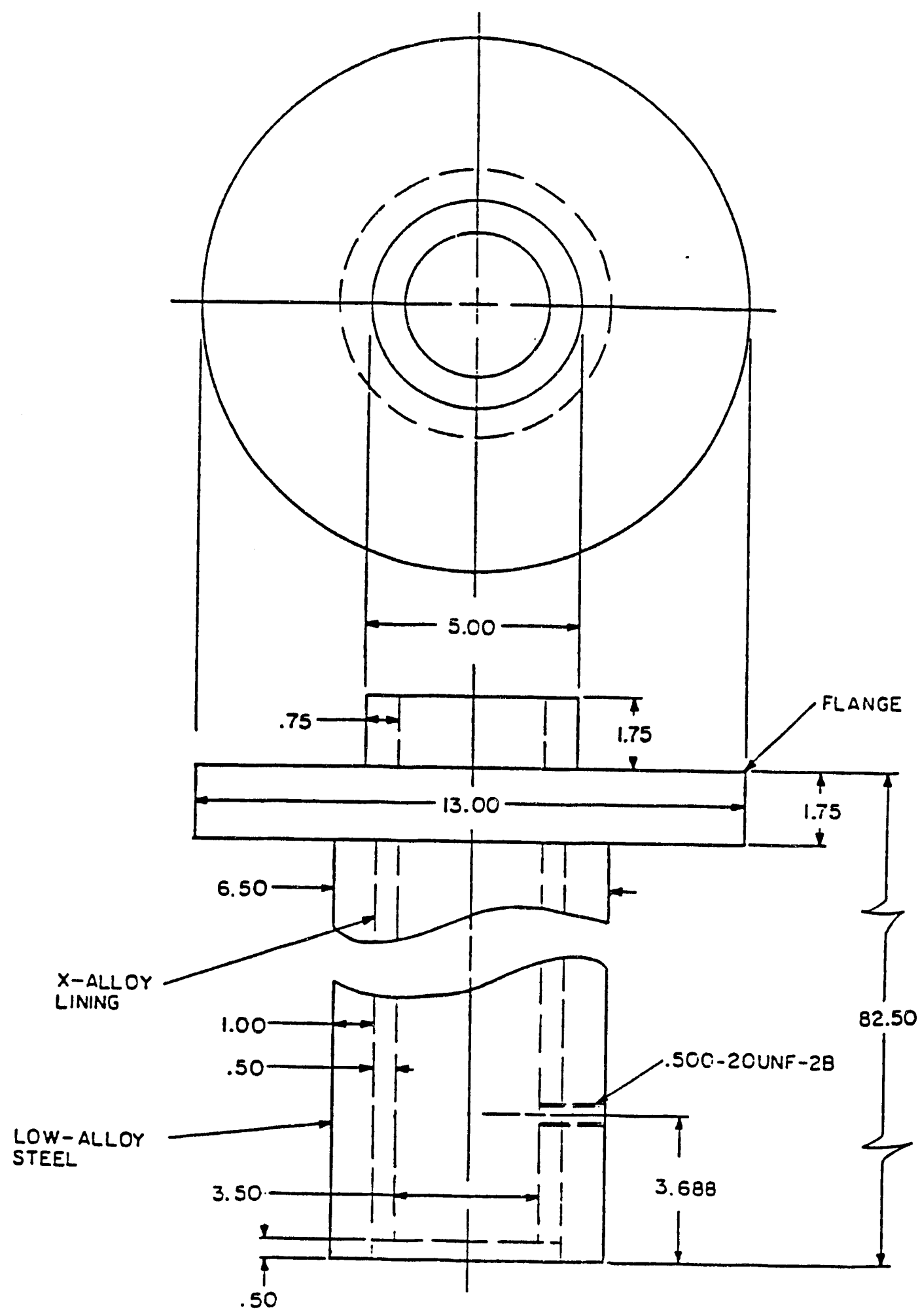

Figure 4.16. Extruder Barrel for Vaporizer, As Received. (All Dimensions are in Inches). 
problems will be minimized by the use of high-purity steam and a furnace inert atmosphere, the severe conditions created by elevated temperatures and pressures deserve careful analysis in order to obtain a safe and operable system. Initial attempts to specify materials and tubing size for the superheater confirmed the presence of a case with extreme operating conditions.

Since the terminology "extreme conditions" is arbitrary, it is difficult to define the requirements for a system to be considered under extreme conditions. However, no definition is complete unless it makes reference to the size of the unit involved and the operating temperatures and pressures. A good indication that extreme conditions are present is the obtainment of negative or imaginary wall thicknesses when using the equations and design stresses provided in the ASME Code (1977).

For the case of extreme operating conditions, the ASME Code safety factors are not applicable since, as mentioned before, they lead to meaningless design results. According to Gasche (1956), "safety factors, as such, have significance only below temperatures of $1000^{\circ} \mathrm{F}$. Because of the limits imposed by materials of construction, the safety factor must become progressively less with increased working pressures. Above $1000^{\circ} \mathrm{F}$, where creep of metals becomes significant, the design must be based on hours of life." On these grounds, the specification of tubing size and materials for the superheater coil was based on the analysis of stresses to produce rupture or 1 percent creep rate in a period of 1000 hours.

Co:asidering only the maximum stress due to the internal pressure, Figure 4.17 illustrates the impossibility of designing the superheater tubing for temperatures above $1300^{\circ} \mathrm{F}$ if the conventional allowable design stresses, for $316 \mathrm{SS}$ or Inconel 625 given in the ASME code, are employed. The figure also prompts the feasibility of a design approach based on hours of life since the short-time tensile strengths of the materials are still appreciably high (about $150^{\circ} \mathrm{F}$ ).

Rupture properties of 304 and 316 stainless steels and nickel-based alloy inconel 625 are presented in Figure 4.18. For comparison, the behavior of carbon steel is also illustrated. Note that rupture properties of $316 \mathrm{SS}$ re adequate for the estimated tubing stress; however, one finds that the expected creep rate after 1000 hours of operation will be higher than 1 percent even for 316 SS. Further analysis showed that a creep rate of around 5 percent cold be expected after $1000 \mathrm{~h}$ at the design conditions. It is important to realize, however, that creep effects will be important in defining failure of tube fittings that are outside the superheater and, for this reason, subject to somewhat lower temperatures and thermal stresses. Rupture effects, on the other hand, will be controlling the failure of the superheater coil inside the furnace chamber.

\subsubsection{Design of Real-time Computer Process Control System}

The concept of real-time computing in 1983 was often misunderstood or oversimplified when applied to data acquisition and control. There is a significant difference between an operation accomplished in real-time and real-time computing. Realtime operations are those in which a physical phenomenon is observed or acted upon 


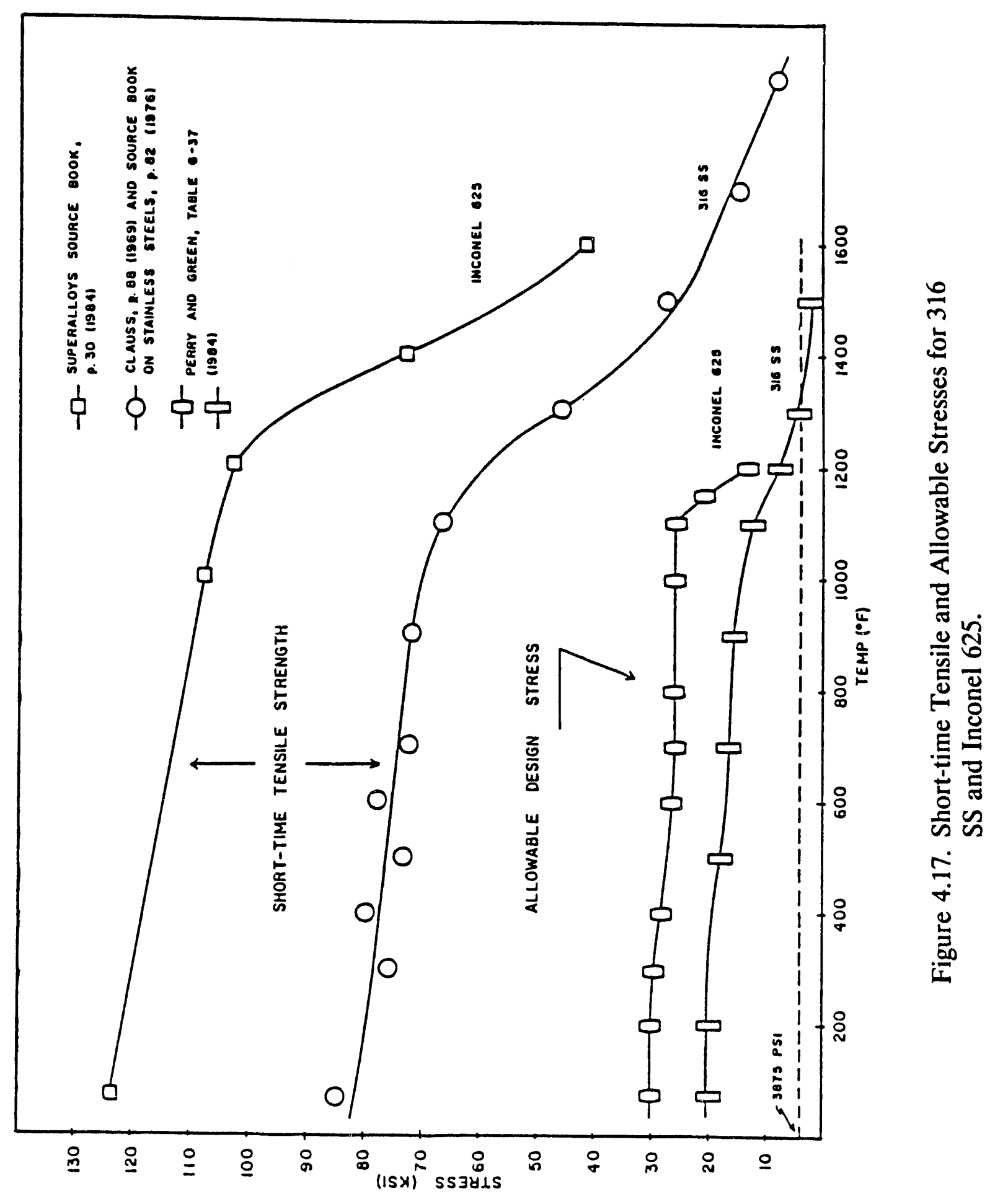




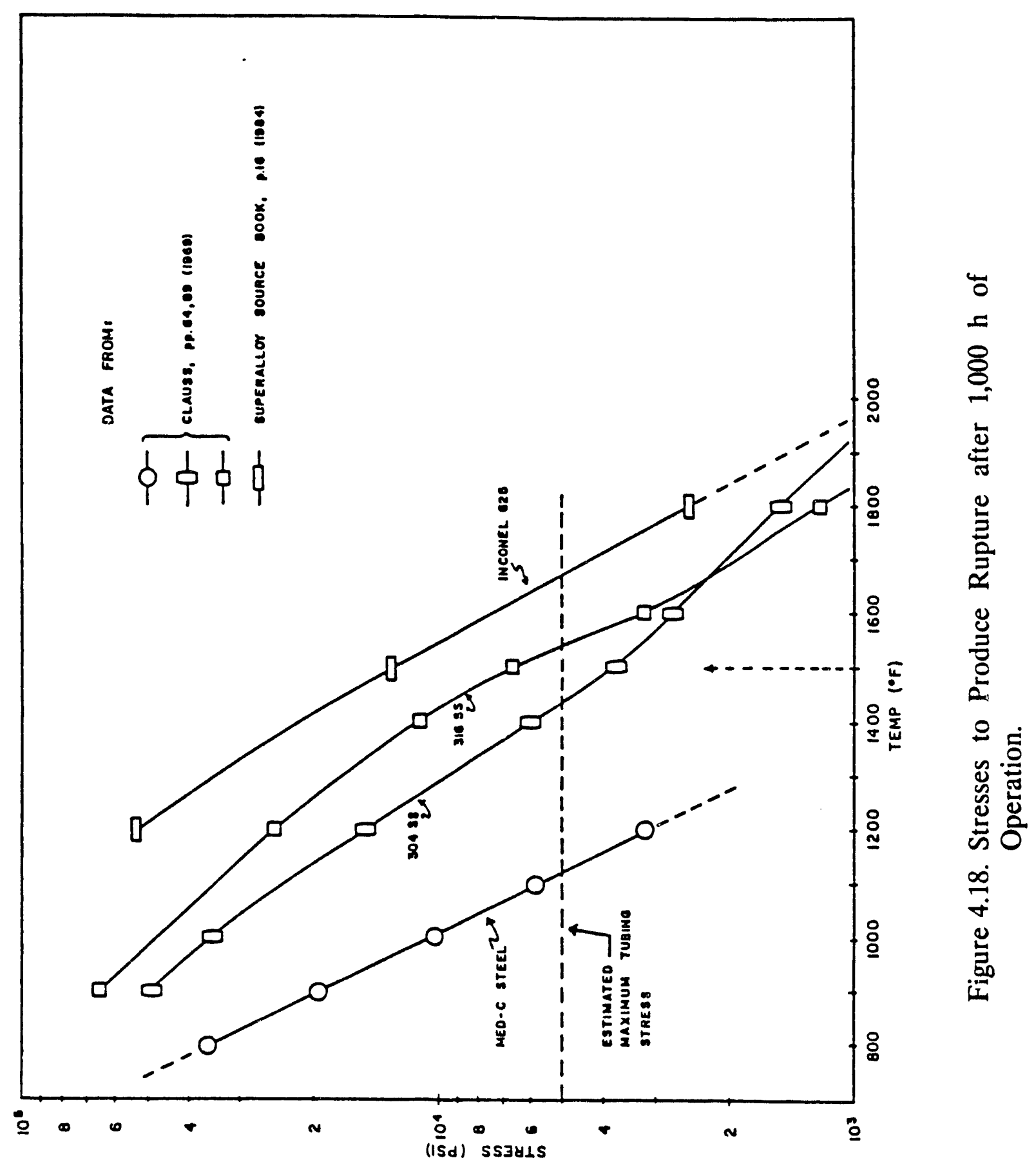


concurrently with the phenomenon itself. This in itself is the broadest definition of a realtime operation. On the other hand, real-time computing is a well-defined concept with specific computing objectives and levels of operation (Franklin and Powell 1980, Kou 1980, Katz 1981).

Real-time computing is a method of computing which causes a computer to execute multiple tasks concurrently according to a priority scheme and time schedule. The word concurrently must be stressed, because the central processing unit of a computer can process only one machine instruction at a time, and the idea of real-time computing is to make a computer seem like it is processing many tasks simultaneously. In computing operations which are not real-time, much of a computer's time is spent waiting for input or output from external devices, or poling for active signals from user terminals. In real-time computing, tasks are executed according to a status assigned to them depending on their operating state. Programs which must be executed do not have to wait for other programs to finish execution.

A real-time program (task) for a typical real-time operating system can have several operating states (Mellichamp 1983). The 'executing' state occurs when a program has control of the central processing unit (CPU). It is the highest priority task on queue which is ready to run. A program is in the 'ready' state when it is scheduled to run but is waiting for a higher priority task to finish execution. A program is in a 'suspended' state when some external event (i.e., I/O or inter-task) must be completed before the program can finish execution. An 'inactive' task is one which has completed execution and has terminated itself, or has not been activated by the user or other tasks.

A major concept in real-time computing is the basic system time (BST). The BST is actually a time interval defined by the periodic interrupting of the central processing unit by an external hardware device.

The initial real-time computer-controlled control system was designed by Andrews, as shown in Figures 4.19-4.23. A 6502 microprocessor was used for real-time computing and had capability by virtue of its non-maskable interrupt (NMI) function. Upon activation of the NMI pin (transition of $+5 \mathrm{~V}$ to $0 \mathrm{~V}$ ), the microprocessor starts execution at a location specified in memory. This memory location has the starting address of the task scheduler program, and this address is specified by initial loading of the scheduler into memory.

The basic system time is determined by the rate at which the microprocessor NMI pin is being activated. A programmable interval timer is used to generate these interrupts at a rate relative to the crystal oscillation rate which cycles the microprocessor through individual machine operations.

\section{Real-Time Program Priority Structure}

The programs which make up a real-time computing system was divided into four categories within a relative priority scheme. The real-time task scheduler was executed by non-maskable interrupts of the CPU and was the highest priority program. It is executed 

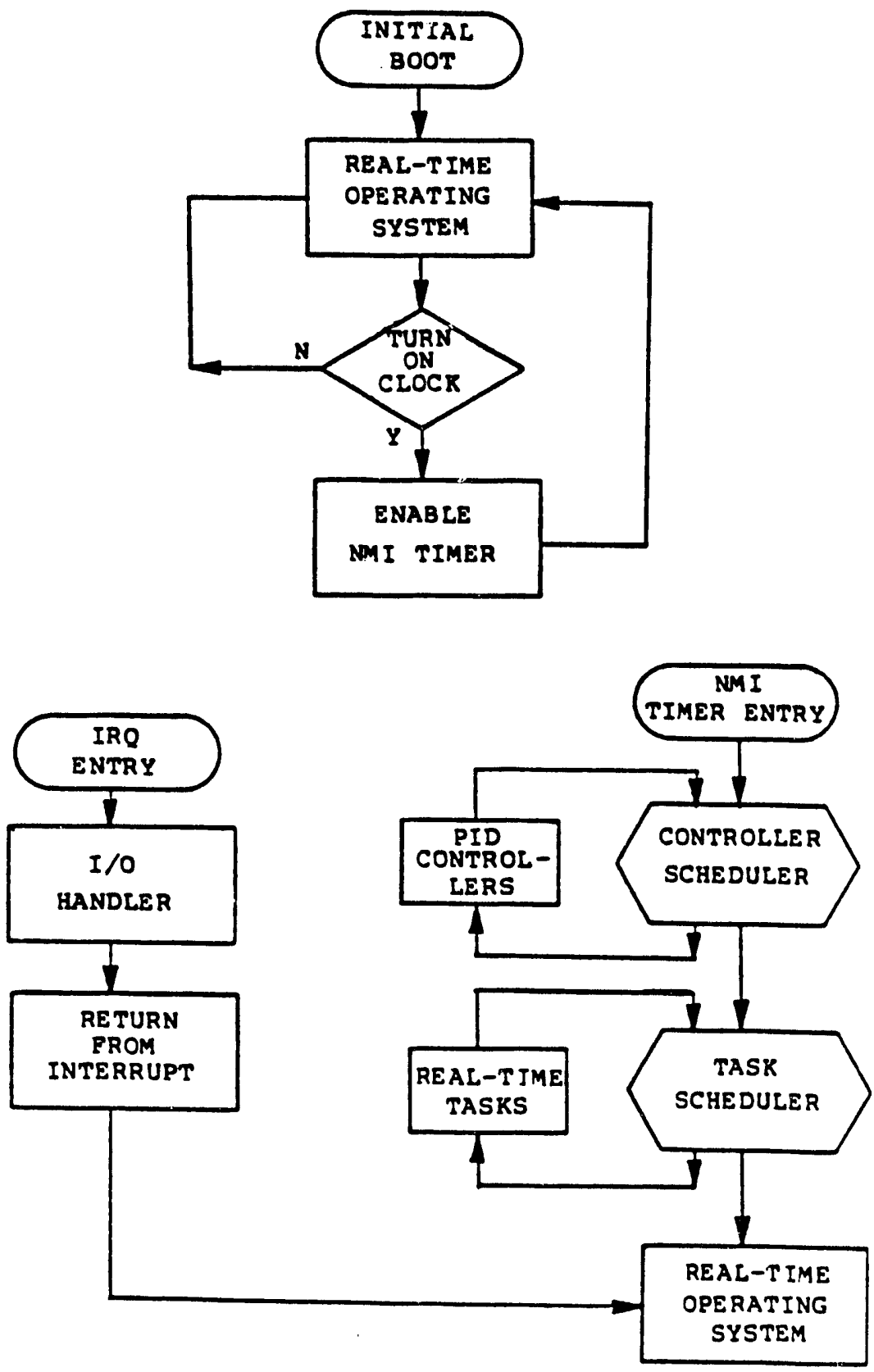

Figure 4.19. Real-Time Program Structure. 


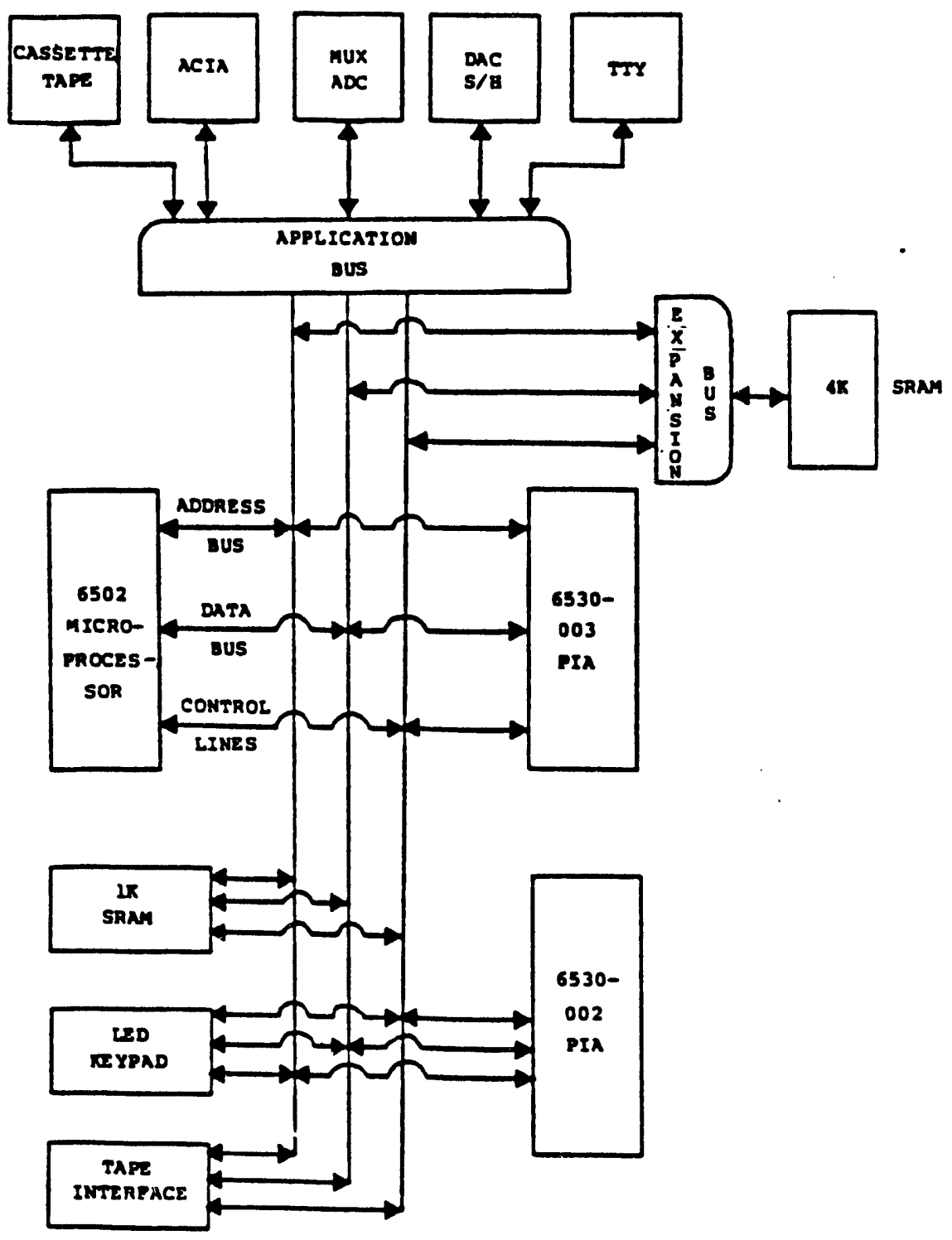

Figure 4.20. KIM Microcomputer System. 


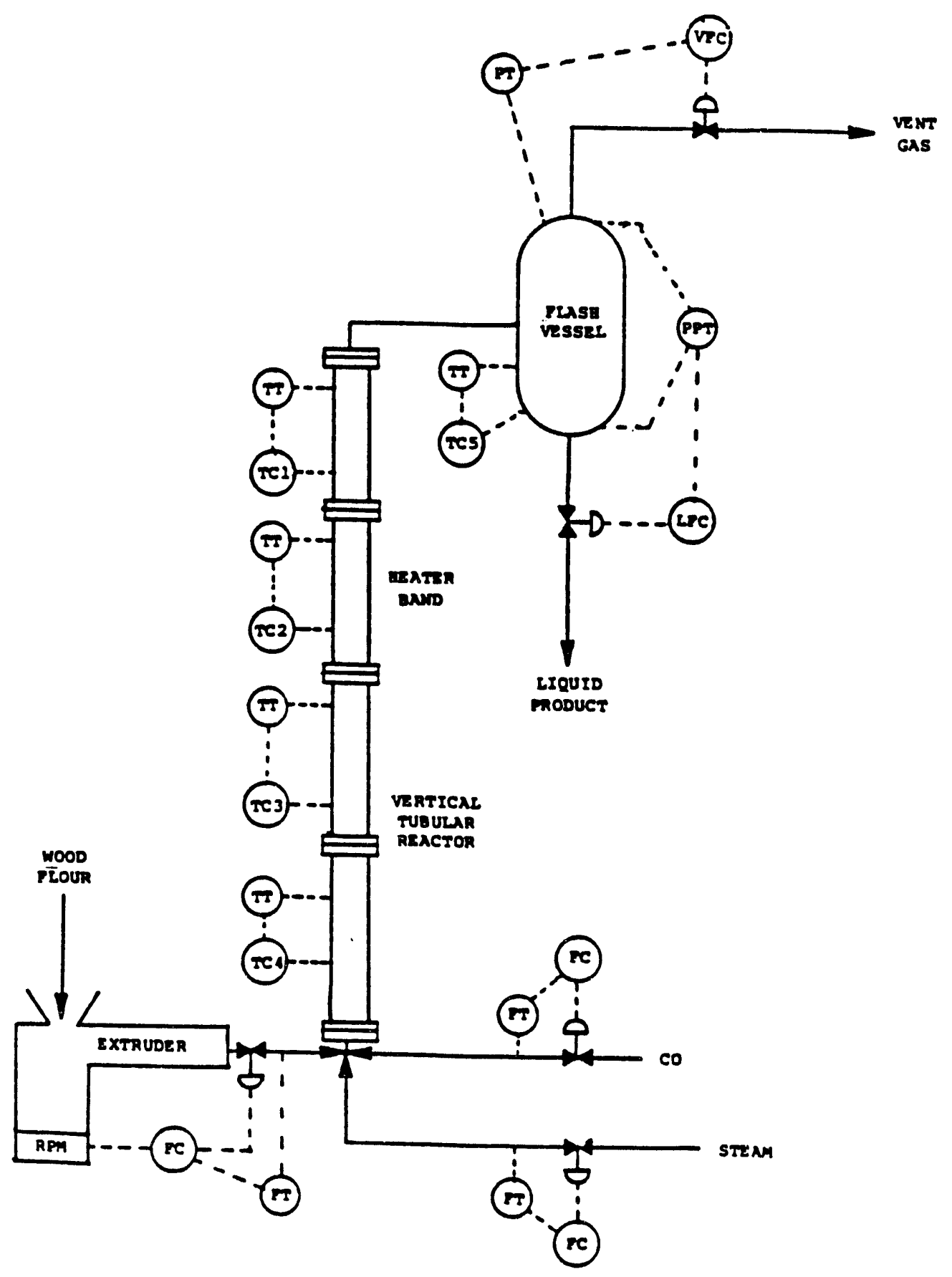

Figure 4.21. Biomass Liquefaction Process Control Schematic. 


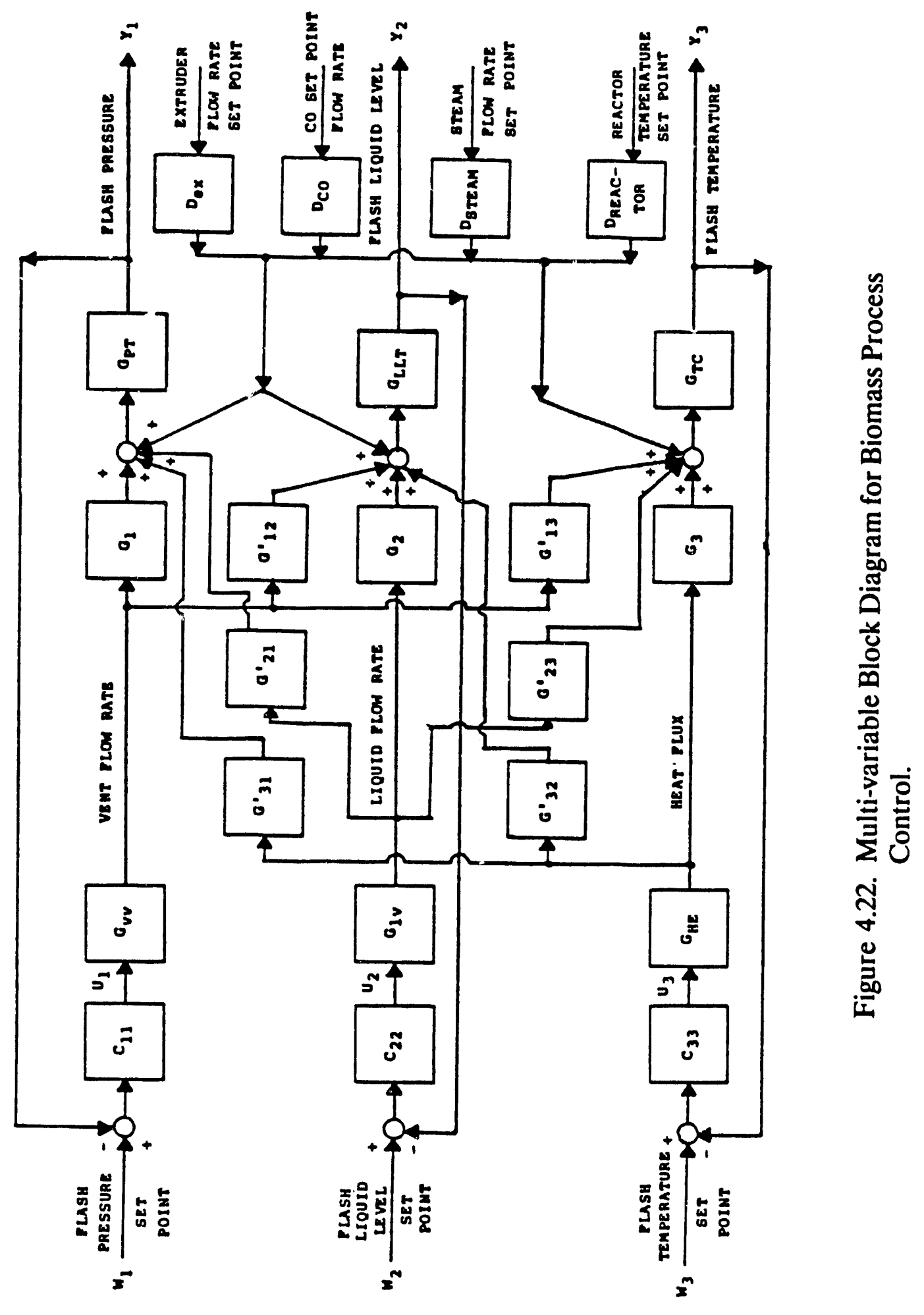




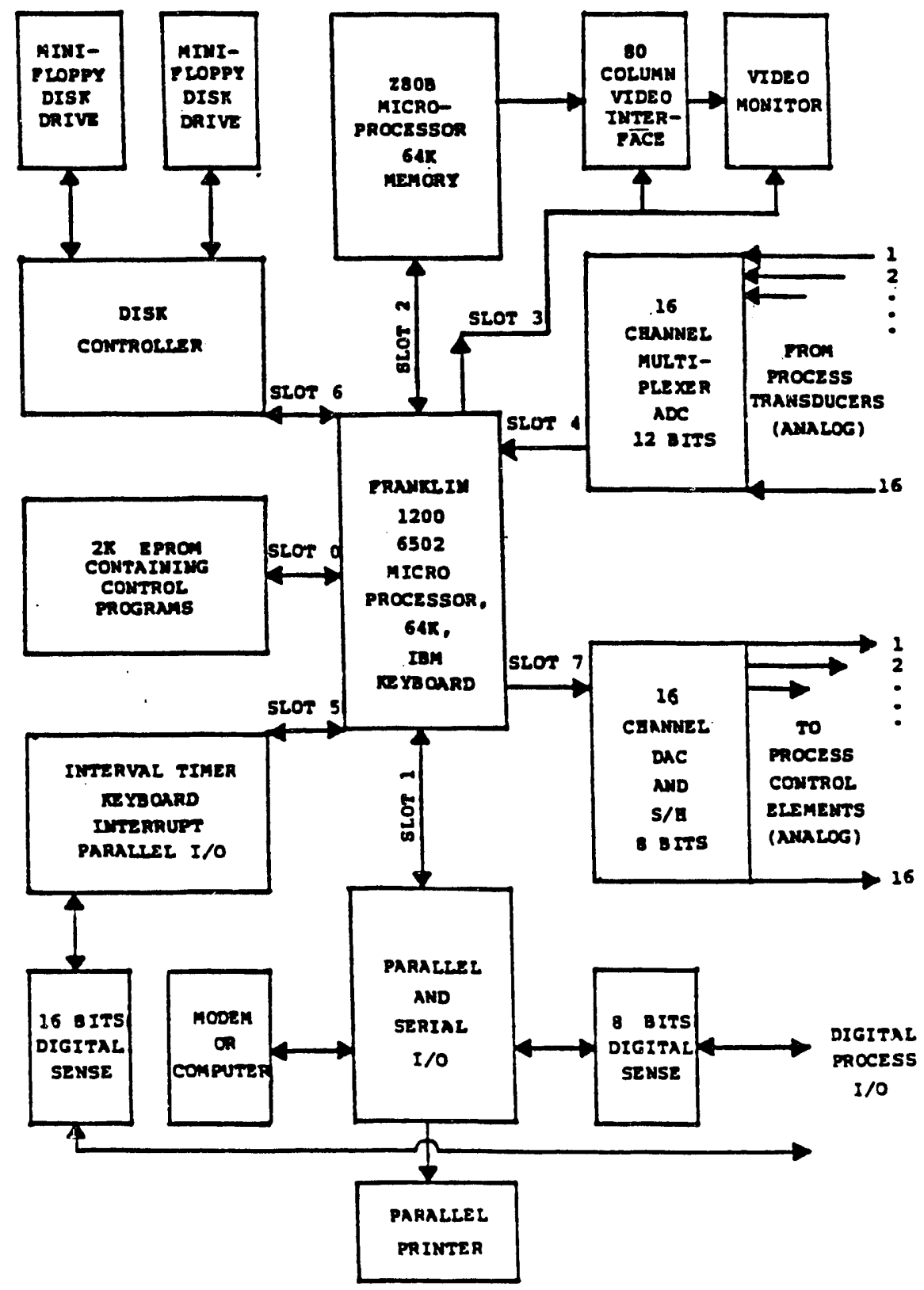

Figure 4.23. Franklin Microcomputer Control Hardware. 
regardless of the state of any other program, and must not be interrupted until task scheduling is completed.

The locking out of lower priority programs by higher priority programs is an important consideration in deciding a priority for process control programs. In order to maintain the integrity of the sampling operation, control programs must be serviced to within some reasonable margin of their sample interval. Placing PID control programs at the highest priority level under the task scheduler would insure other programs could not lock out control programs.

For the biomass process, the microprocessor has process control as a major priority, and was important that controllers be serviced regardless of the operating state of other real-time programs. For this reasons, the real-time operating system put the PID control programs at the highest priority level in the system.

To visualize the sequence of real-time program events, a macro-flow schematic of the real-time program structure is shown in Figure 4.19. The initial boot entry refers to the loading and initial execution of the PID, RTTS, CRTOS, I/O handler, and execution monitor programs.

The PID controller program uses the same type of priority scheme as the RTTS except that PID control programs cannot be interrupted. Therefore, regardless of whether a control loop is processed first or last, there cannot be more than a two millisecond per controller lag in actual sample time before a controller is serviced. For 16 controllers, this offset is negligible compared to the typical 1000 millisecond sample rates to be encountered. For more controllers and smaller sample times, faster sampling loops should be configured as lower indexed controllers; i.e., 0-8.

The real-time operating system can be considered a keyboard monitor (Mellichamp 1983 ) and responds to the interrupts generated by a keyboard. It is scheduled as the lowest priority program and can swap itself with other system monitors by setting a logic combination for entry and re-entry. The operating system is automatically initiated for immediate execution upon loading and can be booted into any priority level.

The KIM microprocessor utilized for the biomass liquefaction control is one of the first systems utilizing the 6502 microprocessor. The KIM system, shown in Figure 4.20, has a single printed circuit board which contains the 6502 microprocessor (MPU), two Peripheral Interface Adapters (PIA), 1000 (1K) bytes of Random Access Memory (RAM, light emitting diode (LED) display and keypad, and a cassette tape interface for program storage. The KIM operating system software resides in two PIA's. An application connector and a expansion connector allow for full utilization of the KIM and other operating systems.

The KIM operating system (KOS) contains a minimum number of tasks for program development and I/O. The single KIM board is serviced by KOS programs for cassette tape storage, and a parallel interface to a keyboard and LED display allowing for single byte memory modification and program execution. Other KOS programs are utilized with 
additional hardware wired to the application connector. These programs allow for use of a serial teletype interface, interval timers, and paper tape storage. An additional $4 \mathrm{~K}$ of memory is wired to the expansion connector to bring total system RAM to $5 \mathrm{~K}$.

Hardware added to the KIM system via the application connector included a teletype interface, cassette tape recorder, and an asynchronous communication interface adapter (ACIA). The teletype interface is an ASCII link to one of the PIA's that contains a teletype monitor. This monitor allows for simple memory display and modification. The cassette interface also uses one of the PIA's for storage and loading of memory. Machine language programs were developed using the KIM teletype monitor to load and the cassette tape interface to save memory. The ACIA was necessary as a link between CRTOS and a user terminal. The basic function of the ACIA is to convert a serial character transmission into a digital word. The ACIA can be programmed to operate in various modes, among them being interrupt mode. This ACIA generates the IRQ interrupts necessary for activation of the I/O handling program in the real-time operating system.

\section{Microprocessor/Process Interface Hardware}

The microprocessor interface consisted of digital and analog circuits needed to scale, select, and convert process signals to digital signals and vise versa. The analog interface consists of a multiplexer and an ADC for signals from process transducers and a DAC with $\mathrm{S} / \mathrm{H}$ for each analog output. As is usually the case, each analog channel required an operational amplifier circuit for scaling process signals to the range of the ADC and DAC. The process interface circuitry was developed so that additional channels would be added in modules provided additional space and power are available.

The ADC accepts scaled process inputs from an integrated circuit multiplexer presently hardware configured for eight process inputs. A voltage range of $-10 \mathrm{~V}$ to $+10 \mathrm{~V}$ is resolved into 12 bits or 4096 digital levels with an integrated circuit ADC. The multiplexer select and ADC duration is a relatively fast 40 microseconds. However, the MPU must waste the time needed to process 20 machine instructions. The digital output of the $\mathrm{ADC}$ and channel select pins are wired to the digital interface and then on to the MPU.

Analog process signals vary from millivolts to several volts. Individual amplifiers are used to maximize the input voltage range usage of the ADC. Single inverting op-amp circuits are used for scaling of process signals, and differential amplifier circuits were used to feed back valve-position. Micropotentionmeters in the op-amp feedback loops were used for gain adjustment. However, resistors must be replaced for major scaling changes (i.e., thermocouple to level transducer).

The DAC sample-hold circuit has individual DAC's for each output channel. The hold function is performed by latching the digital input as opposed to holding an analog output. Typical op-amp sample-hold circuits must be refreshed to compensate for voltage sag in the hold mode (Wait et al. 1975), and require a relatively long sampling delay. With an individual DAC for each output, the sample is held in a digital state which exhibits no 
sag and is sampled in microseconds. The analog output voltage exhibits a negligible amount of sag from the DAC, and does not need to be periodically refreshed. Since DAC's are relatively inexpensive, this method is much more desirable than multiplexing the DAC output to individual op-amp sample-hold circuits.

\section{Controller Real-Time Operating System}

The controller real-time operating system (CRTOS) is an assembly language program for modification and display of PID controller and RTTS parameters. This program is also used to shift control from the operating system to another. The CRTOS is an interrupt driven operating system activated by maskable interrupts from an external hardware device. It is an interactive program that guides the user through operation with simple keyboard responses.

With the KIM microprocessor system, five options are available for complete control system utilization. These options include: (1) modification of zero page memory, (2) modifying and displaying controller parameters, (3), turning on the real-time clock, (4) jumping to KIM operating system, and (5) modifying and displaying RTTS parameters. The CRTOS structure allows for options to be added without major software changes, and options can be initiated with a keyboard response or user scheduled real-time programs. The CRTOS does not include an option for program development; however, a jump to the KOS allows for machine language program development.

The CRTOS like the RTTS is driven by hardware interrupts. However, there is a major difference between these interrupts. As mentioned earlier, the RTTS is activated by non-maskable interrupts (NMI) from an interval timer. This means the RTTS is executed for each NMI regardless of the current microprocessor state. On the other hand, the CRTOS is activated by maskable interrupts (IRQ) from an ACIA. These IRQ interrupts can be software masked by other programs, thereby locking the CRTOS from user access. This is necessary for uninterrupted operation of the RTTS and user real-time programs.

The CRTOS is a keyboard monitor and responds to depression of keys at a serial keyboard printer/CRT terminal. Each time a key is depressed, the serial terminal sends an ASCII representation of the character on the key to the ACIA. When the ACIA data register is filled with the digital representation of the ASCII character, an IRQ interrupt is generated. If the IRQ interrupt pin is unmasked, the microprocessor detects the interrupt and starts executing the CRTOS program. 


\subsection{IMPLEMENTATION OF THE REAL-TIME COMPUTER PROCESS CONTROL SYSTEM}

The biomass liquefaction process is operated in a continuous mode. To simplify the real-time computer control system, it has been divided into several individual systems, namely, extruder-feeder system, carbon monoxide system, superheated steam system, vertical reactor system, off-gas let-down vessel system, and liquid-product pressure let-down vessel system.

\subsubsection{Extruder-Feeder Control System}

The important controllable parameters are flow rate and temperature of the extruderfeeder. The slurry is a pseudo-homogeneous non-newtonian liquid. Initially, flow through the extruder-feeder is controlled by adjusting the screw speed manually. An analog temperature controller is used to control the barrel temperature of the extruder-feeder.

\subsubsection{Carbon Monoxide Control System}

The flow rate of $\mathrm{CO}$ into the reactor is an important variable for control and liquefaction. A DDC loop operated by a micro-computer is desired to control about 24 $\mathrm{lb} / \mathrm{hr}$ maximum flow of $\mathrm{CO}$ to other reactor mixing zone. This flow controller is a noninteractive first-order control loop.

\subsubsection{Superheated Steam Control System}

The vaporizer system is the most unstable and complex sub-system of the superheated steam process. In this system, water is vaporized near its critical temperature and pressure. Three control loops are implemented for precise control of the system. A high-pressure metering pump is used as the final control element for the water level inside the vaporizer. A pressure control loop is used to keep pressure under the critical point. A pressure transducer signal is used to manipulate the controller output to the heater relay. A temperature controller is not needed for the critical temperature, as steam has a linear relationship of pressure and temperature. Flow rate of steam to the reactor mixing zone is also an important control variable. Flow rate of steam, measured by the volumetric flow meter, is used to regulate the flow through the final control element (control valve) by the flow controller.

The superheater has a temperature controller for its silicon heaters to prevent the overheating of the steam. A signal from a thermocouple is fed back to manipulate the controller output to the three-phase power relays. Complete discussion of the steam superheater design, instrumentation and operating procedure can be found in the MS thesis of Reyes (1985). 


\subsubsection{Vertical Reactor Control System}

Wood flour, carrier oil, $\mathrm{CO}$ and steam are reacted in a vertical plug-flow reactor at 1000 to $3000 \mathrm{psi}$ and $350^{\circ} \mathrm{C}$ to $400^{\circ} \mathrm{C}$. The conversion of wood flour to wood oil varies with reaction time, reaction temperature and reaction pressure. Four independent PID temperature control loops are required for the ultimate four reactor sections in order to maintain the reaction temperature at a desired setpoint value. The pressure of the reactor is maintained by the off-gas pressure of the pressure let-down vessel.

\subsubsection{Off-Gas Pressure Let-down Vessel Control System}

The gas from the reactor is flashed from the liquid product inside the high-pressure let-down vessel. The gas and liquid let-down systems are treated separately to provide better understanding of the control system strategies.

The off-gas pressure of the let-down vessel control loop is one of the most critical loops. The control valve is not only used to regulate the off-gas pressure of the let-down vessel but also, the reactor pressure is maintained by this control loop. Pressure let-down from 3000 psi to $750 \mathrm{psi}$ is achieved in this operation. This control loop is both a multivariable and interactive. This control loop has an extruder-feeder flow rate, a CO flow rate and a steam flow rate as disturbances. Also let-down vessel temperature, product liquid level and off-gas pressure are three coupled control variables involved in the control loop. A complete analysis of these control variables and disturbances is important for the computer modeling and simulation of control loops before the implementation of the digital control strategies. Isermann (1981) and Harris and Billing (1981), have developed tuning methods and analysis for the multi-variable control loop, which can be used to improve performance of the control loop.

The second stage of the off-gas pressures let-down involves another control loop, similar to the above loop. The control of the loop will be achieved in the second phase of the unit development when and if ever installed in the process.

\subsubsection{Liquid-Product Pressure Let-Down Vessel Control System}

The flashed liquid product inside the let-down vessel is a liquid wood oil and unreacted wood flour. To maintain stability within the let-down vessel and reactor, the design specifies a constant liquid level. Any major disturbance occurs inside the let-down vessel would affect the entire system, especially the reactor process conditions. Continuous liquid-level measurement and control would stabilize the liquid-product let-down vessel system. The continuous level measurement signal is used to manipulate the controller output. This control loop is also multi-variable and interacting with the same disturbances and control variables as described in the off-gas let-down system.

In order to reduce noise and voltage fluctuations in signal processing and transmission, 4-20 ma output from the transducers and 4-20 ma input for the final control elements were essential, as the control room is more than 50 feet away from the process instruments. 


\subsubsection{Extruder-Feeder Sensors}

Seven pressure transducers and thermocouples are mounted on the extruder-feeder in three different zones; melting zone, compression zone and feeding zone. These data are needed for the complete analysis of the process dynamics. A schematic layout of the instrumentation is shown in Figure 4.24.

It would be difficult to mount all the instruments individually on the $4 \mathrm{ft}$. long and 1$3 / 4$ " ID extruder-feeder barrel. The mounting of a pressure transducer and a thermocouple onto the same mounting hole are detailed in Figure 4.25. A 6" long stainless steel threaded tube filled with high temperature silicon grease is used to isolate the high temperature from the pressure transducers. The relationship between length of tube and temperature is shown in Figure 4.26 (Dynisco, Technical data sheets).

Precise Sensors Inc.'s Model \#113-3, flushed diaphragm pressure transducers were specified for pressure measurement on the extruder-feeder. These transducers have a combined non-linearity and hysteresis of less than $\pm 0.25 \%$ of Full Scale Output (FSO) with repeatability of less than $0.081 \%$ and a rise time of 10 micro-seconds. The maximum operating temperature of the transducer is $149^{\circ} \mathrm{C}$ and pressure ranges are from $0-3000$ to 0-5000 psi. Highly sensitive signal conditioners are used to convert the $30 \mathrm{mv}$ FSO to 4-20 ma current outputs for 0.1 to 500 ohms load. These Precise Sensors Inc. signal conditioners are matched with their pressure transducers and have $a \pm 0.02 \%$ of range measurement accuracy with infinite resolution.

The extruder-feeder system uses seven thermocouples to measure the slurry temperature which ranges from $40^{\circ} \mathrm{C}$ to $150^{\circ} \mathrm{C}$, depending on the thermocouple location on the barrel. Twelve inch long Iron constantant ungrounded thermocouples were specified for good resolution at these temperatures. The Omega Engineering Inc.'s model \#1CSS316U-12 with a 3/16 inch sheath diameter can be used at temperatures as high as $760^{\circ} \mathrm{C}$ with almost linear output in $\mathrm{mV}$.

\subsubsection{Superheated Steam Sensors System}

The vaporizer, where boiling at the critical pressures and temperatures occurs, is one of the most important components of the superheated steam system. Most of the instrumentation of the system lies in and around the vaporizer. A schematic layout of the instrumentation for the superheated steam control system is shown in Figure 4.27. The vaporizer has two level point switches, the high and the low, for level control; a pressure transducer and a power relay for pressure control of the heaters; a thermocouple; and a flow controller with a flowmeter and control valve as the measuring and final control elements. The superheater has two thermocouples and two pressure transducers for the calculation of temperature and pressure drop across the superheater. Five ON/OFF AOVs are used for safe operation of the system and as bypass lines. 


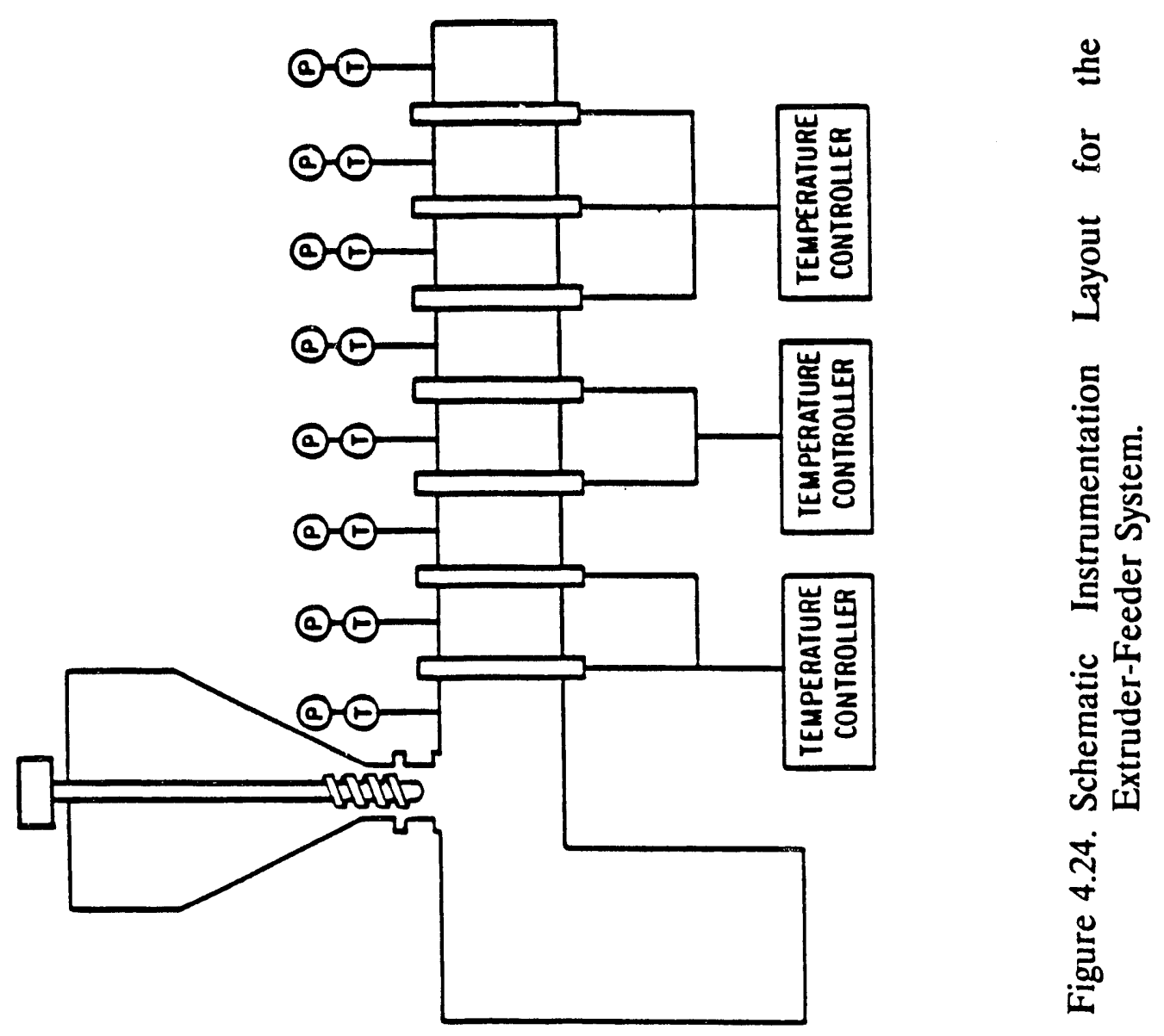




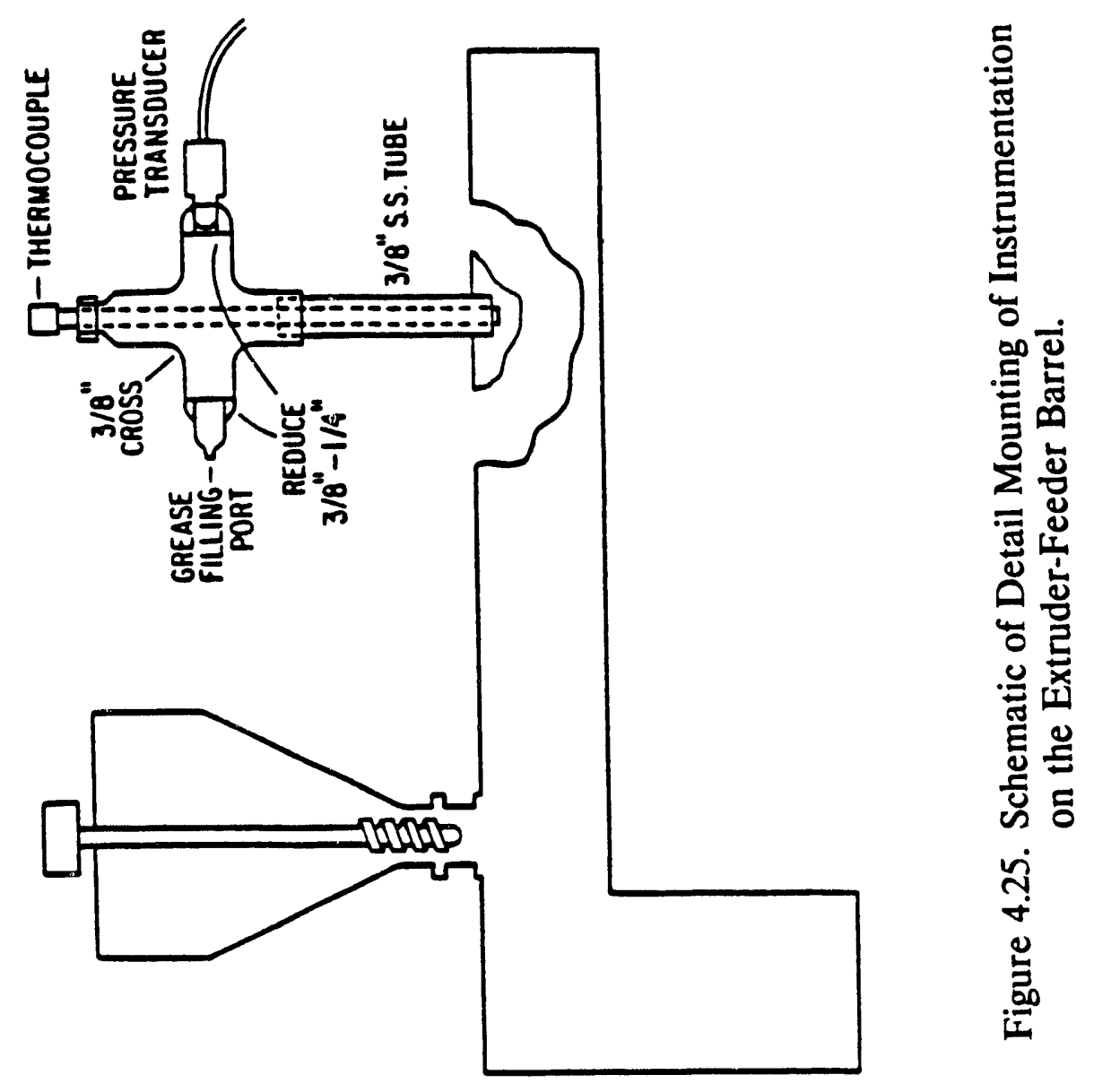




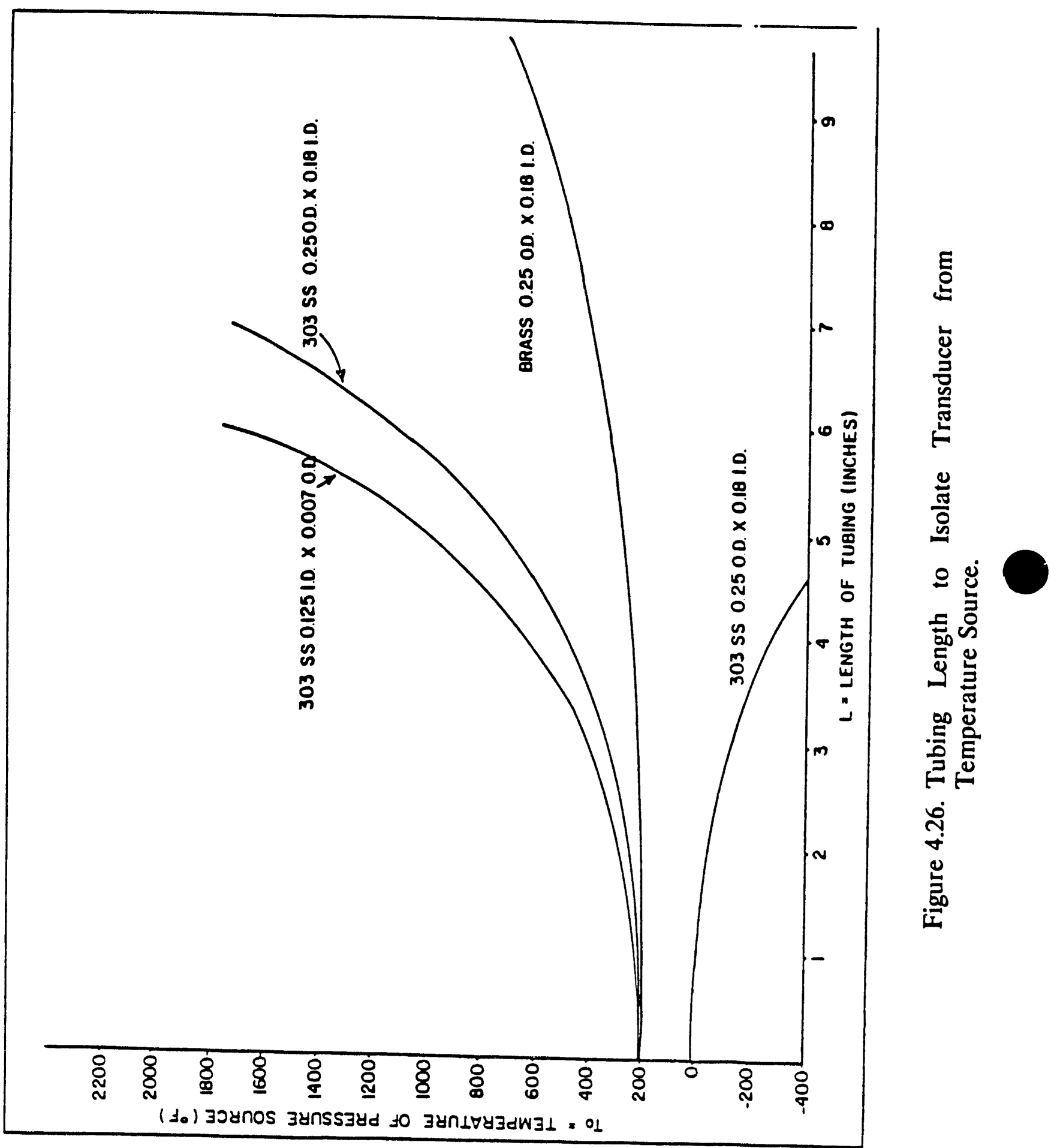




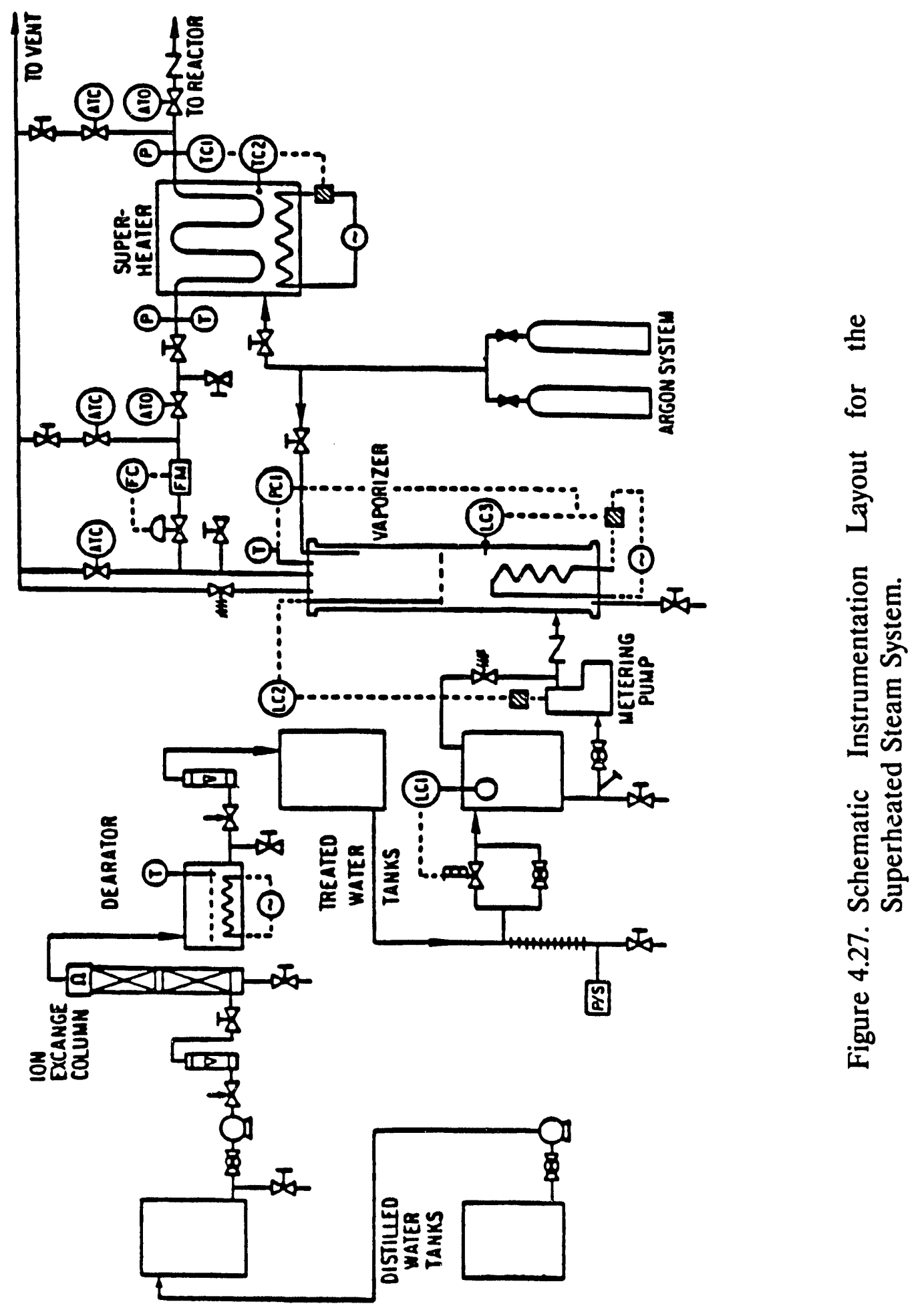


Precise Sensors Inc's Model \#5550 pressure transducers were specified with the same specifications as described in the $\mathrm{CO}$ system section. In order to isolate the transducers from the high temperatures, 6-9" of stainless steel tube coil is used. The maximum operating temperature of the pressure transducer is $149^{\circ} \mathrm{C}$.

Initially, the flow controller was to measure the flowrate of steam after the superheater. But in the superheater there are no disturbances or obstructions to change the flowrate from the vaporizer. The revised design consists of a flow meter and control valve. This arrangement increased the availability of the flow meter and the control valve. Maximum steam flowrate is constrained to at $\mathbf{4 0} \mathrm{lbs} / \mathrm{hr}$ to the reactor mixing zone. The flowrate of the saturated steam is measured by the precise turbine flow meter, specially made by Flow Technology Inc. This flow meter can measure the flowrate from 0.0035 to $0.70 \mathrm{ACFM}$ at $370^{\circ} \mathrm{C}$ and 3100 psi. A pulse converter is used to change frequency output from the flow meter to 4-20 ma or 1-5V output signal.

A critical service control valve is needed to control the low flowrate to the reactor at $3100 \mathrm{psi}$ and $370^{\circ} \mathrm{C}$. A Masoneilan Model \#5061 Wee-Willie control valve is designed for this type of low flowrate and high pressure and temperature application. The Wee-Willie Valve is also a custom-made angle-control valve with an alloy 25 trim and plug. The actuator of the valve is DOMOTOR, which has high thrust, stiffeners and large stroke for smooth flow control. An extended bonnet is used for higher temperature applications of the steam.

\subsubsection{Vertical Reactor Control Sensors}

Data from the thermocouples, pressure transducers and sampling ports are required to obtain Residence Time Distribution (RTD), and the pressure and temperature relationships of the reactor system. A schematic of the instrumentation layout for the vertical reactor system is shown in Figure 4.28. Each section of the reactor has five thermocouples at equal distance measuring the wall temperatures of the reactor. Each spool and the flange has a thermocouple, a pressure transducer and a sampling port to measure the actual temperature, pressure and conversion of slurry, respectively.

Four PID control loops have four power relays as the final control elements to drive the heaters at the desired reaction temperature in the each reactor section.

Five normally closed AOV's and five normally open AOVs were needed for the sampling system at each reactor spool and the flange. The AOVs are driven by lowpressure, electrically-actuated solonoid valves. Autoclave Engineers Inc. AOVs were specified for the sampling operation.

All 25 thermocouples in the reactor are 12" long ungrounded iron constantant probes, the same as described in the Extruder-feeder system section.

In order to avoid plugging of slurry and inaccuracy of pressure measurement of the transducers, a flush-diaphragm type of pressure transducer is essential for this system. 


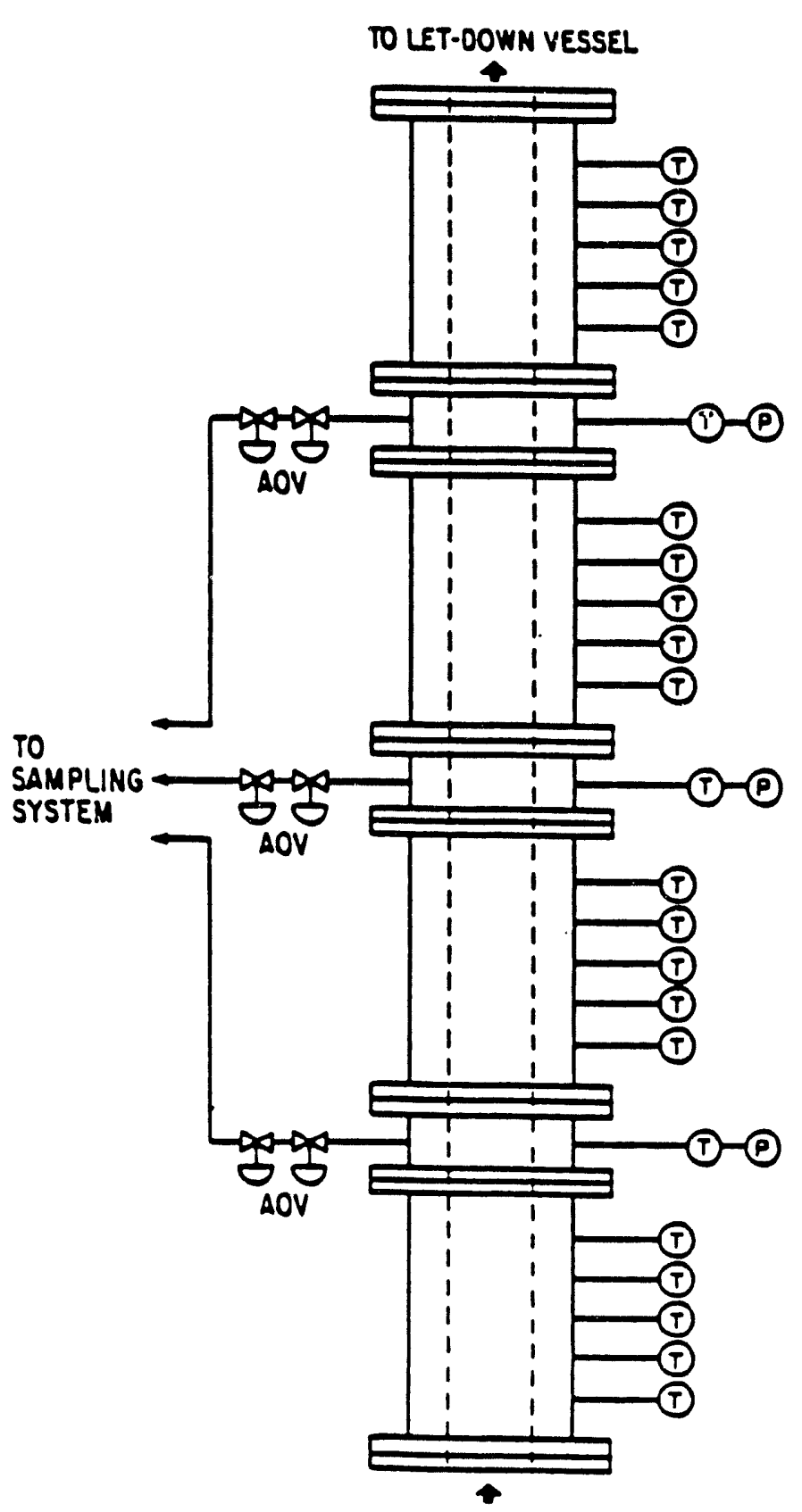

FROM EXTRUOER-FEEDER

Figure 4.28. Schematic Instrumentation for the Vertical Reactor System. 
Dynisco pressure transducers are well-known to the plastic industries for this purpose. These stain-gauge transducers are designed for use at high temperature and pressure applications. In addition, they can be mounted easily on the reactor without any temperature isolation techniques. Dynisco Model \#PT 462E pressure transducers, with a range of 0-5000 psi, were specified. These transducers have a combined error of nonlinearity and hysteresis of $\pm 1.0 \%$ of FSO and repeatability within $\pm 0.2 \%$ of FSO, with infinite resolution. The maximum operating temperature of the transducers is $400^{\circ} \mathrm{C}$ with $80 \%$ of FSO internal shunt criibration resistance. Dynisco Model \#SCM 600 matched signal conditioners are used to convert the pressure transducer signals $10-40$ millivolts (mv) to 4-20 ma output signals. The linearity of the signal conditions is $0.1 \%$ of FSO with a response time of only 10 milliseconds from $10 \%$ to $90 \%$ FSO and accuracy of $0.1 \%$ of FSO.

\subsubsection{Off-Gas Pressure Let-Down Vessel Control Sensors}

The Off-gas let-down vessel system is one of the most critical systems of the AERBL unit. This system contains four thermocouples, three pressure transducers, a control valve as a final control element and twelve ON/OFF AOVs as shown in Figure 4.29.

Initial operating procedures for the Off-gas let-down vessel system are to control pressure of the let-down vessel and purge out all the gas to the vent. Two heat exchanges, a medium-pressure let-down vessel and a light-product recovery will be installed in the latter part of the development of the unit.

The pressure transducers specified for the first stage of the pressure let-down system were the Dynisco Model \#PT462E with a 0-5000 psi range and the Dynisco Model \#SCM600 matching signal conditioners. The specifications are the same as described in the Vertical reactor system section. Pressure transducers used after the first heat exchanger could be lower temperature transducers, such as Precise Sensor Inc.'s Model \#113-3. These are as accurate as the Dynisco transducers but can be used up to $150^{\circ} \mathrm{C}$ and are more economical.

Iron Constantant ungrounded thermocouples are within the range of these process conditions 12" long thermocouples with the same specifications as those of the extruderfeeder system are also used for temperature measurement.

Masoneilan's Model \#29000 service MICROPACK Control Valve with a $\mathrm{C}_{\mathrm{v}}$ of 0.6 was specified as the final control element for the off-gas pressure controller. The estimated $\mathrm{C}_{v}$ for the valve is 0.01 at $350^{\circ} \mathrm{C}$ and 3000 psi. Specifications of the valve are the same as described in the CO system except for a difference in the flow coefficient. $\left(\mathrm{C}_{\mathrm{v}}\right)$.

Twelve AOVs were specified for the emergency pressure relief and sampling system. Out of the 12 AOVs, four are normally open and the other eight AOVs are normally closed. 


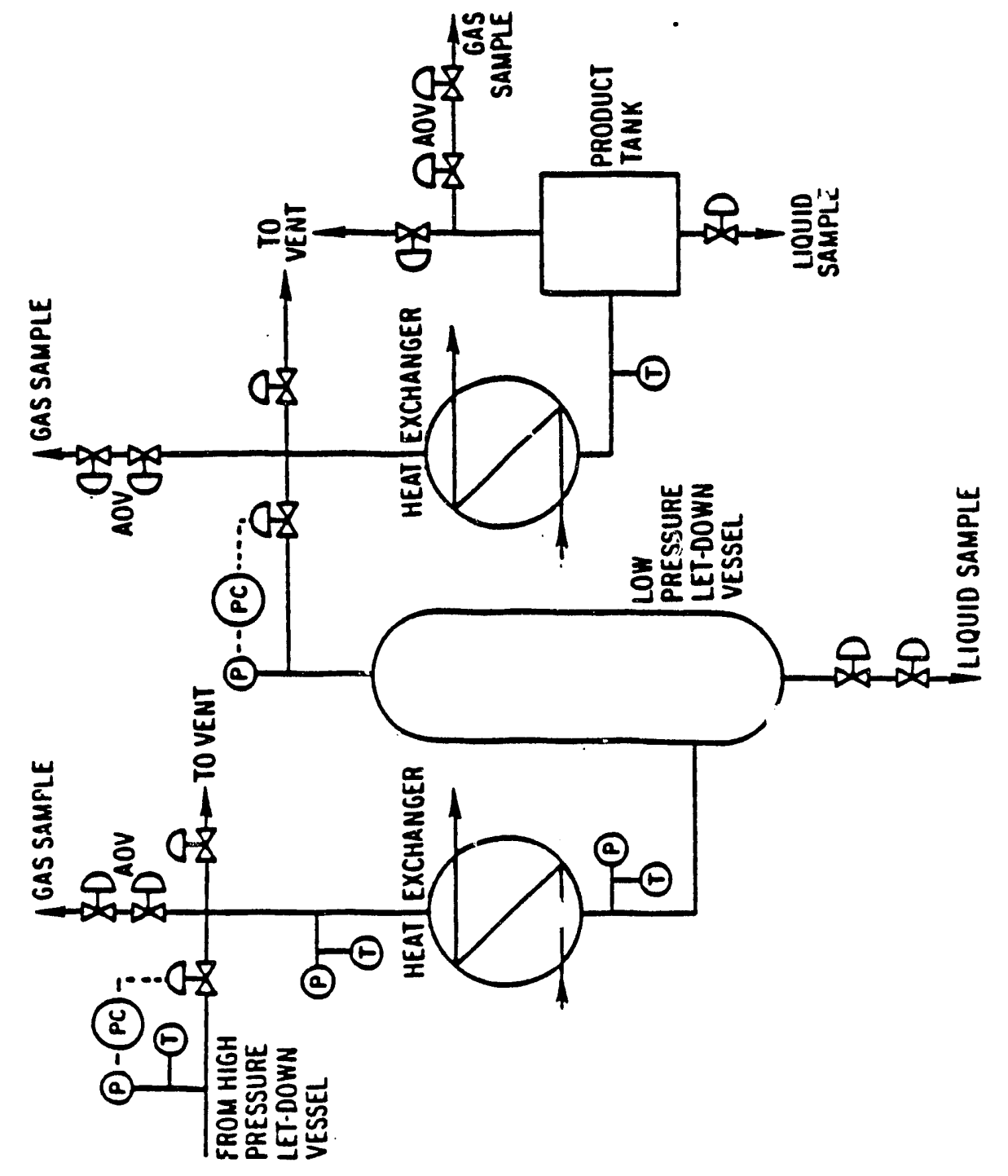

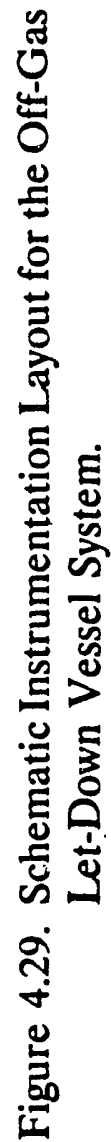




\subsection{THE COMPUTER HARDWARE DEVELOPMENT}

Digital computer interface hardware is composed of two sub-systems, namely, interface control hardware and process control hardware. Before discussing the development of the hardware, it is important to overview the 6502 based Franklin ACE-1200 micro-computer system. The 6502 based micro-processor was used for the direct digital control, data acquisition and the real-time scheduler. The ACE- 1200 system utilizes a 6502 based 8-bit micro-processor with 64 kilobytes of memory, two floppy disk-drive units and a floppy disk controller card. The resident ROM has Franklin Basic and Franklin Assembly monitor routines. The micro-processor board hardware is compatible with the APPLE-He micro-computer. The compatibility of the mother board hardware allows many custommade hardwares to be used for the ACE- 1200 system. the Franklin ACE- 1200 mother board has seven expansion slots available for $\mathrm{I} / \mathrm{O}$ operations and System expansion.

A Z-80 based micro-processor board with another $64 \mathrm{~K}$ of memory and an 80-column board are also available for the system when they are needed. These features are not useful at the present time, as the control real-time operating system (CRTOS) is based on 6502 instruction codes. The transfer of 6502 codes to Z-80 instruction codes can be achieved with little difficulty. However, interrupting both micro-processors in the time-sharing facilities required communication routines. Also, the 6502 clock speed is only $1 \mathrm{MHZ}$ while the Z-80 microprocessors work at $3 \mathrm{MHZ}$ clock speed. Another major difficulty of using both processors at the time sharing environment routine and the CRTOS routine is that it is difficult to fit into the present size of memory of the Franklin ACE-1200.

\subsubsection{Interface Control Hardware}

The micro-processor commands for the input/output (I/O) depend upon the hardware design of the micro-computer. There are two common methods for producing the commands by the micro-computer; memory mapping and isolation of the I/O ports. The 6502 based micro-processor control System uses the memory mapping procedure. In this method, the decoder causes the micro-computer to function as though it were reading or writing to memory, so the "port" becomes effectively like a memory address. A block of memory addresses is set aside as the input and output channels. For input, the microprocessor system simply reads these memory locations and for output operation, the computer simply writes to these memory locations.

A Digital to Analog Converter (DAC) for the analog output system is used to convert the digital-word (binary numbers) to the equivalent analog voltage. The digital word is considered as a percentage or fraction of the same reference signal.

The process control system initially had eight control loops, which required eight output channels to the DAC. Interactive structure Inc.'s Model \#AO3, 8-bit output system is designed for 8 individual channel configurations. The $\mathrm{AO} 3$ was used at $\mathrm{O}-10 \mathrm{v}$ in the unipolar voltage range and -5 to $\pm 5 \mathrm{v}$ for the bipolar range. Linearity of the $\mathrm{AO}$ \# is $\pm 1 \mathrm{LSB}$ and conversion time is 3 microseconds. 
The Analog to Digital Converter (ADC) was used for converting analog signals into their corresponding binary numbers. The analog input system is normally made of ADC, multiplexers and sample holds. Analog signals are generally represented in fixed-point forms.

Interactive structures Inc's Analog input system \#AI13 was specified for the control and data acquisition systems. The AI13 is a 12-bit ADC with 16 input channels and eight different input, full scale ranges in unipolar and bipolar modes. The conversion time of each input signal is 20 microseconds. The 12-bit ADC for the 0-5v unipolar input range measures input step up to $0.00122 \mathrm{v}$ per unit number $\{1$ (Hexadecimal) $\}$.

An interval timer circuit using a 6532 timer chip was developed and constructed (Andrews, 1983) for the 6502 based micro-processor control system (Franklin ACE-1200) to operate the Control Real-Time Operating System (CRTOS). The keyboard activation circuit was developed to generate IRQ interrupts by keyboard depression. Implementation of the ADC and the DAC on the Franklin ACE-1200 expansion slot started crashing the interval-timer clock circuit after a few hours of operation. A mis-match logic circuit of the interval timer necessitated the custom-made real-time clock board.

"Thunderclock Pius" is a real-time clock with three software selectable interrupt rates at 64,256 , and $20480 \mathrm{~Hz}$. This real-time clock has a built-in interval timer and a clock, which provides month, date, day, our, minute and second. A combination of the clock and interval timer is used to run and store the real time data acquisition program, as time from the clock is useful for analysis of the data. The Thunderclock has on-card batteries to keep the clock/calendar running when the power of the computer is off.

Figure 4.30 illustrates the 6502-based microprocessor (Franklin ACE-1200) system control hardware after complete hardware installation, including I/ O module expansion. the 6502-based microprocessor is the heart of the Franklin ACE-1200 system. Out of eight expansion slots of the ACE-1200 system, the I/O device occupies four slots and one slot each is occupied by the real-time clock and the disk drive controller board. Slot \#7 on the ADC board is dedicated to PID controllers for feed-back measurement and Slot \#5 is multiplexed from 16 to 18 channels for data acquisition.

\subsubsection{Process Control Hardware}

Process interface hardwares are used to make I/O hardwares compatible with the process transducers and other analog devices.

The ADC used 0-5v as input but most of the process signals are all in 4-20 ma, 0-10v or mv range. The conversion of the signal is made by developing two circuits: one for $4-20$ ma input to $0-5 \mathrm{v}$ output and another from $0-25 \mathrm{mv}$ input signals of thermocouples of $0-5 \mathrm{v}$ output. 


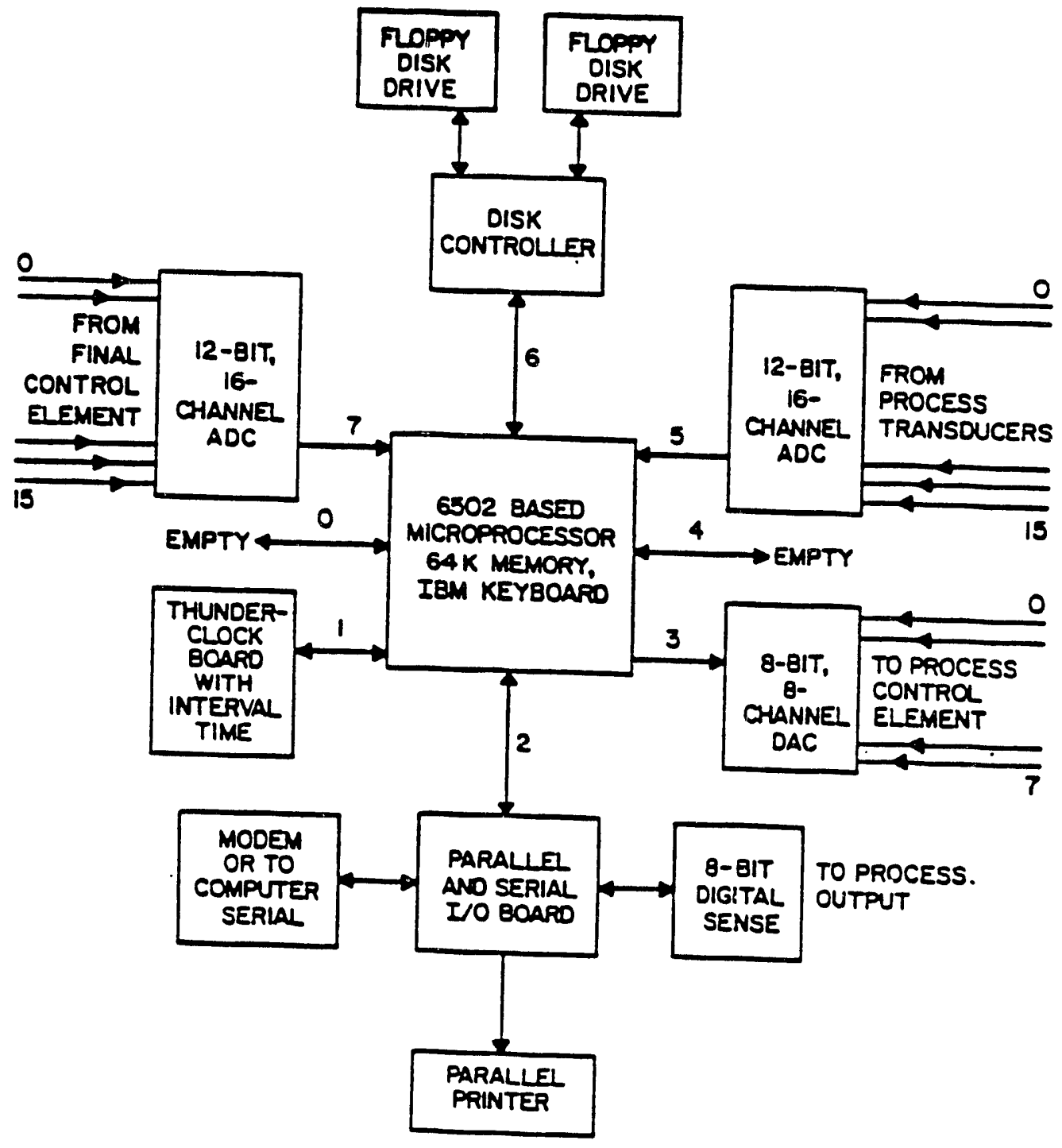

Figure 4.30. Franklin ACE-1200 Microcomputer System Control Hardware. 
To transform 4-20 ma to $000-5 \mathrm{v}$, resistors of equal calibration to the transducers of the signal conditioners input impedance are used across the input current signal. For better accuracy and resolution, operational amplifiers (Op-amps) can be used.

For the other circuit, thermocouple output is measured in $\mathrm{mv}_{\mathrm{s}}$, which are amplified into volts. For 50 feet of cable, from the process area to the control room, mv signals will create a voltage drop across the line.

- Noises from other signals in the line may also create a voltage drop across the line. Figure 4.31 illustrates the op-amps circuit for each thermocouple signal. The op-amps is used to amplify the signal at a gain of 200 . The circuit has zero and span calibration features. Thermocouples interfacing with the electronic cold junction for $\mathbf{n}$ numbers of thermocouples are shown in Figure 4.32. Note that only common (negative) leads of thermocouples are tied together at the cold junction.

The DAC has 0-10v output and all the final control elements use 4-20 ma as an input signal. A conversion from the $0-10 \mathrm{v}$ to the $4-20 \mathrm{ma}$ circuit is needed for interfacing the DAC to the process. The op-amps circuit for voltage to current conversion is shown in Figure 4.33 for each DAC channel. The op-amps are calibrated by resistors for each final control element and their input load impedance. the zero and the span calibrations are included in the circuit for final adjustment.

\subsubsection{The Software Design}

The Control Real-Time Operating System (CRTOS) Software, written by Andrews (1983), was adopted as the control algorithm of the AERBL unit and the MSW process. This software was written for sixteen PID control algorithms and eight real-time schedule programs. The PID control algorithm can be expanded up to 256 control loops when necessary.

The CRTOS has three main programs: The PID, the RTTS (Real-Time Task Scheduler) and the interactive I/O programs for the screen. For complete discussion of software algorithms, readers can refer to M.S. Thesis, Andrews (1983).

The CRTOS program was not tested with the ADC and the DAC for the FranklinACE-1200 system. Modification of the program was done to make the ADC and the DAC board compatible to the CRTOS. Also, the new real-time clock board required modification of the CRTOS, as Thunderclock generates IRQ interrupt vectors. The PID algorithm of CRTOS was originally written and tested for the KIM 6502-microprocessor at the laboratory control apparatus in the Department of Chemical Engineering, which uses negative input and output voltages; whereas biomass control unit utilizes positive input and output voltages for the process instrumentation. As the PID algorithms were transferred to the Franklin ACE-1200 system without modification from the KIM microprocessor, I/O routine modification was done for the positive input and output voltages. 


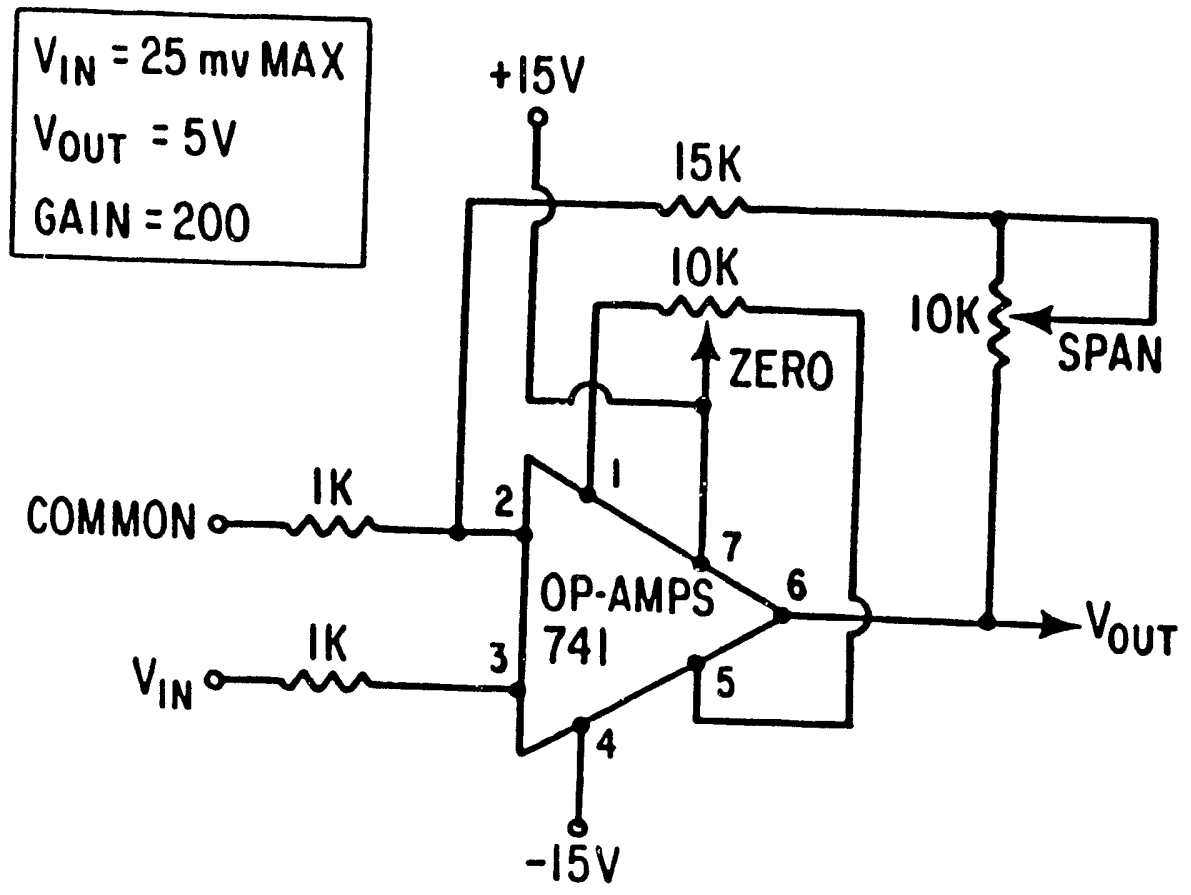

Figure 4.31. Op-Amps Circuit for the Thermocouples. 


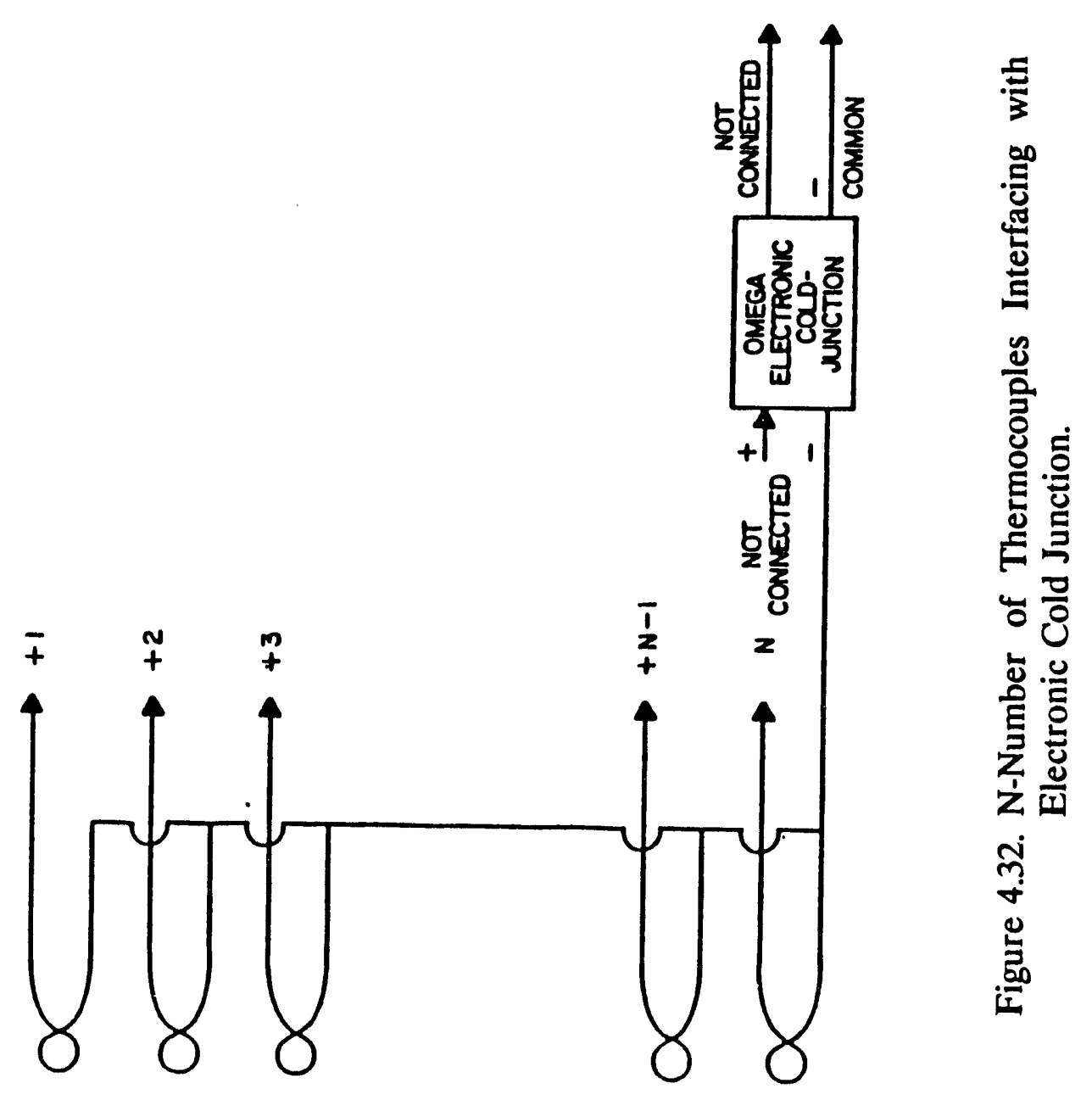




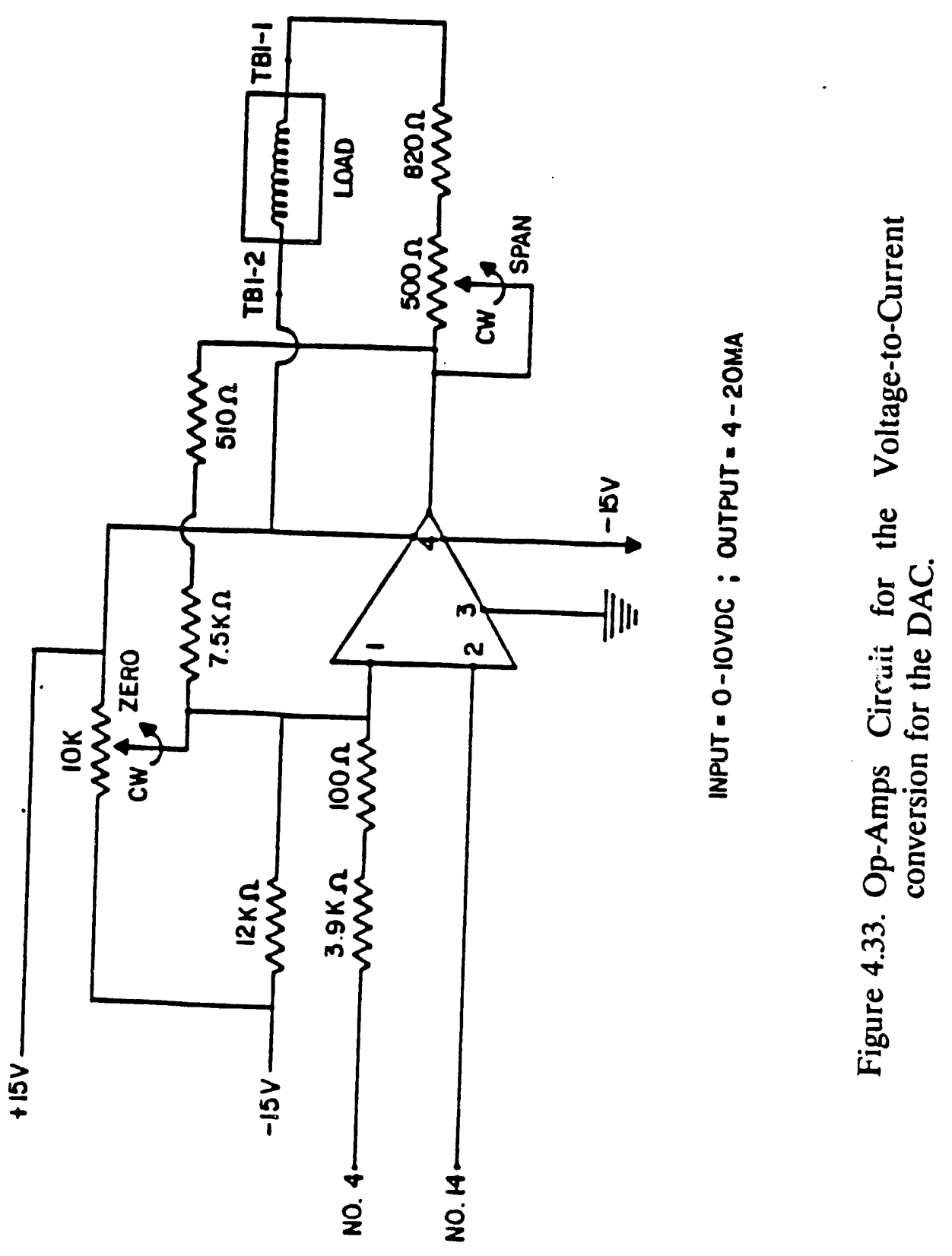




\subsubsection{Data Acquisition Strategy}

It should be noted that $\mathbf{1 1 5}$ data points are required by biomass liquefaction for mass balance, heat balance and residence time distribution calculations. A data acquisition system was developed for data collection. The standard ADC board has sixteen multiplexed channels. This board is multiplexed to 128 channels using sixteen Burr Brown 8-bit multiplexer. An individual channel is selected by utilizing the three external bits. The 6502 based Franklin ACE-1200 has annucitor special locations from CO58 to COSF (Hexadecimal) for the game I/O. Each Annucitor (four one-bit output) has two addresses available for the ON/OFF state. The schematic strategy for multiplexing the 16 channels to 128 channels is shown in Figure 4.34. Desired channels are accessed by first addressing the multiplexer through the proper ADC channel and then selecting the required channel ' $y$ the annucitor bits. A data-acquisition, real-time algorithm is written by sampling each ciannel in sequential fashion, incrementing a sampled channel by one after reading each channel. the sample data are stored in the memory and then transferred to the floppy disks for permanent storage.

The data acquisition program is scheduled by the real-time task scheduler of the CRTOS. Extra care is needed to schedule the data acquisition routine, as the PID routine uses the same clock. Small sampling periods of the PID controller can crash the CRTOS. The transfer of data from memory to floppy disks is possible when the real-time clock is off, as the disk drive uses the Direct Memory Access (DMA), which can also crash the real-time clock. A proper operating and scheduling procedure is used to run the data acquisition program.

\subsection{CONSTRUCTION OF LIQUEFACTION PLANT}

Construction of the experimental liquefaction unit began in June, 1983, while the process design and mechanical design were still in progress.

\subsubsection{Process Structure and Concrete Pads}

Structural steel for the reactor and related vessels support were procured and delivered, together with the necessary rebar and concrete for structure foundation, process concrete slab, and drum storage. concrete slab. The excavation, leveling and forms were placed for four footings for the vertical structure, for a $27-\mathrm{ft}$. 28 -ft. process slab, and for a 12 -ft. $x$ 27-ft. storage area. All concrete for these three items were poured. The four vertical steel corner structures were mounted by crane.

\subsubsection{Major Process Equipment}

During September, 1983 the mechanical design was nearly completed. The control valves were ordered; also, a renovated extruder-feeder purchased in the Houston, Texas area was nearly ready for shipment. Construction was directed toward the process area, concrete wail, the structure for the hoist, and initial construction of the frame for the steam superheater. 


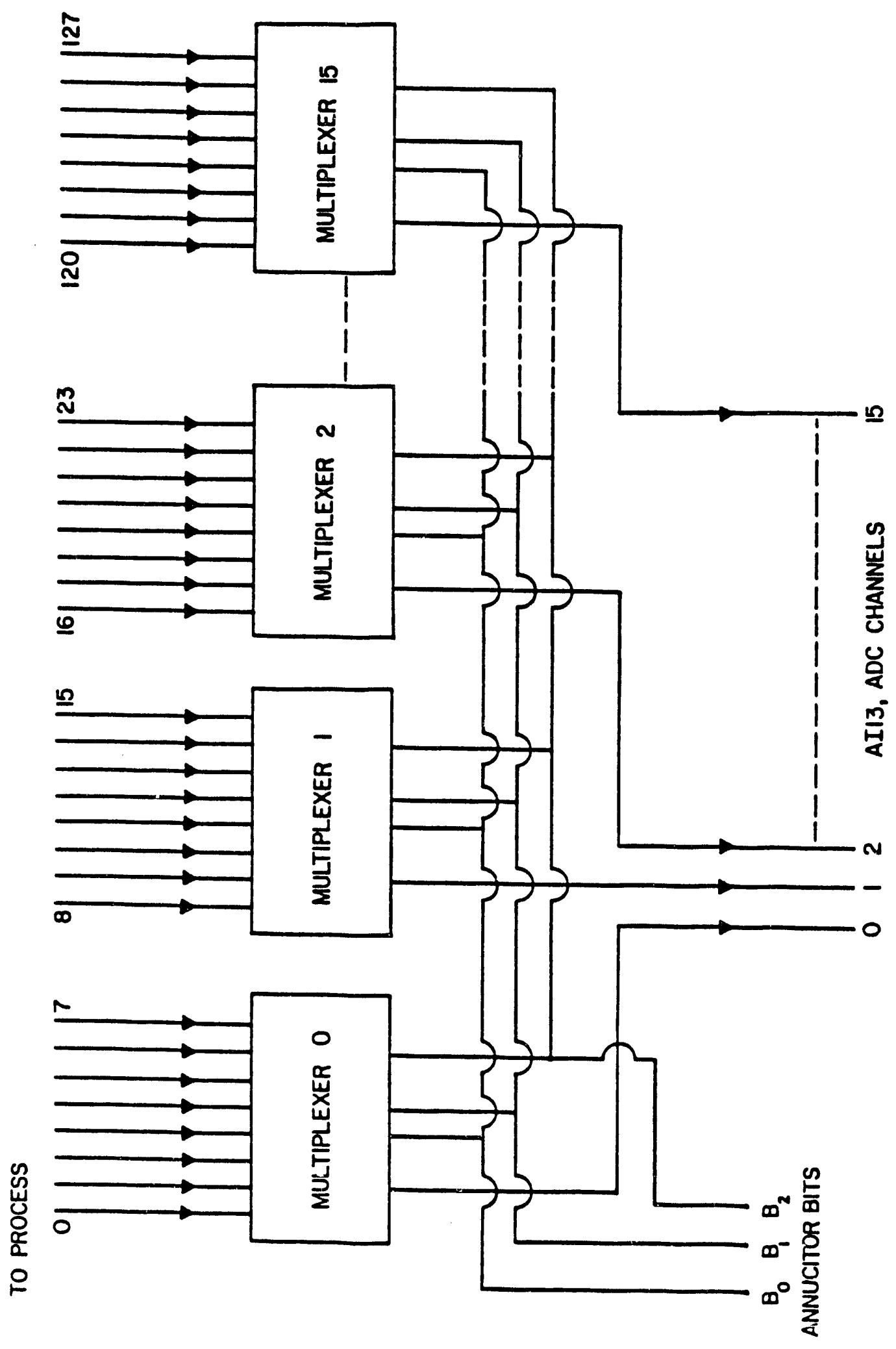

总 
During November, 1983, procurement of instrumentation continued with most vendors selected. With respect to the steam superheater, which was constructed on site, the vendors for electrical ciements, refractory and high-temperature tubing were contacted and selected. With respect to the verijcal reactor, some used Xalloy-linect extruder barrels were utilized. Autoclave Engineers was considered for fabricating the high-pressure let-down vessel, but eventually a used Xalloy-lined extruder barrel was utilized.

During January, 1984, the extruder-feeder barrel was disassembled and taken to the University Instrument Shop, where a series of holes were drilled and tapped through the thick barrel wall so that pressure transducers and thermocouples could be installed for its operation. The design of the steam superheater was modified to make it a more compact unit.

The most important event of May, 1984 was the acquisition of several important items of biomass liquefaction equipment from the dismantled DOE Albany, Oregon facility. Shortly after the equipment became available for purchase by anyone interested, Dr. Don White inspected the equipment in Albany, Oregon on May 7, 1984. A reasonable purchase price was negotiated by Gary McAtee of Battelle Pacific Northwest Laboratories. The equipment purchased included one carbon monoxide compressor, two small Bran-Lubbe wood flour slurry pumps (to be used for oils and catalysts), one heat exchanger (to be used to preheat carbon monoxide), two medium-pressure let-down vessels and some miscellaneous electrical switches and boxes.

During June, 1984, the necessary three sections of used 3 1/2-I.D. Extruder barrels were located and orders placed for their purchase. These have steel barrels, lined with corrosion-resistant "Xalloy," an alloy similar to Hastalloy C, and are designed for 10,000 psi pressures. One section was used for the vaporizer for the steam superheater, one section for the high-pressure let-down vessel, and one section as a spare.

Much construction progress was made during the summer of 1984 through the hiring of a crew of ten undergraduate and graduate students majoring in chemical engineering. A senior undergraduate student in chemical engineering was appointed construction foreman. He assigned specific tasks to other undergraduate students, as well as interfacing with Dr. White, Dr. Wolf, and several graduate students, all devoted to this project. One person looked after each major process system, namely the extruder-feeder system, the reactor system, the CO compression system, the steam superheater system, the catalyst system, the feedstock preparation system, the let-down system, the instrumentation system, the microprocessor system, the sampling and product collection system and analytical procedure. All personnel by necessity crossed lines to achieve all necessary theoretical calculations, design calculations, selection of equipment specifications, procurement, construction and installation.

With the extra undergraduate student help available during the summer of 1984 , numerous construction tasks were completed, including but not limited to the following: 
1. Installation of the corrugated steel roof over the outside storage area.

2. Installation of the supplemental main electrical power boxes.

3. Installation of the electrical conduit to the process area and installation of individual unit power.

4. Installation of the extruder-feeder, bolting it to the concrete floor but with supporis that can be moved vertically and horizontally.

5. Installation of the carbon monoxide compressor.

6. Partial construction of the steam superheater.

7. Installation of the air compressor and some of the lines to process instrumentation.

8. Installation of the supports for the flanged reactor sections, so that this support within the larger structural steel support will not interfere with the removal of individual reactor sections.

\subsubsection{Disruption of Construction}

Funding for FY85, beginning October 1, 1984, was not approved until early 1985. A small advance in the Fall of 1984 kept some construction work in progress but essentially no work was done in November/December 1984. Fortunately, funds were transferred in January, 1985 and construction was resumed.

\subsubsection{Completion of Construction}

The design and construction of the experimental liquefaction unit was sufficiently complete in January, 1985 that initial shake-down runs at low pressures could be initiated. The design and construction required approximately 16 months of work, but was spread over 21 months (May 1983 to January 1985) due to the "spreading out" of the authorized funding.

It should be noted that the procurement and installation of all electrical and control sensors, together with the real-time computer control system, was not completed until November 1985. Consequently, experimental runs at high pressure were limited in nature until these facilities were completed, at which time it was possible to operate by remote control for safety purposes.

A pictorial presentation of the completed facility can be visualized by the various views shown in Figures 4.35 - 4.39. 


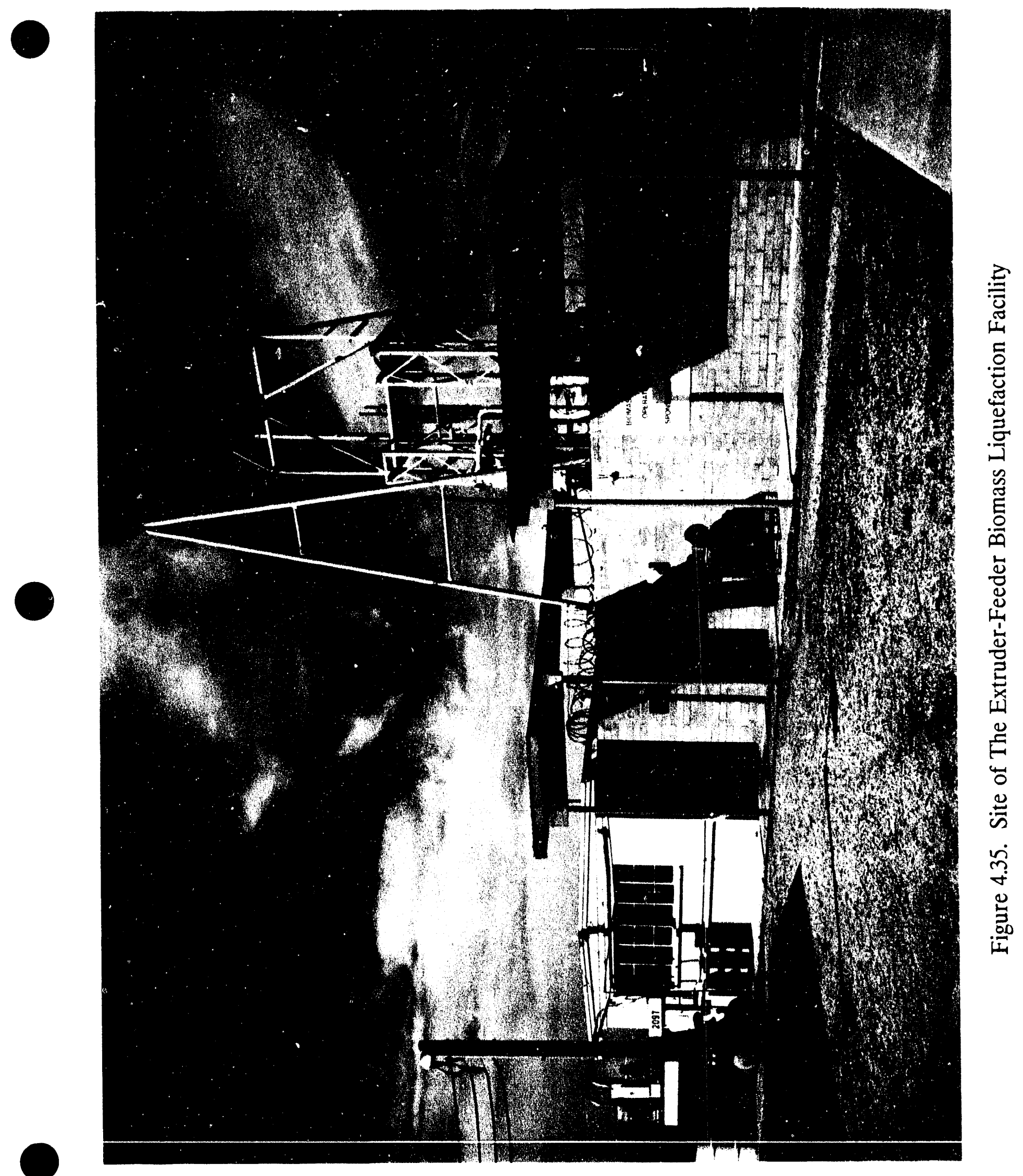




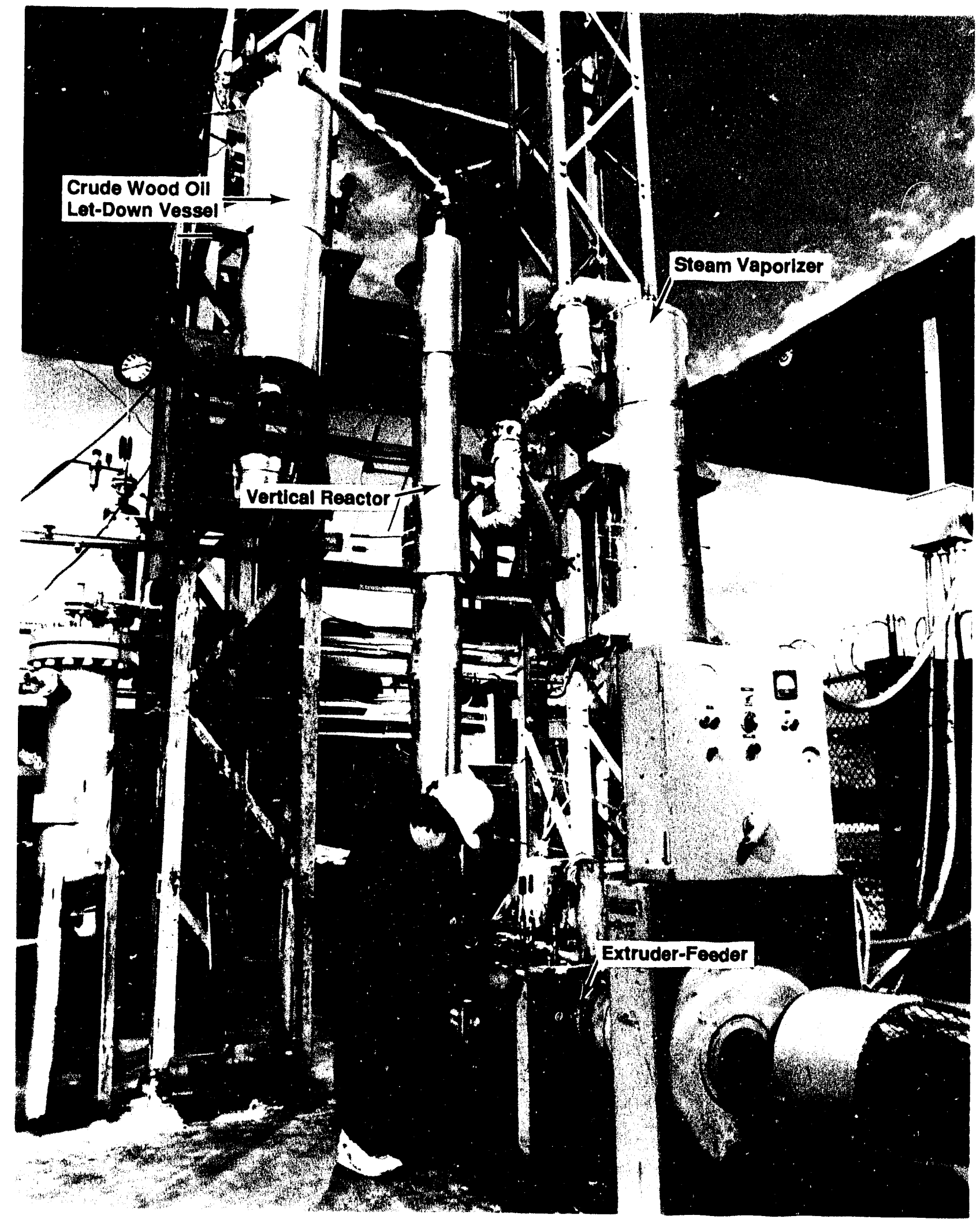

Figuire 4.36 Major Equipment Components of The Extruder-Feeder Liquefaction Facility. 


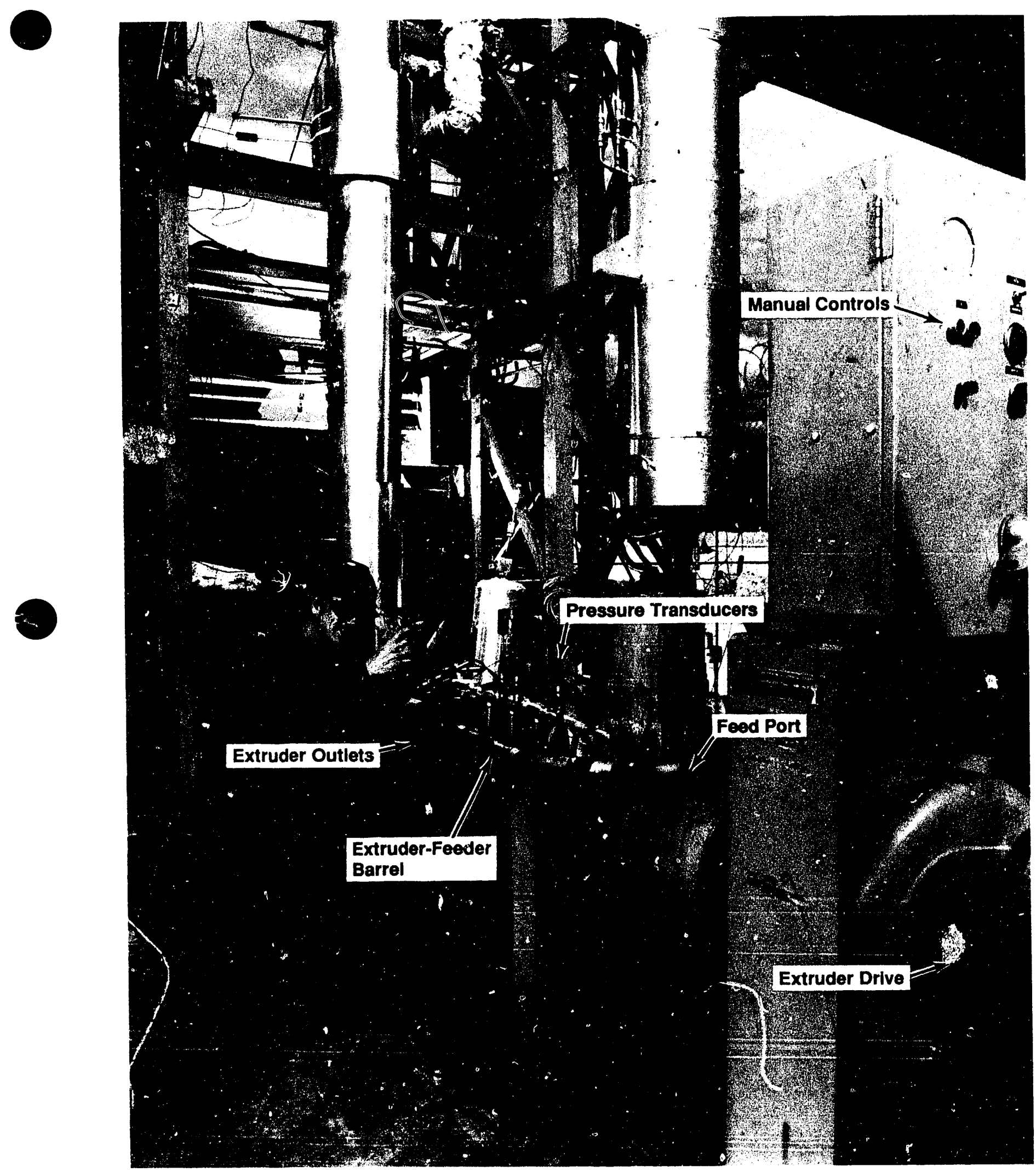

Figure 4.37 Details of The Extruder-Feeder Liquefaction Facility. 


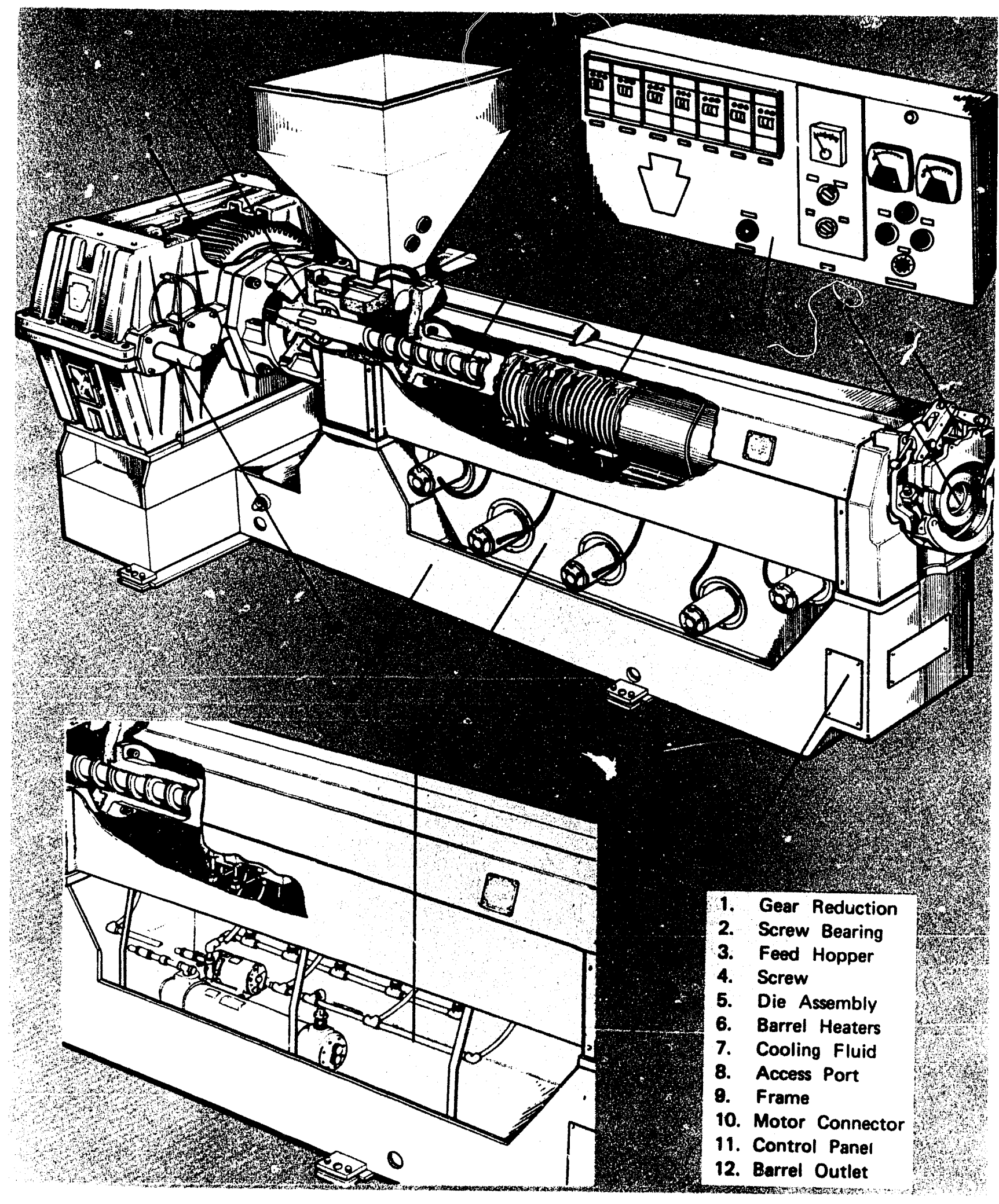

Figure 4.38 Typical Commercial Single Screw Extruder. 


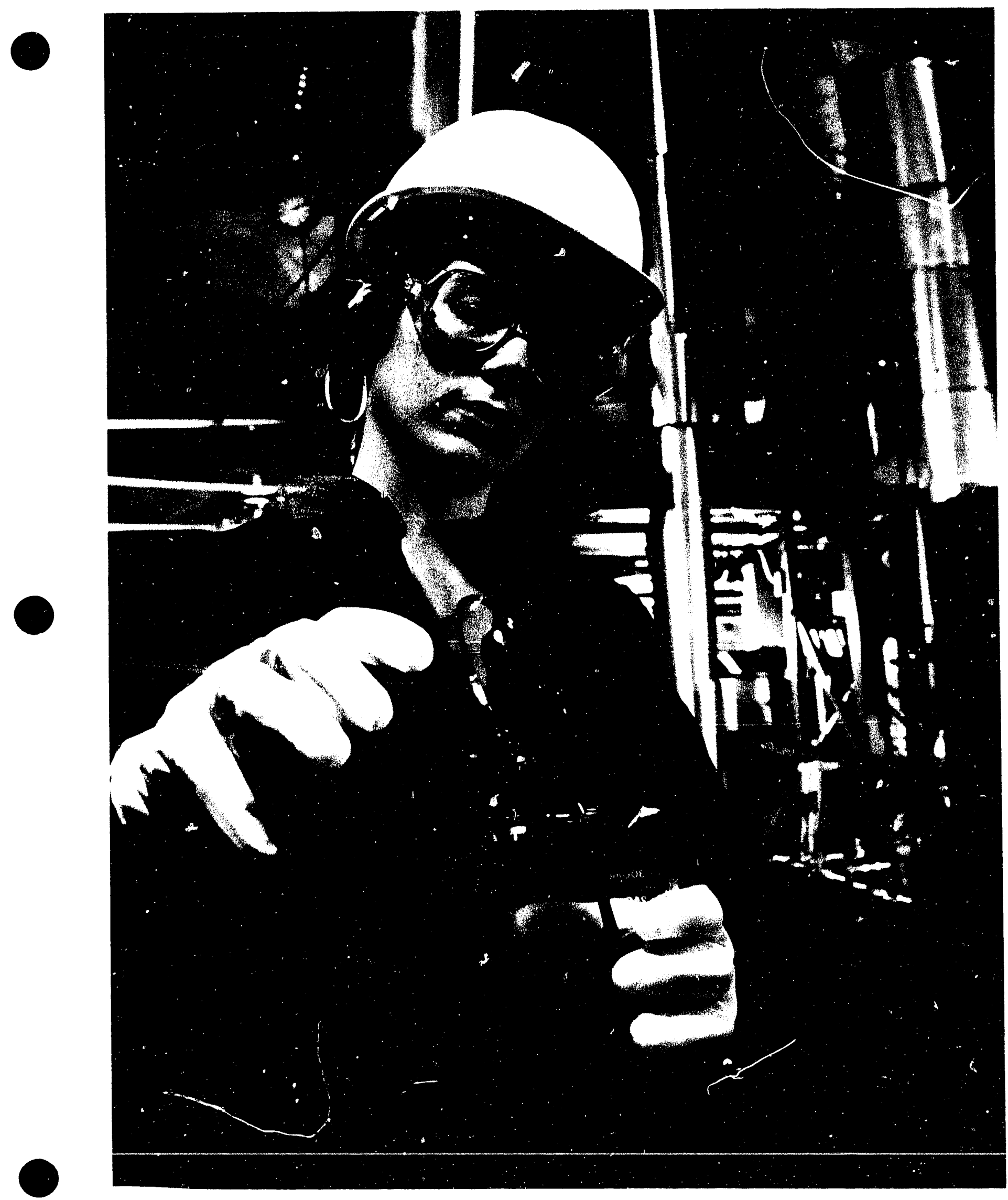

Figure 4.39 Technical Operator Showing Viscosity of Hot Crude Wood Oil. $4-69$ 


\subsection{NOMENCLATURE}

$\begin{array}{lll}\mathrm{a} & = & \text { Constant in Equation } 4.3 \\ \mathrm{~b} & = & \text { Constant in Equation } 4.3 \\ \mathrm{E}_{\mathrm{e}}= & \text { Equilibrium composition of gases } \\ \mathrm{f} & = & \text { fugacity } \\ \mathrm{h} & = & \text { Conversion per pass } \\ \mathrm{K} & = & \text { Equilibrium constant } \\ \mathrm{Q} & = & \text { Extrudate flow rate } \\ \mathrm{n}_{\mathrm{he}}= & \text { Number of Heating elements } \\ \mathrm{N} & = & \text { Molar concentration } \\ \mathrm{P} & = & \text { Pressure } \\ \mathrm{Sr} & = & \text { Radiation surface } \\ \mathrm{S} & = & \text { Amount of steam } \\ \mathrm{X} & = & \text { Fraction of material } \\ \mathrm{Y} & = & \text { Fraction of material }\end{array}$




\subsection{REFERENCES FOR PART 4}

American Society of Mechanical Engineers, ASME Boiler and Pressure Vessel Code, Section VIII, Division I: Pressure Vessels. ANSI/ASME BPV-VIII-1. New York (1977).

American Society for Metals. Source Book on Stainless Steels. Metals Park (1976).

Andrews, N.W., "Microprocessor-Based Real-Time Process Control of Biomass Liquefaction," MS Thesis, University of Arizona, Tucson, Arizona (1983).

Clauss, Francis J., "Engineer's Guide to High-Temperature Materials," Reading: AddisonWesley Publishing Company (1969).

Franklin, G.F., and Powell, J.D., "Digital Control of Dynamic Systems," Addison-Wesley, Reading, Massachusetts (1980).

Gasche, F., "Design of Reactors and Closures," Industrial Engineering_Chemistry 48, 838 (1956).

Harris, C.J., and Billings, S.A., "Self-Tuning and Adaptive Control Theory and Application," New York, The Institue of Electrical Engineers (1981).

Iserman, R., "Digital Control Systems," Springer-Verlaga, Berlin (1981).

Katz, P., "Digital Control Using Microprocessors," Prentice-Hall, London (1981).

Kou, B.C., "Digital Control Systems," Holt, Rinehart, and Winston, New York (1980).

Mellichamp, D.A., "Real-Time Computing with Application to Data Acquisition," Van Nostrand Reinhold, New York (1983).

Reyes, B.F., "Development of a High-Pressure, High-Temperature Superheated Steam System," MS Thesis, University of Arizona, Tucson, Arizona (1985).

Sculthorpe, W., "Design of High-Pressure Steam and High-Temperature Water Plants," New ork: Industrial Press, Inc. (1972).

Wait, J.V., Huelsman, L.P., and Korn, G.., "Introduction to Operational Amplifier Theory and Applications," McGraw-Hill, New York (1975). 


\section{Part 5}

Shake-down Operations and

Initial Experimental Runs 


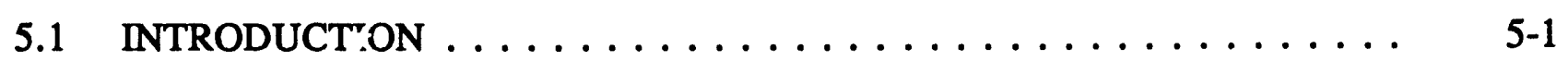

5.2 INITIAL CHECK-OUT OF EQUIPMENT UNITS $\ldots \ldots \ldots \ldots \ldots \ldots$ 5-1

5.3 SAFETY EVALUATION OF HIGH PRESSURE BIOMASS LIQUEFACTION FACILITY $\ldots \ldots \ldots \ldots \ldots \ldots \ldots \ldots \ldots \ldots$

5.4 PREPARATION OF SIX-VOLUME SAFETY MANUAL . . . . . . . 5-4

5.4.1 Certain Top Priority Procedures $\ldots \ldots \ldots \ldots \ldots \ldots$ 5-5

5.5 PREPARATION OF OPERATING PROCEDURES $\ldots \ldots \ldots \ldots \ldots$ 5-5

5.6 PHILOSOPHY FOR SHAKE-DOWN OPERATIONS $\ldots \ldots \ldots \ldots$ 5-6

5.7 EXPERIMENTAL SHAKE-DOWN RUNS $\ldots \ldots \ldots \ldots \ldots \ldots \ldots$ 5-7

5.7.1 Run 1 - January $1985 \ldots \ldots \ldots \ldots \ldots \ldots \ldots \ldots$. . . . . . .

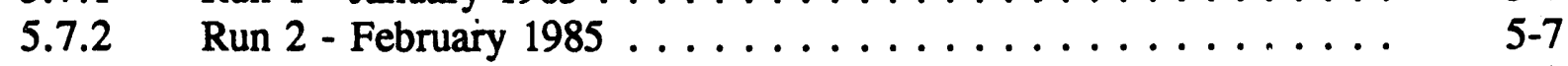

5.7.3 Run 3 - March $26,1985 \ldots \ldots \ldots \ldots \ldots$. . . . . . . . . .

5.7.4 Six Runs with Crammer-Feeder in Series with Extruder-Feeder . . 5-10

5.7.5 Two Runs wtih Alkaline Catalysts - May $1985 \ldots \ldots \ldots$ 5- . . . .

5.7.6 Four Runs for Retter System Operability . . . . . . . . . 5 5-11

5.7.7 First Major Run Using Albany Vacuum Bottoms . . . . . . . 5 5-11

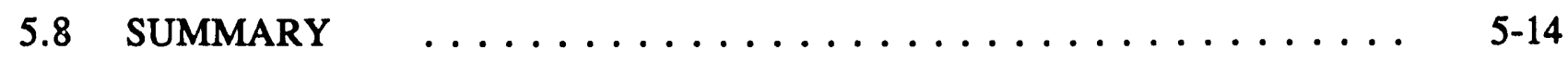

5.9 REFERENCES FOR PART $5 \ldots \ldots \ldots \ldots \ldots \ldots \ldots \ldots \ldots$ 5-15 


\section{List of Tables}

Table

Page

5-1

Birch (hardwood) Feedstock for August 29, Liquefaction Run . .

5-13

$5-2$

Analysis of Products and Process Samples (8/29/85) . . . . . . 5 5-13

$5-3$

Heat of Combustion for Liquefaction Run (8/29/85)

5-14

\section{List of Figures}

Figure

Page

$5-1$

Viscosity of Typical Petroleum Asphalt . . . . . . . . . 


\section{PART 5}

\section{SHAKE-DOWN OPERATIONS AND INITIAL EXPERIMENTAL RUNS}

\subsection{Introduction}

As stated at the end of Part 4, the construction of the experimental biomass liquefaction was sufficiently complete by late January, 1985, that runs could be made upon the process as a whole at low pressures. Previously, during the period July, 1984 through October, 1984, various individual units of the process had been checked out for operability. Nothing was done in November and December, 1984, due to lack of funding (White et al. 1984).

Shakedown runs upon the process as a whole proceeded form late January through August, 1985. A total of 15 shakedown runs were made, climaxed by the August 29, 1985 run which produced the first crude wood oil with no contaminants, that is, it utilized fresh wood flour and "recycled" wood oil in the form of Albany vacuum bottoms (White et al. 1985 $a, b, c, d)$.

\subsection{Initial Check-out of Equipment Units}

Shake-down operations were begun in July, 1984 on the individual units. A temporary power line was brought in from a nearby large irrigation pump substation in order to check out the mechanical performance of the extruder-feeder, the air compressor and the carbon monoxide compressor. The permanent power substation by Tucson Electric Power Company required a detailed listing of all electrical loads before replacing the existing transformer with a larger one.

The success of the extruder-feeder generating 3,000 psi outlet pressure depended on having a reasonably high apparent viscosity for the carrier fluid in the wood flour slurry. Normally, wood oil vacuum bottoms were used, but due to the scarcity of vacuum bottoms inventory, the Albany wood oil was purposely oxidized at elevated temperature by blowing air through it in the laboratory to increase its viscosity. These preliminary experiments were successful. Samples were heated for each of two days at $90^{\circ} \mathrm{C}$, while cooling at night, without increasing the viscosity appreciably; then by blowing air through one sample at $90^{\circ} \mathrm{C}$ up to 75 minutes, the apparent viscosity of the wood oil was increased from about 260 centipoises to about 6,000 centipoises. This material was utilized to check out successfully the operability of the extruder-feeder.

\subsection{Safrty Evaluation of High Pressure Biomass Liquefaction Facility} utilizing

Prior to integrated process hake-down operations, a safety evaluation was conducted,

(a) information from Rust Engineering in its operation of the Albany liquefaction unit, (Rust Engineering, 1981)

(b) Battelle PNL while dealing with high pressure experimental facilities and 
(c) the Risk Management Department at the University of Arizona.

The safety considerations became the basis for preparing the operating procedures.

In the biomass liquefactions reactions performed, hydrogen, carbon monoxide and catalysts are used; thus having safety problems of high temperatures, high-pressure and problematic gases. The tests carried out in the Extruder-Feeder-Reactor experiments provide a better understanding of the reaction kinetics especially the water gas shift reaction and a distribution between the various components of the biomass or the liquefaction process. Battelle Pacific Northwest Laboratories while dealing with a similar process have already identified various areas of potential problems and hazards in the operations of such reactions and processes (See Volume 5 on work by Rust Engineering). These problems are a result of various operating conditions that exist in these experiments as follows:

1) Extreme pressures

2) Extreme temperatures

3) Rate of reaction

4) Possibility of explosion

5) Mechanical failures

6) Power failures

7) Utilization of toxic gases and products

The design took these factors into account and therefore the experimental facility was constructed accordingly. The equipment was located in an open area and behind a strong wall in order to avoid problems of explosions or poisoning. In addition, alarm systems and rupture disks were included in the design. Each operator was required to be trained before he can join the experimental team. The extruder-feeder could reach the stage when solids are accumulated in the screw channels and the power for turning the screw exceed the allowed levels. The operator should be able to stop the rotation of the screw immediately if such a problem occurs if the circuit breaker fails to respond. Since flammable materials at high temperatures are inv. :lved, appropriate instructions were given on how to deal with fire that may occur in case of a leak, disk rupture or even an explosion. Special care was given to the two gases $\mathrm{H}_{2}$ and CO. The first is only produced during the shift reaction while the other is being supplied as a feed gas to the system.

The $\mathrm{CO}$ gas poses a separate problem due to its being poisonous and special care was given to this problem since $\mathrm{CO}$ has no odors. Good ventilation and flush out conditions were provided for this gas. The superheated steam, although not poisonous, is a dangerous material in this unit since it is very hot and at very high pressure. A high velocity jet of hot steam is very dangerous. This is of special importance since there is little awareness of a potential danger from steam and lack of attention in such a case could be expected. Periodic testing was made with the safety devices and the various valves for correct operation and reactions to signal inputs. While an experiment was in progress, all operational inputs were made from the control room and from a feed operator room. 
Safety was a major concern throughout the design and construction phases of the project. Not only were safety features built into the system, but additional experience was utilized form ongoing coal liquefaction work by Exxon, Gulf Oil, Hydrocarbon Research, Inc., Sandia Labs and others which were visited by Dr. White prior to this project. Biomass Liquefaction data were reviewed from reports published by LBL at Berkeley, (Ergun 1980), Rust Engineering and Bechtel at Albany (1981), Battelle Pacific Northwest Laboratory (Elliott 1982, Nelson et al. 1984), SRI International (1980) and Econenergy Associate (1980). Meetings were held with other experts, such as: Engineers Inc.; Archie Deutschman, Jr., retired from the University of Arizona High-Pressure Lab; Department of Risk Management and Safety at the University of Arizona; and the niechanical design section of the Division of Physical Resources. These various groups were brought into the design process to review the design results. Finally, contingency calculations on safety aspects of proposed laboratory extruder-feeder Biomass Liquefaction system as reported on January 31,1984 in a special report to Battelle Pacific Northwest Laboratories, resulted in a better understanding of safety aspects.

In establishing appropriate operating procedures, the certain safety features were considered. The basic design premise was to force operators to shut down the operation while remaining outside the process area. In general, the control panel was designed with two shutdown switches (one manual and one electrical). In the event of a rupture of the reactor vessel or fire, a control switch would dump the contents of the reactor vessel into a large vent vessel. As an alternative, one could also disconnect all electric power to the building via a main switch to turn off the electric heaters and other related equipment. These two safety options were built into the system to provide alternative safety remedies in the event of an accident.

Other design safety features include monitors and adequate fire protection. All piping, electrical tracing and insulation had outside coatings to prevent moisture seepage. Also, the outside coating was designed to keep oil spills from soaking into the insulation and being a source of small fires. In addition, two $\mathrm{CO}$ monitors and two $\mathrm{H}_{2}$ monitors were located inside both the process areas and the control room. These monitors were under continuous maintenance and an alarm would sound if danger should arise.

Because fire is always a danger, adequate fire fighting equipment was available. Should a large fire occur, such that the Tucson Fire Department is required, a city fire plug is located within 200 feet of the laboratory and is easily accessible. The laboratory was also equipped with a large $\mathrm{CO}_{2}$ fire extinguisher, a dry chemical extinguisher and a wet chemical extinguisher in the event of a small fire. Lastly, a drum of speedy-dry, to provide spill control and fire blanket was on hand. These necessary precautions were designed to help insure the safety of the personnel involved.

To insure against injury from possible CO leaks, an air conditioner and fan will provide a slight positive pressure inside the laboratory control room. In this fashion, any escaping $\mathrm{CO}$ gas will not come into the operating room. 


\subsection{Preparation of Six-Yolume Safety Manual}

A comprehensive series document on procedures and regulations were prepared and were made available at various locations for easy access. These procedures and regulations were presented as a six-volume loose-leaf notebook set, so that new and revised sections could be inserted. The first two volumes presented specific procedures and regulations. Volume 3 through 6 provided back up material based on experience outside the Department of Chemical Engineering, and was consulted

(a) upon every new phase of a given project, and

(b) when in doubt about a given point. The subjects and sources of each volume are as follows:

\begin{tabular}{|c|l|}
\hline Vilume No. & \multicolumn{1}{|c|}{ Subject and Source } \\
\hline 1 & $\begin{array}{l}\text { Biomass Direct Liquefaction Using } \\
\text { Autoclave }\end{array}$ \\
\hline 2 & $\begin{array}{l}\text { Biomass Direct Liquefaction Using } \\
\text { Continuous Extruder-feeder Reactor System }\end{array}$ \\
\hline 3 & University of Arizona Safety Manual \\
\hline 4 & $\begin{array}{l}\text { Autoclave Operating and Safety Procedures } \\
\text { of Other Organizations }\end{array}$ \\
\hline 5 & $\begin{array}{l}\text { Rust Engineering Procedures for Albany, } \\
\text { Oregon Biomass Liquefaction Facility }\end{array}$ \\
\hline 6 & $\begin{array}{l}\text { Biomass Manual of Hazardous Materials } \\
\text { Related to Direct Liquefaction }\end{array}$ \\
\hline
\end{tabular}

Two sets of these six-volume sets were available at all times to all employees and students at the following locations:

1. Campbell Extruder-feeder Biomass Liquefaction Facility

2. Biomass Analytical Laboratory, Geology 41B

Two sets were also available for emergency use as follows:

1. Office of Dr. Don H. White, Geology 142.

2. Administrative Office, Department of Chemical Engineering, Geology 103. 


\subsubsection{Certain Top Priority Procedures}

The operating procedures and safety regulations were made top priority for the personnel of the biomass research group under two conditions:

1. A newly-hired employee or a newly-appointed student to the Biomass Research Group.

2. Personnel engaging for the first time upon a new or different phase of research

Personnel under the above situations were required to:

1. Become familiar with all six volumes of operating procedures and safety regulations mentioned above and list those items appropriate to the new assignment or research project.

2. Pass a written test on Item 1 .

3. Go through the equipment check list, operating procedure check list and the safety regulation check list for the new project or initial assignment of a new employee or new student.

4. Outline or write an initial operating procedure and set of safety regulations, if a new phase of the research were involved.

As a guide a general check list was used while proceeding through Items 1-4 above, because the existing material in Volumes 1-6 did not always contain all the necessary material covering a new situation on a new phase of research.

The general approach to safety was to simultaneously

(a) call attention to the existing University of Arizona Safety Regulations (as published by the Department of Risk Management and Safety).

(b) utilize a check list of "worksheets" in outline form that generally would apply more specifically to biomass liquefaction.

\subsection{Preparation of Operating Procedures} following:

A first version of an operating manual was prepared in January, 1985, covering the

1. Preparation of Experiment Check List,

2. Normal Operating Procedures, 


\section{Post Operating Check List,}

4. Emergency Conditions.

This version was published as Appendix II of Quarterly Report for November 1984 - January 1985 to the DOE (White et al. 1985a). Similarly, detailed instructions for operating the RealTime Microprocessor Control System was written and published as Appendix I in that same report.

These operating procedures were expanded and revised over the three years (1985-1988) of experimental runs.

\subsection{Philosophy for Shake-Down Operations}

As stated earlier, the shake-down operations of the individual units and parts of the system were first tested in order to reach the goal of production of wood oil from wood flour in a continuous operation of the system. The philosophy for successful shake-down operation is to proceed in stages namely from low pressures and temperatures then gradually increasing them to the required level of $3,000 \mathrm{psi}$ and $375^{\circ} \mathrm{C}$. The shake-down period was planned to serve several purposes:

1. Detect any problems in the design and construction in order to correct them.

2. Determine the proper range of desired flow rates, pressures, temperatures and slurry concentrations, together with other pertinent operational procedures.

3. Analyze the start-up and shut-down problems as well as detailed operational procedures.

4. Train the research group on the operational and safety procedures of the various units and get acquainted with the mechanical aspects of the project. Initially, gear-oil was used as the carrier liquid due to its appropriate physico-chemical properties at low pressures and temperatures, relating by simulation the real conditions at 3,000 psi and $350^{\circ} \mathrm{C}$.

During the shake-down operations and initial experimental runs, six operating modes were planned, and followed as much as was practical.

Mode 1 Shake-down operations at pressures up to $200 \mathrm{psi}$ and temperatures to $10^{\circ} \mathrm{C}$.

Mode 2 Shake-down operations at pressures up to 1,000 psi and temperatures to $285^{\circ} \mathrm{C}$.

Mode 3 Shake-dowin rperatiouns ât pressures up to 3,000 psi and temperatures to $350^{\circ} \mathrm{C}$. 
Mode 4 Initial experimental runs with no carbon monoxide, no sodium carbonate catalyst and no steam. The use of steam alone will precede the use of $\mathrm{Na}_{2} \mathrm{CO}_{3}$.

Mode 5 Initial experimental runs with no carbon monoxide but with sodium carbonate catalyst and steam.

Mode 6 Initial experimental runs with carbon monoxide, sodium carbonate catalyst and steam.

\subsection{Experimental Shake-Down Runs}

The experimental process was successfully brought up to design operating conditions over a period of 16 runs made from late January through August, 1985. This was accomplished despite the fact that the full real-time computer control system was not completed until November, 1985. These runs are summarized below:

\subsubsection{Run 1 - January 1985}

Goal: $\quad$ Operate extruder-feeder and reactor with $40 \mathrm{wt} \%$ wood flour $/ 60 \mathrm{wt} \%$ gear oil feedstock at reasonably low temperature of $220^{\circ} \mathrm{C}$, to determine operability and what extruder-feeder outlet pressure can be generated.

Results: After a short period of time the reactor began to build up pressure. Eventually the pressure was maintained at 500 psig with the extruderfeeder only turning at $20 \mathrm{rpm}$. A plugging by the slurry eventually occurred. The clog was apparently caused by the constriction in the valve between the reactor and the pressure letdown system. The slurry backed up into, and clogged the oil line to the reciprocating pump. This made it doubtful whether the oil ever made it into the reactor. Separation of oil and wood flour occurred at the clogged portion of the line. The oil squeezed through but the wood flour stayed behind. This was expected due to the low viscosity of the gear oil carried fluid. This proved that a higher viscosity carrier fluid had to be used. not only to generate output pressure but even for operability without plugging by "squeezing" out the carrier fluid.

\subsubsection{Run 2 - February 1985}

Goal: $\quad$ Repeat run with gear oil fluid (as in January 1985) but run extruder-feeder at highest possible screw speed.

Result: $\quad$ A pressure of 1800 psi was temporarily generated at $100 \mathrm{rpm}$, but the run had to be terminated after 14 minutes, apparently again from a plug where the fairly low gear oil viscosity was squeezed out of the wood flour. 


\subsubsection{Run 3 - March 26, 1985}

Goal: $\quad$ Operate with a much higher viscosity fluid, namely asphalt.

Results: A project highlight resulted, whereby 3,500 psi extruder-feeder outlet pressure was achieved. A $35 \mathrm{wt} \%$ wood flour $65 \mathrm{wt} \%$ asphalt feedstock at 15 screw rpm and about $100^{\circ} \mathrm{C}$ extruder-feeder outlet temperature provided good operability. The pressure of 3500 psi was generated by forcing the slurry through a 1 foot long tube of 9/16-in. dia., attached to the outlet of the extruder-feeder.

\begin{tabular}{|c|r|}
\hline Screw Speed, RPM & Output Rate, g/min \\
\hline 5 & 3 \\
\hline 10 & 11 \\
\hline 15 & 70 \\
\hline 30 & 125 \\
\hline 45 & 210 \\
\hline
\end{tabular}

The asphalt has the characteristics of being a tacky solid at room temperatures, plastic at higher temperatures of $50-100^{\circ} \mathrm{C}$ and very fluid at about $110-120^{\circ} \mathrm{C}$. Moreover, this high fluidity at higher temperatures is in the range of temperature to be used in the reactor. Thus at the appropriate operating conditions pressures in excess of 3,000 psi were obtained with mixtures of wood flour and asphalt in the ranges of 10-50 wt\% wood flour in the asphalt. The asphalt was also easily prepared in the form of granules by grinding it with standard causing equipment. Dry ice was added to the asphalt in order to keep it cold and thus making it brittle and also in order to keep the crushing equipment clean. Without the dry ice, the asphalt would heat up during grinding and become plastic. It sticks to the crushing equipment under these conditions. After the asphalt was reduced to the appropriate size, it was mixed with wood flour and thus the sticking of the pellets was eliminated, even if no dry ice was present.

Petroleum asphalt has the necessary physical properties to be a slurry carrier fluid. It's viscosity increases exponentially as it is cooled from about 160 degrees $F$ to about 20 degrees $\mathrm{F}$, as shown in Figure 5.1. A viscosity of 10,000,000 centipoise could be utilized if ever necessary. In practice, an operating temperature of about 150 degrees $F$, where the asphalt viscosity is about 100,000 centipoise, would be sufficient to generate an outlet pressure of 3,000 psi in the extruder-feeder when operating upon a wood flour slurry anywhere in the range of 40 to 60 wt. \% wood flour. Secondly, petroleum asphalt is similar to wood oil vacuum bottoms in that it is a solid at ambient temperatures. However, it is tacky compared with the brittle nature of wood oil vacuum bottoms. This is an important physical characteristic, if the wood flour feedstock to the extruder-feeder is to be fed as a solid mixture. Fortunately, petroleum asphalt can be manipulated for experimental purposes to overcome its tacky property at ambient temperature, be either (a) cooling it below room temperature where it becomes brittle, or (b) by 


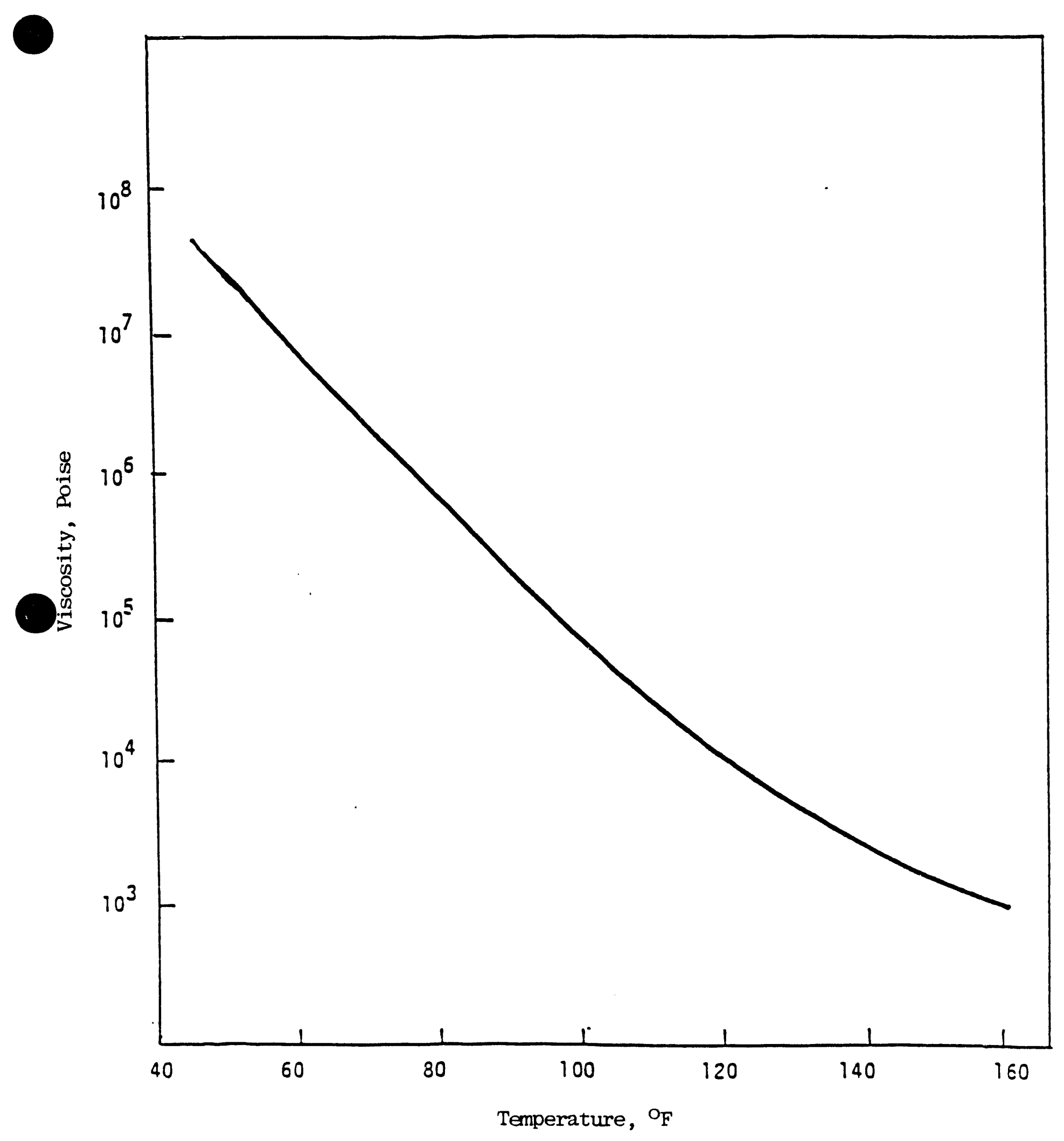

Figure 5.1. Viscosity of Typical Petroleum Asphalt 
further oxidation (cross-linking) until it reaches the brittle stage. The former has been utilized in the initial experimental runs. A roofing grade of petroleum asphalt was selected, which could be easily ground to a fine granule structure by using dry ice. The resultant asphalt granules were kept free-flowing by coating with the finely-ground wood flour and/or any inorganic powder.

\subsubsection{Six Runs with Crammer-Feeder in Series with Extruder-Feeder}

Goal of First Three Runs: Demonstrate operability of crammer-feeder in providing a pressure differential in the feed section of the extruder-feeder.

Results: It was not feasible to use the crammer-feeder in its intended purpose due to the tacky nature of asphalt at ambient or near ambient temperature. Further, it was difficult to coordinate the flow rates of the two units by manual operation without the real-time computer control system (not as yet completed).

Goal for Second Three Runs: Simulate the operation of the vertical reactor at three different temperatures, namely, $340^{\circ} \mathrm{C}, 370^{\circ} \mathrm{C}$, and $400{ }^{\circ} \mathrm{C}$. This was done by electrically heating the tube reactor of Run 3 above after first installing a $1 / 2$ inch gate valve on the 1-foot tube for additional pressure drop resistance.

Results: The system of crammer-feeder, extruder-feeder and valved tube reactor were found to be an operable system. However, the results were erratic and the runs were only partially successful. Pressures at any point between 1000 psi and 3500 psi were a crude wood oil mixed with asphalt was produced successfully controlled. The details of these runs were reported in the Quarterly Report for February --April, 1985 to the DOE.

\subsubsection{Two Runs with Alkaline Catalysts-May, 1985}

Goal: To determine the operability of dry feedstocks and the effects of alkaline catalysts of sodium carbonate and lime, using the designed vertical reactor. These runs were conducted at $20-100 \mathrm{psi}, 375^{\circ} \mathrm{C}$, no carbon monoxide and steam injection at the inlet of reactor.

Results: Feed rates were erratic during the five hours of these two runs, where one run was termed "dry", depending only upon water from the dry wood flour feedstock and water formed during the liquefaction. The second run had some saturated steam injected into the bottom of the reactor, but the steam rate was also erratic and it is not known how much steam was injected. The erratic operation of the extruder-feeder was probably due to the inexperience of handling a dry mixture of powdered feedstock, with some 4 to 5 wt.\% of "inorganic powders" consisting of both sodium 
carbonate and calcined calcium oxide ( $\mathrm{CaO}$ as lime). Therefore, these runs were considered as part of the experience being gained on the operation of the experimental unit. The most important result of these two runs was that the designed vertical reactor was successful, reinforcing the first vertical reactor run made on April 24, 1985.

\subsubsection{Four Runs for Better System Operability}

All process equipment was dismantled, cleaned, inspected and reassembled during the May 20-June 20 period, prior to making four experimental runs in late June. There were no unusual carbon deposits or signs of corrosion. Two valves were damaged from overheating, due to poor control of the electrical heater tracings around the valves and under the insulation surrounding the valves. Some problems were experienced in the re-seating of the metallic ring seals on pressure flanges, due to re-using the same seals that were in use prior to dismantling the pressure equipment.

The objectives of the four runs in June was to repeat the rather unsuccessful runs of May, but with certain modifications. The use of lime was eliminated, and liquid water was injected at the bottom of the reactor rather than steam. The four experimental runs in June (DFWF6 through 9) were conducted back-to-back by nine hours of continuous operation, terminated by a voluntary shut-down at about 7:00 p.m. Sodium carbonate catalyst was dry mixed with the $40 \mathrm{wt}$.\% Douglas Fir Wood Flour feedstock. The extruder-feeder operated continuously but did have periodic fluctuations, due in part to feeding problems. However there was no plugging in the transition zone between the crammer-feeder and the extruder-feeder, or in the feed zone of the extruder-feeder, as experienced at times during the May runs. This problem was solved by circulating chilled water around these two zones.

It was obvious from these runs that the experimental liquefaction unit had good operability, but that steady operations and process control could be improved, even at low pressures by (a) running extruder-feeder tests on the more-highly instrumented extruder-feeder in the Chemical Engineering Laboratory, (b) modifying the liquid oil product collection system, and (c) putting more of the microprocessor digital control system into operation.

\subsubsection{First Major Run Using Albany Vacuum Bottoms:}

An important experimental run on the continuous extruder-feeder biomass liquefaction unit on August 29, 1985. This experimental run resulted in another technical highlight, in that wood oil vacuum bottoms were used successfully, so that no foreign materials were in the system.

An experiment with asphalt as the carrier simulator was made on July 11,1985 , but much of the work related to this experiment was continued during the month of August. This included the collection of material from the extruder-feeder, reactor and let-down vessel, and analysis of these materials and products. Also the experimental unit was dismantled, repaired wherever necessary, cleaned and reassembled for future experimentation. Feedstocks with $40 \mathrm{wt}$. \% and 
42 wt. \% wood flour in asphalt and $\mathrm{Na}_{2} \mathrm{CO}_{3}$ as a catalyst were used. This was a direct continuation of earlier work which was started several days before and was shut down because of a rainstorm. When proper temperatures were achieved the experiment was started with feed supply and some water supply instead of the superheated steam that was not operational that day. This experiment ran smoothly for almost three hours, about half the time with $\mathbf{4 0} \mathrm{wt}$. \% wood flour and half the time with 42 wt. \% wood flour.

The radioactive tracer was again successfully used for determining the flow conditions in the system. The experiment on August 29 was made with vacuum bottoms as a carrier which is considered to be the real carrier in this process. Although some technical problems occurred the experiment was considered a highlight in this project and wood oil was produced under normal operating conditions using the real carrier of wood oil vacuum bottoms. The feed was $40 \%$ wood flour in the vacuum bottoms, with both $\mathrm{Na}_{2} \mathrm{CO}_{3}$ as a catalyst and superheated steam as a heat source.

It appeared that a low viscosity wood oil was made during the August 29, 1985 experimental run. The materiai in the sxtruder-feeder reactor and let-down vessel was collected and prepared for analysis. Some characterization of the wood oil was done by using a laboratory vacuum fractionation unit. Eight fractions of oil were obtained with very low viscosity and a residue of vacuum bottoms which were analogous to the Albany vacuum bottoms. A comparison was also made with the vrood oil obtained from Albany under vacuum fractionation conditions. The laboratory vacuum fractionation unit was used also in order to learn of the problems that might be involved in the fractionation of wood oil. Such information was needed to supply to the companies approached for purchasing a vacuum distillation unit, and in order to assess the proposed unit. Also this information was helpful to assess the feasibility of constructing a unit with or without acquiring major components of the system.

Even though useful experimental data were being obtained using petroleum asphalt as a feedstock carrier, everyone concerned with this DOE project wanted to move as fast as possible to "an all-wood-oil system", using wood oil vacuum bottoms as a feedstock. Therefore, in parallel with the activities using asphalt as the fluid carrier, it was decided to make one short experimental run on "an all-wood-oil system" by using some of the precious Albany wood oil vacuum bottoms in the limited inventory at the University of Arizona. This experimental run was made on August 29, 1985 of 3.5 hours duration with operating conditions of $375{ }^{\circ} \mathrm{C}, 3,000$ psi, sodium carbonate catalyst and steam injection. The feedstock conditions are given in Table 5.1 as follows: 
Table 5.1. Birch (hardwood) Feedstock for August 29, 1985 Liquefaction Run

\begin{tabular}{|l|l|l|l|l||}
\hline $\begin{array}{l}\text { Typical Comp., } \\
\text { wt. \% }\end{array}$ & 41 & Cellulose & Hemi-cellulose & Lignin . 1.40 Other \\
\hline Mild Treatment & Probably 5-10\% loss in wt. & 22 & 10 \\
\hline $\begin{array}{l}\text { Slurry } \\
\text { Feedstock }\end{array}$ & $\begin{array}{l}40-42 \text { wt. \% wood flour } \\
55-53 \text { wt. \% Albany vacuum bottoms } \\
\text { High sodium carbonate concentration }\end{array}$ \\
\hline
\end{tabular}

Process operability was very good; the vacuum bottoms performed as good or better than petroleum asphalt. The experimental unit was not yet in shape from a safety standpoint to take samples while in operation at full pressure of 3,000 psi. Therefore, the unit was shut down while still hot, and samples were taken of the product and at different locations in the vertical reactor the next day. The ultimate analysis of these samples are shown below in Table 5.2 1

\begin{tabular}{|c|c|c|c|c|c|}
\hline \multirow{2}{*}{$\begin{array}{l}\text { Product/ } \\
\text { Process Point }\end{array}$} & \multicolumn{5}{|c|}{ ULTIMATE ANALYSIS, WT, \% } \\
\hline & C & $\mathbf{H}$ & $\mathbf{N}$ & 0 & TOTAL \\
\hline Reactor (entrance) & 60.86 & 5.61 & 0.00 & 30.70 & 97.17 \\
\hline Reactor (outlet) & 70.44 & 5.76 & 0.16 & 18.13 & 94.49 \\
\hline $\begin{array}{l}\text { Let-down vessel: } \\
\text { Sticky Phase } \\
\text { Solid Phase }\end{array}$ & $\begin{array}{l}81.21 \\
85.53\end{array}$ & $\begin{array}{l}8.21 \\
7.65 \\
\end{array}$ & $\begin{array}{l}0.41 \\
0.16 \\
\end{array}$ & $\begin{array}{l}7.93 \\
9.09 \\
\end{array}$ & $\begin{array}{r}97.76 \\
100.43 \\
\end{array}$ \\
\hline $\begin{array}{l}\text { Extracted Product (THF } \\
\text { solubles) }\end{array}$ & 83.13 & 8.90 & 0.38 & 5.62 & 98.03 \\
\hline Extract Residue & 64.82 & 4.10 & 0.08 & $* 17.15$ & 86.15 \\
\hline $\begin{array}{l}\text { Vacuum Distillate (bulk } \\
\text { product) }\end{array}$ & 82.71 & 9.07 & 0.13 & 6.52 & 98.43 \\
\hline
\end{tabular}

Also, the heats of combustion of all of the samples of Table 5.2 were determined and are shown below in Table 5.3 


\begin{tabular}{|l|r|}
\hline \multicolumn{1}{|c|}{ Table 5.3. Heats of Combustion for Liquefaction Run (8/29/85) } \\
\hline \multicolumn{1}{|c|}{ Product/Process Point } & Heat of Combustion BTU/16. (dry)* \\
\hline Reactor (entrance) & 11,000 \\
\hline Reactor (exit) & 16,900 \\
\hline Let-down vessel & \\
Sticky Phase & 16,000 \\
Solid Phase & 15,900 \\
\hline Extracted Product (THF solubles) & 16,400 \\
\hline Extract Residue & $* 10,500$ \\
\hline vacuum Distillate (bulk product) & 16,300 \\
\hline *Believed to have a high sodium carbonate content; heating value probably much higher. \\
\hline
\end{tabular}

\subsection{SUMMARY}

A number of runs were made using petroleum asphalt as the feedstock carrier and finally, the asphalt was replaced by Albany wood oil vacuum bottoms from our limited inventory to make, for the first time, a "non-contaminated" wood oil on August 29, 1985. Process equipment operability was beyond expectations, as was also the quality of the wood oil product. Four technical highlights were reported for these initial shake-down experiments as given below.

March 26, 1985

Operated extruder-feeder on 36 wt. \% wood flour/65 wt. \% petroleum asphalt, generating 3,500 psi outlet pressure.

April 22, 1985

First tar-like wood oil was made during a continuous 3 1/2 hour run, which was voluntarily terminated.

April 24, 1985

Generated up to 3,000 psi at extruder-feeder outlet for first time while connected to reactor.

August 29, 1985

Replaced petroleum asphalt in feedstock with Albany wood oil vacuum bottoms, operated at 3,000 psi with sodium carbonate catalyst and steam, making the first "non-contaminated" wood oil, with low oxygen content.

One series of experiments varied the wood flour concentration in the feed from 30 to 50 wt. \%. Another series of experiments varied the temperature of the liquefaction reactor from $350{ }^{\circ} \mathrm{C}$ to $400{ }^{\circ} \mathrm{C}$. In essentially all cases the process equipment demonstrated mechanical 
operability beyond expectations. Essentially all runs were terminated voluntarily.

More details on these experiments are found in the Quarterly reports by White et al. (1989, a,b, 1985 a,b,c,d).

\subsection{REFERENCES FOR PART 5}

Ecoenergy Associates, "A Technical and Economic Assessment of PERC and LBL Wood-to Oil Conversion Processes," Contract No. 4-L40-0742M-1 (1980).

Ergun, , S., "Biomass Liquefaction Efforts in the United States", LBL-10456, UC-61, Lawrence Berkeley Laboratory, Berkeley, California (February 19, 1980).

Elliott, D.C., "Bench Scale Research in Biomass Direct Liquefaction", Proceedings of the 14th Biomass Thermochemical Conversion Contractor's Meeting, CONF-820685, June 23-24, 1982, Arlington, Virginia.

Nelson, D.A., Molton, P.M., Russell, J.A. and Hallen, R.T., "Application of Direct Thermal Liquefaction for the Conversion of Cellulosic Biomass", IEC Product Research and Development, 23, 471 (1984).

White, D.H. and D. Wolf, Proceedings of the 1985 Biomass Thermochemical Conversion Contractors' Meeting, CONF-8510167, October 15-16, 1985, Minneapolis, Minnesota. 


\section{Part 6}

\section{EXPERIMENTAL RUNS ON THE CONTINUOUS}

EXTRUDER-FEEDER LIQUEFACTION UNIT 


\section{Part 6}

\section{Experimental Runs on the Continuous Extruder-Feeder Liquefaction Unit}

6.1 GOALS OF EXPERIMENTAL RUNS $\ldots \ldots \ldots \ldots \ldots \ldots \ldots \ldots$ 6-1

6.2 EXPERIMENTAL RUNS WITH UA REAL-TIME CONTROL SYSTEM . . 6-1

6.2.1 Budget Spread-Out/Labor Intensive $\ldots \ldots \ldots \ldots \ldots \ldots$ 6-1

6.2.2 Achievement of Good Operability . . . . . . . . . . 6. 6-5

6.2.3 Flow Conditions in the System ............... $6-6$

6.2.4 Feedstock Pretreatment .................. 6-7

6.2.5 Good Quality Wood Oil by Liquefaction with No

Carbon Monoxide, No Catalyst and Low Water . . . . . . . . 6-7

6.2.6 Demonstration of Long Continuous Run . . . . . . . . . . 6-7

6.2.7 Vacuum Distillation .................... 6-8

6.2.8 Albany TR9 Crude Wood Oil as Wood Flour Carrier . . . . . . . 6-8

6.2.9 Initiation of Work On All-Arizona Crude Wood Oil . . . . . . . 6-9

6.3 SECOND GENERATION OF COMPUTER CONTROL USING THE

FIX SOFTWARE PROGRAM $\ldots \ldots \ldots \ldots \ldots \ldots$. 6 .10

6.3.1 Introduction $\ldots \ldots \ldots \ldots \ldots \ldots \ldots \ldots \ldots \ldots$ 6-10

6.3.2 The FIX Shell: Multi-Tasking Executive ........... 6-12

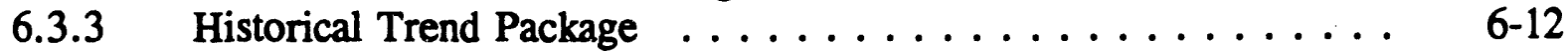

6.3.4 C Data Base Access ................... 6-12

6.3 .5 The FIX Scheduler . . . . . . . . . . . . . 6-13

6.3.6 FIX Report Generator . . . . . . . . . . . . . . 6-13

6.3.7 On-Line Spreadsheet Interface $\ldots \ldots \ldots \ldots \ldots \ldots \ldots$ 6-13

6.3.8 Real-Time Add-In for Symphony . . . . . . . . . . . . . 6-13

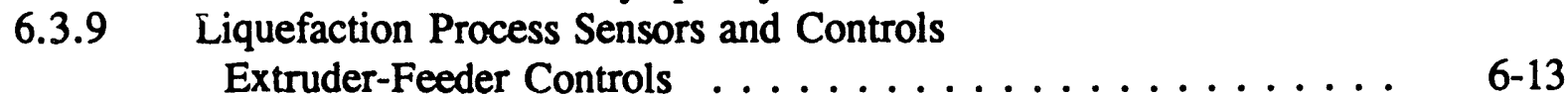

6.3.10 Software Implementation . . . . . . . . . . . . . 6-17

6.3.11 Microprocessor Hardware . . . . . . . . . . . . . . 6 6-18

6.3.12 Experimental Runs using FIX Software $\ldots \ldots \ldots \ldots \ldots$ 6-20

6.4 EXPERIMENTAL RUNS WITH THE FIX SOFTWARE PROGRAM $\ldots .6$ 6-29

6.4.1 Review of Safety and Health Requirements . . . . . . . . . . 6-29

6.4 .2 Improved Operability . . . . . . . . . . . . . . 6-42

6.4.3 Data Acquisition by the F16 FIX Software $\ldots \ldots \ldots \ldots 6$. $\ldots$.43 
6.5 SIGNIFICANT LIQUEFACTION CONSIDERATIONS $\ldots \ldots \ldots \ldots \ldots$. . . . .

6.5.1 Quality and Yield of Crude Wood Oil Product . . . . . . . . 6-43

6.5.2 Understanding the Key Liquefaction Reactions . . . . . . . . . . 6-44

6.5.3 Stability of Crude Wood Oils ............... 6-45

6.5.4 Experimental Runs with Two-Stage Carbon Monoxide Compressor 6-45

6.5.5 Closure of Material Balances ............... $6-46$

6.5.6 Preparation of Large Sample of All-Arizona Crude Wood Oil ... 6-46

6.6 REFERENCES FOR PART $6 \ldots \ldots \ldots \ldots \ldots \ldots \ldots \ldots \ldots$ 6-48 


\section{LIST OF TABLES}

Table 6.1. Summary of Goals of Experimental Runs With Real-Time

Computer Control Using U.A. Software . . . . . . . . . . .

Table 6.2. Summary of Goals of Experimental Runs with Real-Time

Table 6.3. Computer Control Using the FIX Software .........

Table 6.4. Air Operated Safety Valves

\section{LIST OF FIGURES}

Figure

Page

6.1. Scaled Diagram of the Location of Temperature and Pressure Sensors on the Extruder-Feeder ............. 6 6-14

6.2. Scaled Diagram of the Location of Temperature and Pressure Sensors on the Reactor ............... . . 6- . . . . . . .

6.3. Biomass Liquefaction Unit Overview Run-Time Display . . . . . . . . . . . . 6-22

6.4. Extruder-Feeder Run-Time Display . . . . . . . . . . . . . . . . . . . . . . . . 6-23

6.5. Biomass Liquefaction Unit Run-Time Text Display . . . . . . . . . . . . . . . . 6-24

6.6. Lower Reactor Run-Time Display . . . . . . . . . . . . . . . . . . . . 6-25

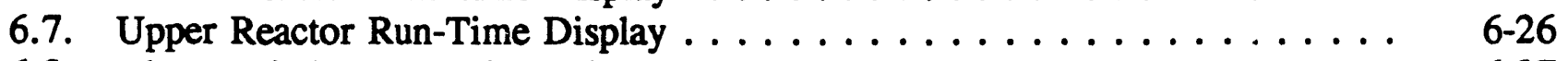

6.8. Alarm Window Run-Time Display . . . . . . . . . . . . . . . . . . . . . 6-27

6.9. Temperature Profile at Several Locations of the Unit for Run R4 . . . . . . . 6-30

6.10. Pressure Profile at Several Locations of the Unit for Run R4 . . . . . . . . 6-31

6.11. Steady State Temperature Profile for Run R4 . . . . . . . . . . . . . . . . 6-32

6.12 Steady State Pressure Profile for Run R4 . . . . . . . . . . . . . . . . 6-33

6.13. Pressure Response for Controlled Period . . . . . . . . . . . . . . . . . 6-34

6.14. Process Hardware and Software Interfacing for Pressure Control . . . . . . . 6-35

6.15. Off-Gas Valve Response for Controlled Period . . . . . . . . . . . . . . . . 6-36

6.16. Steady-State Extruder-Feeder Temperature Profile . . . . . . . . . . . . . . 6- . . . . . . . . . . . . . . . . .

6.17. Extruder-Feeder Inlet Temperature . . . . . . . . . . . . . . . . . 6-38

6.18. Wood Flour Concentration vs. Temperature . . . . . . . . . . . . . 6-39

6.19. Number of Carrier Recycles vs. Temperature . . . . . . . . . . . . . . . . 6-40

6.20. Extruder-Feeder Current Draw ...................... 6 6-41 


\section{PART 6}

\section{EXPERIMENTAL RUNS ON THE CONTINUOUS EXTRUDER-FEEDER LIQUEFACTION UNIT}

\subsection{GOAIS OF EXPERIMENTAL RUNS}

The previously described shake-down operations were generally operated at less than full system pressure, due to the fact that (a) budget limitations (spread out over longer time periods) were imposed by the DOE, and (b) the real-time computer control system was incomplete. However, the expenditures and research goals had to be spread out due to varying and generally ceclining budget appropriations. Consequently, in no given year was full funding made available to the University of Arizona.

Some of the visible demonstrable goals that were established are as follows:

1. Demonstrate good operability of entire liquefaction unit at 3,000 psi.

2. Produce a high heating value of crude wood oil, having about 6-9 wt.\% oxygen and about 16,000 BTU/lb heating value.

3. Demonstrate the ability to make long extended runs without any shut-downs.

4. Make an All-Arizona oil, that is, use only oils made in the Arizona unit for use as recycle oil.

As a result, over the project period of November, 1985 through September, 1988, a total of 42 experimental runs were made with a completed real-time control system in place, wherein (a) the first 33 runs used the UA software and (b) the last nine runs used the FIX software. The goals of these experimental runs are summarized in Tables 6.1 and 6.2 , respectively.

\subsection{EXPERIMENTAL RUNS WITH UA REALTIME CONTROL SYSTEM}

This section summarizes some of the experimental results for the 33 experimental runs made while using the University of Arizona (UA) real-time control system. As previously described, that system connected process sensors to a microprocessor and used real-time software developed as part of this project. These 33 runs were made from November, 1985 through October, 1987, and are described in details in the Quarterly Reports (White et al., 1985, 1986, 1987). Part of these experiments are also summarized in Appendix D.

\subsubsection{Budget Spread-Out/Labor Intensive}

The initial DOE contract (via subcontract from Battelle PNL) provided a reasonable budget and time schedule for this project. However, in no given year was the full funding made available to the University of Arizona and, consequently, the expenditures and research goals were spread out. The project work became labor intensive, that is, funds that were originally budgeted for process developments were reallocated in part for labor to accomplish immediate goals. A detailed examination of expenditures show that when the project funding was 


\begin{tabular}{|c|c|c|}
\hline \multirow{2}{*}{$\begin{array}{l}\text { Table 6. } 1 . \\
\text { Run No. }\end{array}$} & \multicolumn{2}{|c|}{$\begin{array}{l}\text { Summary of Goals of Experimental Runs with Real-Time Computer } \\
\text { Control Using UA Software }\end{array}$} \\
\hline & Date & Goal \\
\hline $\mathrm{F} 1$ & $11 / 18 / 85$ & Operability of Liquefaction Unit \\
\hline F2 & $12 / 20 / 85$ & $\begin{array}{l}\text { Start-Up with Old Feedstock/Products in Extruder-Feeder and } \\
\text { Reactor }\end{array}$ \\
\hline G1 & $02 / 19 / 86$ & Operability and proper shut-down procedures \\
\hline G2 & $03 / 19 / 86$ & Liquefaction at high temperature $\left(400^{\circ} \mathrm{C}\right)$ \\
\hline G3 & $04 / 16 / 86$ & Liquefaction with no catalyst, no $\mathrm{CO}$ and low water \\
\hline G4 & $05 / 29 / 86$ & Liquefaction at steady pressure of $3,000 \mathrm{psi}$ \\
\hline H1 & $06 / 26 / 86$ & $\begin{array}{l}\text { Effect of soaking aqueous } \mathrm{Na} 2 \mathrm{CO} 3 / \text { feedstock at } 60^{\circ} \mathrm{C} \text { as } \\
\text { pretreatment }\end{array}$ \\
\hline $\mathrm{H} 2$ & $06 / 27 / 86$ & Same as above \\
\hline H3 & $06 / 30 / 86$ & Same as above \\
\hline $\mathrm{H} 4$ & $07 / 02 / 86$ & Pretreatment with $60^{\circ} \mathrm{C}$ soak, but no $\mathrm{Na} 2 \mathrm{CO} 3$ \\
\hline H5 & $07 / 14 / 86$ & $\begin{array}{l}\text { Soak pretreatment with } \mathrm{Na} 2 \mathrm{CO} 3 \text { catalyst and } \mathrm{CO} \text { during } \\
\text { liquefaction }\end{array}$ \\
\hline $\begin{array}{c}\text { I1 } \\
\text { thru } \\
\text { J1 }\end{array}$ & $\begin{array}{l}07 / 29 / 86 \\
07 / 31 / 86 \\
10 / 23 / 86\end{array}$ & Demonstrate a long continuous run with a voluntary shut-down \\
\hline $\mathrm{J} 2$ & $10 / 30 / 86$ & Operate at higher feedrates for shorter residence times \\
\hline K1 & $01 / 07 / 87$ & Same as above \\
\hline $\mathrm{K} 2$ & $02 / 02 / 87$ & Operate in "recycle mode," using reactor effluent as feedstock \\
\hline $\mathrm{L} 1$ & $03 / 20 / 87$ & $\begin{array}{l}\text { Preparation/operation with } 300 \mathrm{lb} \text {. of feedstock for use in several } \\
\text { "recycle" experiments }\end{array}$ \\
\hline L2 & $06 / 09 / 87$ & $\begin{array}{l}\text { Operation of extruder-feeder with makeshift horizontal pipe- } \\
\text { reactor to establish conditions for pumpability of "new recycle" } \\
\text { feedstocks }\end{array}$ \\
\hline $\mathrm{L} 3$ & $06 / 10 / 87$ & Same as above \\
\hline M1 & $07 / 14 / 87$ & $\begin{array}{l}\text { Produce larger quantity of reactor effluent operating in recycle } \\
\text { mode }\end{array}$ \\
\hline M2 & $07 / 17 / 87$ & Same as above, plus close material balance \\
\hline M3 & $07 / 23 / 87$ & Same as above \\
\hline
\end{tabular}




\begin{tabular}{||l|l|l||}
\hline M4 & $08 / 03 / 87$ & $\begin{array}{l}\text { Operate at lower wood flour in feedstock and lower } \\
\text { temperatures, to overcome plugging problems of recycle mode }\end{array}$ \\
\hline N1 & $08 / 20 / 87$ & Same as above \\
\hline N2 & $08 / 21 / 87$ & Same as above, except higher water content \\
\hline N3 & $09 / 09 / 87$ & $\begin{array}{l}\text { Make near All-Arizona crude wood oil with good material } \\
\text { balance closure }\end{array}$ \\
\hline O1 & $09 / 10 / 87$ & Same as above \\
\hline O2 & $09 / 11 / 87$ & Same as above \\
\hline P1 & $09 / 17 / 87$ & Same as above \\
\hline P2 & $10 / 07 / 87$ & Operate with month-old feedstock and reactor products in system \\
\hline P3 & $10 / 16 / 87$ & Operate with recycle reactor product plus fresh wood flour \\
\hline P4 & $10 / 20 / 87$ & Same as above \\
\hline
\end{tabular}


Table 6.2. Summary of Goals of Experimental Runs with Real-Time Computer Control Using the FIX Software.

\begin{tabular}{|c|c|l||}
\hline Run No. & Date & \multicolumn{1}{|c||}{ Goal } \\
\hline Q1 & $03 / 07 / 88$ & $\begin{array}{l}\text { Operate liquefaction unic with larger piping on reactor outlet and } \\
\text { new piping on liquid product }\end{array}$ \\
\hline Q2 & $03 / 11 / 88$ & Same as above, except using shorter piping on liquid product line \\
\hline Q3 & $03 / 17 / 88$ & Same as above \\
\hline R1 & $06 / 30 / 88$ & $\begin{array}{l}\text { Increase output rate, make larger quantities of product per run } \\
\text { and seek smoother operability with the good control system }\end{array}$ \\
\hline R2 & $06 / 06 / 88$ & Same as above \\
\hline R3 & $06 / 10 / 88$ & Same as above \\
\hline R4 & $06 / 16 / 88$ & $\begin{array}{l}\text { Same as above, but lower concentration of recycled reactor } \\
\text { effluent }\end{array}$ \\
\hline S1 & $07 / 13 / 88$ & $\begin{array}{l}\text { make longer run with good operability, and be closer to an All- } \\
\text { Arizona wood oil }\end{array}$ \\
\hline S2 & $07 / 20 / 88$ & Same as above \\
\hline
\end{tabular}


terminated in September, 1988, approximately 60 percent of the anticipated funding had been expended to accomplish about one-half of the proposed work.

\subsubsection{Achievement of Good Operability}

The completion of the real-time computer control system in November, 1985 helped improve process operability. Short experimental runs in November and December, 1985 proved that material produced from a previous run cannot be left in the system for longer than a few days, without plugging problems on the start-up of the next run.

The proof of plugging at this stage of process development was detected in many instances by the use of a radioactive tracer. For the experimental run scheduled for December 20, 1985 (Run F2), the reactor was full with material left over from the previous experiment, on November 18, 1985. The first stage of the experiment was to heat the extruder-feeder, reactor and connecting lines to the desired temperatures and start feeding the extruder-feeder. The tracers added at the beginning of experiment proved that there was no flow into the reactor since the tracer did not pass the valve at the connecting cross line located between the extruderfeeder and the reactor, even though the valve was fully open and the extruder-feeder had produced a pressure of 3500 psi. The Geiger Counter clearly detected the stationary tracer at the tip of the extruder-feeder outlet. Therefore, from this point on, the liquefaction system was flushed out at the end of each run with a petroleum asphalt, which could be left in the system until the next run. Further details are given in the November 1985-January 1986 Quarterly report (White et al., 1986a).

Operability was further improved by removing the valve between the extruder-feeder and the reactor, and increasirig the size of that line. It was decided that the valve served no useful purpose, and in fact without it, the extruder-feeder then served as a "pressure relief valve" for the liquefaction system. The interconnecting piping and a cross were installed of 1.75 inch inside diameter, matching the I.D. of the reactor.

More optimum operating conditions were also explored at this time. Before the Run G1 of February 19, 1986, the extruder-feeder was operated separately, and mixtures of 38 wt.\% wood flour (WF) and 62 wt. \% vacuum bottoms (VB) were pumped at several temperatures, i.e. 135,165 , and $200^{\circ} \mathrm{C}$ so as to determine the best operating conditions of the extruder-feeder. A temperature of around $165^{\circ} \mathrm{C}$ near the outlet end of the extruder-feeder was found to be the appropriate temperature for our purpose and was indeed the controlled temperature of the barrel for run $G 1$.

Run G1 was smooth and operated at pressures of up to 1,000 psi and at reactor temperatures of around $375^{\circ} \mathrm{C}$. Before shutdown the feed was changed to $23 \mathrm{wt} . \% \mathrm{WF}$ and 77 wt. \% asphalt so as to displace the normal feedstock from the reactor. This procedure was used in order to initiate the next run without having to clean the system from the reactive hard vacuum bottom-based feedstock. Further details on Run G1 are given in the February-April 1986 Quarterly report (White et al., 1986b). 
The final major modification of the process equipment to assist operability involved the installation of larger diameter piping and long-sweep elbows to the reactor outlet. When experimental Run L1 was made on March 20,1987, it operated for only three hours before plugging problems occurred. Otherwise, run conditions appeared good. The unit was then dismantled and cleaned for analyzing the plugging problems. One of the conclusions was that it was difficult to control precise conditions in the small interconnecting piping between the reactor and the pressure let-down vessel. The reactor had a 1.75 inch ID and the outlet piping was 0.375 inches ID. The outlet piping was changed to an ID very close to that of the reactor. Further details on the Run L1 are given in the February-April 1987 Quarterly report (White et al., 1987b).

\subsubsection{Flow Conditions in the System}

\section{Slurry Flow Patterns by Radioactive Tracer}

The Extrusion Research Team had developed in the 1970's a useful technique for determining experimentally the Residence Time Distribution in single screw extruders by means of neutron-activated manganese dioxide (Wolf and White, 1975). The half-life of this radioactive tracer is 2.46 hours, such that there is no radinactive disposal problem from the use of this radioactive material.

During the shakedown runs, this technique was used to measure the flow of feed through the liquefaction unit. As indicated above in Section 6.2.2, it was also useful in determining plugs in the system. Calculations using radioactive tracer flow data indicate that the viscous pseudo-homogenous slurry exhibits near-plug flow in the reactor. Further details are given in the August-October 1985 Quarterly report (White et al.,.1985d).

\section{Gas Flow Patterns by Off-gas Analysis}

It can be argued that good dispersion of the carbon monoxide gas and steam vapors in the viscous wood flour feedstock slurries would result in much of the gas phase moving through the reactor at essentially the same velocity as the liquid/solids phase. It can also be visualized that as carbon dioxide gas and water vapor are generated from the wood flour feedstock by the liquefaction process, the total volume of the gas phase would increase to the point where it would "break loose" from the liquid/solid pseudo-homogenous phase and move out of the reactor at a higher velocity than that of the reactor effluent liquid phase.

Time and funding did not permit obtaining data upon the true gas phase flow patterns. However, some experimental data based upon (a) the off-gas chromatographic analyses and (b) the velocity of carbon monoxide through the system when first injected indicate that gases do separate from the liquid/solid phase. In fact, there was some indication of gas phase channeling. This phenomena was further supported by more sensitive reaction data (than in biomass liquefaction) by test runs in the experimental unit on behalf of an industrial company. These calculations were based on the off-gas flow rates and composition of a number of experimental runs, some of which are given in Appendix D. 


\subsubsection{Feedstock Pretreatment}

In the period May-July, 1986, a variety of feedstock pretreatment techniques were explored, with the objectives of (a) swelling the wood flour with water and (b) impregnating the wood flour with the sodium carbonate catalyst. The parameters explored were as follows:

1. Four varieties of fluid carrier, namely, black Albany vacuum bottoms, brown Albany vacuum bottoms, roofing-grade asphalt and Albany TR-9 crude wood oil.

2. Excessive wetting of the wood flour up to $200 \mathrm{wt} . \%$ and then sun-drying to various degrees of dryness.

3. Soaking the wood flour at various temperatures for periods up to 48 hours.

4. Varying amounts of sodium carbonate catalyst.

One preferred procedure that was adopted and used for many subsequent runs was carried out as follows:

1. Spray a sodium carbonate solution upon dry wood flour and mix thoroughly, usually in weighed quantities to provide a 2 wt.\% $\mathrm{Na}_{2} \mathrm{CO}_{3}$ and $20-30 \mathrm{wt}$.\% moisture.

2. Soak the moist, impregnated wood flour and/or slurry (with carrier fluid) in plastic bags at $70^{\circ} \mathrm{C}$ for either 24 or 48 hours. The closed plastic bags maintained the desired moisture concentration. Further details are given in the May-July 1986 Quarterly report (White et al. 1986c).

\subsubsection{Good Quality Wood Qil by Liquefaction with No Carbon Monoxide, No Catalyst and Low Water.}

Experimental Run G3, on April 16, 1986, demonstrated that a low-oxygen wood oil could be obtained by liquefaction without using catalyst and/or carbon monoxide. Further, pressure was held at 2,000 psi, which is lower than normally considered necessary for successful direct liquefaction. These results were achieved at temperatures on the high side $\left(375-400^{\circ} \mathrm{C}\right)$ and a long residence time of about two hours. The distillate of the reactor effluent was found to have 7.5 wt.\% oxygen. Further details are given in the February-April 1986 Quarterly report (White et al., 1986b).

\subsubsection{Demonstration of Long Continuous Run}

There was interest in demonstrating that the liquefaction unit could be operated continuously for a considerable length of time. The limited manpower was divided into two 12hour shifts, and a long run was started on July 29, 1986.

The long run of July 29 through 31 (Run I1) ran smoothly for more than 52 hours with only one interruption to fix a leak in the top of the reactor. During this run all the various types of available vacuum bottoms were used up. At the end of the 52 hours and no vacuum bottoms, we switched to recycled material of our product starting with low concentration of solids and gradually increasing it. However, at this point, the experiment was discontinued due to a plug 
in the reactor of the type experienced during the run on July 14, 1986. This plug was probably due to the inexperience of operating with the new types of feedstocks utilized near the end of this 52-hour run. Further details on Run I1 are given in the August-October 1986 Quarterly report (White et al., 1986d).

\subsubsection{Vacuum Distillation}

Vacuum distillation of the reactor effluent crude oil products serves the dual purpose of (a) providing the process product having a viscosity slightly higher than petroleum Fuel Oil No. 2 and (b) providing a heavy vacuum bottoms to serve as the fluid carrier for fresh wood from feedstock in the recycle mode. Laboratory distillations were carried out routinely on this project for analytical purposes, operating at $2-5 \mathrm{mmHg}$ abs. pressure and a temperature cut-off at $550^{\circ} \mathrm{F}$. This cut-off temperature is lower than that practiced by the Albany biomass liquefaction plant and by the petroleum industry.

For the continuous extruder-feeder liquefaction unit, a commercial Pope vacuum still was purchased in mid-1986 and installed in late 1986. It was initially operated with an 80 wt.\% kerosene/20 wt.\% asphalt mixture for shake-down operations. Unfortunately, an equipment failure of the Pope vacuum still occurred on March 3, 1987. While operating the Pope vacuum still, a water cooling line slipped off a connection due to water pressure, and the resultant temperature differentials caused the glass evaporator body to shatter beyond repairs. This was a serious set-back because more vacuum bottoms were needed at that point in time for future experimental runs. Due to the high cost of evaporator replacement, it was decided to defer such costs until it could be determined whether or not a suitable feedstock could be made from the Albany TR-9 crude wood oil by another technique. It should be noted that Albany crude wood oil TR9 is a very viscous liquid, even at $150^{\circ} \mathrm{C}$, and is a tacky sclid at room temperature. It was decided to utilize the extruder-feeder as a "mild pretreater" to make a suitable WF carrier oil. Further details are given in the August-October 1986 Quarterly report (White et al., 1986d).

\subsubsection{Albany TR-9 Crude Wood Oil as Wood Flour Carrier}

Following the failure of the Pope vacuum still, the Albany TR-9 wood oil was indeed shown to be a good substitute for wood oil vacuum bottoms as the fluid carrier for wood flour feedstock slurries. As stated above, it is a tacky solid at room temperature but is a viscous fluid at $150^{\circ} \mathrm{C}$. This viscosity was further increased by one pass through the extruder-feeder under mild temperature and short residence time. These conditions were easily established by a few experiments using only the extruder-feeder.

A major effort was then initiated in April, 1987, to prepare some 300 pounds of feedstock, based on using the Albany TR-9 crude wood oil as the carrier. This quantity was necessary in order to then recycle the University of Arizona reactor effluent product several times in order to make "an all-University of Arizona crude wood oil". White birch wood flour was mixed with an equal amount of sodium carbonate solution, so that the soaked wood flour wood contained five pounds of $\mathrm{Na}_{2} \mathrm{CO}_{3}$ per 100 pounds of dry wood flour. It was pretreated further by soaking in plastic bags (no moisture lost) at $70^{\circ} \mathrm{C}$ for 45 hours. It was then mixed by hand with liquid Albany TR-9 heated to $150^{\circ} \mathrm{C}$, to give a $50 / 50$ wt-ratio mixture of wood flour/TR-9 
on a dry basis, and then immediately passed through the extruder-feeder only. The residence time in the extruder-feeder was about three minutes, entering at about $25^{\circ} \mathrm{C}$ and exiting at about $99^{\circ} \mathrm{C}$. Further details are given in the May-July 1987 Quarterly report (White et al., 1987c).

\subsubsection{Initiation of Work On An All-Arizona Crude Wood Oil}

In setting the goals for FY1987, it was judged important to make an "All-Arizona" crude wood oil. This goal was accomplished during the period August 20 - September 17, 1987 (Runs N1-P1).

An All-Arizona crude wood oil is defined as a liquefaction liquid oil product of lowoxygen content derived from wood flour, which is processed entirely in the biomass liquefaction facility at the University of Arizona. It should be reiterated that any continuous biomass liquefaction process would require (a) some method of continuously feeding solid biomass into a pressure system, (b) some method of "flowing" the solids through the system, and (c) some method of mixing or dispersing carbon monoxide with the solid biomass for good mass transfer for the necessary chemical reactions. The extruder-feeder process utilizes the heavy ends vacuum bottoms for these purposes, and obtained these materials from the Albany biomass liquefaction plant in the form of vacuum bottoms and a viscous TR-9 crude wood oil (solid at room temperature).

Since the extruder-feeder liquefaction unit is a continuous, once-through experimental facility, it was necessary to simulate operations in a recycle mode to achieve an All-Arizona wood oil. This was accomplished by starting with a $40 \mathrm{wt} \%$ WF/60 wt \% TR-9 feedstock for experimental Runs N1 and N2, which processed a total of 320 pounds of feedstock and generated about 172 pounds of liquid pressure let-down product. The some 30 pounds of light overhead liquid oil product was kept separate and not blended into the about 172 pounds of crude oil. Likewise, the some 20 pounds of residual wood oil in the system at the end of the run were not combined with the 172 pounds of product. A first "recycle mode" was achieved by adding fresh wood flour to N1-N2 wood oil product and processed in Runs O1-O2. A second recycle was carried out in a similar manner for Run P1. The resultant reactor effluent was then vacuum distilled to provide "An All-Arizona" crude wood oil. It is believed that this product contained very little of the original viscous Albany TR-9 wood oil, because (a) during each of the three once-through operations involved, some $7-10 \mathrm{wt} \%$ of wood oil produced is of a low viscosity that is carried overhead and thus separated form the main liquid wood oil of each of the four passes and (b) the final reactor effluent product (third pass) was $44 \mathrm{wt} \%$ insoluble in THF. Normally, less than one percent of freshly made wood oil is insoluble in THF. Therefore, it is believed that most of the $44 \mathrm{wt} \%$ THF insolubles were cross-linked or polymerized TR-9 wood oil, caused by the severe processing it was exposed to during four passes of liquefaction. This immobilized TR-9 wood oil did not distill overhead with the All-Arizona wood oil.

An analysis of the All-Arizona wood oil showed that it contained around $8 w$ t $\%$ oxygen. Its other characteristics were similar to those previously described for the oils from earlier runs. 
Further details provided upon Runs $\mathrm{N} 1, \mathrm{~N} 2, \mathrm{O} 1, \mathrm{O} 2$, and $\mathrm{P} 1$ are summarized in Appendix D. Details of these runs are given in the Quarterly reports of August-October 1987 through May-July 1988 (White et al., 1987d, 1988a,b,c).

\subsection{SECOND GENERATION OF COMPUTER CONTROL USING THE FIX SOFTWARE PROGRAM}

\subsubsection{Introduction}

For continuous runs of the advanced extruder-feeder reactor biomass liquefaction unit, a real-time computer control system is advantageous. The design of the biomass liquefaction unit included such a real-time microprocessor system for control and data acquisition. The first generation of process control and data acquisition for the biomass liquefaction project was written in-house using a 6502 microprocessor system in assembly language as outlined in Section 4 (Andrews, 1984). This system was successfully tested and implemented on the biomass liquefaction unit by Joshi (1985). Later this system was translated from assembly language to C language (Wong 1986). Due to the rapid advancements with state-of-the-art for control and data acquisition software programs, a powerful commercial software program called FIX was purchased from Intellution, Inc. The FIX is a powerful set of programs for process control and data acquisition. (Davenport 1989). Work on the FIX software started in late 1986 and was first used in Run M1 on July 18, 1987.

The objective was to implement the control and data acquisition strategies on the iinmass liquefaction unit, taking advantage of its existing sensors and controls. A four-step process was used for implementation of the modified control system, namely, (a) conceptual development, (b) upgrading of instrumentation, (c) FIX software implementation, and (d) supplemental hardware implementation.

Implementation included utilizing traditional control strategies (PID and ON/OFF) as well as some non-traditional strategies for feeding carbon monoxide and superheated steam.

\section{Hardware}

With the purchase of the FIX from Intellution, Inc., the software program was transferred to an IBM Personal Computer (made available by the Department of Chemical Engineering) and some additions were included as described below. The IBM computer was dedicated to this liquefaction project. The standard IBM PC was upgraded to $512 \mathrm{~Kb}$ of memory with the addition of a multi-function board. This board, in addition to the increased memory, also had a parallel printer and a battery powered clock port. Also, a $20 \mathrm{Mb}$ hard disk was added, in addition to the one floppy disk drive. Also, an enhanced color graphics adapter board was used for high-resolution graphics displays, along with a Sysdyne enhanced graphics color monitor. A RS422 communications card for simple communication with the D/A and A/D system was installed. 


\section{Software}

The FIX is a state-of-the-art industrial process control and data acquisition system for use with an IBM PC. It allows easy implementation and use without any programming, but also allows more advariced users the opportunity to add their own programs in the $\mathbf{C}$ programming language. The FIX is supplied with all the necessary software needed to perform data acquisition and process control. The operator need only create his own data base and display, and inform the system of the hardware being used for D/A and $A / D$.

The FIX gathers data through the various sensors at a selected time rate and displays the values in "engineering" units $\left({ }^{\circ} \mathrm{C}\right.$, psi, etc.) on color displays. The FIX can then process that information and change reactor outputs. The FIX can support up to 3,000 "blocks". Each block represents a different function (for example, an analog input block receives analog data from other process area, an analog output gives output values to the process, a PID block performs PID control, etc.). These different blocks can then be chained together to produce a process control "loop". The FIX can process between 20-30 of these control loops per second. The FIX displays and updates the values received from the process in real-time. It can store the data to disk for historical trending and graph displays. The following is a list of all of the major components of the FIX.

\begin{tabular}{||l|l||}
\hline SAC (Scan, Alarm, Control) & Lead/Lag \\
\hline DBC (Data Base Create) & Ratio/Bias \\
\hline DBB (Data Base Builder) & Signal Selector \\
\hline Analog Input & Dead Time \\
\hline Analog Output & Totalizer Block \\
\hline Digital Input & Statistical Process Control \\
\hline Digital Output & Program Block \\
\hline Historical Trend & Device Block \\
\hline Calculation Block & Boolean Logic \\
\hline Register Value & Draw \\
\hline Coil Value & Creating Displays \\
\hline PID Control Blocks & Line \\
\hline Drum Sequencer & Circle \\
\hline Ramp Block & Box \\
\hline On/Off Conirol Block & Bar \\
\hline
\end{tabular}




\subsubsection{The FIX Shell: Multi-Tasking Executive}

The FIX Shell is a very efficient and easy-to-use program that provides a time-shared multi-tasking environment for IBM-PC DOS programs that can run up to sixteen different programs concurrently, each with its own priority level. Programs operating under the shell have full access to all DOS commands and therefore, any packaged program (such as Lotus 1-2-3) or user-written program can be run.

There are two different kinds of programs that operate under the Shell, foreground programs and background programs. Background programs allow one to enter and leave them without stopping the prograin from running, whereas foreground programs stop running as soon as one leaves it. This is a powerful program that allows one to do many tasks at the same time.

\subsubsection{Historical Trend Package}

The historical Trending Package provides an automatic and comprehensive means of collecting, saving, and displaying process data. The Historical Trend Package is broken down into 3 parts: Historical Trend Assign, Historical Data Collection, and Historical Data Display.

Historical Trend Assign (HTA) is the program that informs the FIX what data to retrieve, and at what time periods. It allows the operator to enter the tagnames used by the Data Base Builder (DBB) that will be collected for historical trending, and the rate at which each block's data is stored to the disk.

Historical Data Collection is the program that saves the values of the different blocks defined in the historical trend assign to disk. Historical Data Collection is a background program that runs under the FIX She"'. Therefore, any other program can be run at the same time as Historical Data Display.

The Historical Data Display program produces graphical displays of other data collected by the Historical Data Collection Programs. It can display up to 8 different variables or a value versus time axes, each in a different color. The operator can select the time range and can pan and zoom the display to view additional details. The Historical Data Display package can also create spreadsheet of PC-DOS compatible files with the data so it can be used by other programs. It can also make a hardcopy of the graphs, as well as a printout in tabular form.

\subsubsection{Data Base Access}

As was stated earlier, the FIX was designed so.that no computer programming was needed to use the FIX. The C Data Base Access package allows one to enhance the FIX's capabilities by writing programs in the $C$ language that have access and can read from, or write to the FIX's Data Base as well as the Scan Alarm and Control package. Since this package allows self-written programs, it makes the FIX infinitely powerful and adaptable. 


\subsubsection{The FIX Scheduler}

The FIX Scheduler is used to run any executable file at a specific time or based on a specific event. It is broken into two programs: The scheduler menu and the actual scheduler. The scheduler menu is an interactive program that lets one add, modify or delete programs that are to be scheduled. There are two types of schedules: Time-based schedules allows one to schedule a program at a specific time or a specific interval of time (e.g. every four hours). An event-based schedule runs every time a digital tag (input or output) changes from open to close. The actual scheduler is a background program that runs under the FIX Shell. It looks through the Scheduler.Menu and when it finds a program to be run (based on the time or an event) it then executes it.

\subsubsection{FIX Report Generator}

The FIX Report Generator is a program that, in conjunction with the Scheduler, will print out a report at a scheduled time. This report can include test data, tables or graphs of trend data.

\subsubsection{On-Line Spreadsheet Interface}

The on-line spreadsheet interface allows one to create $\mathrm{C}$ spreadsheet compatible files from a display called from VIEW. It reads the data from the various links on the screen and stores them in a file.

\subsubsection{Real-Time Add-In for Symphony}

The Real-Time Add-In for Symphony provides a means of connecting the FIX's process data base to Symphony, which receives the data in real-time. This allows the operator to use the computation ability of Symphony to perform complex calculations.

\subsubsection{Liquefaction Process Sensors and Controls}

\section{Extruder-Feeder Controls}

The extruder-feeder heaters are controlled through a PID cuntrol loop on the computer. Cooling is accomplished by a water sprayer with on/off control. The location of the temperature and pressure readings on the extruder-feeder are detailed on Figure 6.1.

\section{Reactor Controls}

Two control objectives for the reactor (in addition to residence time) are controlling the temperature and the pressure. The two main sections of the reactor are controlled through PID control loops with electrical heater bands. The other, secondary heaters are controlled through on/off controllers. These included the heaters on the overhead piping and the heaters on the cross. The pressure is controlled through a PID control loop which opens and closes the off-gas control valve. The location of the temperature and pressure readings on the reactor is shown in Figure 6.2. 


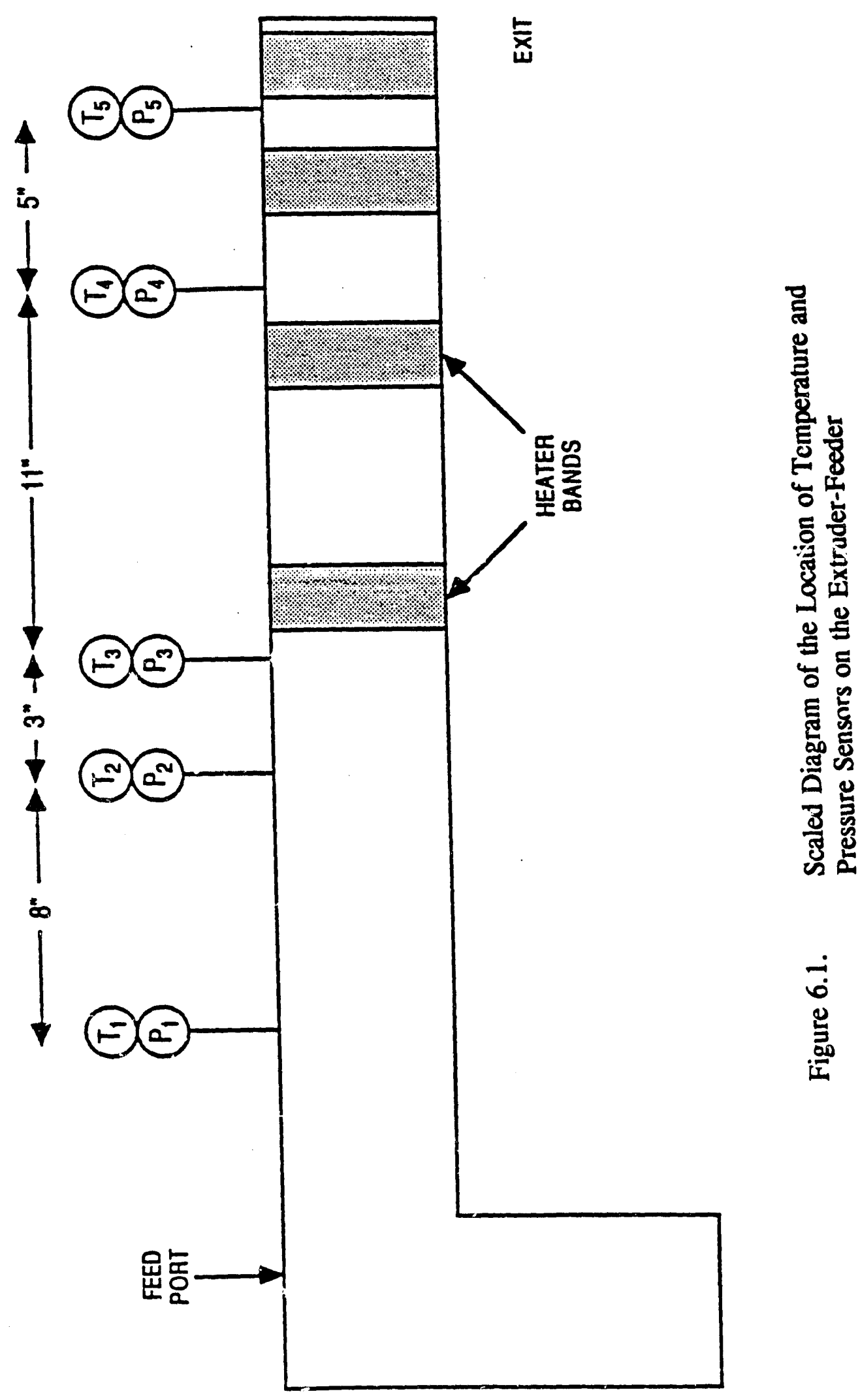




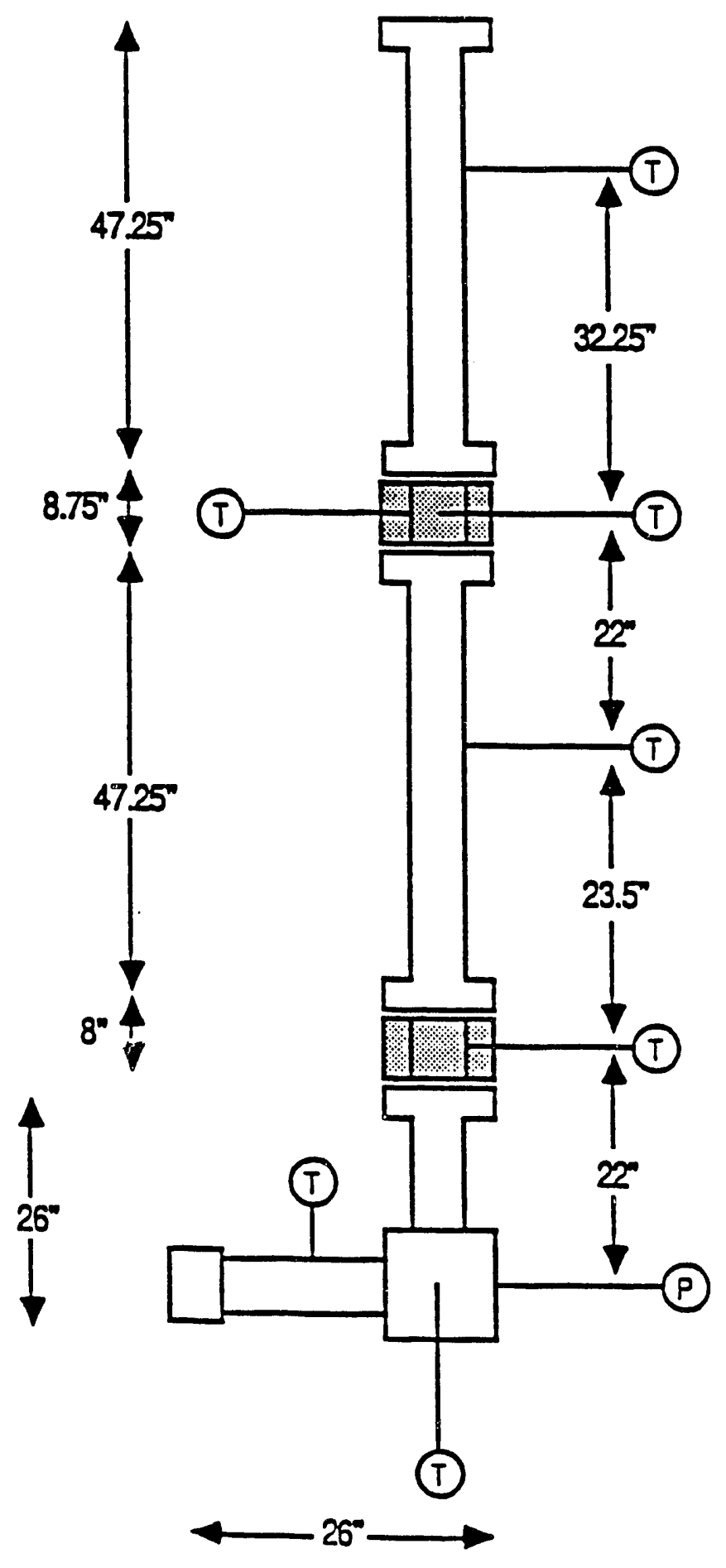

Figure 6.2. Scaled Diagram of the Location of Temperature and Pressure Sensors on the Reactor 


\section{Liquid Oil Pressure Let-Down Controls}

In the pressure let-down vessel, reactor products are accumulated before removal from the system. The temperature is controlled through a PID control loop. The liquid-level in the pressure let-down vessel is to be controlled with a control valve which opens and closes based on the readings from a nuclear gamma ray detector. This was the most convenient first method of control that could be used because of the severe pressures and temperatures in the let-down vessel as well as the highly viscous nature of the material inside. The control valve, as well as a manual externally operated valve in parallel have their temperatures controlled by on/off controllers and heater tapes.

\section{Qff-Gas Controls}

The off-gas system contains the most important control loop in the system. Reactor pressure is controlled by a PID control loop that opens and closes the off-gas control valve which regulates the flow of gas from the reactor. In order to prevent the gas from partially condensing in the off-gas line and the control valve, these lines and control valve ar heated. The temperature is controlled using on/off control.

\section{Carbon Monoxide Feed Controls}

The original design of the $\mathrm{CO}$ feeding system was as follows. $\mathrm{CO}$ is fed from a battery of cylinders into the $\mathrm{CO}$ compressor where it is compressed to $4800 \mathrm{psi}$. The compressed gas is fed into a surge tank which maintains a large amount of gas at the outlet pressure. The compressor then shuts off until the surge tank pressure drops below 4500 psi. A low flow control valve and turbine flowmeter are used to control the flowrate of $\mathrm{CO}$.

\section{Superheated Steam Feed Controls}

The design of the steam system (Reyes, 1985) included its own, stand-alone control system. This system was incorporated with the other systems through the main, computer controller system. Also, some modifications to the existing system had to be done to achieve operability.

\section{Safety System Controls}

Another important aspect of the control system is that it also serves as the safety system for the biomass liquefaction unit. The system has two audio alarms, a bell that goes off when the temperature exceeds some safety limit, and a siren that goes off if the pressured exceeds some safety limit. A visual strobe is also incorporated into the system that turns on when the reactor compound is unsafe for entry. Besides the alarms, the control system is used with various air operated valves which can be opened remotely in case of emergency. A list of the locations of these various valves is given in Table 6.3. 
Table 6.3. Air-Operated Safety Valves

Carbon Monoxide Vent Valve

Off-Gas Control Valve By-pass

Let-Down Vessel Emergency Pressure Release

Vaporizer Pressure Relief

Superheater Pressure Relief

Superheater By-pass

\subsubsection{Software Implementation}

As mentioned above, the FIX is a powerful set of programs for process control and data acquisition. No programming is necessary to use the FIX, but programs can be written in C language to access the FIX's information. The FIX control programs operate under the FIX Shell, which is a real-time multi-tasking environment for the IBM PC. Control strategies are entered to the database on a block by block basis. There are about 25 different types of blocks available for implementing control strategies.

Display links are used to link displays together, therefore creating a hierarchy of the displays. A password can be included in any display preventing unauthorized process parameter changes. Function keys can be customized using special links for repeatedly used keystrokes.

Originally, four different displays were made to represent the biomass unit First was the overview screen with a schematic of the entire liquefaction unit. The other three displays represented different segments of the biomass liquefaction unit. These screens were the extruderfeeder, the connecting cross and lower reactor, the upper reactor and the pressure let-down/offgas system. Each picture displays a schematic of the area as well as the important information from that section. Besides a schematic of the entire unit, the overview screen displayed several system pressures and temperatures. Links for tuning the pressure control PID block were also included on this display as well as links for changing the control status from manual to automatic, and for changing the setpoint. The extruder-feeder display included a schematic of the extruder-feeder along with the five pressure readings and the temperature readings on the extruder-feeder. Eventually the cross pressure was also added so that when the horizontal pipe reactor was used all the data could be displayed on this one screen. Links for changing the extruder-feeder heater PID control tuning parameters, automatic/manual status and setpoint were also included on this display. The computer status, time and date were included, as well as two lines of the alarm messages. The other three displays (cross and lower reactor, upper reactor, and let-down/off-gas system) represented the schematics of the respective areas as well as the temperature and pressure data from these areas. No special links were included. A sixth display was also made which was the alarm screen. It is a full screen that displays the alarm messages received from $\mathrm{DBB}$. These screens were hooked together so that the next display could be called up with the page-up key and the previous display could be viewed with the page-down key. The display screens were setup so one could get a good idea about the state of the system. If the readings were blue, then they were too low. If the readings were red, then they were too high. 
White meant the readings were at the correct operating range. Yellow meant that there was a bad reading, signifying a broken or disconnect thermocouple or pressure transducer.

Historical Trending data obtained during experimental runs can be automatically stored onto the hard disk drive for later display and analysis using the historical data trending package. The historical data trending package is broken into three parts: assigning the data points, collecting and storing the data and displaying the data (either in graphical or text form).

The Historical Trend Assign (HTA) program is used to tell the FIX what data is to be taken, and how fast the data will be taken. The tagnames supplied in DBB are used by the Historical Trend Assign program to tell what data is to be taken. There are three time parameters used by HTA to correctly take and store the data; the file length, the base collection time, and the scan period.

There are four modes for modes for data collection: Sample, average, high and low. In sample mode, the data taken at the end of the scan period is stored. In average mode, the samples taken at the base collection rate are averaged and stored every scan period. In high and low mode, the highest and lowest data taken at the base collection rate during the scan period are stored. Both the sample mode and average mode are used for each data point in this process.

Two programs are used for displaying the historical data: Historical Data Display (HDD) and Historical Data Report (HDR). Historical Data Display is used for creating graphs on the screen or for printing. Up to eight different data points can be displayed at once. HDD provides for zooming and panning of the data for customizing the graphs. Historical Data Report is used for listing the data. A sample listing from this program is given in Table 6.4. Besides being able to point out the data in tables, HDR also make Lotus compatible files. This is useful for making calculations using the data.

\subsubsection{Microprocessor Hardware}

Many different A/D and D/A hardware systems are available that are supported by the FIX software. It was important that the hardware system chosen for the biomass liquefaction project would be flexible enough to handle the ever-changing needs. The A/D and D/A hardware used was OPTO-22 OPTOMUX because of modular nature. The control and data acquisition could therefore be built up slowly until the system was complete. OPTO-22 OPTOMUX is a family of intelligent control stations with plug-in modules. The available stations come in boards that can accommodate up to sixteen modules. One of the desirable features of OPTO-22 is that both inputs and outputs can be mixed on the same board.

There are two types of stations: Analog and digital. The analog stations are for analog signals such as thermocouple readings. The digital stations are for on/off data, pulse counting and pulse duration counting. These stations communicate with the microcomputer through an RS422 adapter card which plugs directly into the PC bus. Up to 256 stations can be linked together in two different modes: Multi-drop mode and repeat mode. In multi-drop mode a total of 5000 feet of wire can be used. IN repeat mode, 5000 feet of wire can be used between each station, as the signal is retransmitted by each station. The addresses set by the jumpers on the 
Table 6.4. Historical Data Report Sample

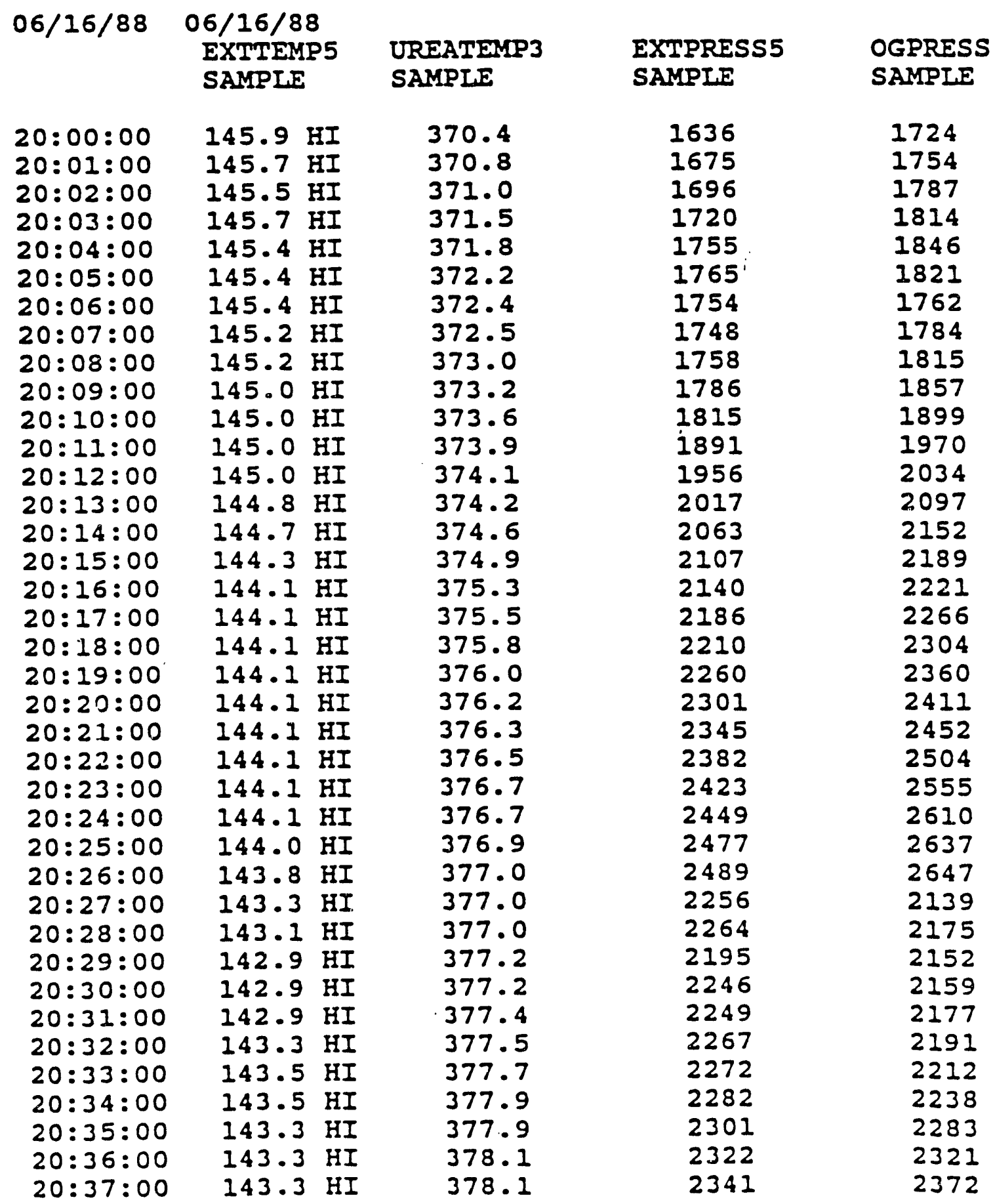


OPTO-22 brain board are used by the FIX to properly poll the correct data point. These addresses are broken into three parts. The first part is the communication port on the computer that is used for OPTO-22 communication. In our case this is two, as COM port two is used. The second part is the address supplied on the brain board. This is given in hexadecimal and has legal values from 00 to FF. The three boards currently in use have addresses FF, FE and FD. The final part is the location on the mounting rack that is connected to the instrumentation. This varies from 0 to 15 depending on what slot is used on the mounting rack.

\subsubsection{Experimental Runs using FIX Software}

The conceptual development started in January 1988, and when the FIX software arrived shortly thereafter, work began on configuring the database and creating the graphic displays. During this time, the OPTO-22 hardware was ordered. The real-time control system using the FIX was installed on the biomass liquefaction unit during the summer of 1987 . Initial testing of the real-time control system was done in September of 1987. The FIX system was then used on extruder-feeder for testing alternate feedstocks from October 1987 - January 1988. Experimental runs were restarted in March 1988, and the FIX real-time control and data acquisition system has been used for every experimental run since then. Some typical printouts of the displays used during each run are shown in Figures 6.3 through 6.8.

Thirteen experimental runs were made on the biomass liquefaction unit using the FIX control system. These runs ranged from testing different feedstocks (different WF concentrations, different carriers) at different run conditions (temperature, pressure, CO flowrates, etc.) to producing All-Arizona Wood Oil. A list of the experimental runs on the biomass liquefaction reactor using the FIX control system is given in Table 6.5.

\section{Typical Experimental Run}

As stated earlier, a total of 13 experimental runs were conducted with the continuous extruder-feeder liquefaction unit, using the FIX control system. However, only one experimental run will be described in detail; Run R4 conducted on June 16-17, 1988 is selected as a typical run, for this detailed description.

The major objective of this run was to (a) operate at a high pressure of 3000 psi and a temperature of $375^{\circ} \mathrm{C}$, and (b) utilize feedstocks of Albany wood oil TR9 and wood flour in various concentrations. These conditions were selected in order to conduct liquefaction at the highest practical temperature that would still be below the critical temperature of water. Sodium carbonate catalyst and carbon monoxide reactant were used. Water content of the feedstock was set at $11 \mathrm{wt} . \%$ in order to result in the water-gas shift reaction being driven far "to the right", that is, forming an excess of $\mathrm{CO}_{2}$ plus hydrogen. A minor objective of this run was to have good lined-out operation for at least four hours.

Before starting the run, the feedstock was prepared and normal maintenance procedures were performed. The reactor, cross, and pressure let-down vessel were thoroughly cleaned in preparation for the run. All the thermocouples were checked and the pressure transducers were calibrated. As the FIX system was started data acquisition was started. Once the reactor had 
Table 6.5. Biomass Liquefaction Runs Using FIX

SECOND SET OF SHAKEDOWN RUNS

$\begin{array}{lllc}\text { RUN } & \text { DATE } & \text { AMOUNT FED } & \text { PRESSURE } \\ \text { Q1 } & 3 / 7 / 88 & 125 \text { Ibs } & 1000 \text { psi } \\ \text { Q2 } & 3 / 11 / 88 & 30 \text { Ibs } & 1000 \text { psi } \\ \text { Q3 } & 3 / 14 / 88 & 108 \text { lbs } & 2500 \text { psi } \\ \text { Q4 } & 3 / 17 / 88 & 20 \text { lbs } & \text { low }\end{array}$

PRODUCTION OF REACTOR EFFIUENT

$\begin{array}{lllc}\text { RUN } & \text { DATE } & \text { AMOUNT FED } & \text { PRESSURE } \\ \text { R1 } & 6 / 3 / 88 & 54 \text { lbs } & 2000 \text { psi } \\ \text { R2 } & 6 / 6 / 88 & 30 \text { lbs } & \text { Iow } \\ \text { R3 } & 6 / 10 / 88 & 30 \text { lbs } & \text { low } \\ \text { R4 } & 6 / 16-17 / 88 & 130 \text { lbs } & 3000 \text { psi }\end{array}$

ALI ARIZONA WOOD OIL

RUN DATE AMOUNT FED PRESSURE

SI $7 / 13 / 88 \quad 95$ lbs $2000 \mathrm{psi}$

s2 $7 / 20 / 88 \quad 200$ lbs $2500 \mathrm{psi}$

ALTERNATE FEEDSTOCKS

RUN DATE AMOUNT FED PRESSURE

$\begin{array}{llll}\text { T1 } & 7 / 27 / 88 & 15 \text { lbs } & \text { low } \\ \text { T2 } & 9 / 16 / 88 & 122 \text { lbs } & 2000 \text { psi } \\ \text { T3 } & 10 / 19 / 88 & 15 \text { lbs } & \text { low }\end{array}$




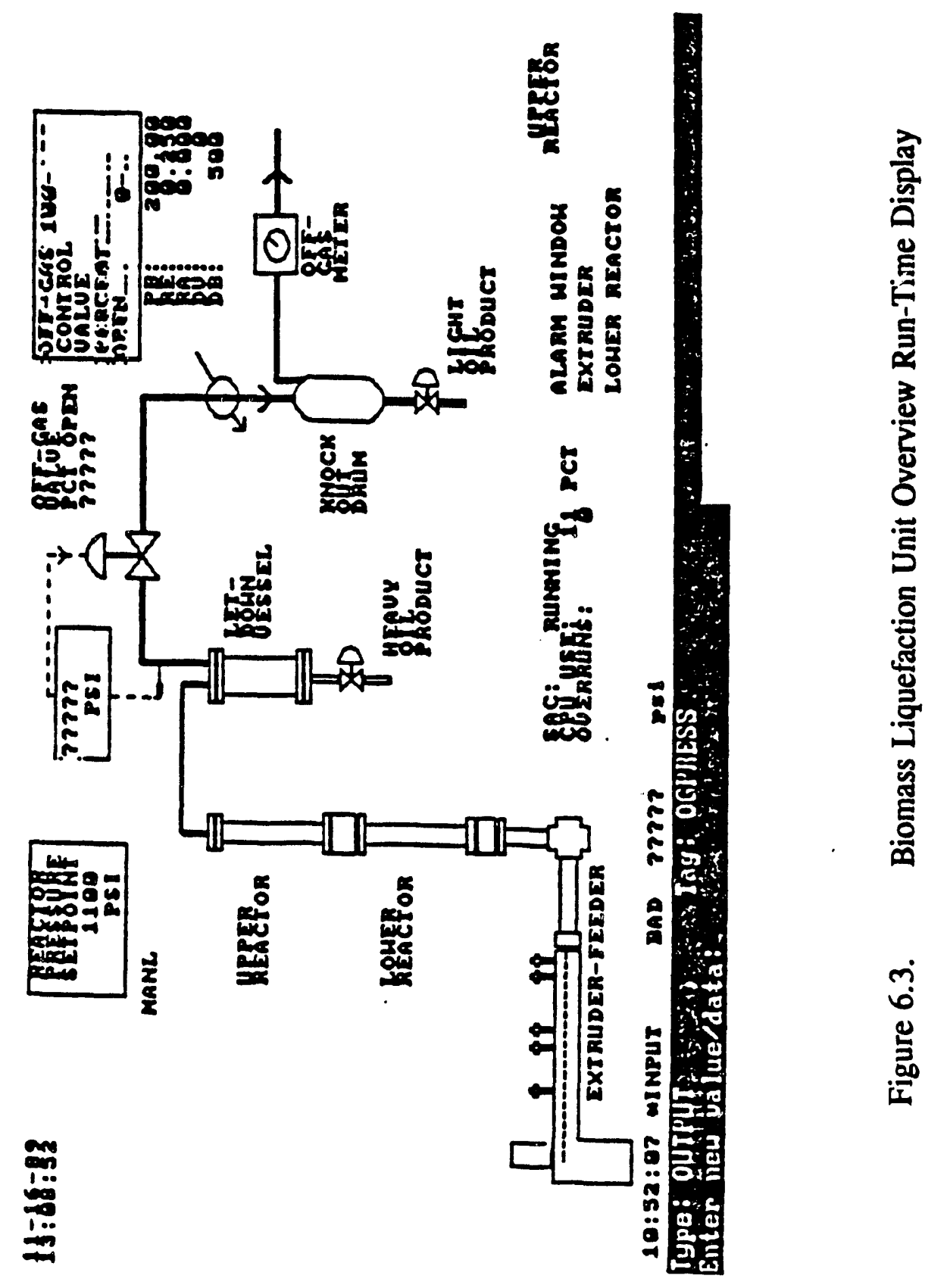

6-22 


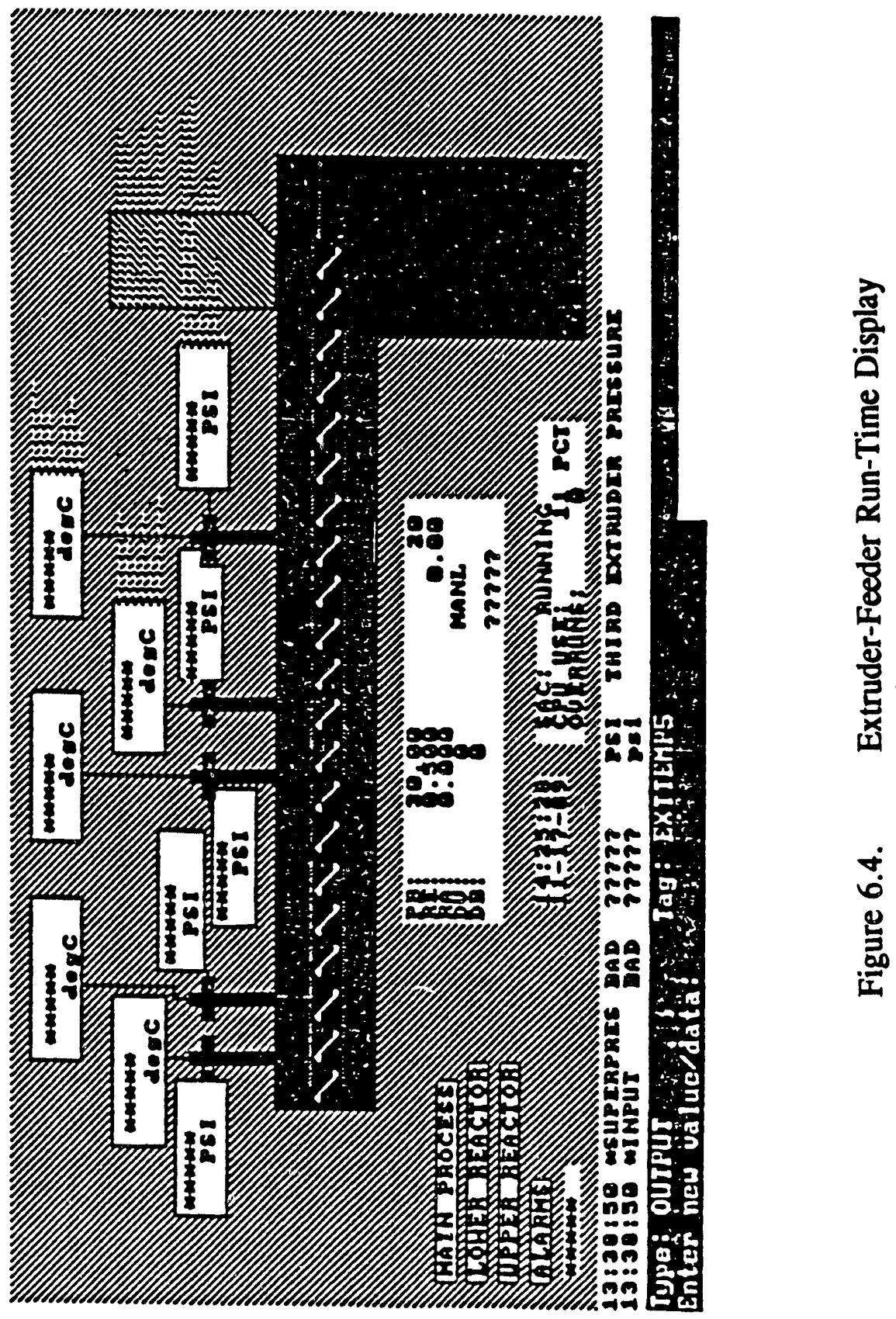




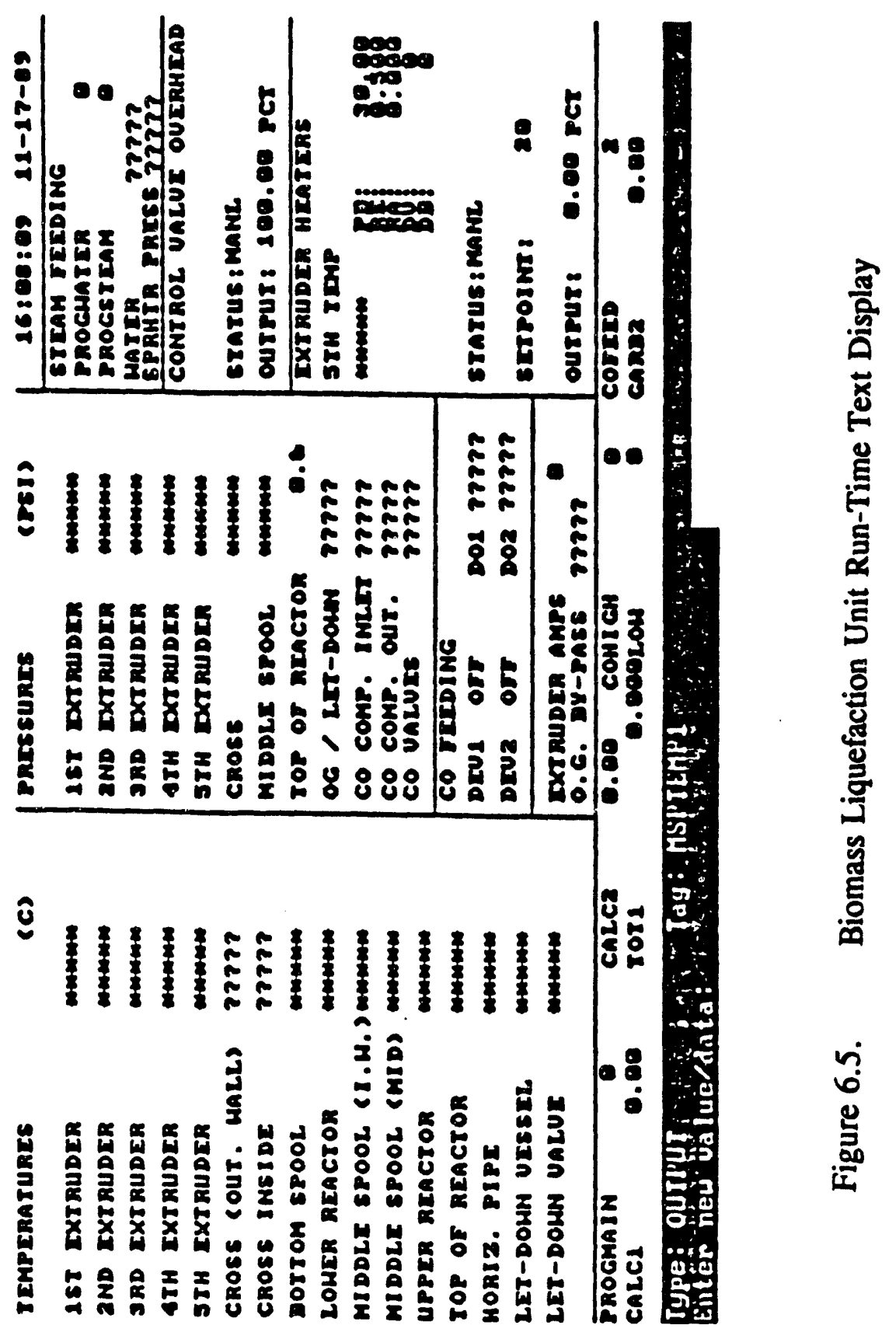




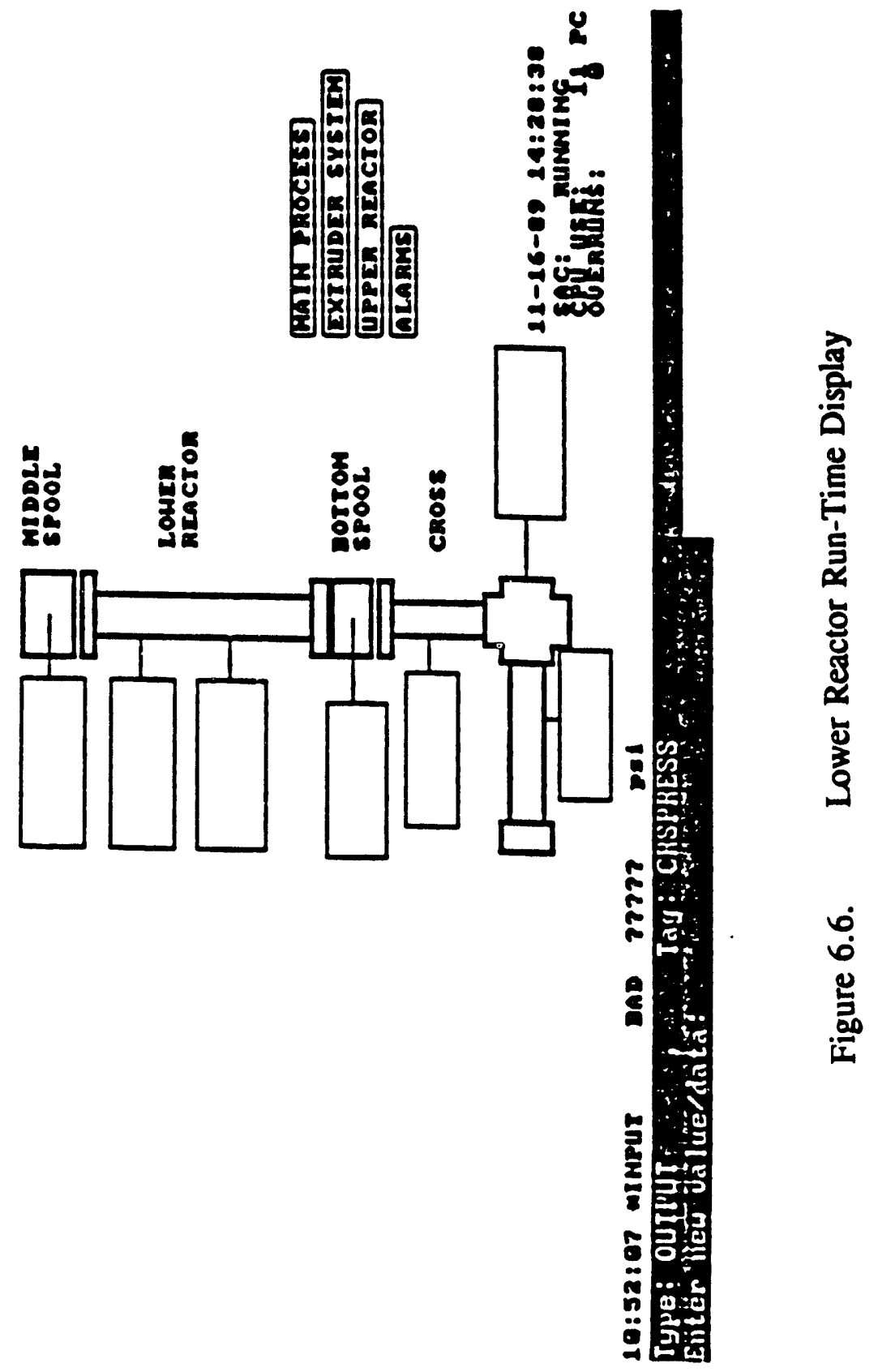




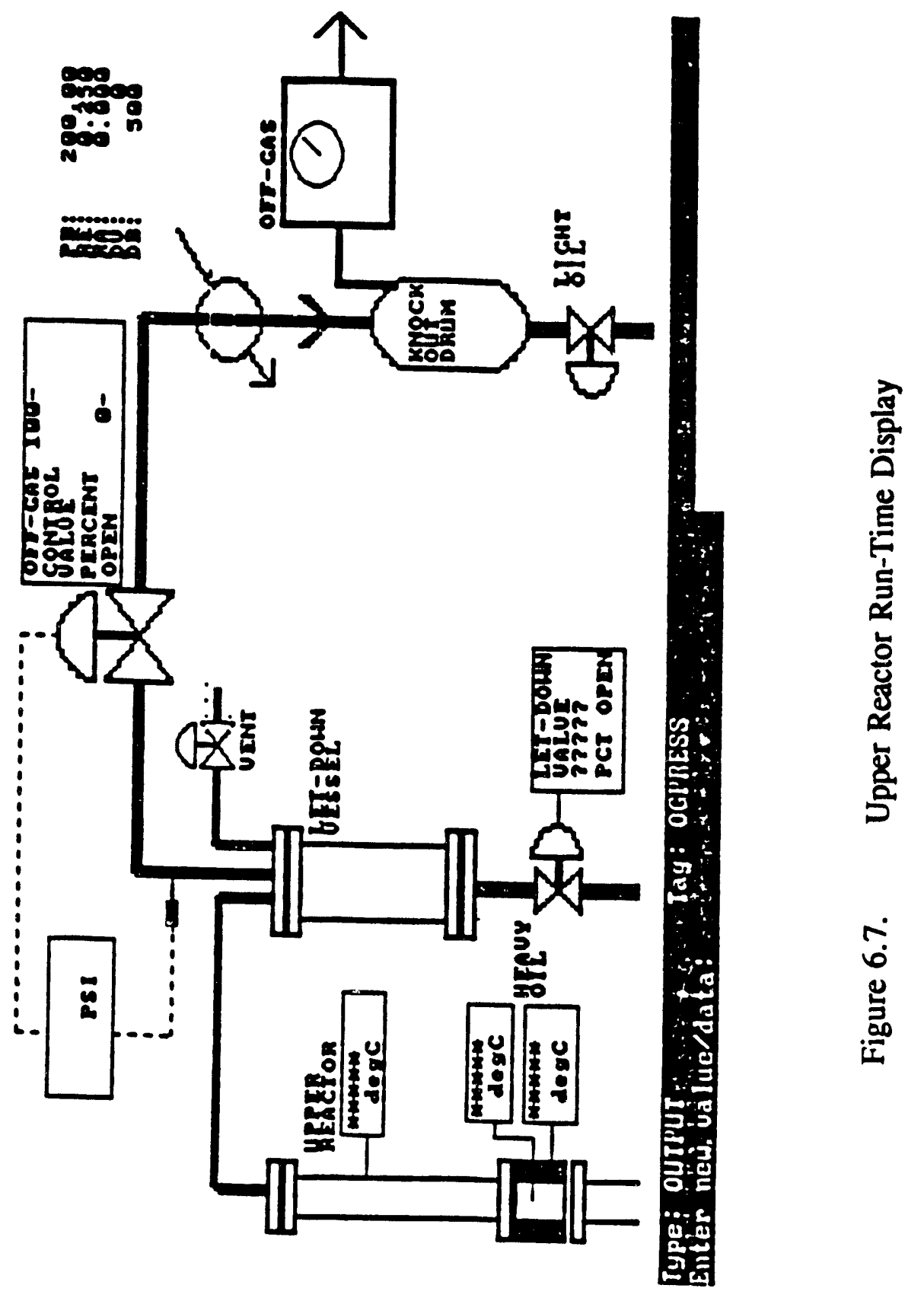



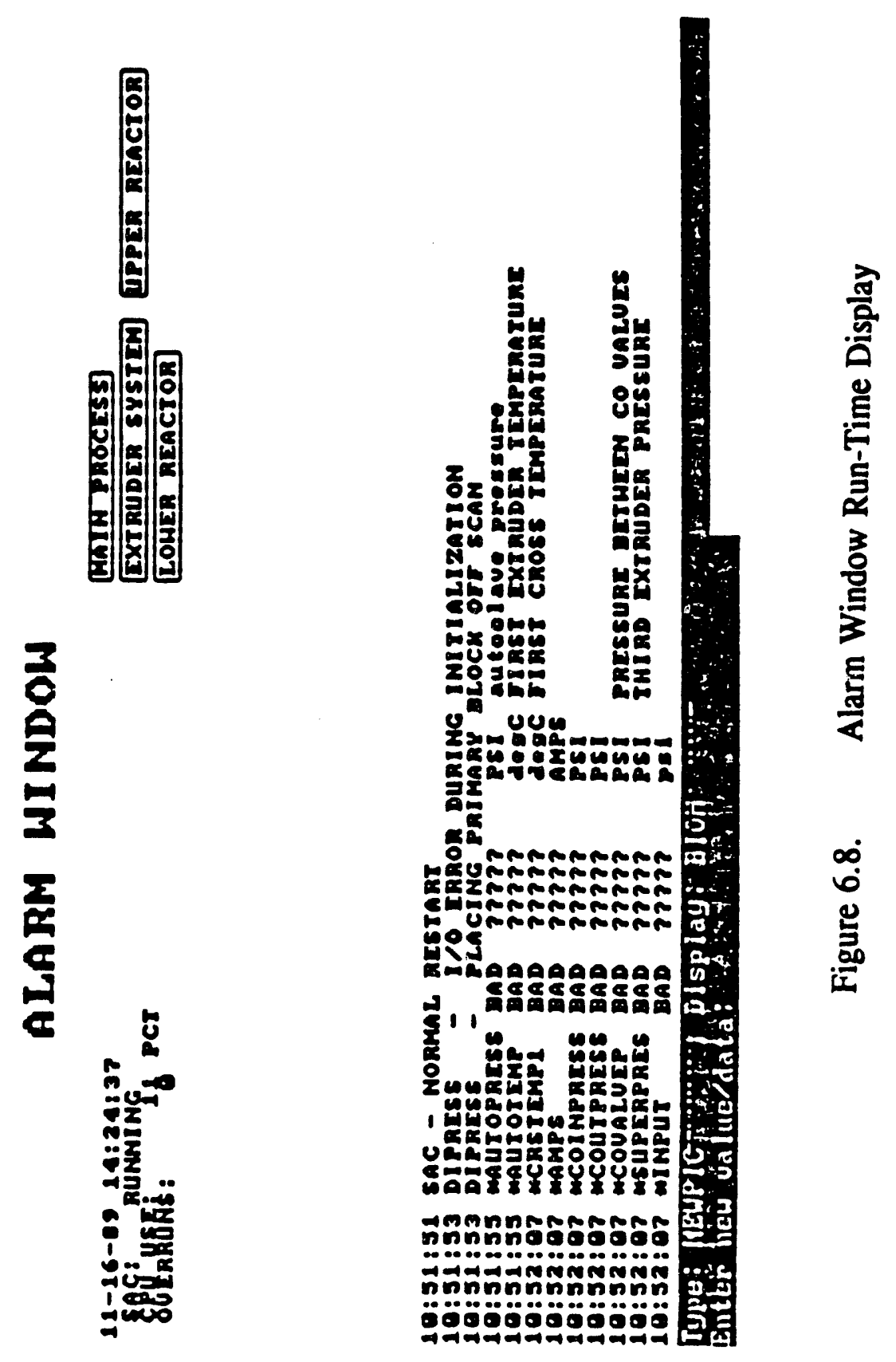
reached desired operating temperature, feeding was started. After $10 \mathrm{lbs}$. of feedstock had been fed, CO feeding was started.

The temperature and pressure profiles for the entire run are given in Figures 6.9 and 6.10. For this run, the desired operating conditions were $125^{\circ} \mathrm{C}$ for the extruder-feeder outlet, $375^{\circ} \mathrm{C}$ for the upper and lower reactors, and $200^{\circ} \mathrm{C}$ for the let-down vessel. Good lined-out operation at pressures of 3000 psi was reached for 6 hours after a transition period three different feedstocks were tested. Run R4 was terminated once the prepared feedstock had all been used. Temperature and pressure during steady state operation are given in Figures 6.11 and 6.12. A total of $130 \mathrm{lbs}$. of TR9/wood flour and $8 \mathrm{lbs}$. of carbon monoxide were fed.

Fourteen data points were taken by the data acquisition system during Run R4, seven temperatures and seven pressures. Two analog outputs were used, one for opening and closing the off-gas control valve, and iuic other for controlling the extruder-feeder outlet temperature. The FIX control system was used to successfully feed carbon monoxide using the previously designed method.

\section{Pressure Profiles in the Reactor}

Pressures of over 3000 psi have been generated in the reactor during experimental runs. The current let-down system uses one let-down vessel and manual release of the product. When operating at high pressures the system is allowed to build as high as possible because product must be collected every five pounds. A typical pressure profile during an experimental run at 1200 psi using tinis method is shown in Figure 6.13. Eventually, a liquid-level controller was planned to be used in conjunction with a second pressure let-down vessel. It is therefore important to know that the pressure can be effectively controlled. The interfacing of the software, hardware and instrumentation for pressure control is shown in Figure 6.14. The steady state pressure shown in Figure 6.13 was achieved by the fast response of the percentage opening of the off-gas control valve, as shown in Figure 6.15. The pressure in the reactor can be effectively controlled within 5 psi.

\section{Temperature Profiles in the Extruder-Feeder}

To insure good feeding during experimental runs, the temperature of the extruder-feeder must be effectively controlled. The temperature at the outlet of the extruder-feeder is controlled using PID control through the FIX. Besides the heating of the extruder-feeder, the feed section of the extruder-feeder must be cooled. This is accomplished using a water sprayer near the feed port with on/cff control. Typically, once the extruder-feeder has heated up and feeding is started, no more heating is required. The biomass feedstocks produce heat through viscous dissipation, and the amount of heat produced is usually sufficient to keep the extruder-feeder at the desired temperature. In fact, some of the feedstocks require cooling of the entire extruderfeeder barrel. The controlled extruder-feeder outlet temperature is shown in Figure 6.16. The temperature in the feed section is shown in Figure 6.17. Depending on the feedstock used, the extruder-feeder operates at different temperatures. The higher the wood flour content and carrier viscosity, the higher the operating temperature. A plot of temperature 's. wood flour content is shown in Figure 6.18. These data is taken from various runs with the heavy carrier being 
TR9 wood oil. Reactor product can be recycled as the carrier, either as is, or after vacuum distillation. The steady state operating temperature at the outlet of the extruder-feeder vs. the number of times the carrier has been recycled is shown in Figure 6.19. The original carrier was TR9 wood oil. Wood flour was added to make the feed $60 \mathrm{wt} . \%$ carrier and $40 \mathrm{wt} . \%$ wood flour.

\section{Mechanical Power Delivered to the Screw}

During experimental runs, the extruder-feeder screw speed is set typically at $95 \mathrm{rpm}$. The current drawn by the motor is read by the data acquisition system. The extruder-feeder draws between 8 ad 25 amps depending on the type of feed, the feedrate, and the pressure generated. If the current goes above 25 amps, then feeding is temporarily stopped until the current falls below that level to avoid overloading the motor. The current drawn by the extruder-feeder during a typical experiment is shown in Figure 6.20.

\section{Performance of the Real-Time Control System}

During operation, three real-time programs are run in the background: The scan, control, alarm and data acquisition program (SCADA); the historical trend collect program (HTC); and the alarm tile handler program. These are listed in the order of priority given to them by the FIX system (SCADA had the highest priority). During normal operation, 22\% of the computer's CPU is being used to perform these three tasks. This includes the reading and storing of all the data, servicing the PID controller, and performing the calculations for $\mathrm{CO}$ and steam feeding. The CPU use can briefly increase to $100 \%$ when disk files are opened or closed. This prevents historical or alarm data from being stored, but all control loops and data acquisition points are serviced. Since the computer use is usually quite low, all the data points can be scanned at a one second rate, and all the data can be stored. If the number of data points to be scanned, the number of controllers, or the amount of calculations performed in real-time are increased, then the scan times will have to be increased.

\subsection{EXPERIMENTAL RUNS WITH THE FIX SOFTWARE PROGRAM}

The FIX software packaged was purchased in 1986 from Intellution, Inc., with a partial donation of the package to the University of Arizona to reduce its cost. The design and adaptation to the continuous extruder-feeder biomass liquefaction unit was accomplished over the period. The first of the nine experimental runs using the more advanced system was Run M1, conducted on July $18,1987$.

\subsubsection{Review of Safety and Health Requirements}

In parallel with the initiation of the design and implementation of the FIX software, a periodic review of the experimental facilities for safety and health requirements was scheduled for December, 1986.

A team from the University's Department of Risk Management made a thorough safety inspection of the high pressure laboratory as part of a routine check of all laboratories in the 


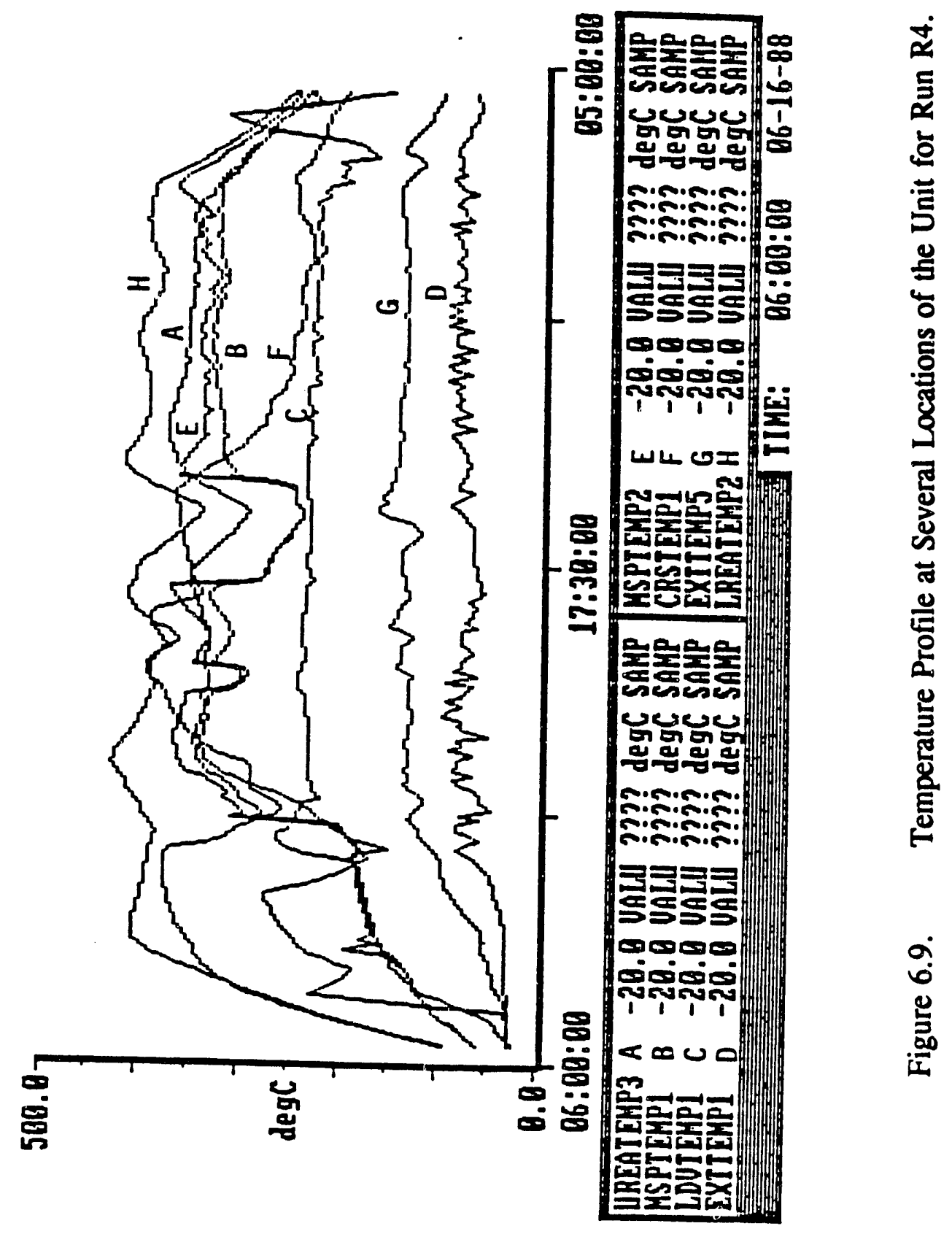




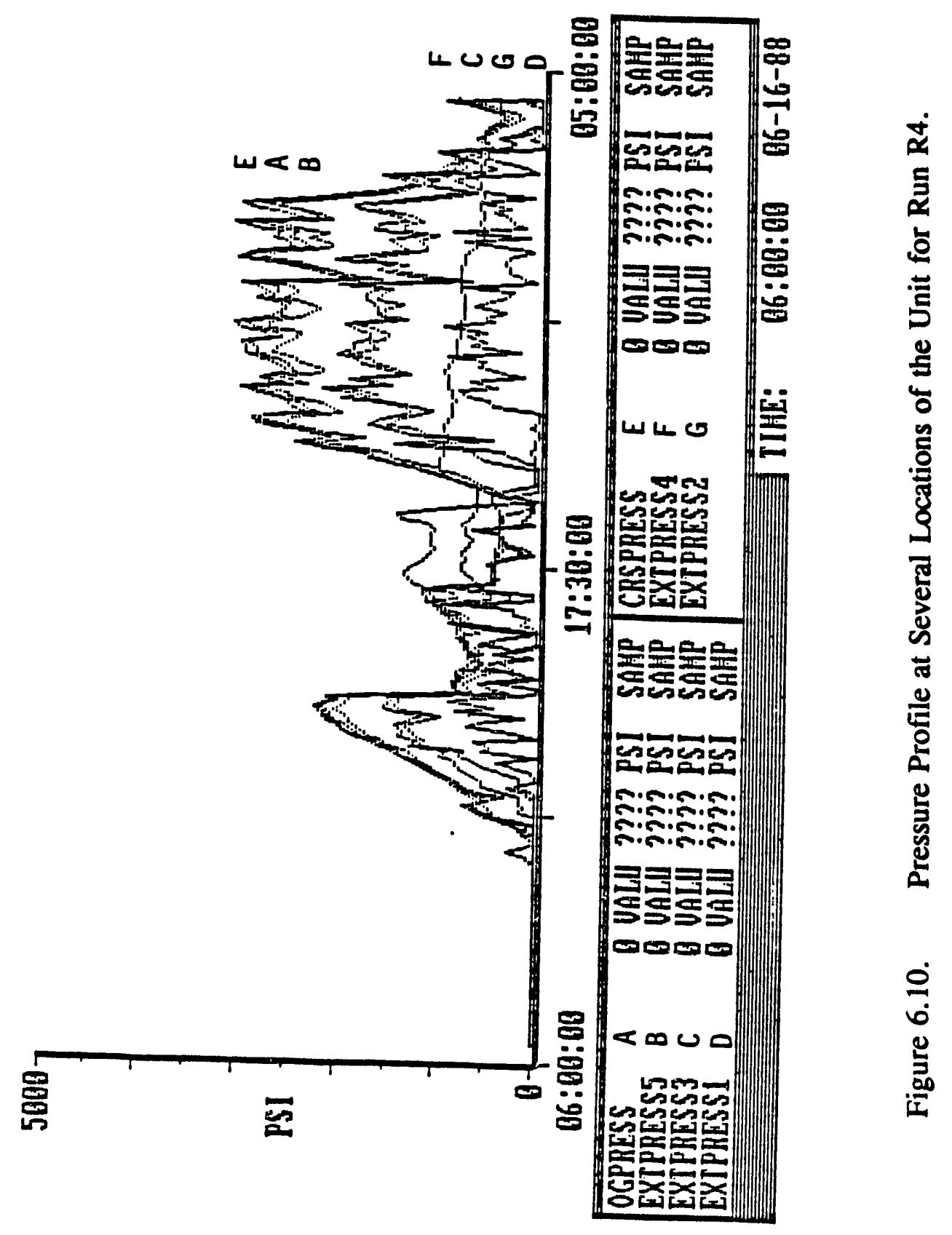




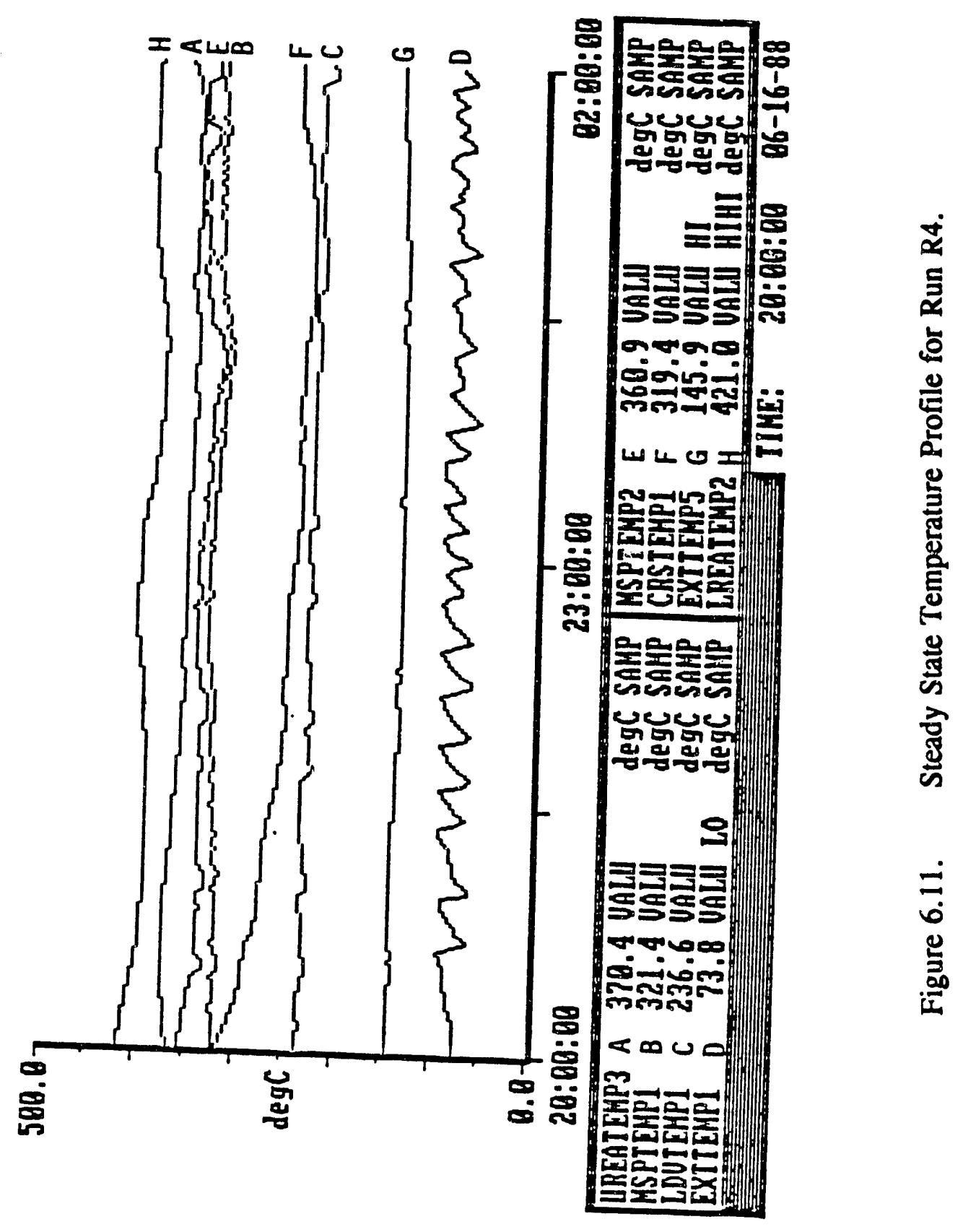




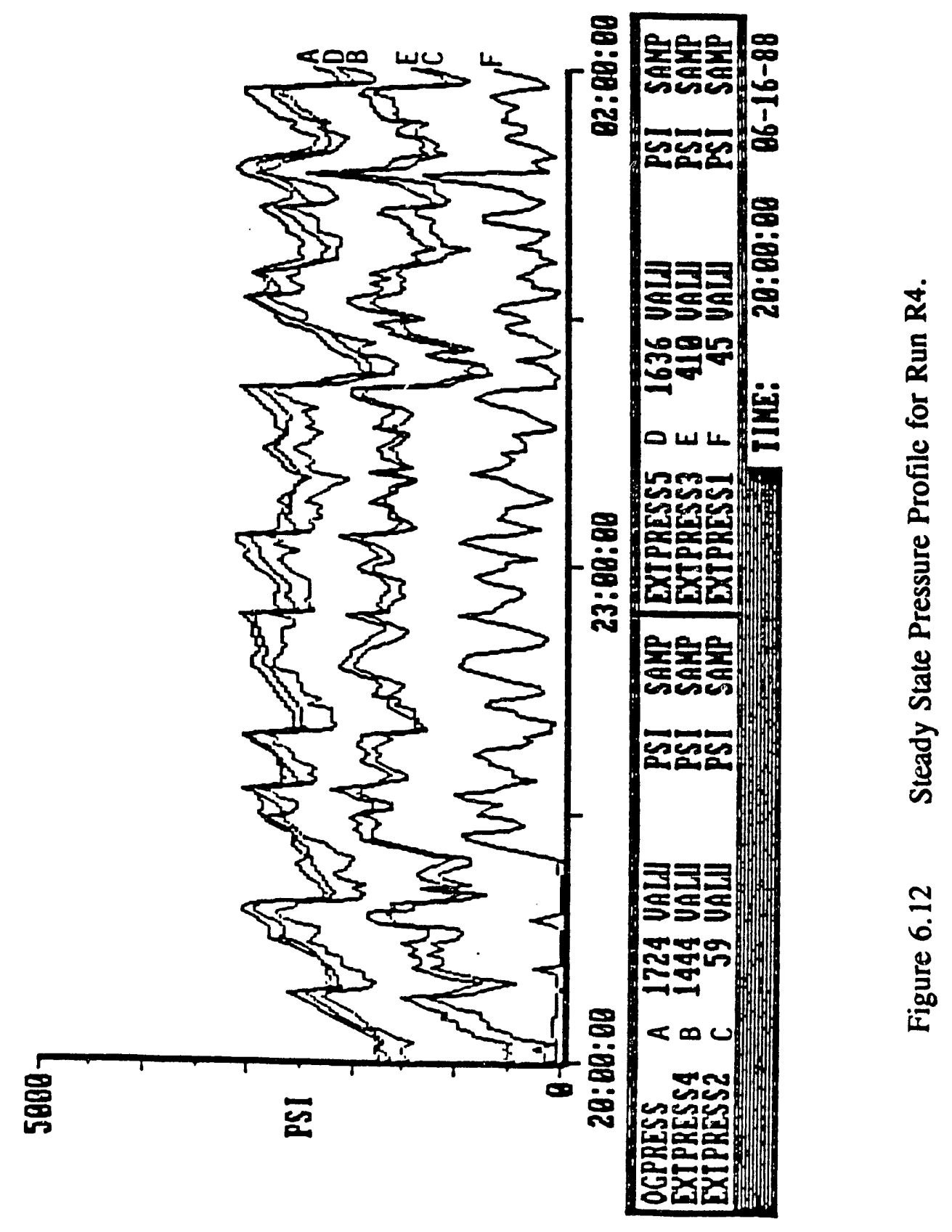




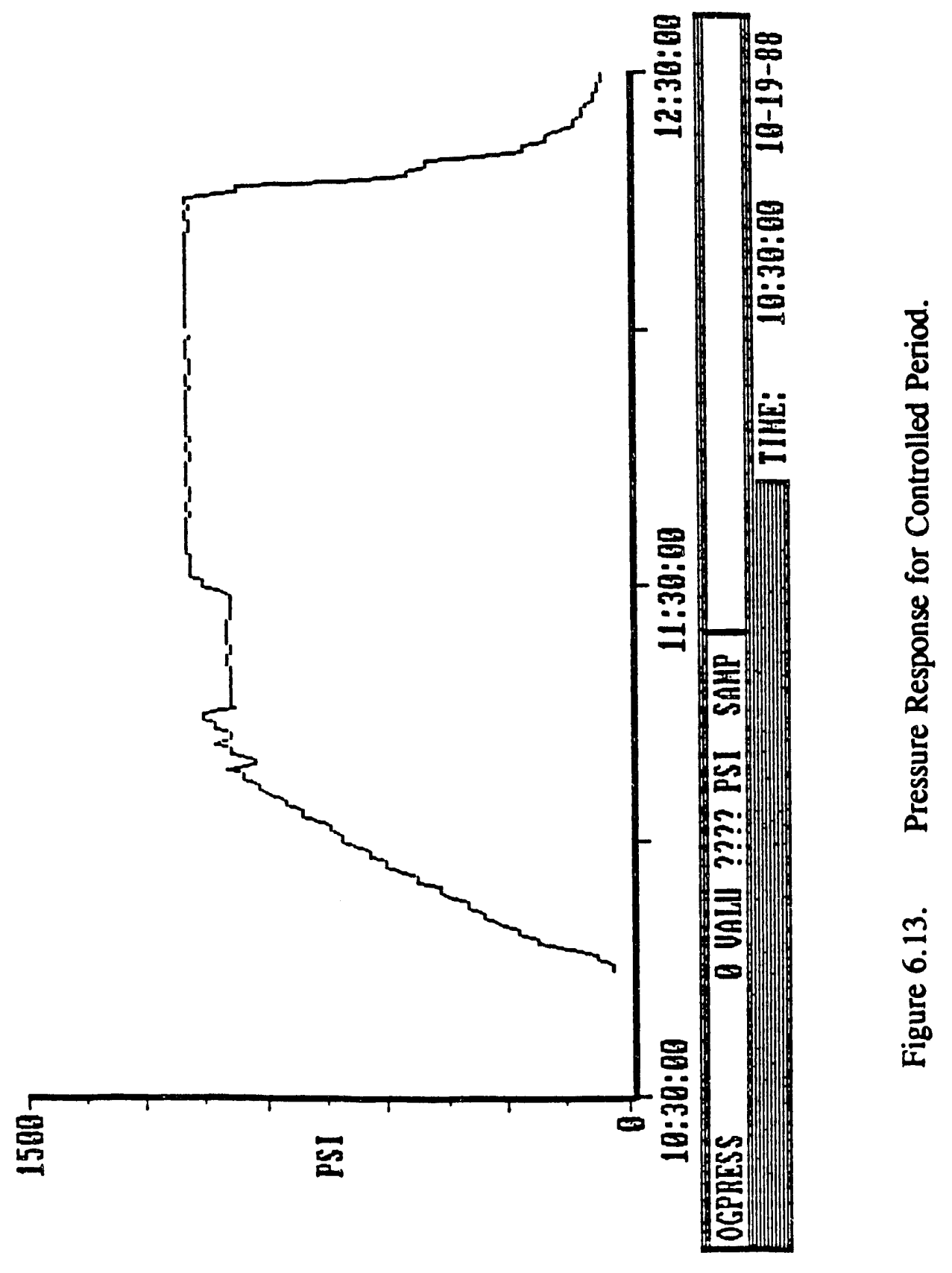




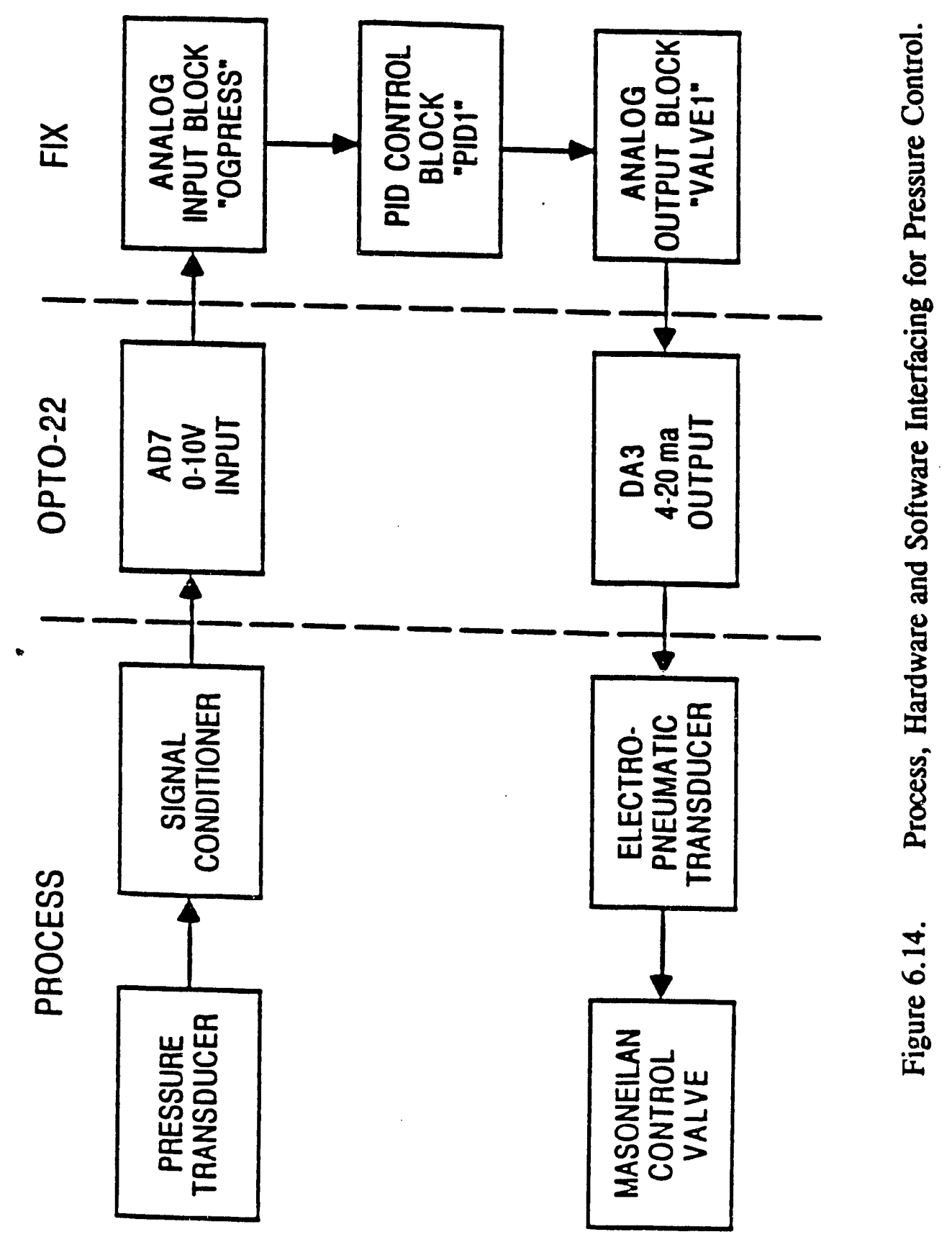




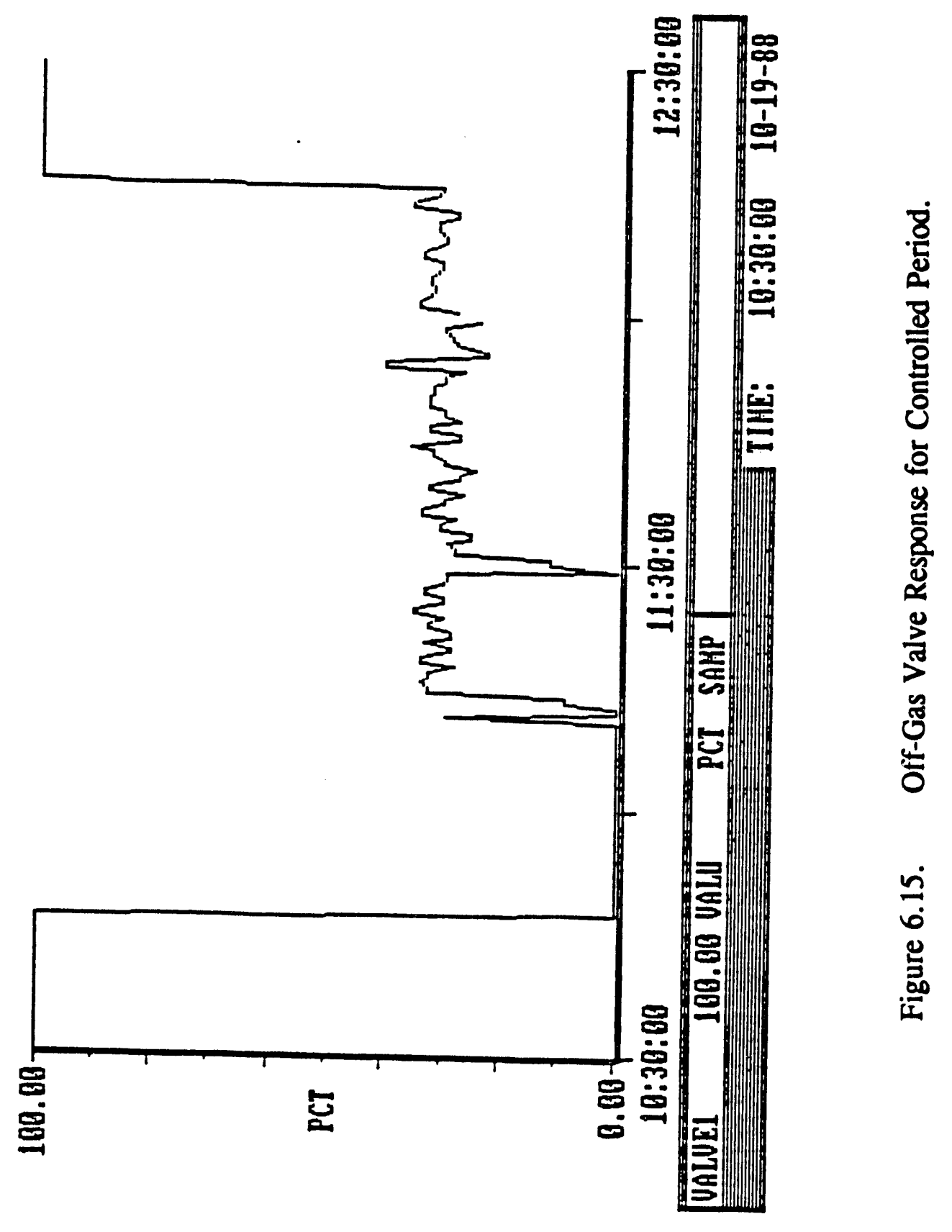




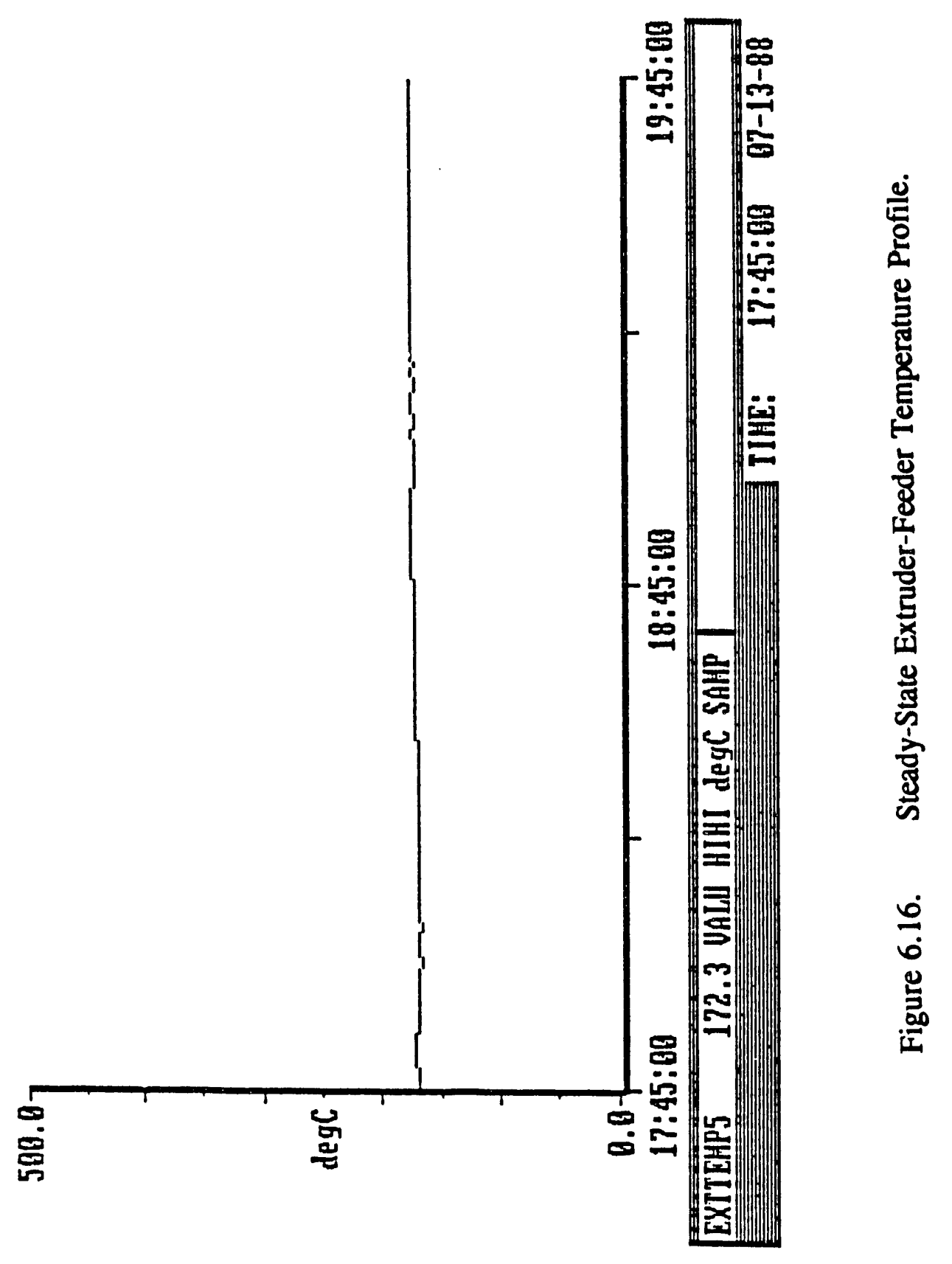




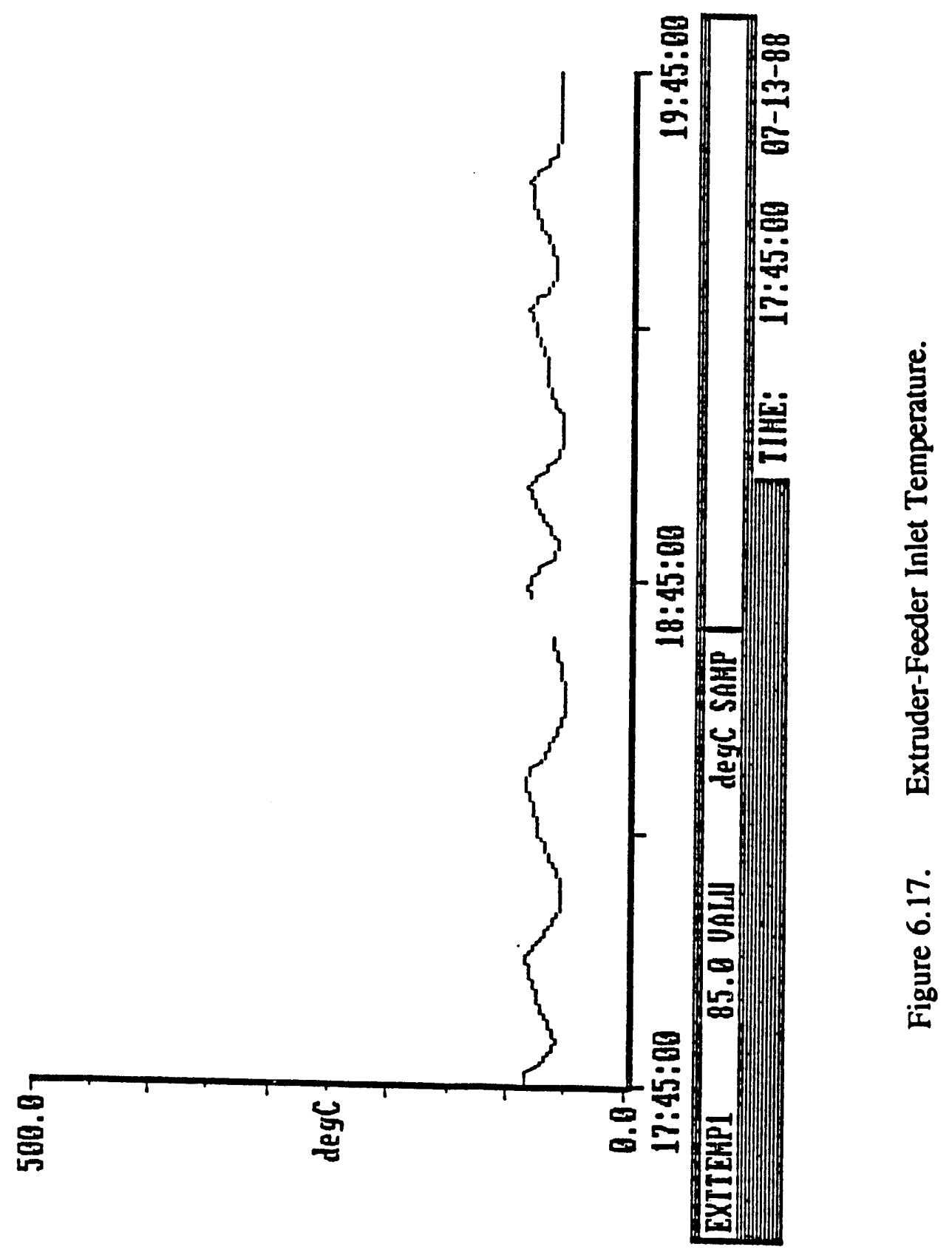




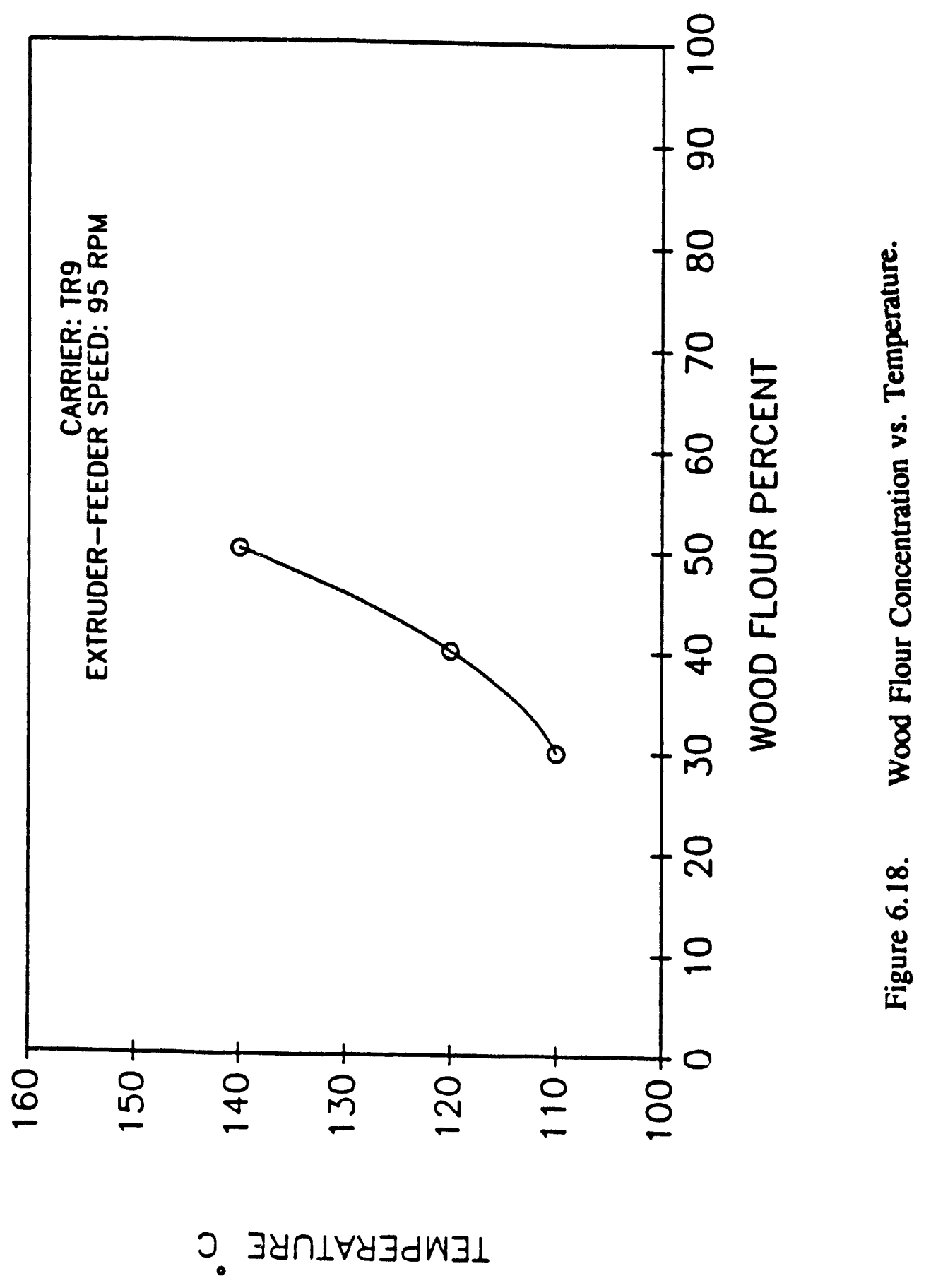




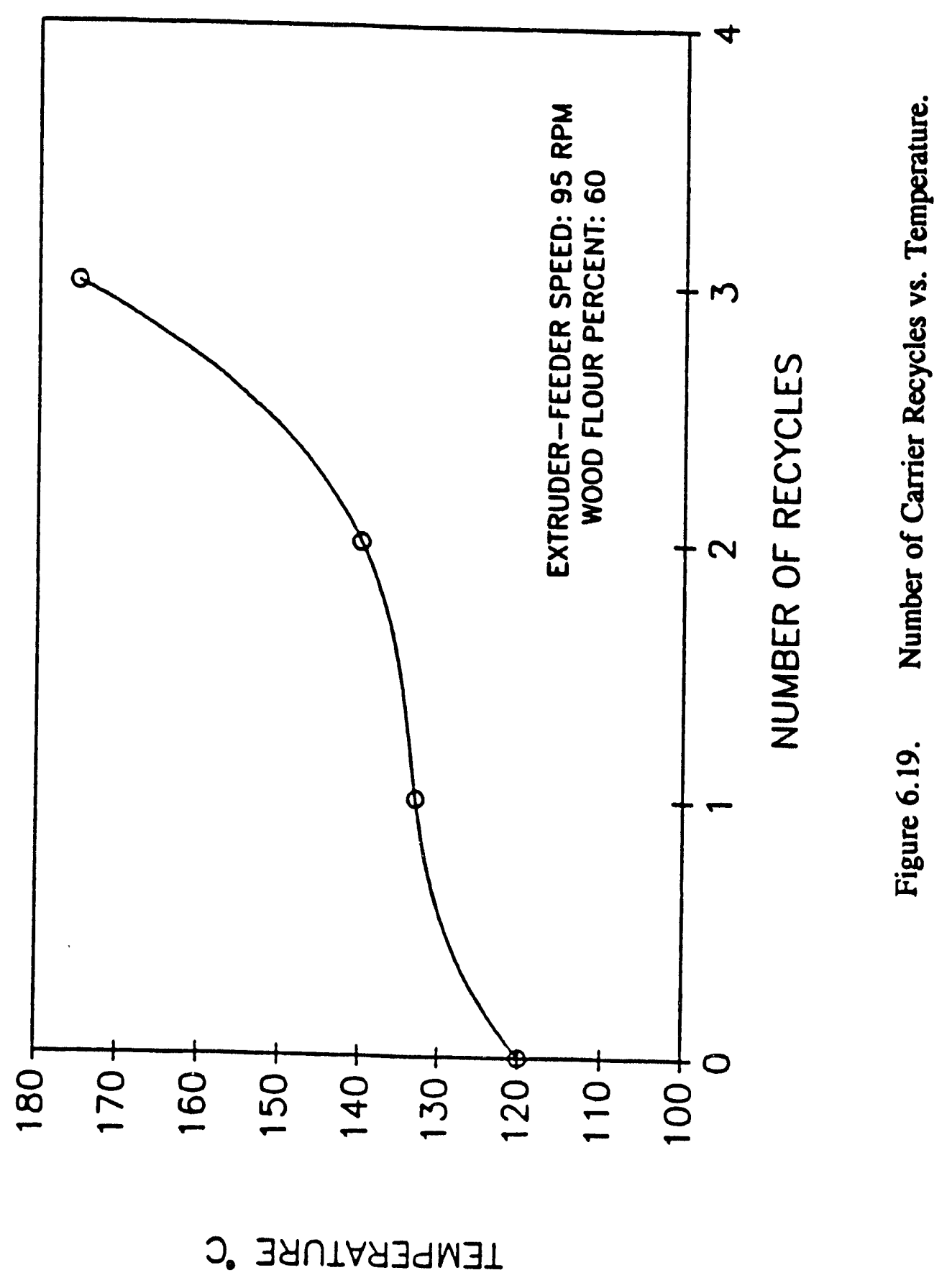




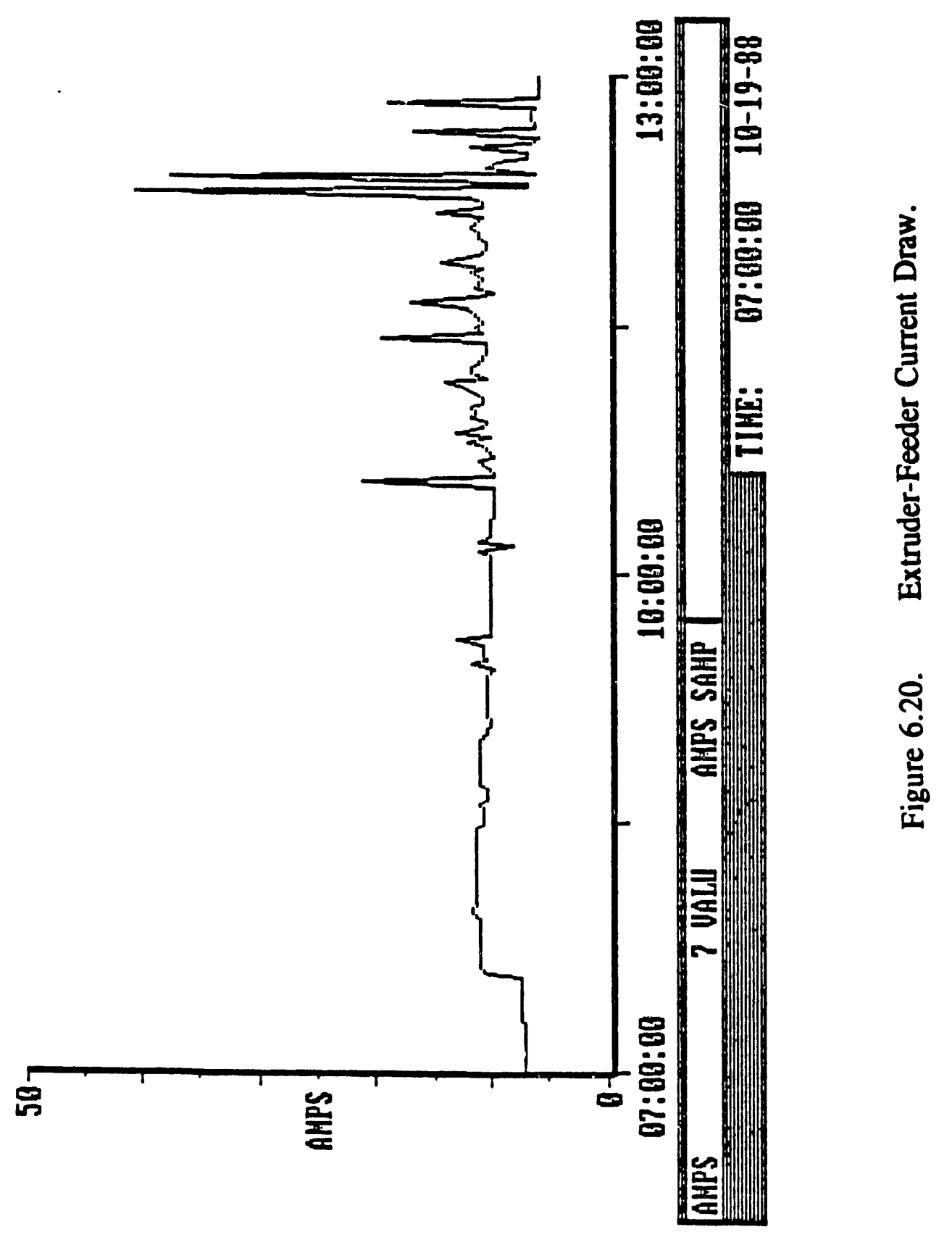


Chemical Engineering Department. Several recommendations were made concerning the electrical wiring on the extruder-reactor unit, which was found to be deficient due mainly to there being no waterproof roof over the process area.

The revised electrical work was begun and a new conduit for the heating band leads was installed before the Christmas holidays of 1986. While checking out the various insulations, representatives from CRB Insulation Supply of Phoenix and from Buche and Associates visited and made their recommendations for improvements.

\subsubsection{Improved Operability}

The utilization of the FIX program in mid-1587 increased the capability for process control and especially for data acquisition and data storage. This occurred just prior to another "anriual-slow-up" due to the delay in funding, such that during November, 1987, another round of process improvements were made with a minimum of expenses compared with the higher level of expenditures required for experimental runs.

The more important equipment modifications that were made are as follows:

1. Installation of larger reactor effluent piping to match as closely as possible the 1.75 inch I.D. of the reactor. This was fabricated in steel, flanged construction, to hold costs to a reasonable level. Corrosion of steel spools used for the two prior years appeared to be minimal, but conosion of projected commercial units continued to be evaluated.

2. Installation of a larger vacuum distillation unit replacing the damaged Pope glass unit. A vertical 4 inch I.D. $\times 8 \mathrm{ft}$. in height batch unit (S.S.) was installed, and connected into the condensing and vacuum system of the damaged Pope vacuum still.

3. Installation of more safety disks in the experimental unit.

4. Installation of an enclosed "two-stage product" collection system, operated slightly above atmospheric pressure. The first drum served as the product drum, with no gases escaping to the atmosphere as in the past. All gases escaping with the liquid product let-down to atmospheric pressure were passed from this first drum into the second surge drum, and then to the gas condensing system. Two 55-gallon drums capable of withstanding 7 psig were used. More complete material balances were achieved with this system.

5. Installation of a 4 inch $\times 8 \mathrm{ft}$. in height pyrex scrubbing system for obnoxious vented gases. This was placed after the overhead product condenser, and before the remaining inert gases go through the wet gas meter prior to venting in the vent stack. 
6. Implementation of various real-time computer control parameters in the new FIX software program for the remote control of the experimental unit.

7. Initiation of a design for using an existing, small $300 \mathrm{ml}$. autoclave unit, fitted with a piston fabricated in the Chemical Engineering machine shop as a "fast-feed injection" for batch autoclave work.

8. Re-integration of the two-stage carbon monoxide compressor into the process system. Prior to this time, carbon monoxide was fed directly from cylinders. The CO compressor (obtained by purchase from the Albany plant surplus) was placed into operation so that continuous runs at 3,000 psi could be achieved. The necessary 1/8 inch I.D. piping from the compressor to the surge tank and then to the liquefaction reactor were installed. The mechanical performance of the compressor had been checked out previously shortly after its purchase.

\subsubsection{Data Acquisition by the FIX Software}

As shown under Section 6.3, the FIX program is powerful for acquiring and storing large quantities of process data. Consequently, as many sensors as practical were installed for use during the last nine runs, made during the period March to September, 1988.

\subsection{SIGNIFICANT LIQUEFACTION CONSIDERATIONS}

The experimental results of this project must be viewed with several significant considerations in mind. This is especially true due to (a) lack of sufficient funding for good process development, and (b) the project being terminated when only 50 percent of the original contact work had been completed. Some of these significant considerations include but are not limited to those discussed below.

\subsubsection{Quality and Yield of Crude Wood Oil Product}

Crude wood oils made by direct liquefaction at high pressures and temperatures give a high quality oil with low oxygen of 6-9 wt. \% and a high heating value of about 16,000 BTU pur pound. Wood oils can be made without carbon monoxide, but its use increases the oil quality. These results were at long residence times but some limited work indicates that nearly the same quality could be produced with a 2-5 minute residence time.

A 100 percent theoretical oil yield of $16,000 \mathrm{BTU} / \mathrm{lb}$. requires from 1.5 to 2.0 pounds of wood feedstock. This is the direct result of reducing the oxygen content of wood feedstock from about $41 \mathrm{wt}$. \% to about $8 \mathrm{wt}$. \% in the liquid product. This product without hydrotreating for further oxygen reduction has a low viscosity and is miscible with petroleum Fuel Oil No. 2. Thus, it could be used as such as a blending stock for Fuel Oil No. 2, or in accordance with DOE goals, it could be hydrotreated in a petroleum refinery for use as a feedstock for gasoline, diesel and jet fuels. 


\subsubsection{Understanding the Key Liquefaction Reactions}

Unfortunately, the funding in the United States and throughout the world on research to obtain a good understanding of the key biomass liquefaction reactions has been extremely low in comparison with the funding made available for understanding coal liquefaction chemical reations. This project had no funding for the reaction mechanisms and kinetics except for (a) varying the concentrations of sodium carbonate catalyst and carbon monoxide as a reactant as parameters affecting wood oil yields and quality, and (b) some bench-scale batch autoclave studies.

Limited data were obtained upon the effect of carbon monoxide reactant. As reported in Section 6.2.5, a good distillate with a high heating value and containing only 7.5 wt.\% oxygen was obtained without using either carbon monoxide and sodium carbonate catalyst. However, there is much experimental evidence that carbon monoxide increases the total yield of distillate liquid oil and decreases the yield of the solid by-product, the latter being similar to bituminous coal in heating value and oxygen content but with no sulfur. Unfortunately, no quantitative data were obtained upon sodium carbonate and carbon monoxide in the continuous extruder-feeder unit, due to funding being terminated with just 50 percent of the contract statement of work completed.

Limited data were obtained using batch pressure autoclaves upon (a) the effect of carbon monoxide upon the quality of oil, (b) the effect of sodium carbonate catalyst upon liquefaction kinetics, (c) the effect of sodium carbonate catalyst upon water-gas shift reaction kinetics, and (d) the effect of carbon monoxide upon the kinetics of further polymerization/cross-linking and stability of crude wood oil. This research was in its early stages when funding was terminated in September 1988, and the work was given some additional financial support in 1989 by the University of Arizona. Some tentative findings of this limited batch autoclave research are as follows:

1. Complete conversion of wood to oil by liquefaction can be achieved in less than 1.6 minutes residence time.

2. Wood oil yields are near theoretical with only small yields of non-oil products, namely, 1-2 percent to hydrocarbon gases and 1-5 percent to char.

3. Carbon monoxide represses secondary reactions of crude wood oil to THF insolubles.

4. Sodium carbonate catalyzes the water-gas-shift reaction, but equilibrium cannot be achieved in even 20 minutes reaction time when starting with water and carbon monoxide far from equilibrium.

Unfortunately, no further funding was available to complete this work. 


\subsubsection{Stability of Crude Wood Oils}

Albany crude wood oils TR-9 and TR-12 stored for about six years in drums in Albany, Oregon and then two years in drums in the hot outdoor weather in Tucson, Arizona were found to be still essentially soluble in THF. Their solubility in THF in 1987 was found to be 95.3 wt. \% and 92.4 wt. \%, respectively, as shown in the tabulation below. The solubility in variouis solvents depends upon their polarity, as shown below:

\begin{tabular}{|c|c|c|c|}
\hline \multirow[b]{2}{*}{ Solvent } & \multicolumn{2}{|c|}{ Percentage Insoluble } & \multirow{2}{*}{$\begin{array}{l}\text { Solvent } \\
\text { Polarity }\end{array}$} \\
\hline & TR-9 & TR-12 & \\
\hline THF & 4.70 & 7.54 & 4.0 \\
\hline Acetone & 28.36 & 12.23 & 5.1 \\
\hline Furfural & 11.05 & 7.56 & 3.8 \\
\hline Ethanol & 31.22 & 6.67 & 4.3 \\
\hline Xylene & 24.38 & 24.50 & 2.5 \\
\hline pentane & 98.99 & 98.99 & -0 \\
\hline
\end{tabular}

However, there were many indications that crude wood oil is not stable at elevated temperatures, except that it's fairly stable in the presence of carbon monoxide. A few exploratory experiments were conducted in batch autoclaves with the following results:

\begin{tabular}{|c|l|l|c|}
\hline & & & $\begin{array}{c}\text { Percentage of } \\
\text { Sample Converted } \\
\text { to THF-insoluble } \\
\text { Residue }\end{array}$ \\
\hline 1 & Sample & Purge Gas & 18.8 \\
\hline 2 & Vacuum Bottoms & Argon & 20.1 \\
\hline 3 & TR9 & Argon & 18.2 \\
\hline 4 & TR9 & Carbon Monoxide & 7.7 \\
\hline
\end{tabular}

It should be noted that the Albany TR9 wood oil had about 4.7 wt. \% THF-insolubles prior to this exposure at $360^{\circ} \mathrm{C}$. Further wood oil stability studies were beyond the scope of this project.

\subsubsection{Experimental Runs with Two-Stage Carbon Monoxide Compressor}

When emphasis was placed upon making longer runs with larger quantities of feedstocks, it became necessary to actuate the large two-stage carbon monoxide compressor obtained from the Alibany, Oregon facility. It had been operated intermittentily during 1986 and 1987, but 
beginning with Run Q1 on March 7, 1988 the CO compressor was utilized in all subsequent runs ( 8 runs in all). The control of $\mathrm{CO}$ feed and process operability were excellent during these runs.

Details were presented in the February-April 1988 Quarterly Report.

\subsubsection{Closure of Material Balances}

A serious effort was made during the period of mid-July to mid-September, 1987 to achieve good closures of material balances. The first attempt on Run M1 and M2 closed within only about 13 percent, but continuous improvements were made so that the two runs in September closed within about one percent, as shown below.

\begin{tabular}{|l|c|c|c|c|c|c||}
\hline Experimental Run & M1 & M2 & M3 & N1 & O1 & P1 \\
\hline Date of Run & $7 / 14 / 87$ & $7 / 17 / 87$ & $7 / 23 / 87$ & $8 / 87$ & $9 / 87$ & $9 / 87$ \\
\hline INPUT, lbs. & 114 & 117 & 77.4 & 320 & 225 & 180 \\
\hline Feedstock & 5 & 18.7 & 9.3 & 18.6 & 5.2 & 8.4 \\
\hline Other & 119 & 135.7 & 86.7 & 338.6 & 230.2 & 188.4 \\
\hline Total & & & & & \\
\hline OUTPUT, lbs. & 50.3 & 65.1 & 39.6 & 171.6 & 191.8 & 148.0 \\
\hline Liquid Oil & 52.7 & 53.1 & 50.9 & 147.4 & 39.3 & 38.3 \\
\hline Other & 16 & 17.5 & 6.2 & 19.6 & 0.9 & 2.1 \\
\hline Difference & 13.5 & 12.9 & 7.1 & 5.8 & 0.4 & 1.1 \\
\hline Deviation, \% &
\end{tabular}

Details on these closures of material balances are given in Appendix D. The sudden termination of funding has prevented the utilization of these data, together with related data, to calculate crude wood oil yields, distillate yields, hydrogen consumption, carbon monoxide consumption, oxygen elimination as water and oxygen elimination as carbon dioxide. Any such calculations based on these limited data could be misleading.

\subsubsection{Preparation of Large Sample of All-Arizona Crude Wood Oil}

As reported in Section 6.2.9, an All-Arizona crude wood oil was achieved by recycling portions of reactor effluents in Runs N1 through P1, August 20, 1987 to September 17, 1987. However, only a small product sample was prepared. Therefore, the period of June, 1988 through July 20, 1988 concentrated upon preparing much larger quantities of feedstock and making much longer runs in the recycle mode in order to be ready for making the All-Arizona wood oil. 
Feedstocks utilized for this series of runs consisted of a mixture of highly recycled materials, resulting ultimately in producing 125 pounds of reactor effluent in Runs S1 and S2 made on July 13 and 20, 1988. About $55 \mathrm{wt}$. \% of this feedstock was the reactor effluent of Run P1 (held over from September 17, 1987), which in turn had used as the carrier for fresh wood flour the second stage recycle products from Runs $\mathrm{O1}$ and $\mathrm{O} 2$. Another $25 \mathrm{wt}$. \% of this feedstock were the vacuum bottoms of Run R4 made on June 16, 1988, after which about 10 wt. $\%$ of the reactor effluent was vacuum distilled to form the subject vacuum bottoms. The remaining $20 \mathrm{wt}$. \% feedstock was fresh wood flour, to represent a total feedstock operating in a high-recycle mode.

A total of 120 pounds of reactor effluent of All-Arizona crude wood oil was accumulated. This crude product was vacuum distilled in 10-pound batch in the large vacuum distillation unit, operating at about $10 \mathrm{mmHg}$ absolute pressure but up to a temperature of only $550^{\circ} \mathrm{C}$. Two onegallon samples of wood oil distillate (saturated witih water) were accumulated. The elemental lanalysis of these two one-gallon samples (never mixed, but rather as accumulated by the 10pound batch distillations), after first removing as much water as possible and adjusting by calculation for residual water, were as follows:

\begin{tabular}{|c|r|r|r|r|}
\hline $\begin{array}{c}\text { Container } \\
\text { No. }\end{array}$ & Wt \% C & Wt. \% H & Wt. \% O & Wt. \% N \\
\hline 1 & 84.33 & 8.92 & 4.87 & 0.30 \\
\hline 2 & 83.21 & 9.44 & 5.75 & 0.34 \\
\hline
\end{tabular}

The first one-gallon sample was shipped to Doug Elliott of Battelle PNL for upgrading by hydrotreating. Unfortunately, funding for that work was also terminated prior to the work being done. Some further analysis of distillation data, funded by the University of Arizona, upon this product are given in Section 7. 


\subsection{REFERENCES FOR PART 6}

Andrews, N. A., "Microprocessor-based Real-Time Process Control of Biomass Liquefaction," M.S. Thesis in Chemical Engineering, University of Arizona, Tucson, Arizona (1984).

Davenport, G., "Development of Continuous Real-Time Computer-Control of a Biomass Liquefaction Process," M.S. Thesis in Chemical Engineering, University of Arizona, Tucson, Arizona (1988).

Joshi, D., "Real-time Digital Control for Biomass Liquefaction System", M.S. Thesis in Chemical Engineering, University of Arizona, Tucson, Arizona (1985).

Reyes, B.F., "Development of a High-Pressure, High-Temperature Superheated Steam System," MS Thesis in Chemical Engineering, University of Arizona, Tucson, Arizona (1985).

Wolf, D., and D.H. White, "Effect of Flight Clearance on Mixing Characteristics in Plasticating Extruders," Society of Plastics Engineers, Annual Technical Conference, 33, pp. 439-442 (1975).

Wong, J. M., "A Non-Plugging Annulus Control Valve for Extrusion of Polymers and Slurries", M.S. Thesis in Chemical Engineering, University of Arizona, Tucson, Arizona (1986). 


\section{Part 7}

Characterization of the Wood Oils 


\section{Part 7}

Characterization of the Wood Oils

Page

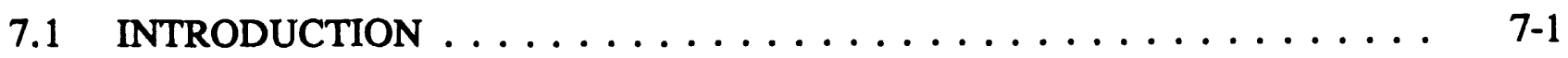

7.2 ANALYTICAL APPROACH FOR CHARACTERIZATION

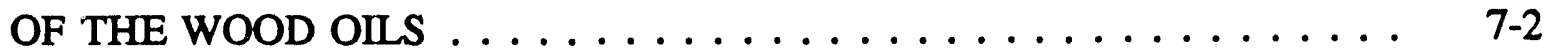

7.3 RESULTS FOR EARLY LIQUEFACTION RUNS $\ldots \ldots \ldots \ldots \ldots \ldots$. $\ldots \ldots$

7.3.1 Elemental Analysis $\ldots \ldots \ldots \ldots \ldots \ldots \ldots \ldots \ldots \ldots$ 7-4

7.3.2 GC/MS Analysis . . . . . . . . . . . . . . $7-7$

7.3.3 Heat of Combustion . . . . . . . . . . . . .

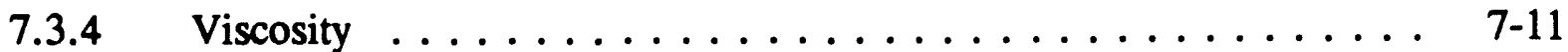

7.3.5 Moisture Content . . . . . . . . . . . . . 7-11

7.3.6 Aromatic Carbon and Hydrogen Content ........... 7-16

7.3.7 Functional Groups Analyses $\ldots \ldots \ldots \ldots \ldots \ldots \ldots \ldots \ldots$ 7-16

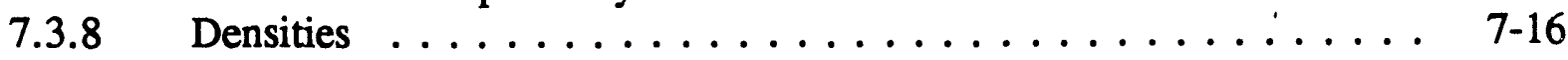

7.4 QUALITY OF EARLY WOOD OILS $\ldots \ldots \ldots \ldots \ldots \ldots \ldots \ldots$

7.4.1 Overall Quality Products $\ldots \ldots \ldots \ldots \ldots \ldots \ldots \ldots \ldots$ 7-20

7.4.2 Albany Vacuum Bottoms $\ldots \ldots \ldots \ldots \ldots \ldots \ldots \ldots$ 7-20

7.4.3 White Birch Feedstock . . . . . . . . . . . . 7-21

7.4.4 Overhead Light Wood Oils . . . . . . . . . . . . 7-21

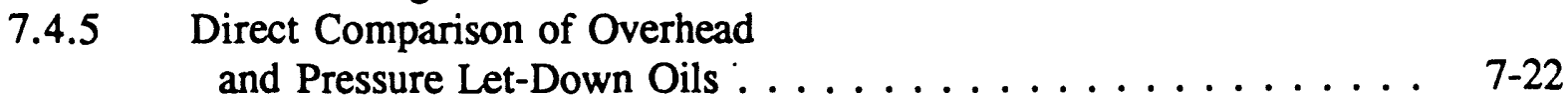

7.4.6 Vacuum Distillation of Early Wood Oils . . . . . . . . . 7-23

7.5 QUALITY OF LATER WOOD OILS $\ldots \ldots \ldots \ldots \ldots \ldots \ldots \ldots$

7.5.1 Experimental Strategy $\ldots \ldots \ldots \ldots \ldots \ldots \ldots \ldots \ldots \ldots$ 7-25

$7.5 .2 \quad$ Elemental Analyses . . . . . . . . . . . . . . . 7-28

7.5.3 Quality of Later Crude Wood Oil Distillates . . . . . . . . 7-28

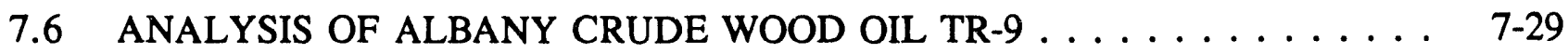

7.6.1 General Techniques . . . . . . . . . . . . . . . 7-29

7.6.2 Species Identification $\ldots \ldots \ldots \ldots \ldots \ldots \ldots \ldots \ldots . \ldots \ldots$ 7-31 
7.7 DISTILLATION OF CRUDE WOOD OILS $\ldots \ldots \ldots \ldots \ldots \ldots \ldots$ 7-31

7.7.1 Arizona Crude Wood Oils $\ldots \ldots \ldots \ldots \ldots \ldots \ldots \ldots$ 7-31

7.8 ALBANY CRUDE WOOD OIL TR-9 . . . . . . . . . . 7-39

7.9 COMPARISON OF WOOD OIL WITH COAL, COAL-DERIVED OIL

AND PETROLEUM $\ldots \ldots \ldots \ldots \ldots \ldots \ldots \ldots \ldots \ldots \ldots \ldots \ldots$ 7-44

7.9.1 Comparison of Wood Oil to Coal . . . . . . . . . . . 7-44

7.9.2 Comparison of Wood Oil with Coal-Derived Liquid Fuels . . . . 7 7-45

7.9.3 Comparison of Wood Oil with Petroleum Oil ... . . . . . . 7 7-45

7.10 SUMMARY OF WOOD OIL PROPERTIES $\ldots \ldots \ldots \ldots \ldots \ldots \ldots$ 7-45

7.11 REFERENCES FOR PART $7 \ldots \ldots \ldots \ldots \ldots \ldots \ldots \ldots \ldots$ 7-48 


\section{List of Tables}

Table

Page

7-1 Continuous Biomass Liquefaction Experimental Conditions . . . . . . . . 7-5

7-2 Elemental Analysis of Crude Wood Oil Obtained by Liquefaction . . . . . . 7-6

7-3 Theoretical Conversion of Wood Flour $\ldots \ldots \ldots \ldots$. . . . . . . . .

7-4 Heat of Combustion, Water Content, and Aromaticity . . . . . . . . . . 7-9

7-5 Typical Data on Ultimate Analyses and Heating Values of Various Coals, Coal Derived Oil and Wood Derived Oil . . . . . . 7-10

7-6 Quality of Wood Oils with Albany Vacuum Bottom Carrier . . . . . . . . . . 7-21

7-7 Analysis of Products and Process Samples (8/29/85) . . . . . . . . . . . 7-22

7-8 Elemental Analysis of Wood Flour Feedstocks . . . . . . . . . . . . . . . . 7-22

7-9 Elemental Analysis of Crude Wood Oil Liquid and Overhead Products . . . . 7-23

7-10 Yield Quantities of Crude Wood Oils for a Three-Run Series . . . . . . . . . 7-23

7-11 Comparison of Liquid Let-Down Oils with Overhead Light Oil . . . . . . . . 7-24

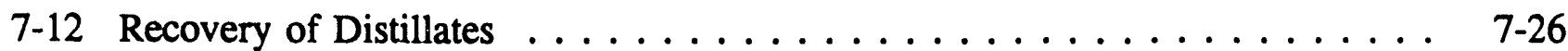

7-13 Elemental Analyses of Crude Wood Oil Distillates . . . . . . . . . . 7-29

7-14 Certain Quality Criteria for Later Crude Wood Oil Distillates . . . . . . . . . 7-30

7-15 GC/MS Data for Crude Wood Oil TR-9 by Elliott (1982) . . . . . . . . . 7-33

7-16 GC/MS Data for Crude Wood Oil TR-9 by Zhao (1987) . . . . . . . . . . 7-35

7-17 MW and Boiling Range of All-Arizona Crude Wood Oil . . . . . . . . . 7-41 


\section{List of Figures}

Figure

Page

7-1 Analytical Procedures for Crude Wood Oil Characterization . . . . . . . . . 7-3

7-2 Typical Output from HP 5970 B Mass Selective Detector . . . . . . . . . . 7-10

7-3 Heat of Combustion as a Function of Carbon Content . . . . . . . . . 7-12

7-4 Heat of Combustion as a Function of Oxygen Content . . . . . . . . . . 7-13

7-5 Heat of Combustion as a Function of Carbon to Oxygen Ratio . . . . . . . . 7-14

7-6 Kinematic Viscosity as a Function of Temperature for Several Distillates .................. 7-15

7-7 Proton NMR Spectra of a Typical Wood Oil Distillate . . . . . . . . . 7-17

7-8 ${ }^{13} \mathrm{C}$ NMR Spectra of a Typical Wood Oil Distillate . . . . . . . . . . 7-18

7-9 Infrared Absorption Spectra of a Typical Wood Oil Distillate . . . . . . . . 7-19

7-10 Schematic of Laboratory Vacuum Still at University of Arizona . . . . . . 7-24

7-11 Effect of Reactor Pressure upon Crude wood Oil Distillate Yield . . . . . . . 7-26

7-12 MWD of the THF Soluble Fraction of Albany Wood Oil TR-9 . . . . . . . 7-27

7-13 Redistillation Curve for All-Arizona Distillate . . . . . . . . . . . 7-33

7-14 MWD of the Second All-Arizona Distillate Fraction . . . . . . . . . . 7-34

7-15 MWD of the Third All-Arizona Distillate Fraction . . . . . . . . . . 7-35

7-16 MWD of the Fourth All-Arizona Distillate Fraction . . . . . . . . . 7-36

7-17 MWD of the Fifth All-Arizona Distillate Fraction . . . . . . . . . . 7-37

7-18 MWD of Heavy Oil Layer from Distillation of Albany Crude Wood Oil TR-9 .................... 7 7-40

7-19 MWD of Light Oil Layer from Distillation of Albany Crude Wood Oil TR-9 . . . . . . . . . . . . . . . . . . 7-41

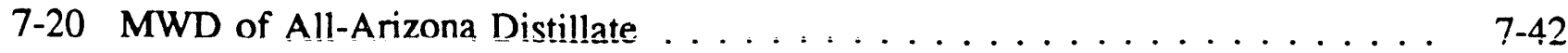


7-21 MWD of THF-Soluble Fraction of Vacuum Bottoms of Albany Crude Wood Oil TR-9 . . . . . . . . . . . . . . . . 7-43

7-22 Comparison of Typical Crude Wood Oil Distillate with a Crude Petroleum Oil 7-46 


\section{PART 7}

\section{CHARACTERIZATION OF THE WOOD OHS}

\subsection{INTRODUCTION}

This Part 7 describes the characterization of wood oil produced by the extruder-feederreactor liquefaction process operated at high temperatures and pressures. The characterization of the wood oil was made by gas chromatography-mass spectrometry (GC/MS), IR, ${ }^{13} \mathrm{C}$ and proton NMR, elemental analysis, viscosity, solvent extraction, distillation, heating value, density and moisture determinations. Results of the elemental analysis show that a low-oxygen crude wood oil was produced over a wide range of temperature and pressure, with or without carbon monoxide as a reducing reagent, and with or without sodium carbonate as a catalyst.

For many years, petroleum has been the world's major source of energy. After the energy crisis of the 1970's, extensive studies were made on the feasibility of obtaining alternative fuels. Among them, coal, oil shale, and biomass appeared to be the most promising because they have also the potential of being converted to liquid products and this be used eventually as petroleum substitutes.

The identification of the chemical products in wood-derived oils and other biomassderived oils is important in the biomass thermochemical conversion processes. The quality of the primary oil produced in the liquefaction of biomass (i.e the proto-oil) is of significance in the decision concerning the further use of the oil either directly as a fuel, with or without blending it witt: other heavy oils, or as a feedstock for upgrading.

The elemental analysis is important because it gives the information on oxygen content of the oil and thus on the amount of hydrogen needed to upgrade it. Chornet and Overend (1985) presented an overview on biomass liquefaction and characterization of proto-oils and placed this in perspective.

For the direct liquefaction of wood oils from Douglas Fir, Elliott (1985) described the results of the analytical efforts dealing with the products form the United States Department of Energy, Biomass Liquefaction Experimental Facility at Albany, Oregon, which produced approximately 80 barrels of wood-derived oil in the period from August 1979 to March 1981. In this analytical work, the GC/MS was used to identify over 100 individual chemical components in the products obtained by solvent extraction and distillation of the crude oil.

Karlsson and Bjornbom (1985) published data on the characterization of peat and biomass liquids, especially the elemental analysis data on the different fractions of oils.

The analytical characterization of biomass-derived proto-oil confirms the polyphenolic nature of the oil. There is general agreement that biomass-derived oils have lower heat content and carbon and hydrogen content and contain more oxygen than petroleuin products. 


\subsection{ANALYTICAL APPROACH FOR CHARACTERIZATION OF THE WOOD OILS}

The analytical approach for the characterization of the wood oils is outlined in Figure 7.1. The crude oil products from the reactor were analyzed, and then separated into desired fractions by both solvent extraction and vacuum distillation. The major crude oil product from the reactor contained the carrier fluid, and the same 5-8 wt.\% light overhead product was condensed and usuaily separated into water and oil layers. A certain amount of analytical work was performed ujon these light overhead products.

A summary of procedures are as follows:

1. The elemental composition of wood oil was determined by a Perkin-Elmer Model 240C Elemental Analyzer.

2. The distillate of wood oil was obtained by vacuum distillation of the reactor effluent at $2-5 \mathrm{mmHg}$ absolute pressure and at temperatures up to $550^{\circ} \mathrm{F}$. The percentage distilled was up to $30 \mathrm{wt} \%$ depending on the operational conditions in the reactor especially the pressures. It appears that higher pressures produce higher percentage of distillates.

3. The moisture content of the distillate of wood oil was determined by the Fisher Titrometer Model 1392 K-F accessory.

4. The viscosity of the distillate of wood oil was measured using the Cannon Fenske Viscometer, which determines the kinematic viscosity by measuring the time needed for a given volume of liquid to flow under the force of gravity through a calibrated glass capillary viscometer.

5. The heating value of the distillate of wood oil was obtained using a Par 1341 plain pocket oxygen bomb calorimeter.

6. The determination of the aromatic carbon and hydrogen content in the distillate of the wood oil was accomplished using both Proton Spectra Bruker WM-250 NMR Spectrometer and Carbon-13 Spectra Bruker AM-250 NMR spectra. The sample of wood oil distillate was dissolved in $\mathrm{CDCl}_{3}$ until a homogeneous solution was obtained. The solution was then transferred to an NMR sample tube. Tetramethylsilane (TMS) was added as an internal standard.

7. The infrared absorption spectra was obtained with a Perkin-Elmer Model 1800 Fourier Transform Infrared Spectrophotometer and was recorded over the range of 500-4000 $\mathrm{cm}^{-1}$.

8. The Gas Chromatograph-Mass Spectrometer used to analyze wood oil distillate samples was built around an HF Mass Selective Detector. The gas chromatograph contains a fused silica column, $25 \mathrm{~m}$ long, of an I.D. of $0.20 \mathrm{~mm}$. The oven temperature was programmed from $50^{\circ} \mathrm{C}$ to $170^{\circ} \mathrm{C}$ at a rate of $20^{\circ} \mathrm{C} / \mathrm{min}$, from $170^{\circ} \mathrm{C}$ to $285^{\circ} \mathrm{C}$ at $3^{\circ} \mathrm{C} / \mathrm{min}$. The apparent pressure in the MS ion source is about $2 \times 10^{-5}$ torr. The data 


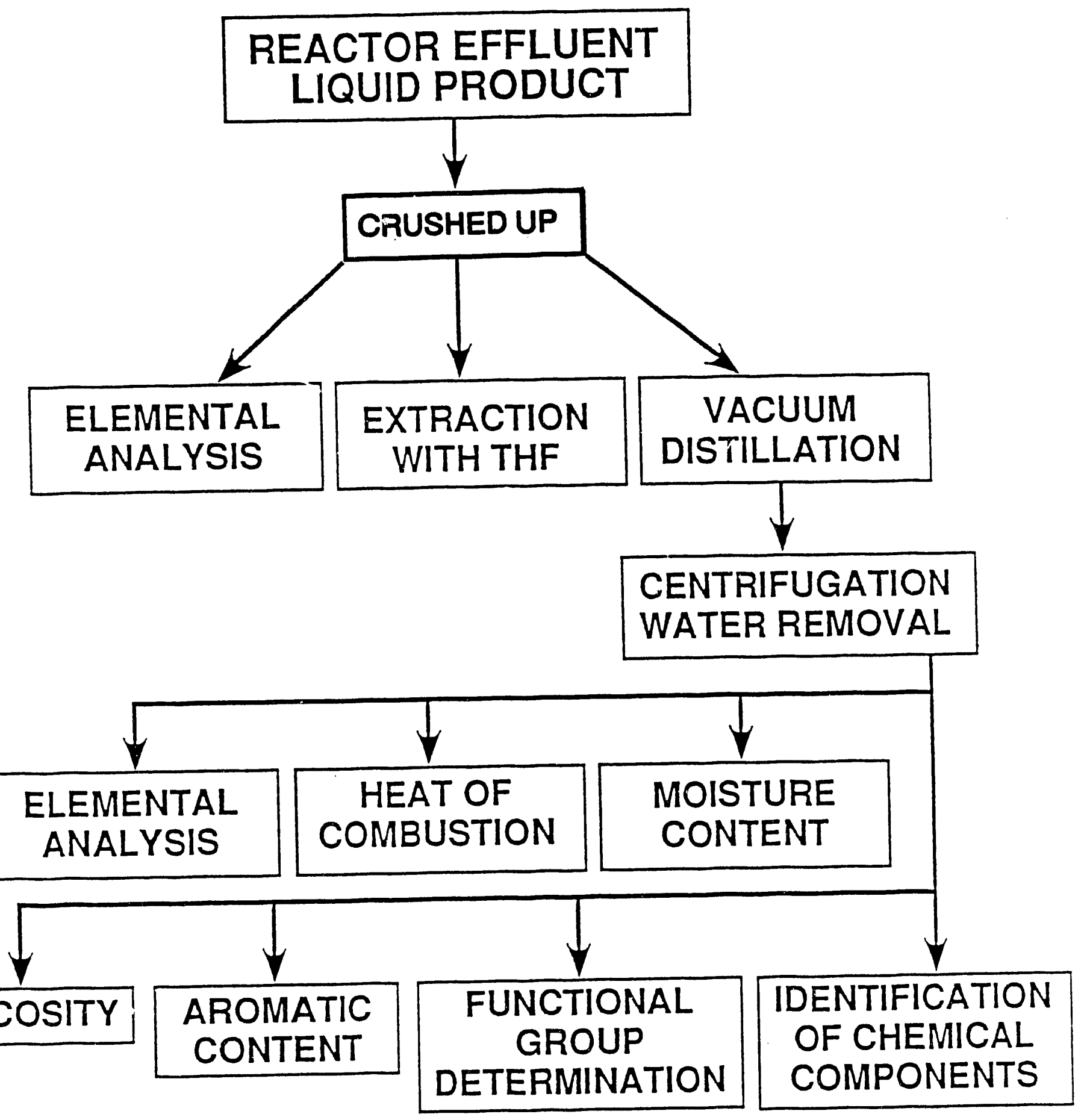

Figure 7-1. Analytical Procedures for Crude Wood 0 il Characterization 
were stored on disk for subsequent analysis using either the HP 59970C chem station or the HP 59870 RTE data system. The five microliters of wood oil distillate was diluted in one $\mathrm{ml}$ of acetone.

9. A volume-calibrated pycnometer was used to determine the density of the crude wood oil distillate.

\subsection{RESULTS FOR EARLY LIQUEFACTION RUNS}

Early experimental runs in the extruder-feeder liquefaction system utilized Albany vacuum bottoms as the wood flour carrier. These vacuum bottoms were used from August 29, 1985 until exhausted in the long run conducted in the period July 29 - July 31, 1986. The experimental operating conditions for some of the early liquefaction runs made during the period August 29, 1985 through July 29, 1986 are shown in Table 7.1. It should be kept in mind that these were exploratory runs covering a range of pressures, temperatures, and catalyst conditions, with no attempt at this point in time to correlate operating conditions with oil yields and oil quality are shown in Table 7.1.

\subsubsection{Elemental Analysis}

Elemental compositions are given in Table 7.2 along with that of feedstocks and carrier oils. Despite the wide range of pressures and temperatures, these data indicate that oxygen content was consistently reduced from approximately $42 \mathrm{wt} \%$ in the wood flour (white birch) to the range of 5-10 wt\% in the oil product, so that hydrotreating it to a transportation fuel should be greatly facilitated by virtue of both lower oxygen content and its liquefied condition. Also, even though the operating conditions were varied over a wide range, there is a relatively small variation in hydrogen content of the oils obtained under the different operating conditions. However, the carbon content varies between $80.00 \mathrm{wt} \%$ and $84.72 \mathrm{wt} \%$ while the oxygen content between 5.24 and $11.93 \mathrm{wt} \%$. The products from the different runs have a hydrogen-tocarbon atomic ratio of approximately 1.3. Nitrogen content for all samples examined was very low in the range of 0.0-0.34 wt\%.

For a few typical wood oil samples the sulfur content was also analyzed and it was found even in the range of 0.08 to $0.24 w t \%$ while the sulfur content of wood is between 0.0 and 0.1 $w t \%^{13}$ (Antal, 1983).

In the liquefaction of wood, oxygen is removed as water and/or carbon dioxide, and therefore there is a large loss of weight of product compared with the feedstock weight even if $100 \%$ of the theoretical conversion is achieved. Under certain liquefaction conditions, the elimination of oxygen from wood can occur approximately 60 percent as water and 40 percent as carbon dioxide (Espensheid and Yan, 1977). Under other liquefaction conditions, the removal of oxygen from wood is claimed to occur approximately 5 percent as water and 95 percent as carbon dioxide (Chen et al. 1981). Assuming the removal of oxygen from white birch wood as being $100 \mathrm{wt} \%, 70 \mathrm{wt} \%, 50 \mathrm{wt} \%, 30 \mathrm{wt} \%$, and $0 \%$ respectively as $\mathrm{CO}_{2}$, and correspondingly, the removal of oxygen from wood as $\mathrm{H}_{2} \mathrm{O}$ varying from $0 \%, 30 \mathrm{wt} \%, 50 \mathrm{wt} \%, 70 \mathrm{wt} \%$, to 100 $w t \%$ respectively, theoretical loss of weight of wood varies from $57.0 \mathrm{wt} \%$ to $46.4 \mathrm{wt} \%$ as 
Table 7.1. Continuous Biomass Liquefaction Experimental Conditions

\begin{tabular}{|c|c|c|c|c|c|c|c|c|c|}
\hline $\begin{array}{l}\text { Run } \\
\text { No. }\end{array}$ & $\begin{array}{l}\text { Date } \\
\text { of } \\
\text { Run }\end{array}$ & $\begin{array}{l}\text { Wood } \\
\text { Flour } \\
\text { (wt. } \%)\end{array}$ & $\begin{array}{l}\text { Vacuum } \\
\text { Bottom } \\
\text { (wt, } \%)\end{array}$ & $\begin{array}{l}\mathrm{H}_{2} \mathrm{O}^{2} \\
(\mathrm{w}, \%)\end{array}$ & $\begin{array}{l}\text { Sadium } \\
\text { Carbonate } \\
\text { (wt. \%) }\end{array}$ & $\begin{array}{l}\text { Temp. } \\
\left({ }^{\circ} \mathrm{C}\right)\end{array}$ & $\begin{array}{l}\text { Press. } \\
\text { (psi) }\end{array}$ & $\begin{array}{l}\text { Rate } \\
(\mathrm{lb} / \mathrm{hr})\end{array}$ & $\begin{array}{l}\text { Res. } \\
\text { Time } \\
\text { (min) }\end{array}$ \\
\hline E1 & $08 / 29 / 85$ & 40 & 60 & 8 & 10 & 350 & 3,000 & 10 & 72 \\
\hline G1 & $02 / 19 / 86$ & 38 & 62 & 12.2 & 2 & 375 & 800 & 6 & 120 \\
\hline G2 & $03 / 19 / 86$ & 38 & 62 & 8.8 & 0 & 375 & 1,000 & 8 & 90 \\
\hline G3 & $04 / 16 / 86$ & 38 & 62 & 15 & 0 & 375 & 1,200 & 7 & 103 \\
\hline G4 & $05 / 29 / 86$ & 40 & 60 & 19.7 & 0 & 375 & 2,300 & 10 & 72 \\
\hline H3 & $06 / 30 / 86$ & 38 & 62 & 15 & 2 & 375 & 3,000 & 3 & 240 \\
\hline $\mathrm{H} 4$ & $07 / 02 / 86$ & 40 & 60 & 15 & 0 & 375 & 3,000 & 8 & 90 \\
\hline I1 & $07 / 29 / 86$ & 35 & 65 & 10 & 0 & 375 & 600 & 3 & 240 \\
\hline P1-A & $09 / 17 / 87$ & 50 & $50^{3}$ & 17 & 10 & 350 & 1,000 & 11 & 150 \\
\hline P1-B & $07 / 17 / 87$ & 45 & $55^{4}$ & 17 & 10 & 350 & 1,000 & 17 & 660 \\
\hline
\end{tabular}

'Albany wood oil vacuum bottoms except for P1-A and P1-B.

${ }^{2}$ Based on wet wood flour.

${ }^{3}$ Albany TR-9 wood oil as carrier/high CO.

${ }^{4}$ Recycle product as carrier/no CO. 


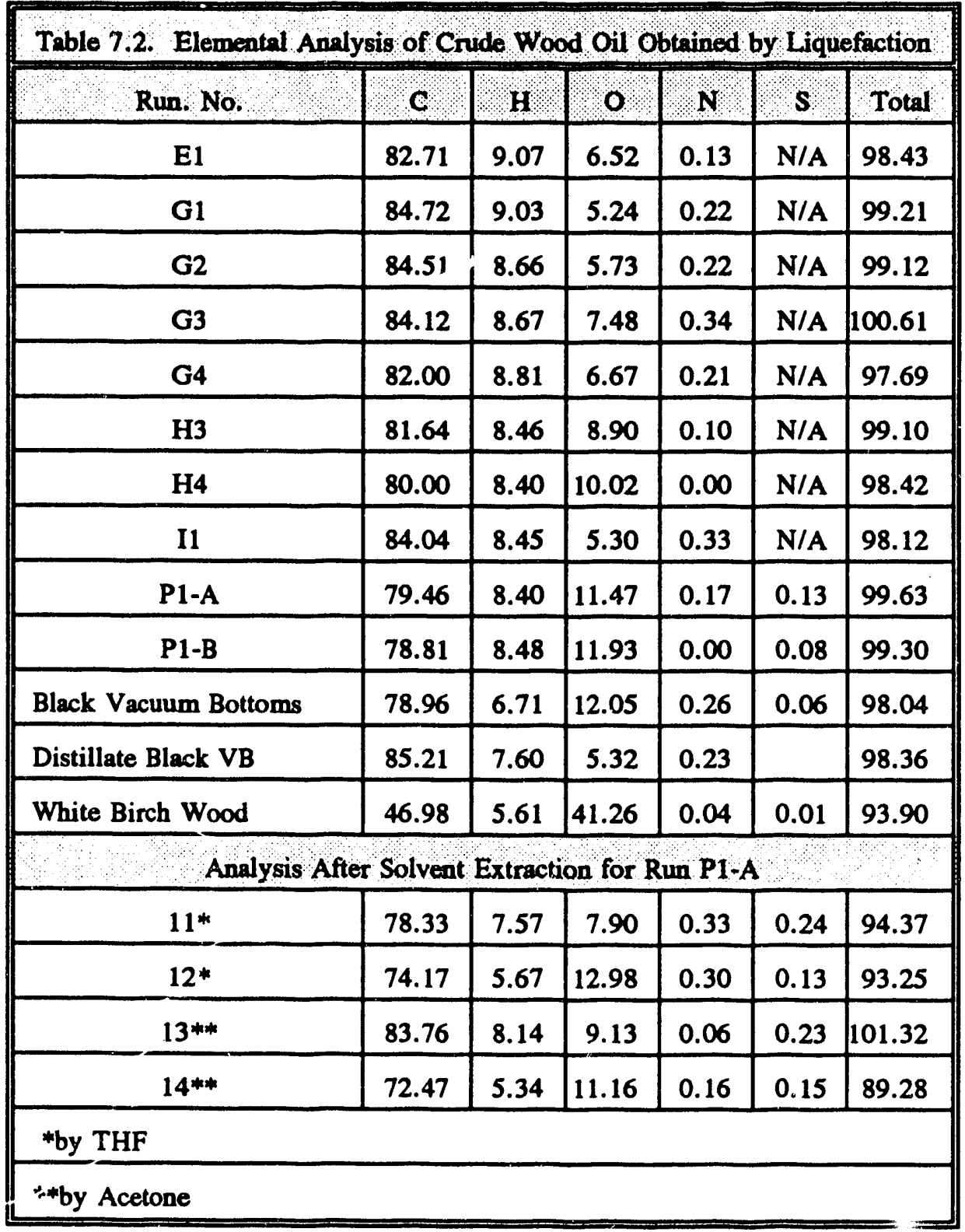


shown in Table 7.3. In these theoretical calculations we assumed no char formation. Thus, 100 pounds of dry white birch wood can theoretically produce about 43 pounds of crude wood oil, under the assumption that the elimination of oxygen from the wood occurs 50 percent as water and 50 percent as carbon dioxide, and can produce 47.4 pounds crude oil per 100 pounds wood feedstock if all the oxygen removed is as water. In two different patents (Espenscheid and Yan 1977, Chen et al. 1981) it is claimed that the $\mathrm{CO}_{2}$ formation and $\mathrm{H}_{2} \mathrm{O}$ formation can be controlled by proper operating conditions and catalyst.

\subsubsection{GC/MS Analysis}

Gas Chromatography-Mass Spectrometry was utilized for this work as the major technique for identifying the individual components in the wood-derived oil. With GC/MS both the qualitative and quantitative data on the various components of the wood oil can be obtained, but in this work only the qualitative data on the chemical composition of the wood oil components were determined. The data obtained from GC/MS are useful, and back up the analytical results obtained from both infrared spectroscopy and nuclear magnetic resonance.

A list of the compounds identified in the distillate of the crude wood oil is given in Table 7.4. A typical output from HP 5970 B Mass Selective Detector is shown in Figure 7.2. The identification of the compounds was made by comparing the experimental sample spectra with catalog spectra. In most cases, there was a good agreement between the two spectra, and the proposed structure is considered to be correct. In such a complex mixture as wood oil, physical isolation of a sufficient quantity of pure single compounds presents a very difficult problem. Hence, elemental analysis, NMR, and similar techniques could not be used alone to provide conclusive identification.

The types of compounds identified in the distillate fall into the following major chemical classes: aliphatic and aromatic hydrocarbons such as octane and anthracene; aromatics (phenols) and their derivatives; furans such as dibenzo furans; ketones such as 4-hydroxy-4-methyl; 2pentanone; esters; alcohols and amines. Other major components are the phenolic derivatives such as 2.4 -dimethyl, phenol.

Table 7.4 provides some insights into the oil products. One distinguishable component found in the wood oil for these early runs was anthracene, which should be ignored as it was not obtained from the birch wood feedstock. Anthracene was used as a carrier oil at the Albany plant where wood oil was produced from Douglas Fir and was never completely removed from the vacuum bottoms. The vacuum bottoms used in this work was obtained from the crude wood oil produced in the Albany plant (Rust Engineering report, 1982), operating on Douglas Fir feedstock.

\subsubsection{Heat of Combustion}

The heat of combustion is one of the most important factors in the evaluation of the wood oil quality. The heats of combustion of the various samples of wood oil obtained under the different operating conditions as outlined in Table 7.1 are reported in Table 7.4, and are compared with other fueis in Tabie 7.5. Their values ranged from 14,500 to 16,000 Btu/ib. 
Table 7.3. Theoretical Conversion of Wood Flour

\begin{tabular}{||l|r|r|r|r|r|}
\hline $\begin{array}{l}\text { Oxygen removed as carbon } \\
\text { dioxide }\end{array}$ & $100 \%$ & $70 \%$ & $50 \%$ & $30 \%$ & $0 \%$ \\
\hline Oxygen removed as water & $0 \%$ & $30 \%$ & $50 \%$ & $70 \%$ & $100 \%$ \\
\hline Loss of weight (wt. \%) & $57.0 \%$ & $53.7 \%$ & $51.6 \%$ & $49.6 \%$ & $46.4 \%$ \\
\hline Yield (wt. \%) & $31.1 \%$ & $40.4 \%$ & $43 \%$ & $44.4 \%$ & $47.4 \%$ \\
\hline
\end{tabular}

NOTE: Based on White Birch wood with analysis: O: 41.26 wt.\%, C: 46.98 wt.\%, H: $561 \mathrm{wt} . \%, \mathrm{~N}: 0.04 \mathrm{wt}$. \%. Liquefaction products have zero oxygen.

\begin{tabular}{|c|c|c|c|c||}
\hline \multicolumn{3}{|c|}{ Table 7.4. Heat of Combustion, Water Content, and Aromaticity } \\
Run No. & $\begin{array}{c}\text { Heat of Combustion*, } \\
\text { BTU/1b }\end{array}$ & $\begin{array}{c}\text { Water Content, } \\
\text { wt. \% }\end{array}$ & $\begin{array}{c}\text { Aromaticity (NMR) } \\
\text { Aromatic/Aliphatic }\end{array}$ \\
\cline { 4 - 5 } & & $\begin{array}{c}\text { C } \\
\text { Ratio }\end{array}$ & $\begin{array}{c}\text { H } \\
\text { Ratio }\end{array}$ \\
\hline 1 & 15,473 & 1.31 & 0.60 & 0.22 \\
\hline 3 & 16,140 & 0.32 & 0.68 & 0.32 \\
\hline 4 & 15,723 & 0.55 & 0.68 & 0.30 \\
\hline 5 & 15,658 & 0.77 & 0.66 & 0.27 \\
\hline 6 & 15,397 & 0.54 & 0.69 & 0.37 \\
\hline 7 & 15,253 & 0.55 & 0.88 & 0.31 \\
\hline 8 & 14,843 & 0.87 & 0.99 & 0.36 \\
\hline *Low Heating Value. & 15,809 & 0.83 & 0.94 & 0.40 \\
\hline
\end{tabular}




\begin{tabular}{|c|c|c|c|c|c|c|c|c|}
\hline \multirow[b]{2}{*}{ Coal Type } & \multicolumn{6}{|c|}{ Ultimate Analysis (dry) (wt. \%) } & \multirow{2}{*}{$\begin{array}{c}\begin{array}{c}\text { Atomi } \\
\mathrm{C}\end{array} \\
\text { Ratio }\end{array}$} & \multirow{2}{*}{$\begin{array}{c}\text { Heatin } \\
\text { g } \\
\text { Value } \\
\text { (BTU/1 } \\
\text { b) }\end{array}$} \\
\hline & C & H & $\mathbf{S}$ & $\mathbf{N}$ & Ash & 0 & & \\
\hline Lignite & 65.7 & 4.5 & 1.0 & 1.2 & 9.2 & 18.4 & 0.82 & 7,100 \\
\hline $\begin{array}{l}\text { Western Sub- } \\
\text { bituminous }\end{array}$ & 62.6 & 4.0 & 1.0 & 1.0 & 13.6 & 17.8 & 0.77 & 9,400 \\
\hline Illinois No. 6 & 70.0 & 4.9 & 3.8 & 1.4 & 9.2 & 10.7 & 0.84 & 11,300 \\
\hline $\begin{array}{l}\text { Eastern } \\
\text { Bituminous } \\
\text { (high-sulfur) }\end{array}$ & 70.4 & 4.6 & 4.6 & 1.4 & 10.5 & 8.5 & 0.78 & 11,700 \\
\hline $\begin{array}{l}\text { Eastern } \\
\text { Bituminous } \\
\text { (low-sulfur) }\end{array}$ & 79.9 & 5.5 & 1.3 & 1.5 & 5.4 & 6.4 & 0.83 & 14,000 \\
\hline $\begin{array}{l}\text { Coal derived } \\
\text { oil }\end{array}$ & 87.20 & 5.3 & 0.8 & 2.3 & 0.01 & 4.2 & 0.73 & $\begin{array}{r}15,540 \\
(16,03 \\
0)^{*}\end{array}$ \\
\hline $\begin{array}{l}\text { Wood } \\
\text { derived oil }\end{array}$ & 84.1 & 8.7 & $\cdots$ & 0.3 & 0.01 & 7.5 & 1.24 & $\begin{array}{r}15,660 \\
(16,45 \\
0)^{*}\end{array}$ \\
\hline
\end{tabular}




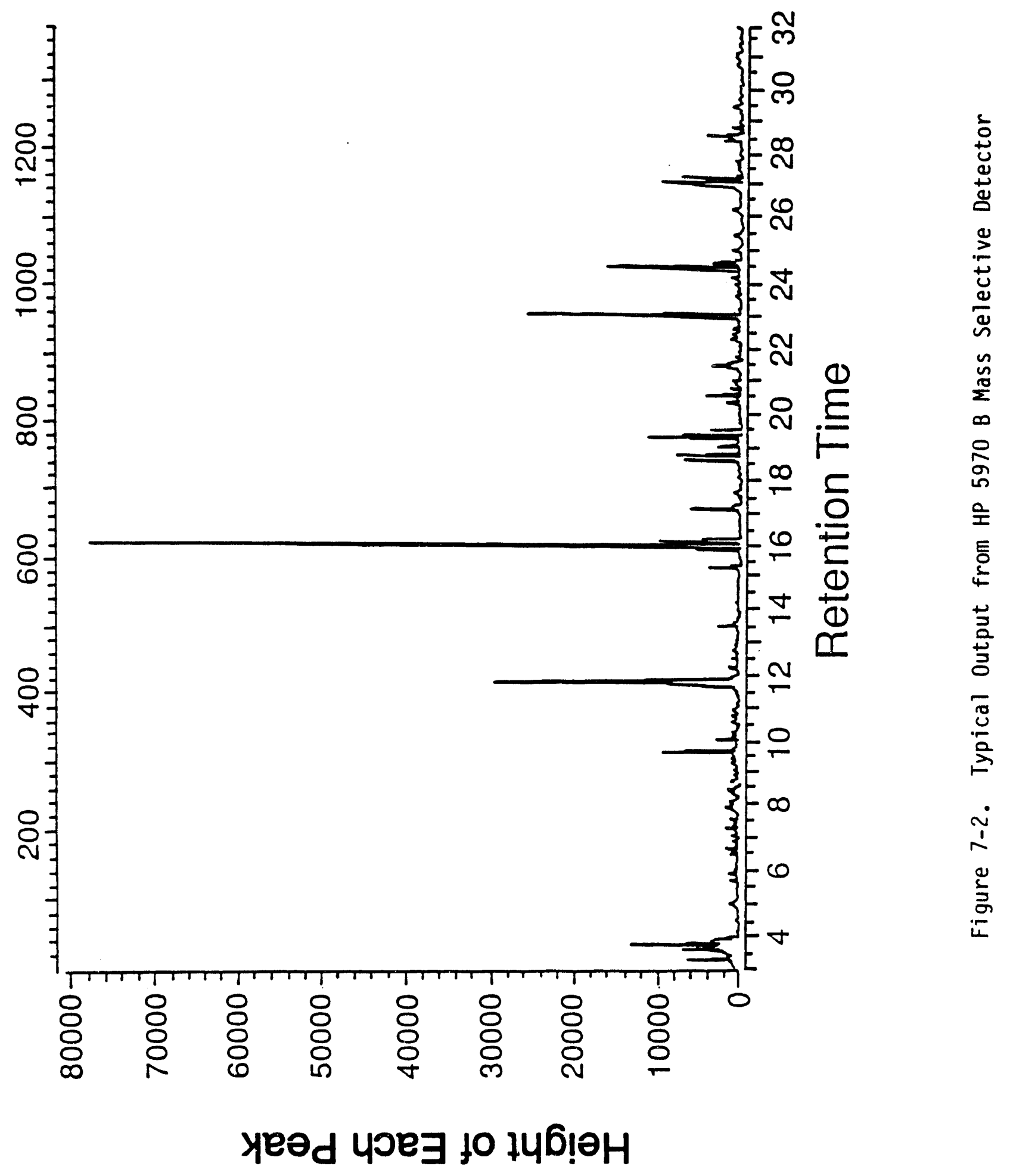


This is slightly less than the heat of combustion of petroleum fuel oils which is due to the residual oxygen content of the wood-derived oil. It is interesting to compare the ultimate analysis data with the heating values obtained. It was found by this comparison that the heating value correlates well with both the oxygen content and the carbon content as seen in Figures 7.3 and 7.4. Basically, the heating values of wood oil increase with the carbon content and decrease with the oxygen content. The combined effect of $C$ and $O$ on the heating value of wood oil shows an increase as the $\mathrm{C} / \mathrm{O}$ ratio increases as shown in Figure 7.5.

Using the multi-variable regression method, an empirical equation for the heating value has been derived, based on the heats of combustion data obtained from ten samples which is given as follows:

$$
\text { L.H.V. }=172.5 \mathrm{C}+144.4 \mathrm{H}-2.120-436.4 \mathrm{~N}
$$

where L.H.V is the low heating value of crude wood oil, and $\mathrm{C}, \mathrm{H}, \mathrm{O}$ and $\mathrm{N}$ are the weight percentage of carbon, hydrogen, oxygen and nitrogen, respectively. Using the above equation, the low heating value of crude wood oil can be estimated from the elemental analysis data within 1-2 percent error. This empirical equation can be compared with the Dulong empirical equation widely used in the coal industry (Perry and Chilton, 1973).

\subsubsection{Viscosity}

The crude reactor effluent wood oil product obtained form the liquefaction process is solid at room temperature but is fluid above $150^{\circ} \mathrm{C}$. The viscosities of the distillates obtained from the reactor effluent product has a low viscosity, varying from 100 to $600 \mathrm{cSt}$ at the temperature of $30^{\circ} \mathrm{C}$.

Viscosity-temperature relationships for typical wood oil distillates are shown in Figure 7.6. Between 20 and $50^{\circ} \mathrm{C}$, they are practically Newtonian liquids. It should be noted that the viscosities of the distillates decrease sharply with the increase in temperature. The derived oils, which are usually in the range of $10 \mathrm{cSt}$ at the temperature of around $25^{\circ} \mathrm{C}$ (Perry and Chilton, 1973).

\subsubsection{Moisture Content}

The Karl Fisher Titration method was applied to determine the amount of water left in the crude wood oil distillates. The distillates were first centrifuged at high rotational speeds for the separation of the entrained water.

The data on the dissolved moisture content of the sample analyzed are also given in Table 7.4. Basically, the dissolved water ranges from 0.3 to $1.3 \mathrm{wt} \%$ in the oil layer. 


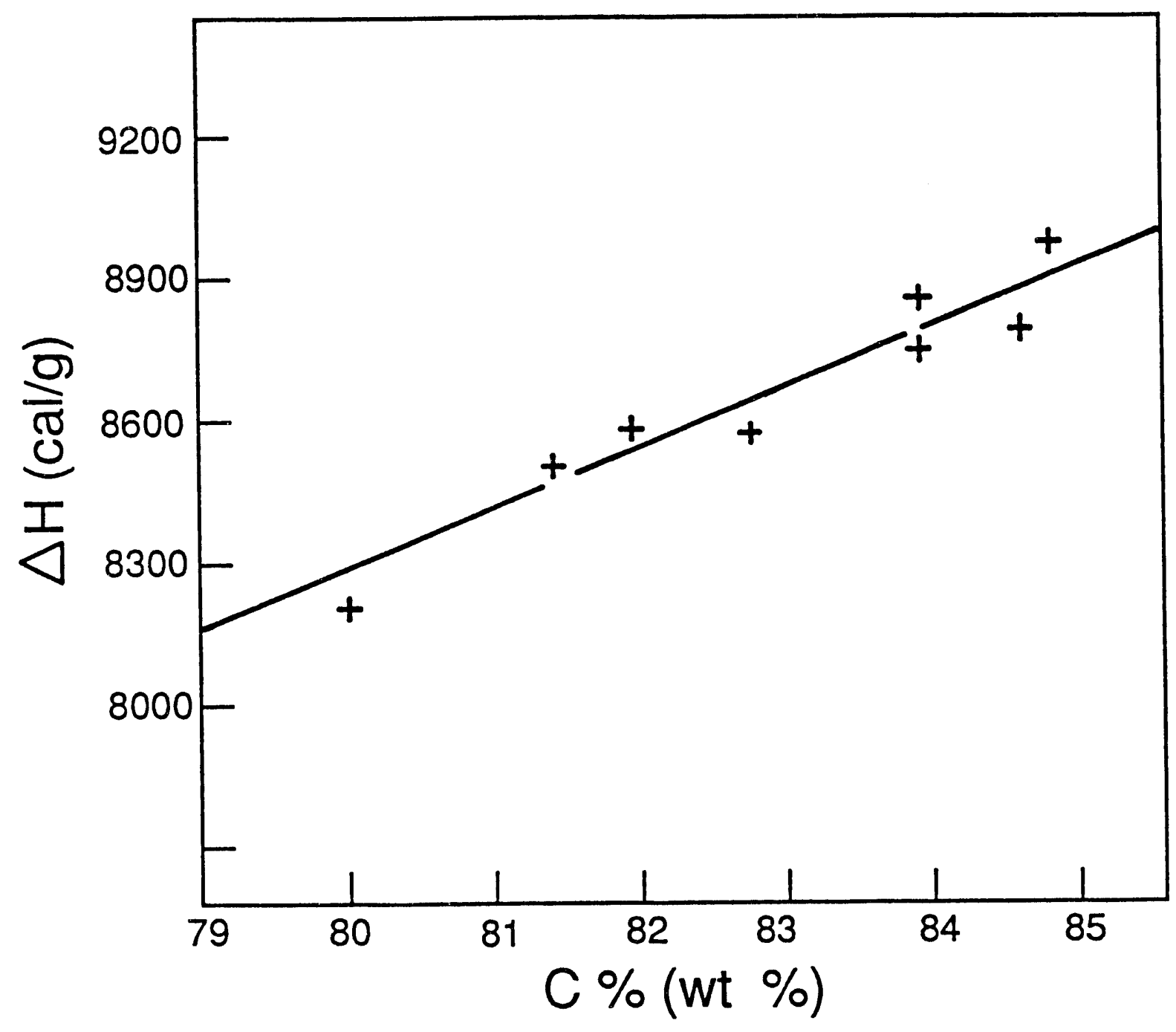

Figure 7-3. Heat of Combustion as a Function of Carbon Content. 


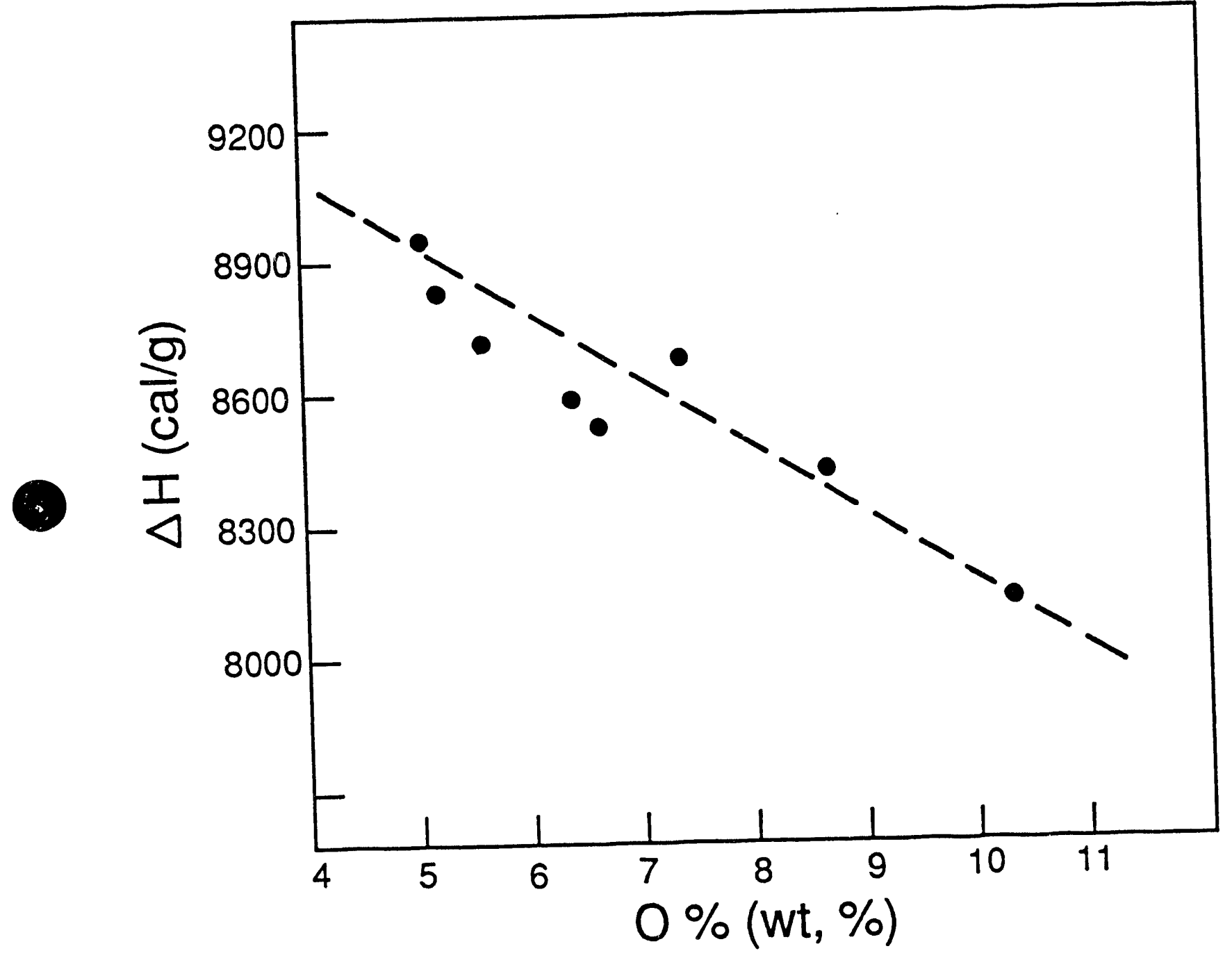

Figure 7-4. Heat of Combustion as a Function of 0xygen Content 


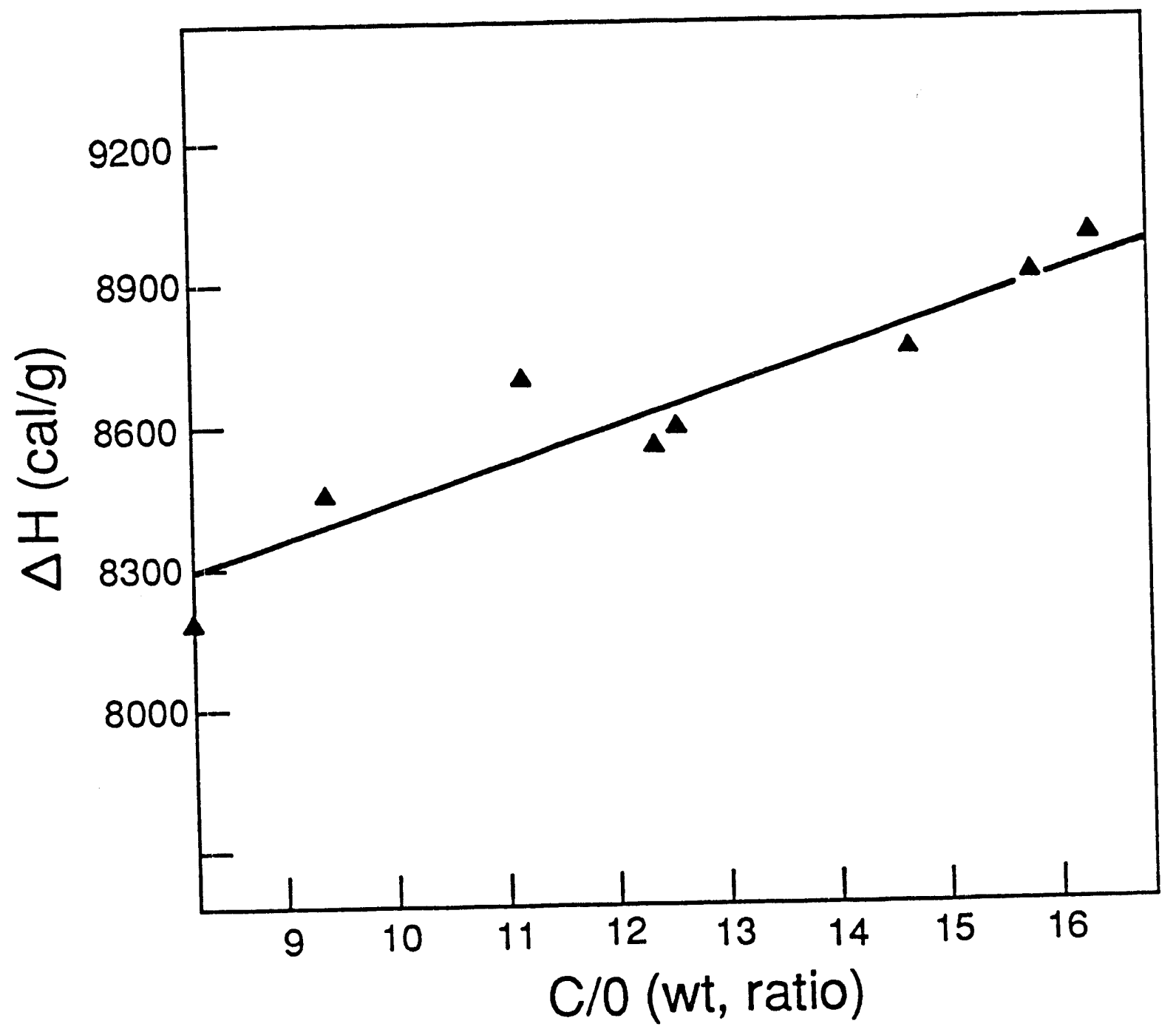

Figure 7-5. Heat of Combustion as a Function of Carbon to Oxygen Ratio. 


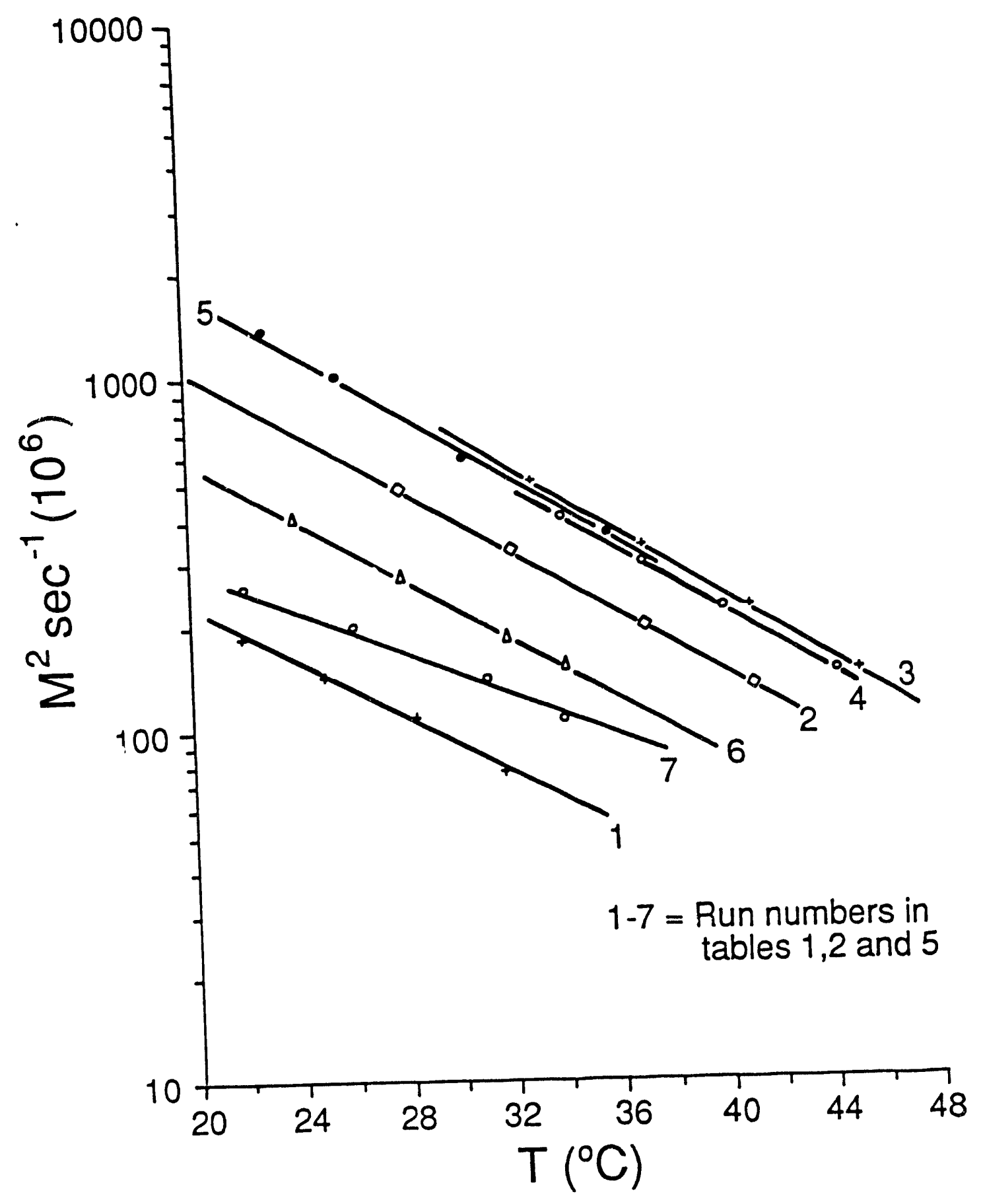

Figure 7-6. Kinematic Viscosity as a Function of
Temperature for Several Distillates. 


\subsubsection{Aromatic Carbon and Hydrogen Content}

Nuclear magnetic resonance spectroscopy of these wood oil distillates indicated a significant fraction of aromatic content. The data obtained form GC/MS supports this result wherein the major aromatics identified are phenol, anthracene, indene and naphthalene. The aromatic bands $\left(3000-3100 \mathrm{~cm}^{-1}\right.$ and $\left.1500-1600 \mathrm{~cm}^{-1}\right)$ in the infrared spectra of wood-derived oil uphold this result, too. Both ${ }^{13} \mathrm{C}$ and proton-NMR tests were also carried out on the distillate samples obtained form crude wood oil. Although the generation of aromatic compounds from cellulose has been recognized for years (Smith and Howard, 1973), it has generally been assumed that the aromatic content of oils derived from biomass is a result of lignin transformation. A typical output from Bruker WM-250 NMR spectrometer is shown in Figure 7.7 which was used to calculate the ratio of aromatic hydrogen to aliphatic hydrogen, while Figure 7.8 shows a typical ontput from Bruker AM-250 NMR spectrometer which was utilized to calculate the ratio of aromatic carbon to aliphatic carbon. Basically, the ratio of aromatic carbon to aliphatic carbon varies from 0.60 to 0.99 and the ratio of aromatic hydrogen to aliphatic hydrogen ranges from 0.22 to 0.40 as shown in Table 7.5. Aromaticity value can also be expressed as the percentage of arsmatic carbon atoms relative to the total of both aliphatic and aromatic carbon atoms. This way, the percentage of aromatic carbon atoms is around $45 \mathrm{~mol} \%$, whereas crude petroleum has aromatic carbon about $14 \mathrm{~mol} \%$.

\subsubsection{Functional Groups Analyses}

Although the infrared analysis cannot be employed alone as a means to offer definitive data on the characterization of wood oil, it is reliable enough to help check out the data obtained from GC/MS. As reported in the section of GC/MS analysis, the major components identified in the wood oil can be grouped into the following: ketones, aliphatic hydrocarbons, aromatic hydrocarbons, phenols, alcohols, amines. Data obtained from the typical output of Perkin-Elmer Model 1800 Fourier Transfer Infrared Spectrophotometer as shown in Figure 7.9 correlates well with the GC/MS data. The infrared spectrum of wood oil shows strong aliphatic C-H stretching bands $\left(3000-3100 \mathrm{~cm}^{-1}\right)$. This indicates the presence of both aliphatic and aromatic hydrocarbons in wood-derived oil. Also in Figure 7.9, two peaks $\left(1600-1750 \mathrm{~cm}^{-1}\right)$ were observed, the larger one representing the carbonyl band $\left(1750 \mathrm{~cm}^{-1}\right)$ of organic acids and the smaller one depicting the carbonyl band $\left(1620 \mathrm{~cm}^{-1}\right)$ of ketones.

In addition to the above information extracted from decoding the spectrum of I.R. one can also say that both alcohol and water could be present in wood oil based on the widest band $\left(3400 \mathrm{~cm}^{-1}\right)$.

\subsubsection{Densities}

The density of the wood oil distillate ranges from $0.96 \mathrm{~g} / \mathrm{ml}$ to $1.05 \mathrm{~g} / \mathrm{ml}$. The data were obtained by the standard picnometric method. 


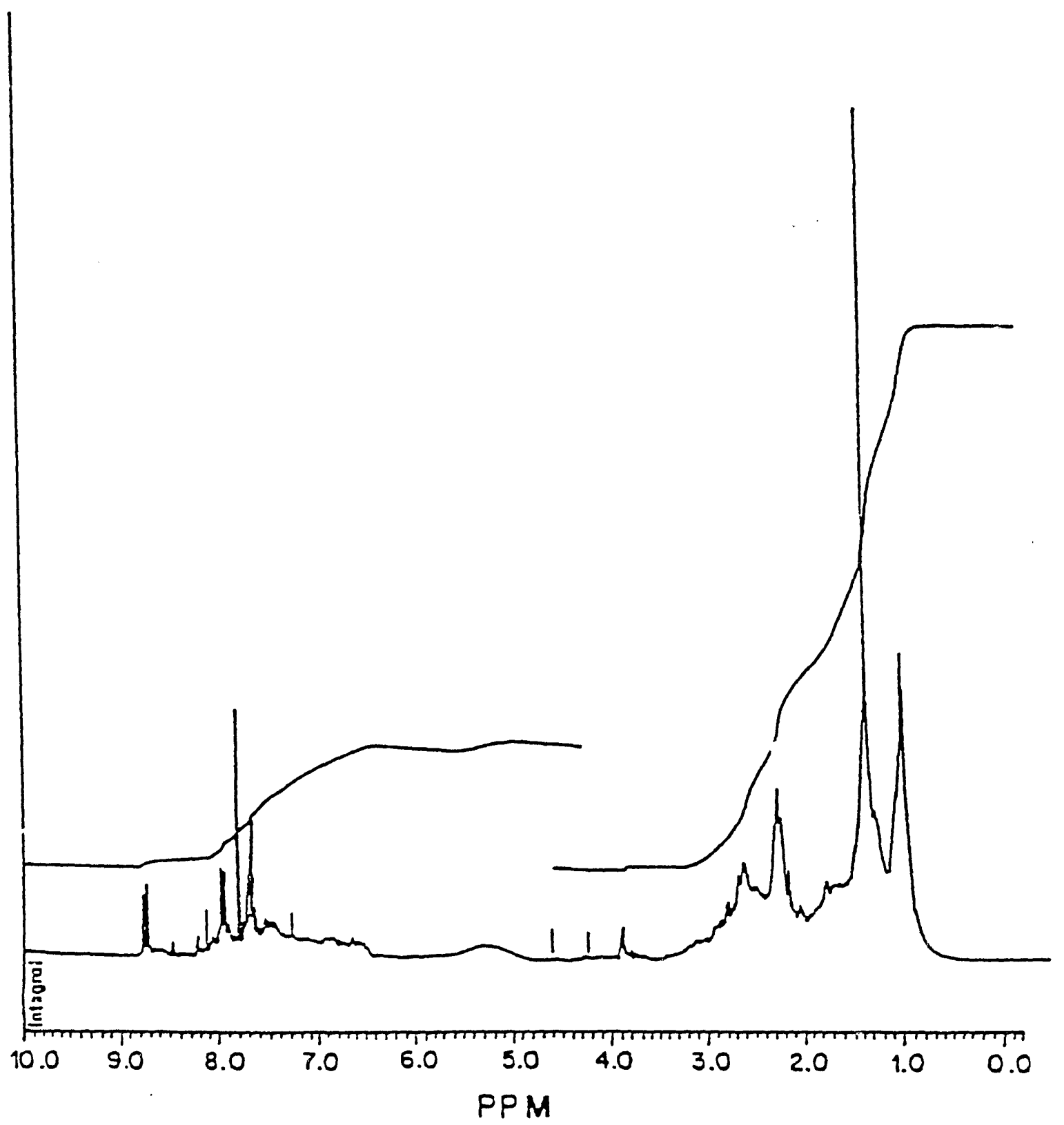

Figure 7-7. Proton NMR Spectra of a Typical Wood Oil Distillate

7-17 


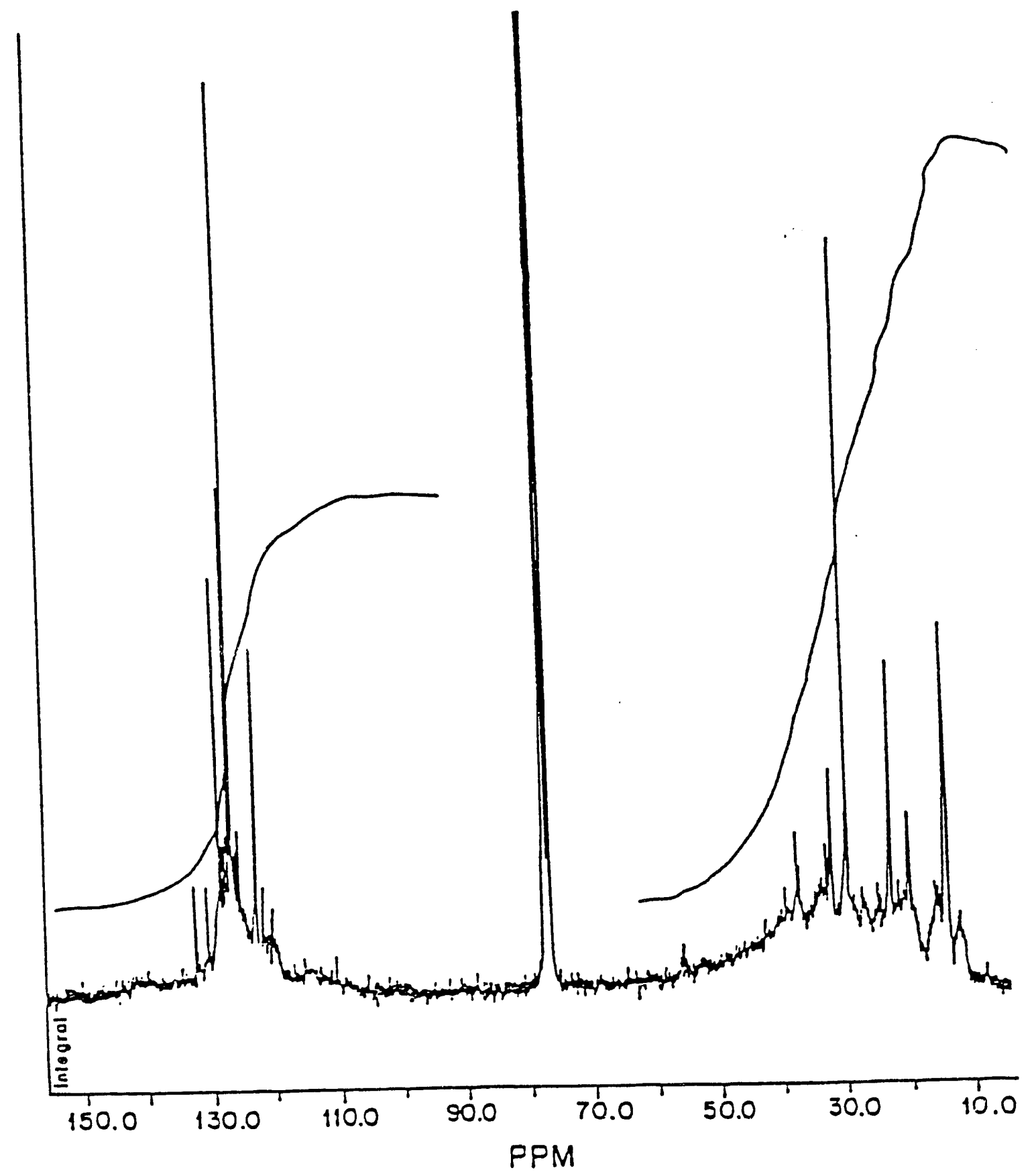

Figure 7-8. ${ }^{13} \mathrm{C}$ NMR Spectra of a Typical Wood $0 i 1$ Distillate

$7-18$ 


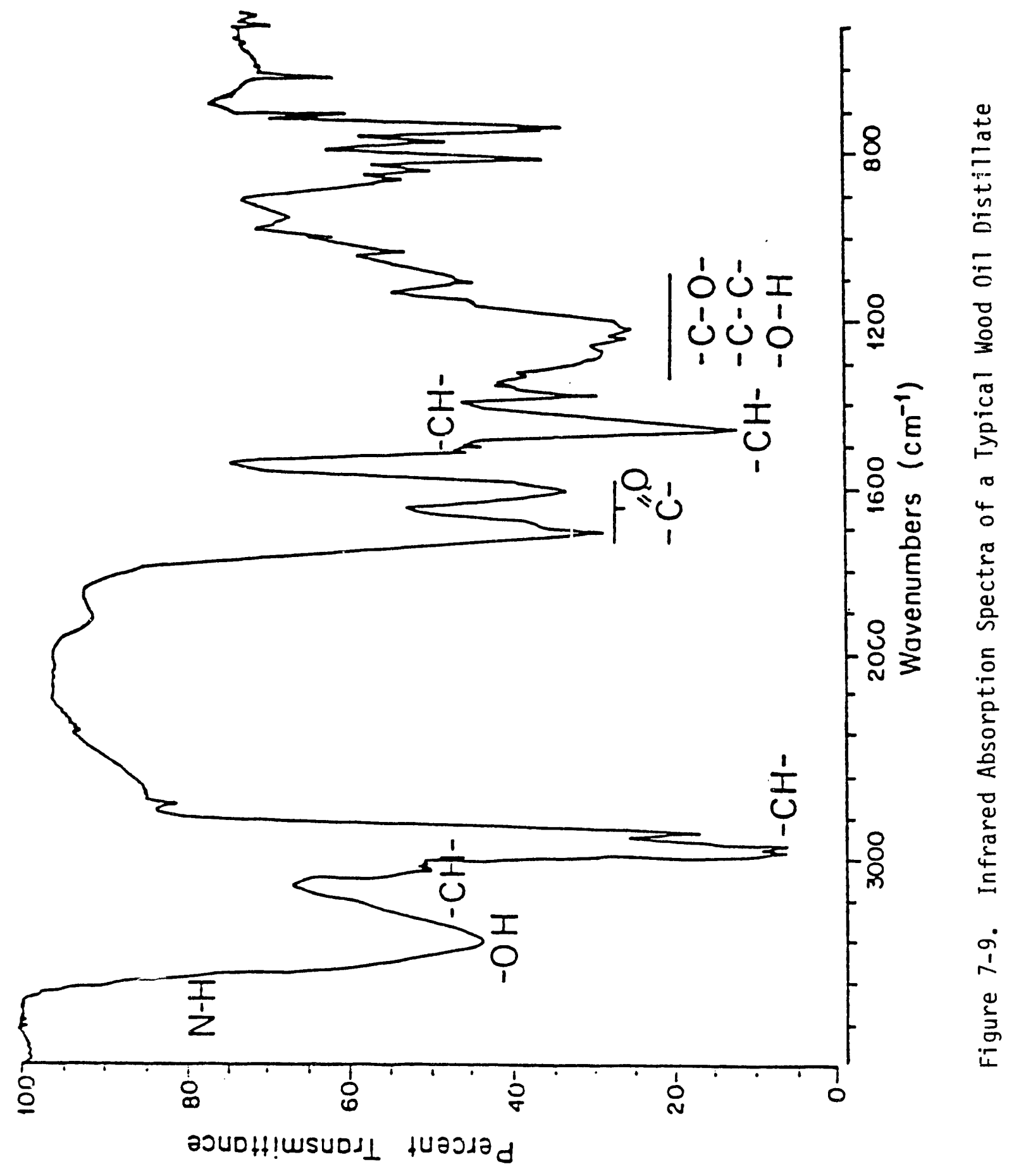




\subsection{QUALITY OF EARLY WOOD OILS}

\subsubsection{Overall Quality Properties}

The early experiments reported in this section produced good quality crude wood oils with high heating values of about $16,000 \mathrm{Btu} / \mathrm{lb}$. and reasonably low viscosities, slightly higher than petroleum Fuel Oil No. 2. More subtle quality properties can be observed by measuring residual oxygen content, aromatic content and the atomic hydrogen to carbon ratios. These qualities are summarized along with rector conditions producing the oils, in Table 7.6.

\begin{tabular}{|c|c|c|c|c|c|c|c|}
\hline $\begin{array}{l}\text { Run } \\
\text { No. }\end{array}$ & $\begin{array}{l}\text { Oxygen } \\
\text { Content } \\
\text { wt. } \%\end{array}$ & $\begin{array}{l}\text { Aromatic } \\
\text { Carbon } \\
\text { Wt. } \%\end{array}$ & $\begin{array}{l}\text { Atomic } \\
\text { Hate } \\
\text { Ratio }\end{array}$ & $\begin{array}{l}\text { Temp } \\
{ }^{\circ} \mathrm{C}\end{array}$ & $\begin{array}{c}\text { Press. } \\
\text { psi }\end{array}$ & $\begin{array}{l}\text { Resid. } \\
\text { Time } \\
\text { (min) }\end{array}$ & $\begin{array}{l}\text { Catalyst } \\
\mathrm{Na}_{2} \mathrm{CO}_{3} \\
\mathrm{Wt} . \%\end{array}$ \\
\hline E1 & 6.52 & 0.60 & 1.32 & 350 & 3,000 & 72 & 10 \\
\hline G1 & 5.24 & 0.68 & 1.28 & 375 & 800 & 120 & 2 \\
\hline G2 & 5.73 & 0.68 & 1.23 & 375 & 1,000 & 90 & 0 \\
\hline G3 & 7.48 & 0.66 & 1.24 & 375 & 1,200 & 103 & 0 \\
\hline G4 & 6.67 & 0.69 & 1.29 & 375 & 2,300 & 72 & 0 \\
\hline $\mathrm{H} 3$ & 8.90 & 0.88 & 1.24 & 375 & 3,000 & 240 & 2 \\
\hline $\mathrm{H} 4$ & 10.02 & 0.99 & 1.26 & 375 & 3,000 & 90 & 0 \\
\hline I1 & 5.30 & 0.94 & $1.2 \mathrm{i}$ & 375 & 600 & 240 & 0 \\
\hline
\end{tabular}

As can be seen from Table 7.6, essentially the same quality of wood oil was made under a wide range of pressure, with or without sodium carbonate catalyst and with or without carbon monoxide. However, it should be noted a good operating temperature (just under the critical temperature for water) was maintained, and residence times were on the high side. What cannot be determined from these data is how much char or highly cross-linked material was formed, which reduces the yield of liquid oil.

\subsubsection{Albany Vacuum Bottoms}

Two types of Albany vacuum bottoms were died as the wood flour carrier during these early runs in the period August 29, 1985 - July 29, 1986. A larger quantity of the black type was used, together with a limited quantity of the brown type used in the last few runs. The elemental analysis of these vacuum and some oil obtained from them at $2 \mathrm{mmHg}$ absolute pressure and $550^{\circ} \mathrm{F}$ are given in Table 7.7. 


\begin{tabular}{|l|r|r|r|r|r|r|}
\hline \multicolumn{7}{|c|}{ Table 7.7. Elemental Analyses of Albany Vacuum Bottoms } \\
\hline $\begin{array}{l}\text { Material } \\
\text { Wt. \% C }\end{array}$ & Wt. \% H & Wt. \% O & Wt. \% N & $\begin{array}{r}\text { Atomic } \\
\text { H/C }\end{array}$ & $\begin{array}{c}\text { Ash } \\
\text { (Calc.), } \\
\text { Wt. \% }\end{array}$ \\
\hline $\begin{array}{l}\text { Black } \\
\text { Vacuum } \\
\text { Bottoms }\end{array}$ & 78.96 & 6.71 & 12.05 & 0.26 & 1.02 & 2.02 \\
\hline $\begin{array}{l}\text { Brown } \\
\text { Vacuum } \\
\text { Bottoms }\end{array}$ & 81.58 & 6.25 & 9.22 & 0.37 & 0.92 & 2.58 \\
\hline $\begin{array}{l}\text { Some } \\
\text { Brown } \\
\text { VB Oil }\end{array}$ & 85.21 & 7.60 & 5.32 & 0.23 & 1.07 & 1.64 \\
\hline
\end{tabular}

These Albany vacuum bottoms were brittle solids at room temperature but can be melted and moved at $150^{\circ} \mathrm{C}$. As one might expect, the atomic $\mathrm{H} / \mathrm{C}$ ratio is considerably lower than that of the various wood oils. The black type of vacuum bottoms was used for the (a) development of the extruder-feeder reported in Part 1, and (b) the rheological data involving Albany vacuum bottoms reported in Part 2.

\subsubsection{White Birch Feedstock}

The feedstock used for the experimental runs in this project was a white birch wood, purchased in the form of a wood flour. Its elemental analysis is given in Table 7.8.

\begin{tabular}{||l|c|c|c|c|r||}
\hline \multicolumn{5}{|c|}{ Table 7.8. Elemental Analyses of Wood Flour Feedstock. } \\
\hline $\begin{array}{l}\text { Form of White } \\
\text { Birch Wood }\end{array}$ & $\begin{array}{c}\text { Wt. \% } \\
\text { C }\end{array}$ & $\begin{array}{c}\text { Wt. \% } \\
\text { H }\end{array}$ & $\begin{array}{c}\text { Wt. \% } \\
\text { O }\end{array}$ & $\begin{array}{c}\text { Wt. \% } \\
\text { N }\end{array}$ & $\begin{array}{c}\text { Atomic } \\
\text { H/C }\end{array}$ \\
\hline Untreated & 46.98 & 5.61 & 41.26 & 0.04 & 1.43 \\
\hline $\begin{array}{l}\text { Pretreated/Water } \\
\text { Leached }\end{array}$ & 45.47 & 5.56 & 40.30 & 0.12 & 1.47 \\
\hline
\end{tabular}

\subsubsection{Overhead Light Wood Oils}

Based on the limited material balance data, for a typical extruder-feeder liquefaction run, about 7-11 percent of the total crude wood oil is flashed overhead and condensed with the overhead water vapors. These overhead oil and water condensates separate into two layers, usually about 50 to 70 percent and oil layer and a 50 to 30 percent water layer. The oil layer is heavier and is the bottom layer. 
The overhead condensate oil is a lighter wood oil with a lower boiling range and a lower viscosity than the liquid product collected from the pressure let-down vessel. These two liquid crude wood oils were compared for some of the experimental runs. Some data on their elemental analyses are given in Table 7.9.

\begin{tabular}{|l|c|c|c|}
\hline $\begin{array}{l}\text { Table 7.9. Quantities of Crude Wood Oils for a Three- } \\
\text { Run Series. }\end{array}$ \\
\hline \\
\hline
\end{tabular}

\subsubsection{Direct Comparison of Overhead and Pressure Let-Down Oils}

The quantities of these two crude wood oil products were carefully determined during three runs when material balances were being determined, and are given in Table 7.10.

\begin{tabular}{|c|c|c|c|}
\hline \multicolumn{1}{|c|}{ Table 7.10. Quantities of Crude Wood Oils for a Three-Run } \\
Series.
\end{tabular}


The reactor pressure and temperature are believed to be the major parameters determining how much oil is flashed overhead from the pressure let-down vessel. However, the effects of other parameters, such as feedstock composition, carbon monoxide and residence time, and product molecular weight distribution, have not been determined, due to the termination of DOE funding.

A comparison of the major liquid product with the lighter overhead oil product often showed a considerable difference, as for example, for Run F2 on December 20, 1985, as shown in Table 7.11.

\begin{tabular}{|l|r|r|r|r|r||}
\hline & Table 7.11. Comparsion of Liquid Let-Down Oil with Overhead Light Oil. \\
\hline $\begin{array}{l}\text { Liquid } \\
\text { Product Let- } \\
\text { Down }\end{array}$ & Wt. \% C & Wt. \%. H & Wt. $\%$ O & Wt. \% N & Atomic H/C \\
\hline $\begin{array}{l}\text { Overhead } \\
\text { Light Oil }\end{array}$ & 80.08 & 3.83 & 11.96 & 0.75 & 0.89 \\
\hline
\end{tabular}

The large difference here may be due to the conditions to which the carrier liquid was subjected and also the fact that a large excess of sodium carbonate was used in this run.

\subsubsection{Vacuum Distillation of Early Wood Oils}

A small, glass-made, laboratory-scale vacuum distillation unit was installed at the University of Arizona in order to obtain information on the distillability of UA-produced crude wood oil. Several experiments were made in the range of temperatures of $80-550^{\circ} \mathrm{F}$ and $2-5$ mmHg abs. pressure.

After trial experiments, good operational conditions for fractionation were obtained. The results obtained show around $30 \mathrm{wt} . \%$ of light oil cut and around $70 \mathrm{wt} . \%$ of the heavy oil cut (vacuum bottom) at temperatures below $550^{\circ} \mathrm{F}$ and at pressures of about $2-5 \mathrm{mmHg}$ abs.

The vacuum bottoms obtained in our lab appeared quite different from that of the Albany plant. They are very brittle at room temperature and are in the form of porous solids.

\section{Experimental Procedure}

The crude wood oil obtaine $i$ from the pressure let-down vessel was first crushed to a fine powder by using a laboratory crusher. Then a sample of 100 grams was sifted into a $500 \mathrm{ml}$. round-bottom flask. The weight of the empty flask had been recorded previously, thus enabling calculation of the weight of the sample. The experimental apparatus used at the University of Arizona is shown in Figure 7.10. 


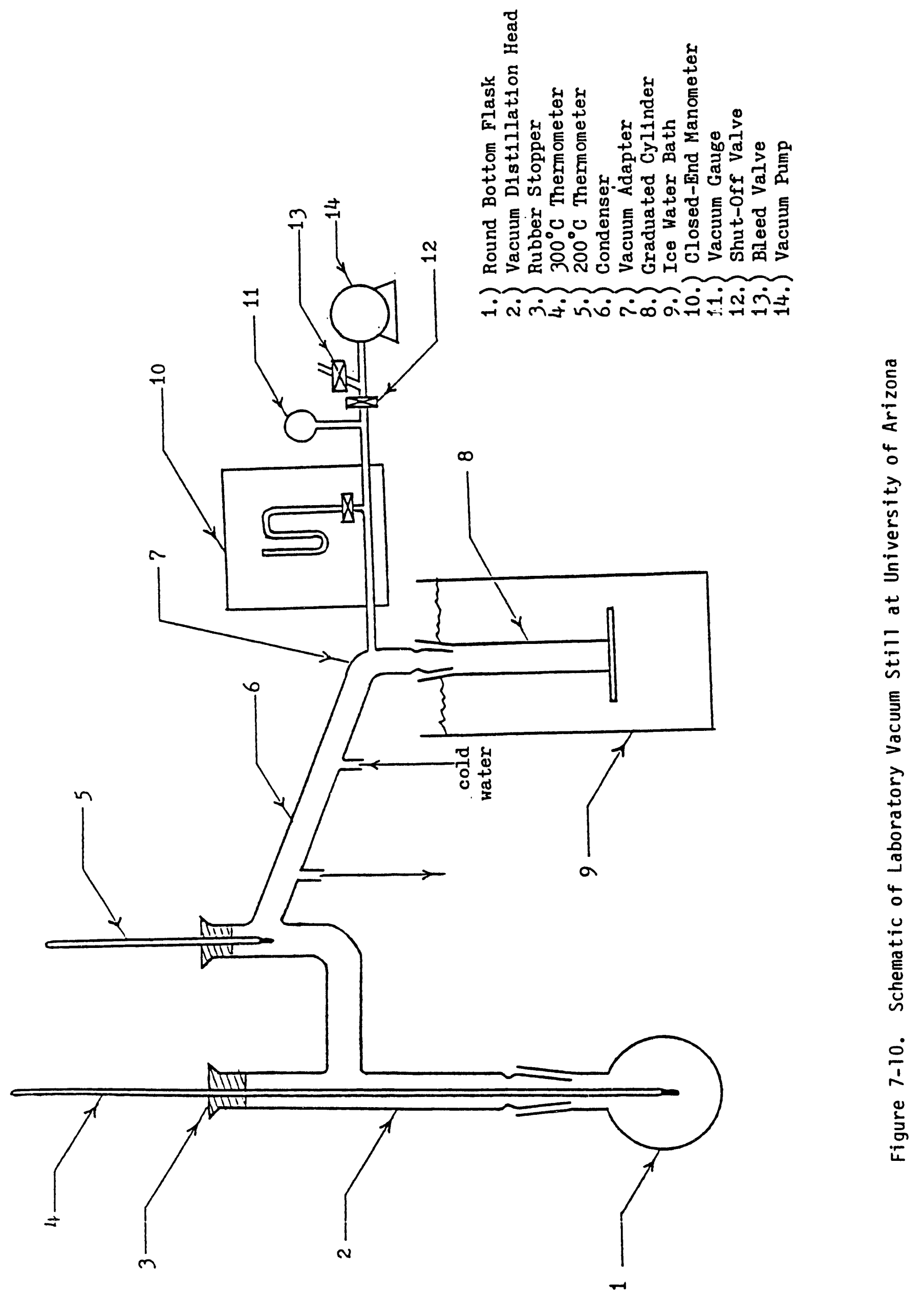


The distillation was performed in the following manner: The pressure was reduced to about $2-5 \mathrm{mmHg}$ and the temperature was raised gradually to $550^{\circ} \mathrm{F}$. The run was stopped when no more condensate was obtained.

\section{Experimental Results}

The experimental results are given in Table 7.12 for the recovery of distillates.

\begin{tabular}{|c|c|c|c||}
\hline \multicolumn{3}{|c|}{ Table 7.12. Recovery of Distillates } \\
\hline Run No. & Date & $\begin{array}{c}\text { Wt. \% } \\
\text { Distillate }\end{array}$ & $\begin{array}{c}\text { Wt. \% } \\
\text { Recovery }\end{array}$ \\
\hline G1 & $2 / 19 / 86$ & 24.7 & 17.5 \\
\hline G2 & $3 / 19 / 86$ & 39.0 & 25.5 \\
\hline G3 & $4 / 16 / 86$ & 27.0 & 19.0 \\
\hline G4 & $5 / 29 / 86$ & 23.4 & 16.0 \\
\hline H3 & $6 / 30 / 86$ & 30.0 & 20.0 \\
\hline H4 & $7 / 2 / 86$ & 27.0 & 23.9 \\
\hline I1 & $7 / 30 / 86$ & 19.0 & 19.9 \\
\hline I1 & $7 / 31 / 86$ & 20.0 & 11.0 \\
\hline
\end{tabular}

\section{Correlation of Distillate Oil Yield with Reactor Pressure}

The higher the pressure under which the crude wood oil was produced, the more distillate was obtained from the crude wood oil. The reason is that the increase in operating pressure reduces the amcunt of volatile materials obtained. This correlation is seen clearly in Figure 7.11. NOTE: Distillability is equal to the wt.\% recovery in the above table.

\subsection{QUALITY OF LATER WOOD OILS}

\subsubsection{Experimental Strategy}

The experimental strategy for producing these later wood oils during the period August 1, 1986 through September, 1988 involved achieving the following goals:

1. Improve process operability by expanding the real-time computer control system (including implementation of the FIX software), enlarging the size of process piping and operating continuously at higher pressures by means of the $\mathrm{CO}$ compressor and other process changes. 


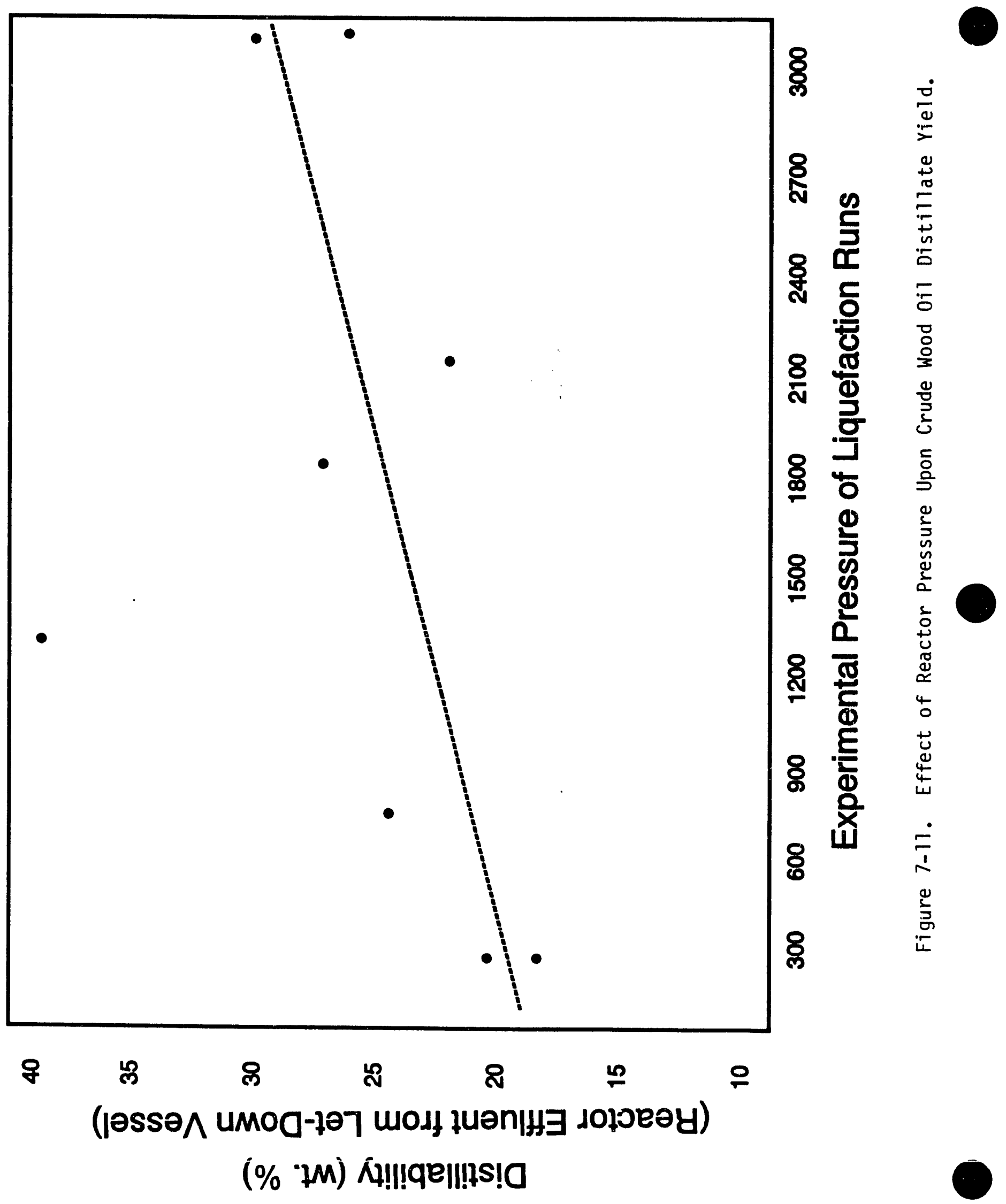




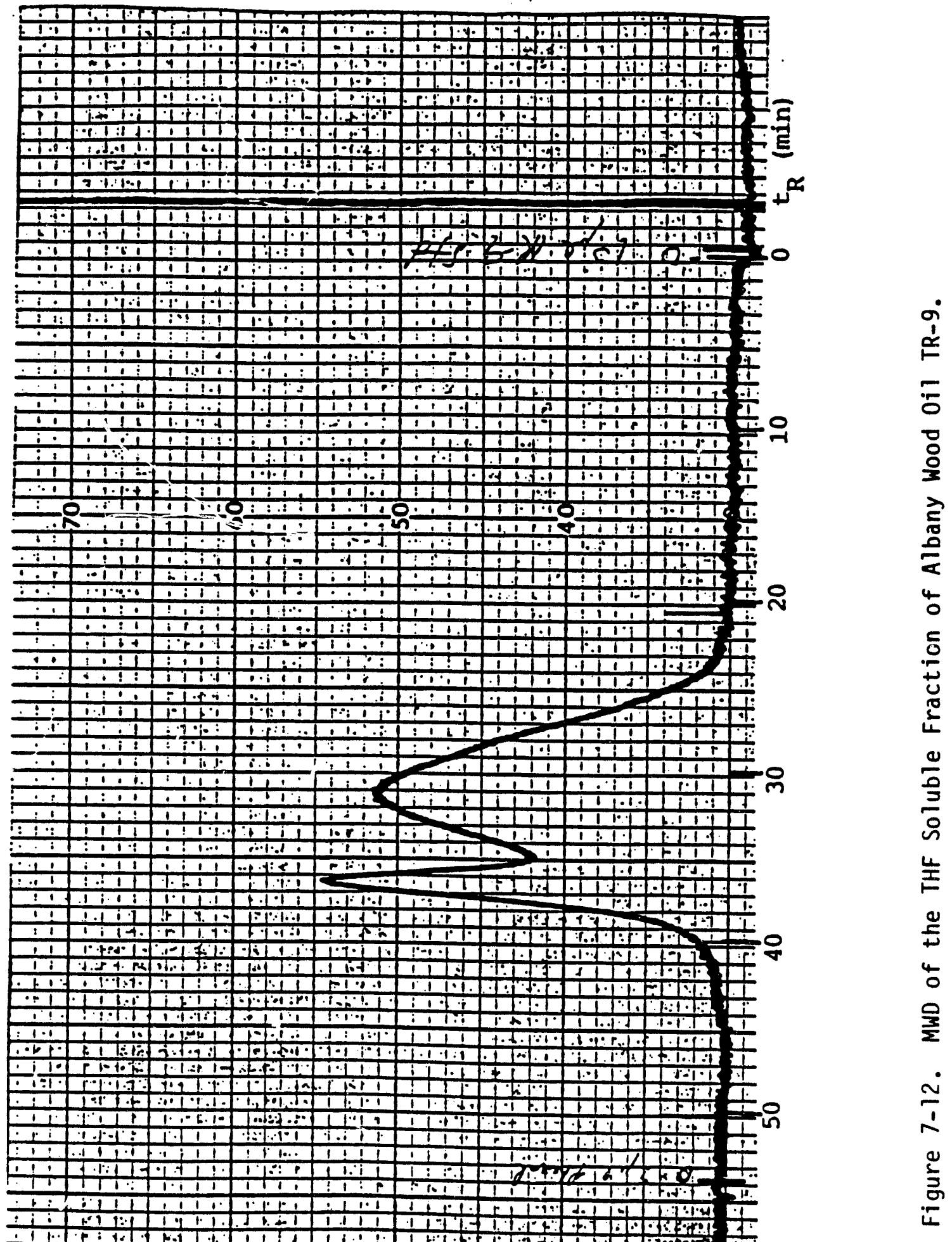


2. Make longer runs at higher feedstock feed rates under steady lined-out operating conditions in order to produce larger samples of crude wood oil for various analyses, including but not limited to hydrotreating by Doug Elliott's group at Battelle PNL.

3. Make an All-Arizona crude wood oil in the recycle mode as part of achieving Goal No. 2 above.

Time and funding concentrated upon the above goals and minimized the amount of analytical work performed upon the 19 experimental runs made during this period. However, some analytical data were accumulated and certain significant results are reported herein.

\subsubsection{Elemental Analyses}

The elemental analyses of 11 crude wood oil distillates are given in Table 7.13.

\begin{tabular}{|c|c|c|c|c|c||}
\hline \multicolumn{2}{|c|}{ Table 7.13. Elemental Analyses of Crude Wood Oil Distillates } \\
\hline Run No. & Date & $\begin{array}{c}\text { Wt. } \\
\text { \% C }\end{array}$ & $\begin{array}{c}\text { Wt. \% } \\
\text { H }\end{array}$ & $\begin{array}{c}\text { Wt. \% } \\
\text { O }\end{array}$ & $\begin{array}{c}\text { Wt. } \\
\text { \% N }\end{array}$ \\
\hline M1 & $07 / 14 / 87$ & 82.00 & 8.90 & 7.77 & 0.18 \\
\hline M2 & $07 / 17 / 87$ & 82.91 & 8.76 & 6.74 & 0.35 \\
\hline M3 & $07 / 23 / 87$ & 82.10 & 8.87 & 6.47 & 0.11 \\
\hline N1 & $08 / 20 / 87$ & 81.81 & 6.98 & 9.46 & 0.06 \\
\hline N2 & $08 / 21 / 87$ & 80.79 & 8.89 & 8.49 & 0.17 \\
\hline O1 & $09 / 10 / 87$ & 78.83 & 6.81 & 11.42 & 0.29 \\
\hline O2 & $09 / 11 / 87$ & 80.67 & 6.56 & 12.52 & 0.28 \\
\hline P1 & $09 / 17 / 87$ & 80.62 & 6.62 & 10.87 & 0.27 \\
\hline Q1 & $03 / 07 / 88$ & 83.10 & 6.30 & 9.20 & 0.20 \\
\hline Q3 & $03 / 14 / 88$ & 78.30 & 6.40 & 15.30 & 0.20 \\
\hline S2 & $07 / 20 / 88$ & 83.27 & 9.18 & 5.31 & 0.32 \\
\hline
\end{tabular}

\subsubsection{Quality of Later Crude Wood Oil Distillates}

As in Section 7.4.1 on the early crude wood oils, a tabulation is given here in Table 7.14 on certain selected quality criteria, namely, oxygen content, atomic $\mathrm{H} / \mathrm{C}$ ratio and heating values for these 11 later crude wood oil distillates. 


\begin{tabular}{|c|c|c|c|c|c|c|c|}
\hline \multirow[b]{2}{*}{ Run No. } & \multirow[b]{2}{*}{ Date } & \multirow{2}{*}{$\begin{array}{c}\text { Oxygen } \\
\text { Content, } \\
\text { wt. } \%\end{array}$} & \multirow{2}{*}{$\begin{array}{c}\text { H/C } \\
\text { Atomic } \\
\text { Ratio }\end{array}$} & \multirow{2}{*}{$\begin{array}{l}\text { Heating } \\
\text { Value, } \\
\text { BTU/lb }\end{array}$} & \multicolumn{3}{|c|}{ Reactor Conditions } \\
\hline & & & & & $\begin{array}{c}\text { Temp, } \\
{ }^{\circ} \mathrm{C}\end{array}$ & $\begin{array}{l}\text { Time, } \\
\text { Min. }\end{array}$ & $\begin{array}{l}\text { Co } \\
\text { Feed } \\
\text { Low }\end{array}$ \\
\hline M1 & 07/14/87 & 7.77 & 1.30 & 16,150 & 380 & 36 & Low \\
\hline M2 & $07 / 17 / 87$ & 6.74 & 1.27 & 16,250 & 420 & 48 & Low \\
\hline M3 & $07 / 23 / 87$ & 6.47 & 1.30 & 16,160 & 340 & 40 & Low \\
\hline N1 & $08 / 20 / 87$ & 9.46 & 1.03 & 15,700 & 330 & 36 & Low \\
\hline N2 & $08 / 21 / 87$ & 8.49 & 1.32 & 15,250 & 340 & 45 & Med \\
\hline 01 & $09 / 10 / 87$ & 11.42 & 1.04 & $\ldots$ & 330 & 48 & Low \\
\hline $\mathrm{O} 2$ & 09/11/87 & 12.52 & 0.98 & 14,770 & 340 & 48 & Low \\
\hline P1 & $09 / 17 / 87$ & 10.87 & 1.24 & $\ldots$ & 310 & 36 & Low \\
\hline Q1 & $03 / 07 / 88$ & 9.20 & 0.91 & 15,220 & 370 & 36 & Low \\
\hline Q3 & $03 / 14 / 88$ & 15.30 & 0.98 & 14,000 & 410 & 40 & Med \\
\hline S2 & $07 / 20 / 88$ & 5.31 & 1.33 & 16,400 & 410 & 36 & Low \\
\hline
\end{tabular}

Again, as for the earlier liquefaction products, good quality crude wood oils were shown to be produced under a variety of operating conditions. However, some trends were detected in these runs, e.g., temperatures in the range of $310-330^{\circ} \mathrm{C}$ tended to produce products with higher residual oxygen, lower atomic $\mathrm{H} / \mathrm{C}$ ratios and slightly lower heating values, despite reasonably long residence times. Again, the effects upon total liquid product yields were not determined--this work was planned for the next experimental phase but never occurred due to the termination of the DOE funding.

\subsection{ANALYSIS OF ALBANY CRUDE WOOD OIL TR-9}

\subsubsection{General Techniques}

Before any information can be obtained on the separation of the crude wood oil products, one must determine the chemical characterization of the oil to be separated. The crude wood oil primarily used throughout this project as the carrier fluid for wood flour feedstock was the product from Test Run \#9 (TR-9) at the PERC process in Albany, Oregon. Many experimental runs used crude wood oil TR-9 as the carrier to feed the wood flour into the reactor through the extrưder in about a $1: 1$ ratio. Later, ar Âil-Ârizona oil was made using its own vacuum botînoms as the recycled carrier oil. 
The first analysis done on the crude oil was soxhletic extraction. It was found that 96.6 percent of TR-9 on a dry basis was soluble in THF, and only three percent of wood flour was THF soluble on a dry basis. This is an indication that the extent of conversion is good since the high MW carbohydrates in wood are broken down and reduced to become THF soluble. In doing the soxhletic extraction, the amount of water in the sample was always determined by K-F titration, so the THF soluble fraction on a dry (water-free) basis could be found; the values ranged from $1-15$ percent by weight.

Viscosity data for wood oil TR-9 showed that it is pseudoplastic. At room temperature, if pulled slowly, it will stretch, but if hit with hammer, it will shatter like glass. The numerical value of the viscosity is highly dependent on the temperature and on the amount of dissolved water present in it.

The pseudoplastic nature of the crude wood oil indicates that it is composed of long molecular chains. The molecular weight distribution (MWD) of the THF soluble fraction of TR9 is given in Figure 7.12. The upper MW limits for Figures 7.12 is about 4000 . The maxima in the distribution has an effective MW of about 260 . The true maxima MW's are less than 260 because some of the compounds in the crude oils can hydrogen bond to THF making their apparent sizes greater than their true sizes.

The MWD can be used to identify likely compounds in the crude wood oil with the aid of other analyses. For example, phenols have been identified as one of the main components in wood oil. Phenols, ali, hydrogen bond to THF which gives them an effective MW higher than their true MW's. The effective MW of phenol is $207 ; 113 \mathrm{MW}$ units greater than its true MW of 94 . This is due to the hydrogen bonding of THF on phenol which increases its effective size. Other phenolic compounds will hydrogen bond to THF. If one assumes the same degree of hydrogen bonding on all phenols, then a phenol of true MW 147 will elute from the column in the MWD maximum of 260 . This would be a phenol with four branched carbons.

The anthracene content can also be determined from these distributions. At $250 \mathrm{~nm}$ in the ultraviolet spectra, anthracene and phenanthrene are very strong absorbers. Using an anthracene standard, an upper limit on its concentration can be made. No distinction was made here between anthracene and phenanthrene since they both absorb nearly equally at this frequency (Simons 1979).

The value of 1.3 percent by wt. of anthracene was found in wood oil TR-9. This supports estimations made by Rust Engineering (1982) for their runs. It differs from the value by D. Elliott (1985), reporting 14.2 percent anthracene by wt. in TR-9. This discrepancy may be explained by the fact that the samples tested were taken from different barrels and hence from different times during the same run. As the run progressed, the anthracene content slowly decreased due to the removal of it in the product stream in the recycle reactor system.

The acid, neutral, and insoluble mass fractions of crude oil TR-9 were found by D.C. Elliott (1982) as shown in Table 7.14. These values were found by dissolving the crude wood oil in excess 5 percent aqueous $\mathrm{NaOH}$. The solution was then extracted with methylene chloride to yield the neutral fraction after stripping off the organic solvent. $\mathrm{HCl}$ was then added to the 
aqueous phase, and then it was re-extracted with methylene chloride to yield the acidic fraction after stripping off the solvent. The insolubles were filtered from the aqueous phase and dried.

The results from various analytical techniques help elucidate the crude wood oil composition. It is composed of a large number of compounds with molecular weights that vary continuously up to about $4000 \mathrm{~g} / \mathrm{mol}$. It is composed entirely of carbon, hydrogen, and oxygen. On a dry basis there are 17 carbon atoms and 18 hydrogen atoms for every oxygen atom in crude oil TR-9. The crude oil is much more aromatic than petroleum. Finally, since there is a large acidic fraction probably due to the phenols and carboxylic acids, the crude oil is capable of absorbing up to $15 \mathrm{wt}$. percent water, depending upon the molecular of a given crude wood oil.

\subsubsection{Species Identification}

Individual chemical species in the crude wood oil have been identified using Gas Chromatography/Mass Spectrometry (GC/MS). The results for wood oil TR-9 are shown in Table 7.15 and 7.16 .

There are some problems with this method of identification. Only the fraction of the crude oil which can be gasified can be identified. Also, the gasification of the crude oil at high temperature causes chemical changes to take place, altering the results.

For crude wood oil TR-9, the largest single group identified by GC/MS is the PolyAromaticHydrocarbons (PAH's). These are not characteristic of wood liquefaction; they come from the anthracene used as a carrier oil during start up.

The GC/MS data in Table 7.16 are for distilled UA wood oil using TR-9 as the carrier oil. Since this oil was first distilled some chemical changes took place and it is slightly different than the crude oil.

As with TR-9, a large number of PAH's were identified in the Arizona crude wood oils. This is to be expected since TR-9 was used as the carrier oil for the distilled oils analyzed. Also, a large number of phenols were identified.

\subsection{DISTILLATION OF CRUDE WOOD OILS}

\subsubsection{Arizona Crude Wood Oils}

The crude wood oil from the experimental Run S2 (All-Arizona oil) was distilled at the plant site in a large batch vacuum still. This distillate had an aqueous and an organic phase. It was then shaken and redistilled in the laboratory at $260 \mathrm{mmHg}$ absolute pressure. The boiling point curve is shown in Figure 7.13. Five cuts were collected, and the boiling point range for each fraction can be seen in the figure. The first fraction contained all of the water and some of the light oil. The last fraction included the highest boiling distillate and the oil left behind in the boiling flask. Each of these cuts were run through the HPLC, and their MWD's can be seen in Figures 7.14 through 7.17. The results are summarized in Table 7.16. 


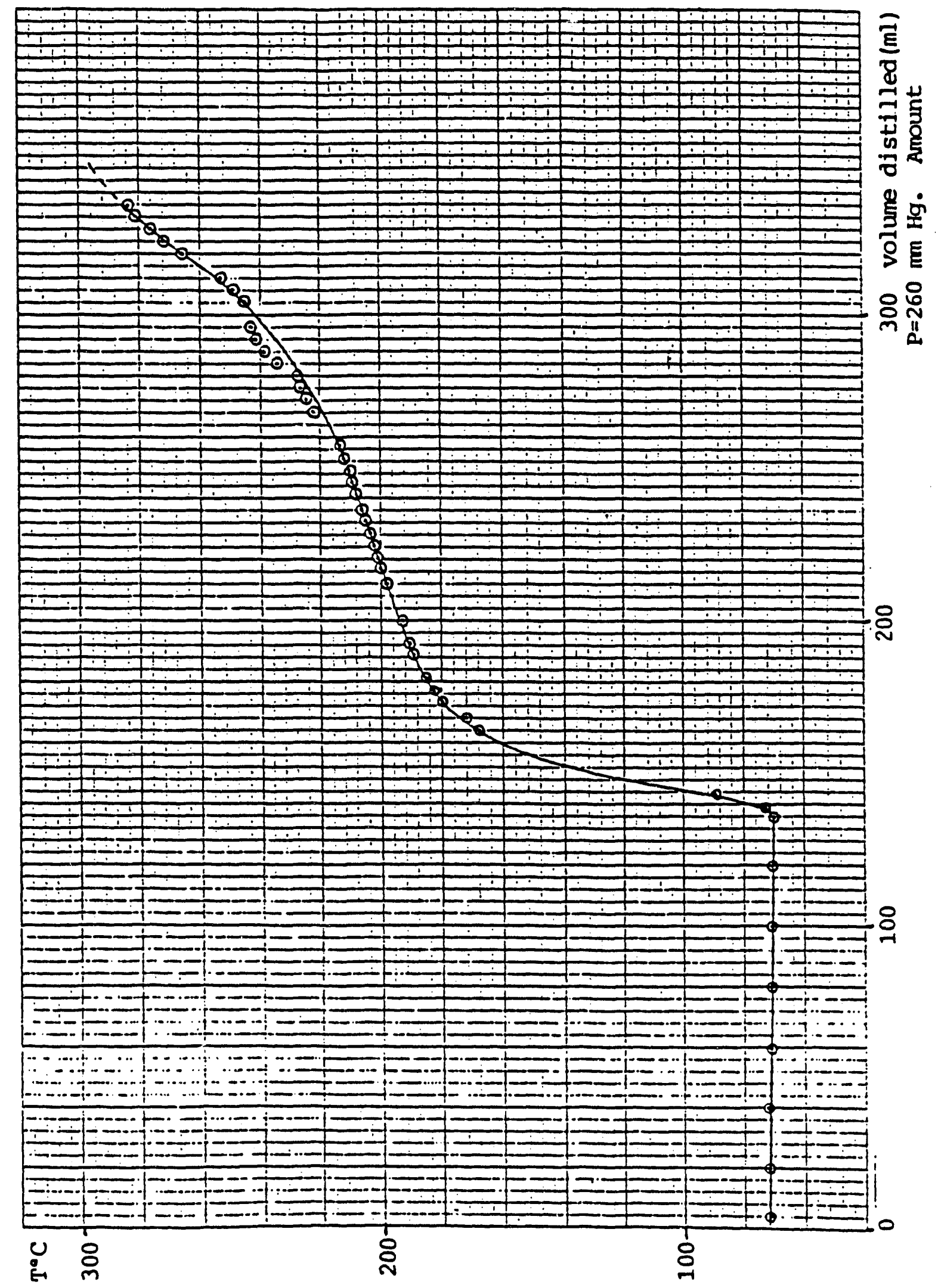

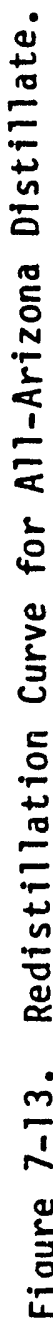




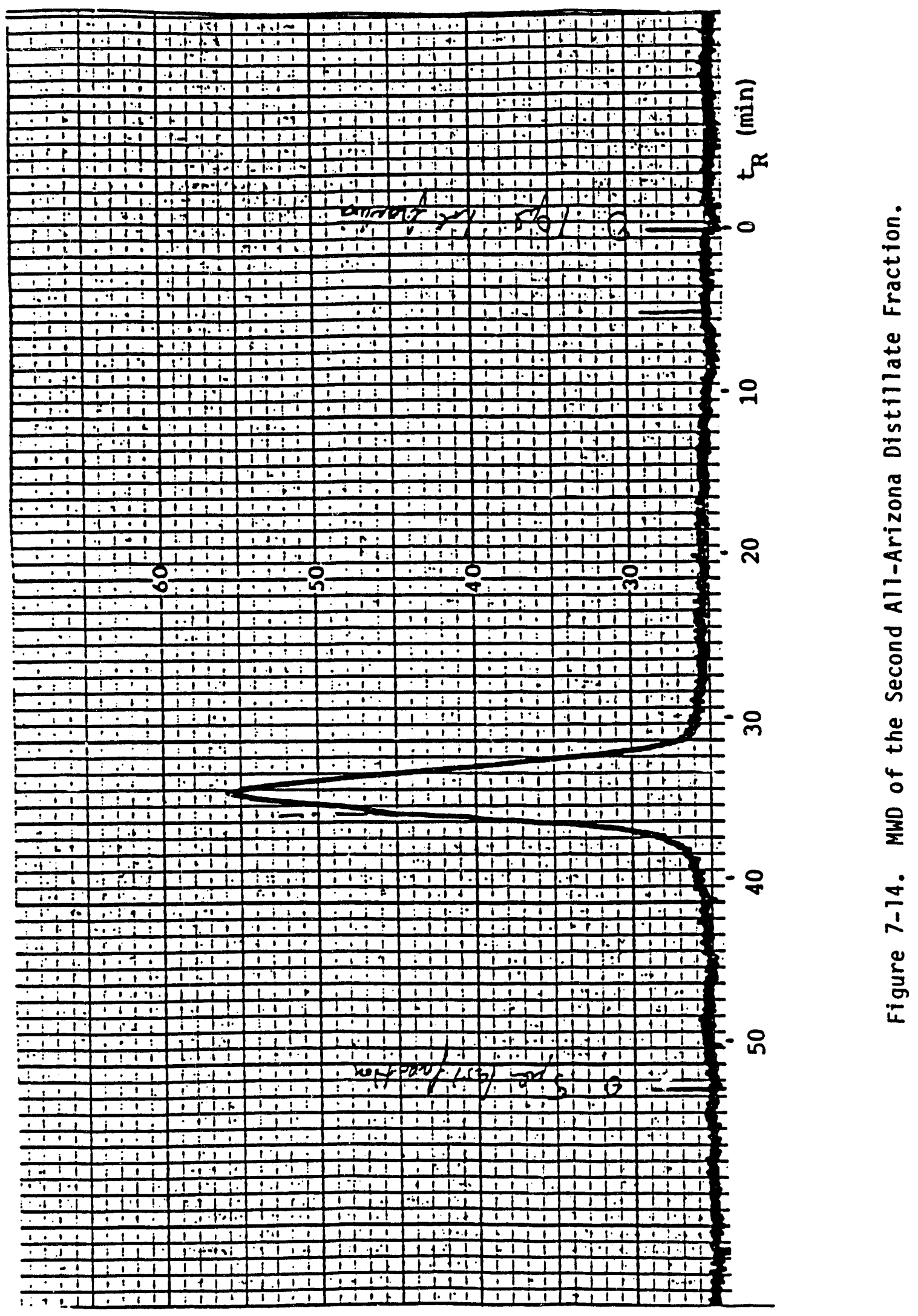




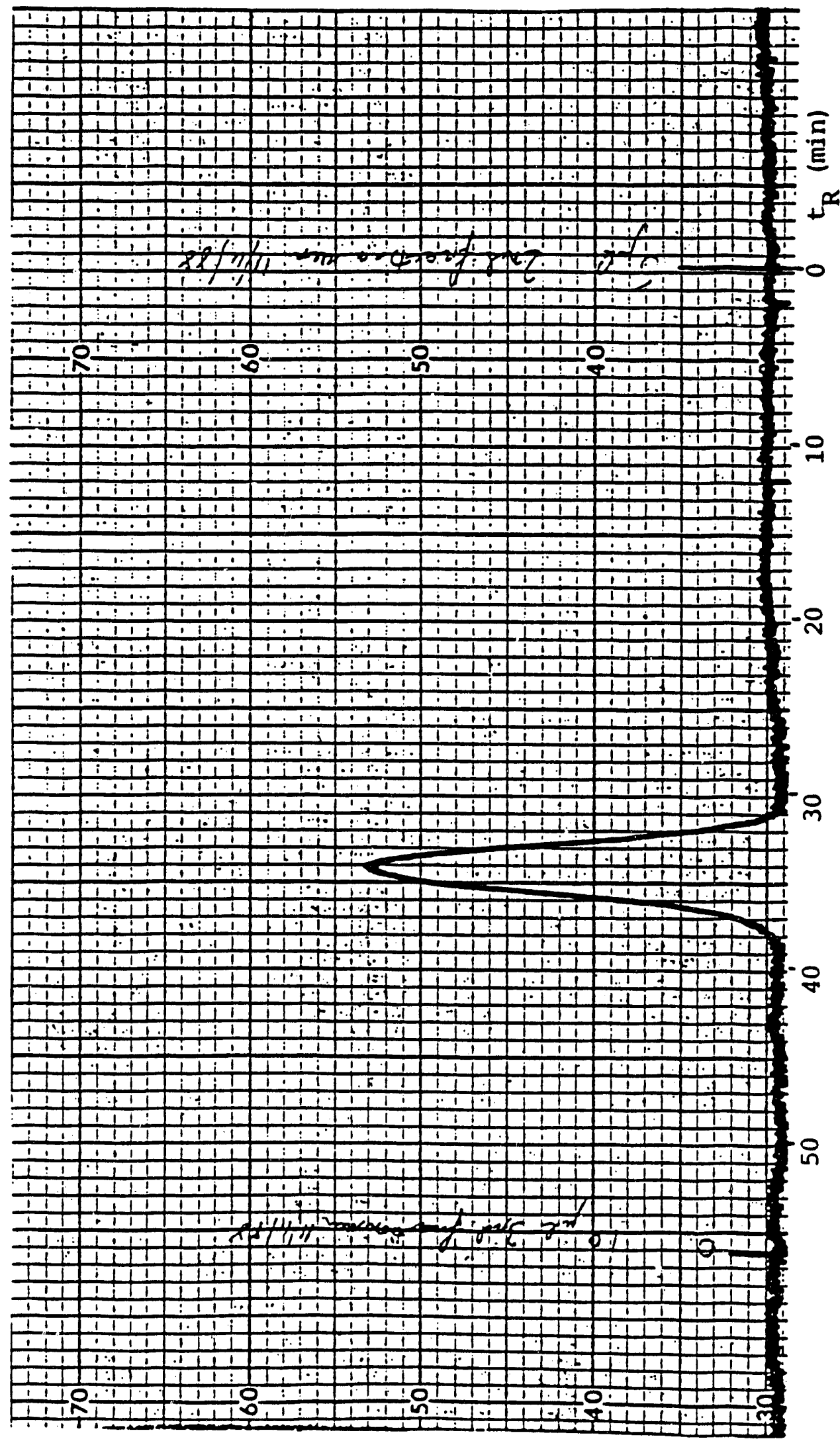

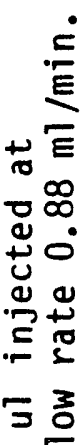

เ

¿ن

잉

苟

5

o

+ is

중

$=$

$\pm 0$

:

r 읕

号

Nㅗㅗ

安

I.

立堊

뭉

$\therefore$ के

$\neq \frac{1}{0}$

综

平

ч

을

疍

오

告 


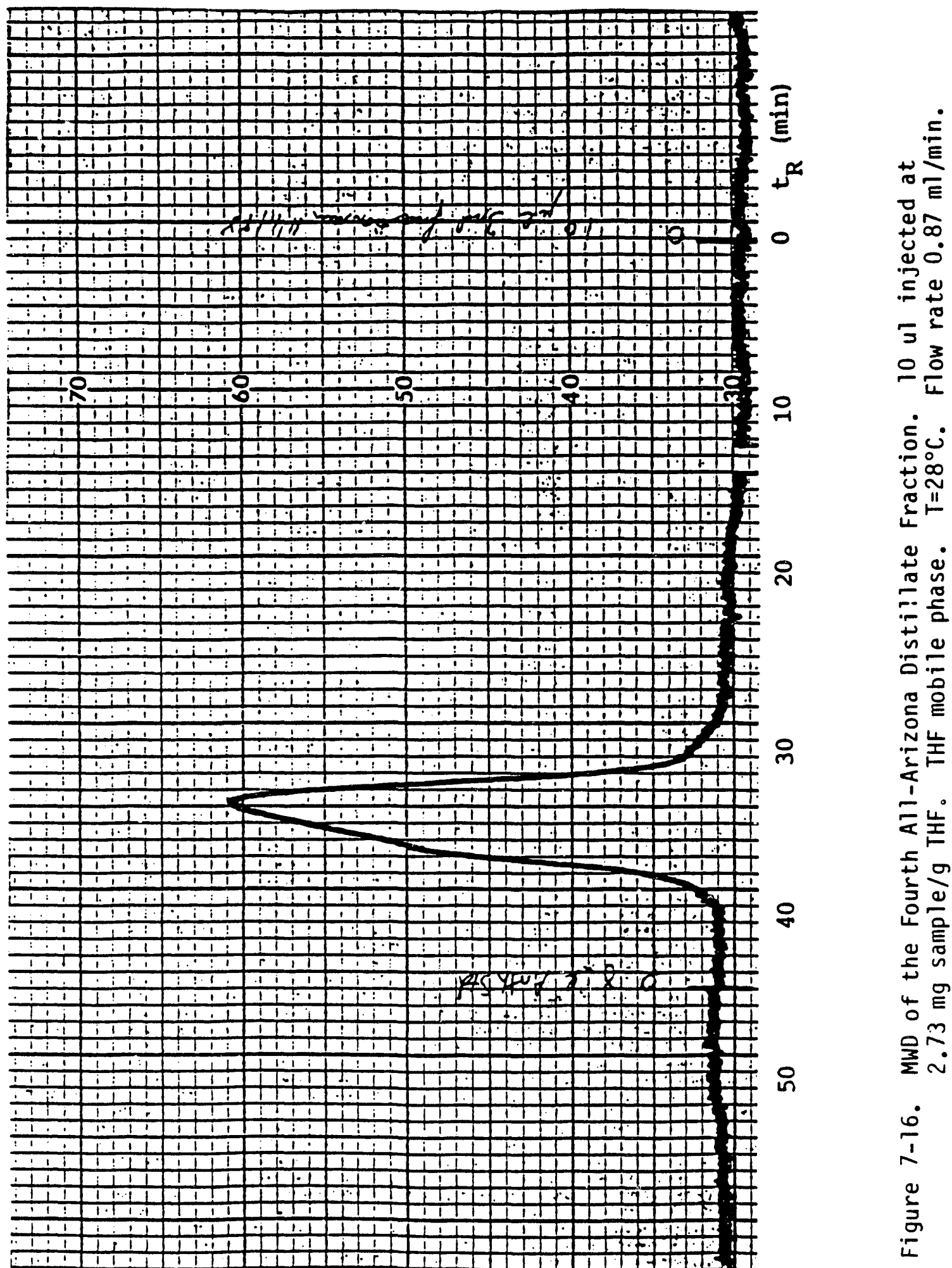




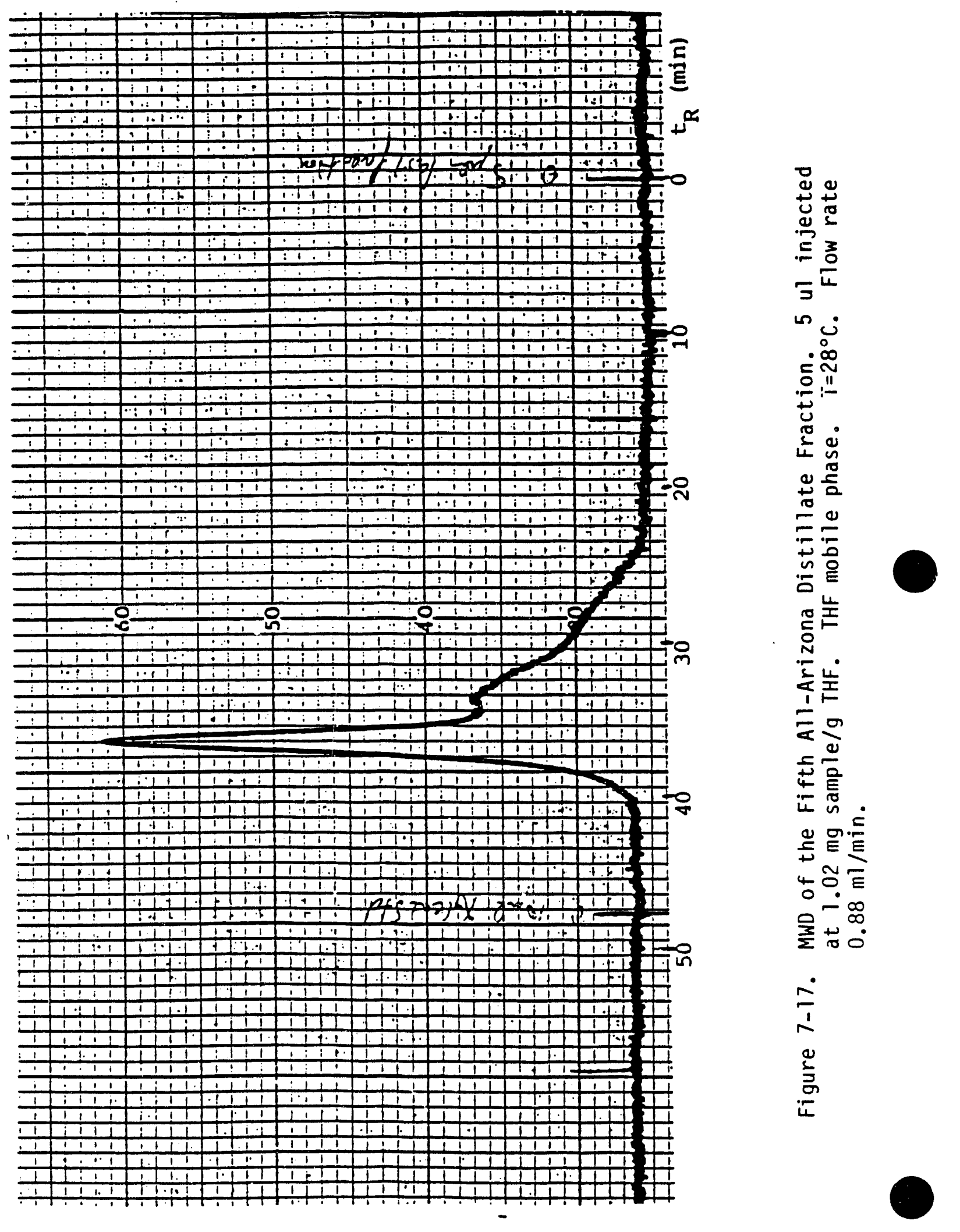




\begin{tabular}{|c|c|c|c|}
\hline \multirow[t]{4}{*}{1} & Aliphatic Hydrocarbon & \multirow[t]{4}{*}{3} & Phenol,3-ethyl- \\
\hline & Pentadecane & & Phenol,3,5-diethyl- \\
\hline & Heptadecane & & Phehnol,2,4-dimethyl- \\
\hline & $\begin{array}{l}\text { Cyclopropane, 1-methyl-2-(1-methyl)-3-(1- } \\
\text { methylethylidene)-cis }\end{array}$ & & Phenol,2,3,6-trimethyl- \\
\hline \multirow[t]{8}{*}{2} & Aromatic Hydrocarbon & \multirow[t]{2}{*}{4} & Ketons \\
\hline & Phenanthrene & & 2-Pentanone,4-hydroxy-4-methyl- \\
\hline & Anthracene & \multirow[t]{3}{*}{5} & Ester \\
\hline & Phenanthrene, 4-methyl- & & $\begin{array}{l}\text { 1,2-Benzenedicarboxylie } \\
\text { acid,dimethyl ester }\end{array}$ \\
\hline & MethylAthracene & & $\begin{array}{l}\text { 1,2-0Benzenedicarboxylie acid,diethyl } \\
\text { ester }\end{array}$ \\
\hline & 5-H-Dibenzo[a,d]-cycloheptene,5-methylene- & \multirow[t]{2}{*}{6} & Furan \\
\hline & 9H-Flourene,9-methylene- & & Dibenzofuran \\
\hline & benzo[b]thiophene,2,7-diethyl- & \multirow[t]{3}{*}{7} & Alcohol \\
\hline \multirow[t]{5}{*}{3} & Aromatics & & benzenemethanol,4-methyl- \\
\hline & Phenol,4-ethyl-2-methoxy- & & 2-Buten-1-OL,3-methyl \\
\hline & 2,3,4,6-0Tetramethylphenol & \multirow[t]{2}{*}{8} & Sugar Derivatives \\
\hline & Phenol, diethyl & & $\begin{array}{l}\text { D-galactitol,2-(acetylmethylamino)-2- } \\
\text { deoxy-3,4,6-tri-o-methyl-1,5- } \\
\text { diacetate }\end{array}$ \\
\hline & Phenol,3-methyl- & & \\
\hline
\end{tabular}

\begin{tabular}{|l|c|r|r|r|}
\hline Table 7.16. MW and Boiling Range of All-Arizona Crude Wood Oil Distillate. \\
\hline \multicolumn{1}{|c|}{ Fraction } & BP Range, ${ }^{\circ} \mathrm{C}(260 \mathrm{mmHg})$ & MW & Mn & Max \\
\hline First & $74-144$ & - & - & - \\
\hline Second & $144-196$ & 188 & 185 & 240 \\
\hline Third & $196-214$ & 195 & 192 & 250 \\
\hline Fourth & $214-254$ & 206 & 199 & 400 \\
\hline Fifth & $254-$ & 508 & 260 & 1600 \\
\hline
\end{tabular}


The SEC results show that the retention volume increases with the boiling point. This is expected since higher MW compounds have higher boiling points. The retention volume is related to the hydrogen bonding capability of the oil because THF can hydrogen bond to some compounds int he oil increasing the molecular size. This is one reason why the average MW's reported here are only approximate. Also, only compounds which are uv absorbers are detected. This should not be a serious limitation because the wood oil is highly aromatic, and the aromatics are strong uv absorbers.

The MW averages were determined using the assumption that the detector output is proportional to the molar concentration of the eluant. This is not entirely true since the detector is a uv detector and the height of the chromatogram is actually proportional to the uv absorbance in a given concentration. More precise values could be found using refractive index in addition to viscometry or LALLS type detectors.

If a solvent was used for the mobile phase with less hydrogen bonding and polarity than THF, there would be less of a difference in the retention time between the phenols and the neutral molecules like anthracene. In this case the uncertainty in the MW would be less. THF was used here because the crude wood oil is very soluble in it and anthracene eluted after the phenols giving better quantitation of it. It should be mentioned that much more work could be done with chromatographic analysis.

The data in Table 7.17 is useful in that it gives information about the nature of the oil. For example, the third fraction has a boiling range between 196 and $214^{\circ} \mathrm{C}$ at $260 \mathrm{mmHg}$. Its average MW is about 195. This means, if this oil is phenolic in nature, it should have 5 or 6 additional carbons in order to give the correct boiling point. This also agrees with the elemental analysis done on the third fraction of TR-9 distillate (which was shown to be very similar to the All-Arizona distillate) by Elliott (1982). He found the percent, elemental composition of the fraction boiling in this range to be: $80.1 \mathrm{C}, 9.4 \mathrm{H}$, and $9.4 \mathrm{O}$ by weight which also indicates a phenol with 5-6 branched carbons.

\begin{tabular}{||l|c|r|r|r||}
\hline Table 7.17. & \multicolumn{3}{|c|}{$\begin{array}{l}\text { MW and Boiling Range of All- } \\
\text { Arizona Crude Wood Oil } \\
\text { Distillate. }\end{array}$} \\
\hline Fraction & $\begin{array}{c}\text { BP Range, } \\
{ }^{\circ} \begin{array}{l}\text { C (260 } \\
\text { mmHg) }\end{array}\end{array}$ & $\mathbf{M}_{w}$ & $\mathbf{M}_{n}$ & $\begin{array}{r}\text { Max } \\
\mathbf{M}_{w}\end{array}$ \\
\hline First & $74-144$ & - & - & - \\
\hline Second & $144-196$ & 188 & 185 & 240 \\
\hline Third & $196-214$ & 195 & 192 & 250 \\
\hline Fourth & $214-254$ & 206 & 199 & 400 \\
\hline Fifth & $254-$ & 508 & 260 & 1600 \\
\hline \hline
\end{tabular}




\subsection{ALBANY CRUDE WOOD OIL TR-9}

A series of distillations were made upon the Albany crude wood oil TR-9 at various pressures. The results indicated a number of points as discussed below.

First of all, as the pressure is increased, the amount left undistilled in the boiling flask increases and the amount distilled decreases. There are two reasons for this. One, as the pressure increases, the boiling points increase and since the distillation runs were terminated once the temperature in the boiling flask reached $400^{\circ} \mathrm{C}$, more material was left behind. The second reason is that at a higher temperature more char is formed which remains as undistilled material.

The second result is that the density of the distilled oil and its chemical composition is slightly dependent on the pressure during the distillation. This means that the oil is not simply being distilled, but it is undergoing a chemical transformation to some degree. This was found by measuring the relative amounts of the distillate which separated into three phases: heavy oil, aqueous, and light oil.

The amount of gases lost at lower pressure is more because of the distillate is in the vapor phase and is lost with the gases.

An analysis of the gases formed during the distillation runs again show some reaction to be taking place. Initially, trapped gases are given off. These are $\mathrm{H}_{2}$ and $\mathrm{CO}_{2}$ whicn were also off-gases from the PERC process. After about 2-3 hours, $\mathrm{CO}$ and $\mathrm{CO}_{2}$ are generated when temperatures reach $100-300^{\circ} \mathrm{C}$ in the boiling flask. The two primary gases generated toward the end of the distillation when the temperature approaches $400^{\circ} \mathrm{C}$ in the boiling flask are $\mathrm{H}_{2}$ and $\mathrm{CH}_{4}$.

The heavy and light oil layers from the distillation of crude wood oil TR-9 and the distillate from the All-Arizona crude wood oil at about $10 \mathrm{mmHg}$ (which has a density less than water) were analyzed by SEC. The SEC chromatograms are shown in Figures 7.18, 7.19, and 7.20. It can be seen that the three samples have similar MWD's.

Soxhletic analysis was done on the material left undistilled in the boiling flask to determine the amount of char. This was compared to the amount of char in the crude wood oil TR-9 before distillation. It was found that 19.3 percent by wt. of the dry TR-9 was converted to a THF insoluble material during the distillations at $50 \mathrm{mmHg}$. This THF insoluble material is thought to be a cross-linked thermoset or char. This reaction is an undesirable effect since this char lowers the yield of liquid oils and may cause plugging when it is recycled through the reactor.

The THF soluble fraction of the vacuum bottoms from the distillation at $50 \mathrm{mmHg}$ were run through the HPLC as can be seen in Figure 7.21. The upper limit of the MW is about 4400 which has not increased from that of the THF soluble fraction of TR-9 before distillation. This indicates that molecules are not combining with themselves to form larger molecules during the distillation. This assumes that the THF insolubles created are of high MW which is reasonable since most low MW compounds are THF soluble. This must mean that the char is formed by 


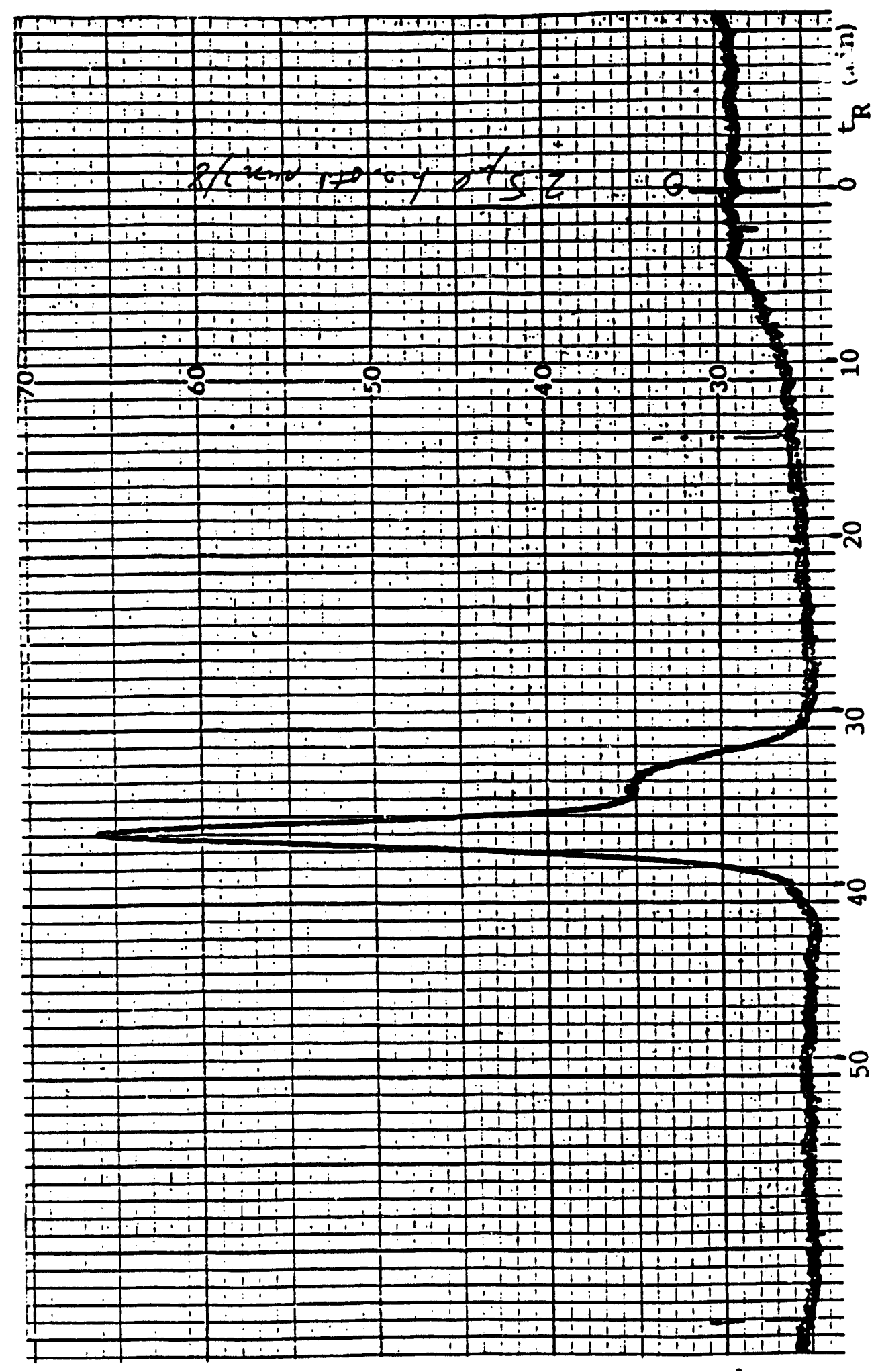

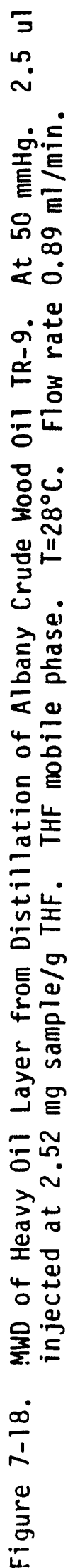

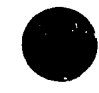



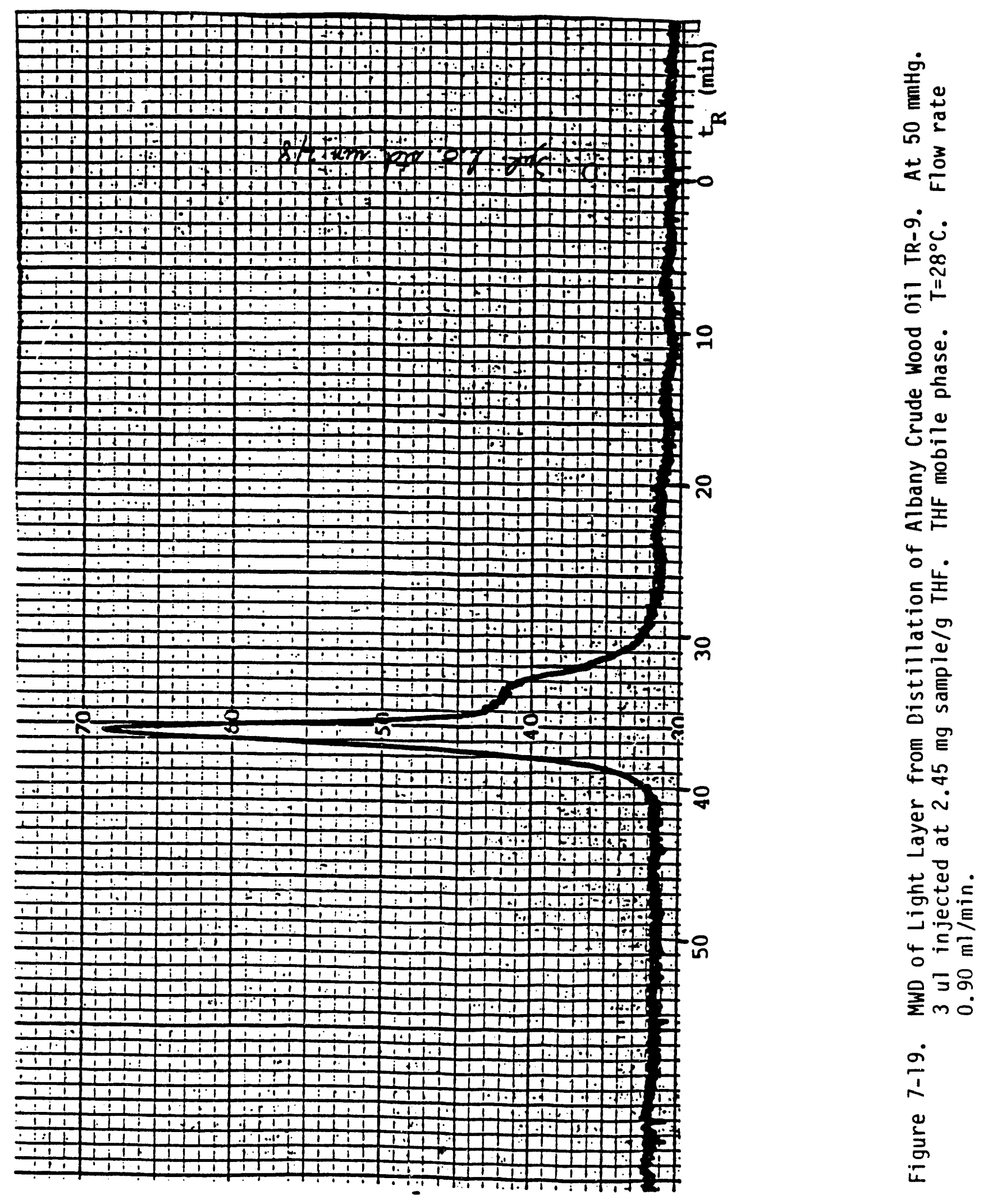


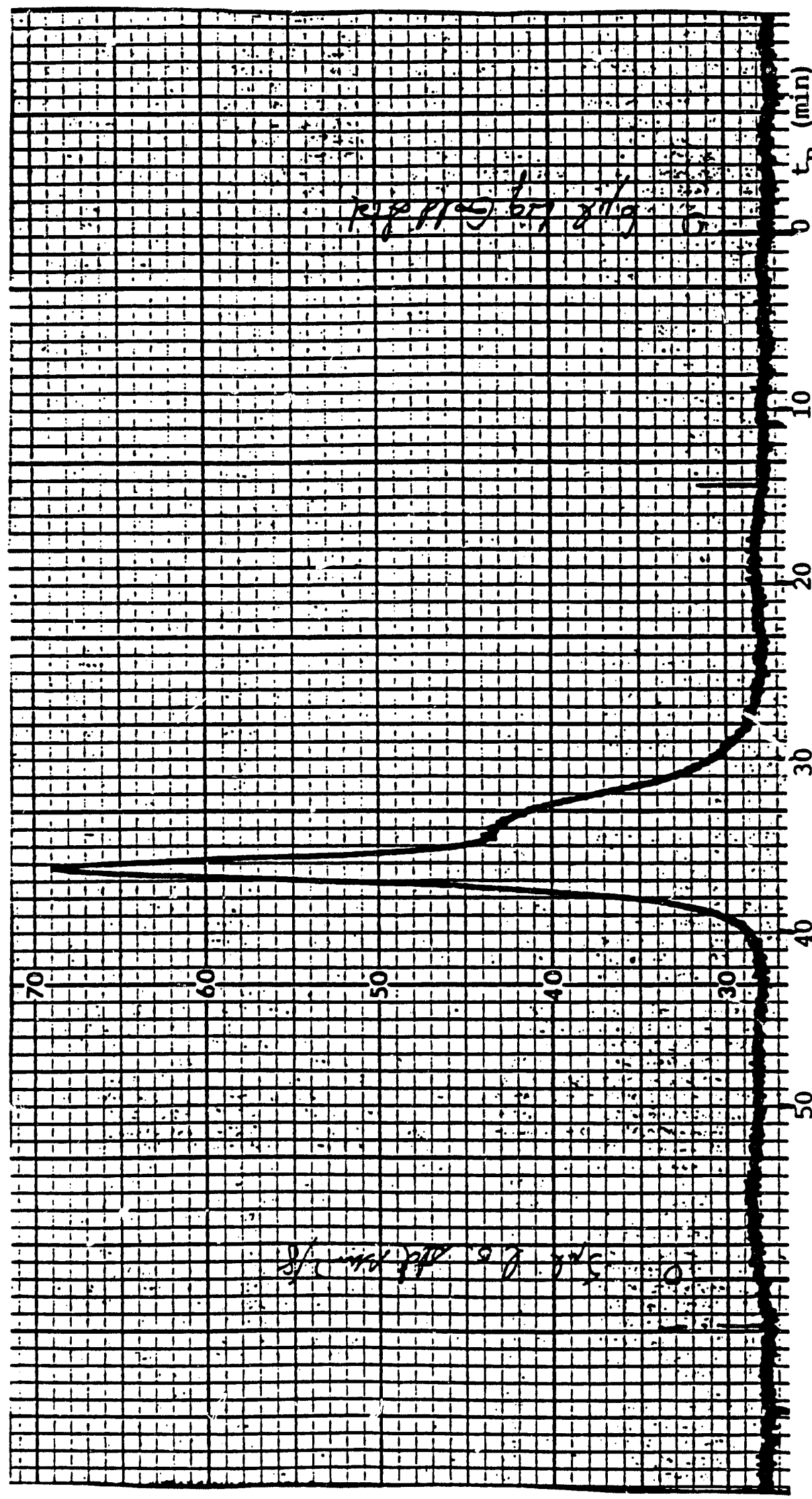

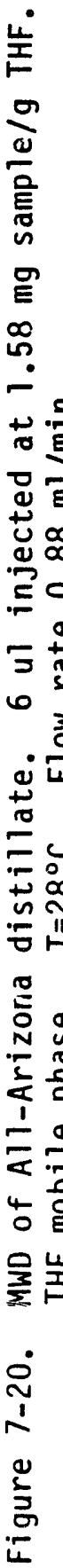




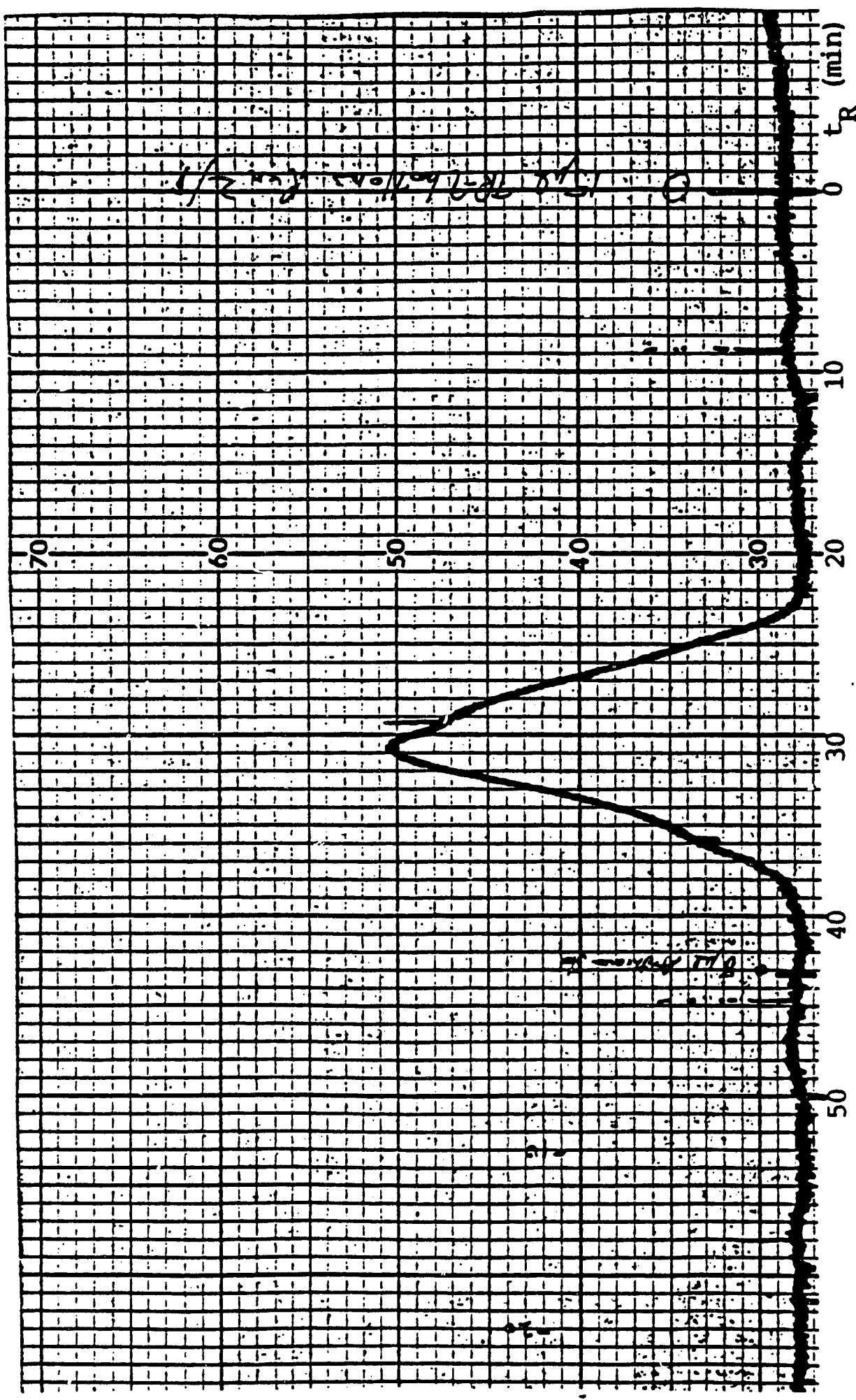

i

$\stackrel{1}{\sim}$

프

o

ن

옹요

은

혼.

ษ

로옹

응

뜸

4 웅

喝

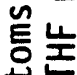

出止。

。

至

ปู่

$>0$

$4 \frac{2}{2}$

○ E

ธั

읕

证

L

$\frac{1}{2}$

กㄷ

응

요웜

岂.

$\neq=\infty$

40

○

ํㅜㅀ는

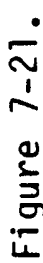

$\frac{1}{5}$ 
molecules growing on already existing char particles or seeds. This is similar to crystallization. To reduce char formation during distillation, the seeds could be removed beforehand. This could be done by dissolving the crude wood oil in THF for example and filtering out these large seed molecules.

No anthracene peak is detected in the THF soluble fraction (Figure 7.21) meaning it was completely distilled over, decomposed, or reacted. By examining the chromatograms from the distillates for the same distillation (Figures 7.18 and 7.19), one can note that the anthracene concentrations to be 2.8 and 3.6 percent by wt., respectively.

The light oil (less dense) layer has some higher MW compounds as shown in Figures 7.18 and 7.19. Since it has less anthracene which is heavier than water, this contributes to making it less dense than water.

The MWD for the All-Arizona distillate, as shown in Figure 7.20 has 2.4 percent by wt. anthracene, which means that actually it is not a complete All-Arizona oil since anthracene is not a product of liquefaction and only a result of its use as a carrier oil for TR-9.

There are also some higher MW compounds than in the TR-9 distillates as shown in Figure 7.20. This is probably because a higher vacuum was used (about $10 \mathrm{mmHg}$ ) to distill the All-Arizona distillate compared to $50 \mathrm{mmHg}$ for the TR-9 distillate. The All-Arizona distillate has a density less than water, which may mean that the higher MW components and the lower anthracene concentration decrease its density relative to the TR-9 distillate.

\subsection{COMPARISON OF WOOD OIL WITH COAL, COALDERIVED OLL AND PETROLEUM}

A comparison was made between the wood oil distillate obtained experimentally and fuels such as coal, coal-derived oil and petroleum, as discussed briefly below.

\subsubsection{Comparison of Wood Oil to Coal}

Because of the highly variable nature of coal, there is a vast number of technical papers and articles, as well as, books dealing with coal properties (Meyers 1981). This section is limited to providing fundamental data on coal and crude wood oil, such as, ultimate analysis on a dry basis, heating value and atomic ratio of hydrogen to carbon in order to compare data with the corresponding data for crude wood oils produced in this work.

From the data in Table 7.5, it can be seen that the oxygen content of various coals ranges from 6.4 to $18.4 \mathrm{wt} \%$, whereas the oxygen content in the crude wood oil distillate is varying from 5 to $10 \mathrm{wt} \%$. The wood oil distillate also has higher heating values in the range of 15,500 $\mathrm{Btu} / \mathrm{lb}$. as compared to the coal heating values which vary between, 7,100 and 14,000 Btu/lb. The atomic ratios of hydrogen to carbon of the wood oil range from 0.88 to 1.28 and the atomic ratios of hydrogen to carbon of coal are between 0.72 and 0.83 . An important environmental consideration is that crude wood oil contains essentially no sulfur and nitrogen. The amount of sulfur in wood is very low and as mentioned above the amount varies between $0.0 \%$ and 0.1 
wt \%. Various coals contain between 0.2 and $7.0 \mathrm{wt} \%$. As for nitrogen, wood contains between 0.1 and $0.25 \mathrm{wt} \%$ while coals have around $1.2 \mathrm{wt} \%$ of nitrogen (Zhao, 1987).

\subsubsection{Comparison of Wood Oil with Coal-Derived Liquid Fuels}

The data on the typical wood oil from the experimental runs and coal-derived liquid fuels (SRC I) is also shown in Table 7.5. The compirison between wood oil and coal-derived SRC fuel indicates that the low heating values of these two fuels are in the range of $15,500 \mathrm{Btu} / \mathrm{lb}$. on a dry basis. The wood oil has a higher atomic ratio of hydrogen to carbon of 1.24 compared

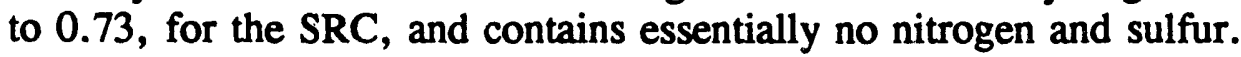

\subsubsection{Comparison of Wood Oil with Petroleum Oil}

The data on the elemental analysis, heat of combustion, viscosity and aromatic carbon of both crude wood oil distillate and petroleum oils are shown in Figure 7.22.

Comparison of wood-derived oil distillate with petroleum shows that the wood oil has lower heat content and carbon and hydrogen, but contains more residual oxygen (wood oil: 7 $w t \%$, petroleum: $1 \mathrm{wt} \%)$. Consequently, the heating value of wood-derived oil is lower than that of petroleum, namely, 15,500 Btu/lb. and 18,000 -20,000 Btu/lb, respectively. Crude wood oil distillate also has a higher viscosity than petroleum.

Petroleum contains paraffins, isoparaffins, aromatics, and naphthene plus organic sulfur, oxygen, and nitrogen compounds. By comparison, crude wood oil is composed primarily of ketones, esters, aliphatic and aromatic hydrocarbons, phenols, alcohols and furans.

Crude wood oil has a significant amount of phenolic derivatives and much less sulfur than the average petroleum crude oil.

\subsection{SUMMARY OF WOOD OIL PROPERTIES}

Some of the physical and chemical properties of wood-derived oils have been determined. White birch wood flour was used as the feedstock in all experiments, and the Albany wood oil vacuum bottom was the carrier oil for the first pass of the feedstock through the reactor. Repetitive runs were made where our crude reactor effluent product was the carrier. Details on the once through runs and repetitive runs are found in the previous Chapter, Part 6 of this report.

Wood oil distillates have good fuel properties, such as, reasonably low viscosity and high heating values. Further, crude wood oils have essentially no sulfur and nitrogen, and thus, wood oils should be attractive from an environmental standpoint.

Oxygen content is reduced from the $42 \mathrm{wt} \%$ in the wood flour to the range of 5-10 wt\% in the oil product. Heats of combustion for the wood oil distillates are in the range of 16,000 Btu/lb. on a dry basis. 


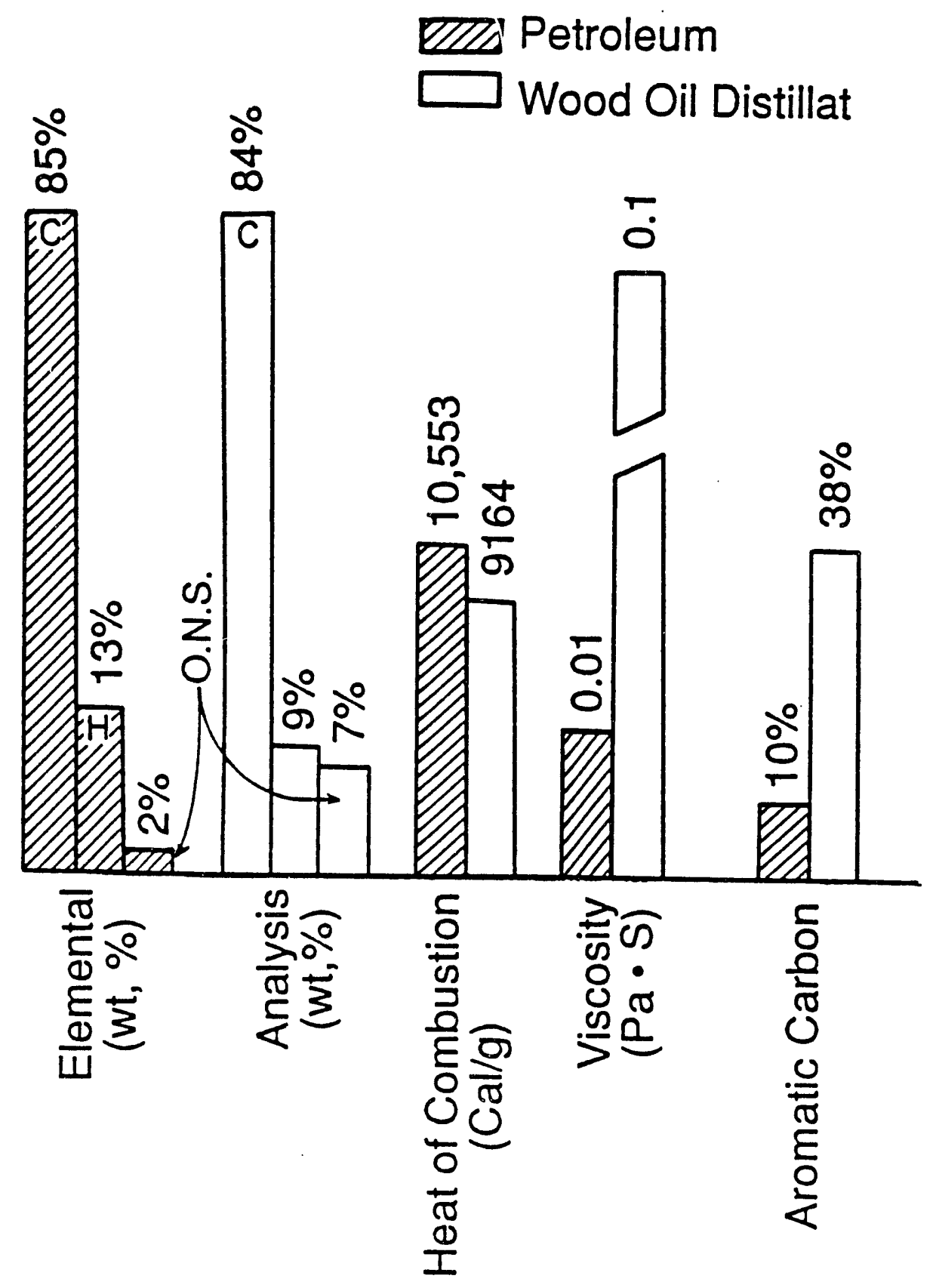

Figure 7-22. Comparison of Typical Crude Wood 0il Distillate with a Crude Petroleum $0 i 1$. 
The viscosities of the wood oil are on the average around $400 \mathrm{cst}$ at a temperature of $30^{\circ} \mathrm{C}$.

The wood oil is higher in aromatic carbon content than representative crude petroleum oils, being $45 \mathrm{~mol} \%$ compared to $12-16 \mathrm{~mol} \%$ for the petroleum. Wood oil is also more acidic than petroleum due to its phenolic content.

About forty components have been identified by GC/MS. They fall into the following major chemical classes: ketones, esters, aliphatic and aromatic hydrocarbons, phenols, furans, alcohols and amines.

Wood oil can be used directly in power plants by blending with other heavy oils or can be upgraded by hydrotreating to a transportation fuel, gasoline, or jet fuel. Upgrading experiments by hydrotreating were performed by Elliott at his laboratories at the Battelle PNL upon the wood oils made in the Albany liquefaction unit. These were successful in making upgraded liquid fuels. However samples of the University of Arizona wood oils were prepared for similar studies and sent to Battelle PNL, but their funding was also terminated and these experiments were never performed. 


\subsection{REFERENCES}

Antal, M.Y., "Biomass Pyrolysis: A Review of the Literature Part I - Carbohydrate Pyrolysis," Advances in Solar Energy, 1, p. 61 (1983).

Appell, H.R. et al., "Conversion of Cellulosic Waste to Oil, " Bureau of Mines, RI 8013 (1975).

Chen, N.Y., Dennis, E.W., Yan, T.Y., and Whitehurst, D.D., "Liquefaction of Carbonaceous Materials," Mobil Oil, U.S. Patent No. 4,247,384, January (1981).

Chen, N.Y., D.E. Walsh, T.Y. Yan and D.D. Whitehurst, "Liquefaction of Solid Carbonaceous Materials." U.S. Patent 4,247,384, issued January 27 (1981).

Chornet, E., and R.P. Overend, "Biomass Liquefaction: An Overview." Fundamentals of Thermochemical Biomass Conversion, edited by Overend, Milne and Mudge, pp. 967-1002 (1985).

Elliott, D.C., "Analysis and Comparisons of Products from Wood Liquefaction." Fundamentals of Thermochemical Biomass Conversion, edited by Overend, Milne and Mudge, pp. 1003-1018 (1985).

Espenscheid, W.F., and T.Y. Yan, "Liquefaction of Solid Carbonaceous Materials, "Mobil Oil, U.S. Patent 4,052,292, October 4 (1977).

Karlsson, O., and P. Bjömbom, "Characterization of Peat and Biomass Liquids." Fundamentals of Thermochemical Biomass Conversions, edited by Overend, Milne and Mudge, pp. 1019-1026 (1985).

Meyers, R.A., Coal Handbook. Marcel Dekker, Inc., New York, NY (1981).

Perry, R.H. and S.C. Chilton, "Chemical Engineering Handbool,", 5th Edition, Sec. 9-4, (1973).

Rust Engineering Corporation, "An Investigation of Liquefaction of Wood at the Biomass Liquefaction Facility, Albany, Oregon." Final Report, prepared under DOE contract DE-AC0178ET-23032 (1982).

Smith, R.C., and H.C. Howard, J. Amer, Chem. Soc., 59:234-6, (1973).

Zhao, Y., "Characterization of Wood Oil Produced by Extruder-Feeder Liquefaction Process," MS Thesis, University of Arizona, Tucson, Arizona (1987). 


\section{Part 8}

CONCLUSIONS AND RECOMMENDATIONS 


\subsection{CONCLUSIONS}

1. A good quality crude wood oil of about $8 \mathrm{wt} . \%$ oxygen content, low viscosity and about $16,000 \mathrm{Btu} / \mathrm{lb}$. heating value can be produced from white birch wood.

2. Yields close to theoretical appear possible, but this was not verified quantitatively.

3. The extruder-feeder process can pump $60 \mathrm{wt} . \%$ wood flour/heavy oil slurries into 3,000 psi reactors, but $50 \mathrm{wt} . \%$ slurries give better operability.

4. The combination of the extruder-feeder and real-time computer process control provides a compact simple process with good operability.

5. A good crude wood oil can be made without sodium carbonate catalyst and without carbon monoxide reactant, but the yield of liquid product is lower.

6. The utilization of carbon monoxide increases liquid yield and may affect oil quality.

7. The utilization of sodium carbonate catalyst promotes the water-gas shift reaction, and may or may not affect the liquefaction reactions in any other manner.

\subsection{RECOMMENDATIONS}

1. The remainder of the 50 percent of the work goals outlined initially in this Subcontract (effect of process parameters, scale-up data and calculations, and economic evaluation) should be completed by additional funding, sometime over the next three years.

2. Other biomass feedstocks, especially solid wastes, should be evaluated.

3. The existing experimental facility should be modified by adding continuous vacuum fractionation, followed by hydrotreating of the distillate over a catalyst prior to pressure let-down, to provide a "two-stage" process for operating flexibility similar to that now used in coal liquefaction research.

4. The existing experimental facility should be modified to study the extruder-feeder in several other process configurations.

5. An engineering design, including scale-up projections, and an economic study should be made at this time in order to guide future work in carrying out Recommendations 1 through 4 above. 
APPENDIX D

Selected Experiinental Runs 


\section{APPENDIX D}

\section{SELECTED EXPERIMENTAL RUNS}

\section{D1.0 EXPERIMENTAL RUN M1}

\section{D1.1 General Description of the Experimental Run}

Experimental Run M1 on July 14, 1987, based on Albany TR-9 crude wood oil as a carrier oil, ran successfully for approximately 8 hours. Some 100 pounds of feedstock of 50:50 WF to TR-9 wt. ratio were processed. Complete process data were recorded by computer acquisition, and certain key data are given here in Figures D1.1 and D1.2 and Tables D1.1 through D1.4.

The following conditions were set for this experimental run. (1) Feedstock of 50/50 wt. ratio of WF to TR-9, (2) Feed rate of $20 \mathrm{lb} / \mathrm{hr}$, (3) CO feed rate of one $\mathrm{lb} / \mathrm{hr}$ feed rate, and (4) Water feed rate of $3 \mathrm{lb} / \mathrm{hr}$. The extruder-feeder temperature was set at $220^{\circ} \mathrm{C}$. and the system pressure was to be 500 psi. However, during operations the temperature of the extruderfeeder was reduced to $170^{\circ} \mathrm{C}$, which appeared to be the appropriate operating temperature for this type of feedstock.

Approximately two hours after the start-up pressure began to build up in the reactor and the feed rate to the reactor was reduced to around $7 \mathrm{lb}$./hr. After the two hours of start-up problems, the operation became normal and the feed rate was increased to around $15 \mathrm{lb} / \mathrm{hr}$. with some fluctuations in the feed rate between $10 \mathrm{lb} / \mathrm{hr}$ and $16 \mathrm{lb} / \mathrm{hr}$. Approximately $90 \mathrm{lbs}$. of feedstock were processed and $24 \mathrm{lbs}$. of asphalt/WF mixture were fed at the end of the run to purge the system. The cumulative feed rate during the experimental run is shown in Figure D1.1. Reactor temperatures were about $360^{\circ} \mathrm{C}$ in the lower reactor and $380^{\circ} \mathrm{C}$ in the upper reactor under steady state conditions near the end of the run. Liquid product let-downs were conducted in such a manner as to keep the pressure constant in the system (i.e. 500 psig). Very little water was injected due to pump problems. Using the equation of state it was calculated that $4.0 \mathrm{lbs}$. of $\mathrm{CO}$ were fed during the run from the CO cylinders as shown in Table D1.3. The condensate contained light oils and water as shown in Table D1.3. The amount of off-gases measured by passing it through the flow meter was $130.7 \mathrm{ft}^{3}$ at atm. pressure.

\section{D1.2 Temperature and Pressure Data}

The extruder-feeder outlet had a temperature range of $157^{\circ} \mathrm{C}$ to $222^{\circ} \mathrm{C}$ with a temperature of about $170^{\circ} \mathrm{C}$ near the end of the run proving to be optimum. The temperature range in the reactor pressure let-down line was $207^{\circ} \mathrm{C}$ to $391^{\circ} \mathrm{C}$ with an average temperature was $313^{\circ} \mathrm{C}$. At the liquid product let-down valve the temperatures ranged from $87^{\circ} \mathrm{C}$ to $312^{\circ} \mathrm{C}$ with an average running temperature of $214^{\circ} \mathrm{C}$. 
In the reactor, pressıres at one point in time were as high as 3,440 psi. This was just prior to the stabilization of the unit and normal operation prevailed. The highest pressure in the let-down vessel was 700 psig and the average was 500 psig.

The temperatures of the various locations on the system are given in Table D1.1, and Figure D1.2. Steady state conditions were attained over the last two hours of the run prior to feeding the wood flour/asphalt purge.

\section{D1.3 Material balances}

The material balances in this experimental run were calculated for the entire period of time, i.e. overall balance, and for some period of time which was considered as a reasonable steady state.

\section{D1.3.1 Overall Material Balance}

The materials fed into the reactor during the whole run between 10:53 a.m. and 6:30 p.m. were:

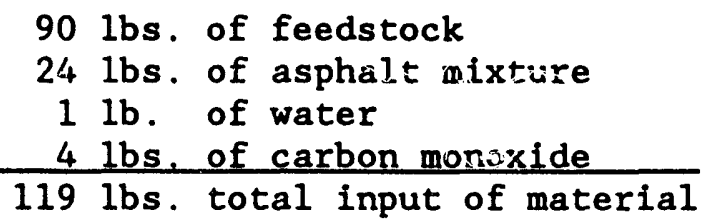

The materials leaving the reactor at this time were:

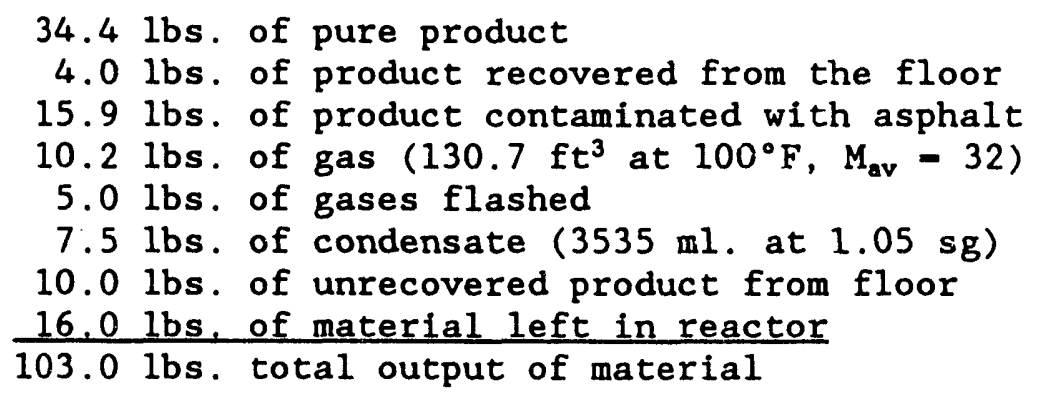

A total of $16 \mathrm{lbs}$. were unaccounted for which is about $15 \%$ deviation.

\section{D1.3.2 Material balances for steady state period}

Analyzing the operational conditions of the run one can see that for a period of four hours between 2:00 p.m. and 6:00 p.m. a good steady state was achieved. Therefore, a material balance over that period of time was made. The data for input and output were as follows: 


\section{Input Material}

$\begin{array}{lr}\text { Feecistock } & 47.0 \mathrm{lb} . \\ \mathrm{CO} \text { supplied } & 4.0 \mathrm{lb} . \\ \mathrm{H}_{2} \mathrm{O} & 0.3 \mathrm{lb} \\ \text { Total } & 51.3 \mathrm{lb} .\end{array}$

\section{Qutput Material}

\begin{tabular}{lrl} 
Liquid product & $23.0 \mathrm{lb}$. \\
Condensates & $7.2 \mathrm{lb}$. \\
Gases released & $10.2 \mathrm{lb}$. \\
Gases flashed & $3.6 \mathrm{lb}$. \\
\hline Total & $42.4 \mathrm{lb}$.
\end{tabular}

The gases released refer to the gases that were measured by the flow meter after the condenser. The gases flashed refer to the gases released during the liquid product released from the let-down vessel. The gases flashed were calculated using the equation of state of gases. The pressure difference in the pressure let-down vessel before and after the product was collected was assumed to be $100 \mathrm{psi}$. The volume of the pressure let-down vessel is $0.27 \mathrm{ft}^{3}$ and the temperature of the gas condensed was $1,000^{\circ} \mathrm{R}$. The calculation was also based on 6 let-downs per hour; thus having flashed the amount of $0.9 \mathrm{lb} / \mathrm{hr}$. An average molecular weight for the gas was assumed the same as the gas obtained in the outlet stream, which was found by gas chromatographic antalysis to be 36 . The balance was close to an accuracy of $14 \%$, which for the most part can be attributed to losses. This is compared to the $15 \%$ obtained from a total material balance.

\section{D1.4 Analytical Data}

The heating value of the same sample was found to be $16,150 \mathrm{BTU} / \mathrm{lb}$.

Vacuum distillation of the product of Run M1 produced $16 \mathrm{wt} \%$ of distillate at operating conditions of $2-3 \mathrm{mmHg}$ absolute pressure and $500^{\circ} \mathrm{F}$.

The elemental analysis for the crude let-down product was as follows:

$$
\begin{array}{lcccc}
\text { Wt. } 8 \mathrm{C} & \text { Wt. } 8 \mathrm{H} & \text { Wt. } 8 \mathrm{~N} & \text { Wt.8O } & \text { Wt.8 Ash } \\
81.60 & 6.25 & 0.12 & 9.44 & 3.94
\end{array}
$$

Elemental analysis of the distillate of the product of Run M1 gave the following results:

$$
\begin{array}{lccc}
\text { Wt. } 8 \mathrm{C} & \text { Wt. } 8 \mathrm{H} & \text { Wt.80 } & \text { Wt. } 8 \mathrm{~N} \\
82.00 & 8.97 & 7.77 & 0.18
\end{array}
$$

Two samples of the off-gas were analysis by the Gas Chromatograph and the results are given in Table D1.4. 
The average molecular weight of the two samples A and B were calculated to be 31.9 and 31.8 respectively.

More details about this experiment are found in the May-July 1987 Quarterly report. 


\section{D2.0 EXPERIMENTAL RUN M2}

\section{D2.1 General Description of the Experimental Run}

Experimental Run M2 was performed on July 17, 1987. Srme 100 pounds of feedstock of 50:50 WF to TR-9 wt. ratio were processed. Complete process data were recorded by computer acquisition, and certain key data are given here in Tables D2.1 through D2.3 and Figures D2.1 through D2.3.

Operational conditions were as follows: (1) Piessure, staged with lime at 500, 700, and $1,000 \mathrm{psi}$, (2) Feed rate, $15 \mathrm{lb} / \mathrm{hr}$, (3) Feedstock, $100 \mathrm{lbs}$. of 50/50 wt. ratio of WF and TR-9, followed by $15 \mathrm{lbs}$. of a mixture of asphalt and WF at a wt. ratio of 80:20 asphalt to WF, (4) Feed, CO, $1 \mathrm{lb} / \mathrm{hr}$, (5) Feed water $1 / 3 \mathrm{lb} / \mathrm{lb}$ of WF, and (6) pressure let-down of product without dropping the pressure in the reactor. Temperatures were held at about $370^{\circ} \mathrm{C}$ in the lower reactor and about $420^{\circ} \mathrm{C}$ in the upper reactor as shown in Taije D2.1.

Feeding began at 9:04 a.m. along with $\mathrm{CO}$ and water and continued without any problems until 5:30 p.m. Water was injected every 5 minutes. Product began coming out of the pressure let-down vessel at 11:07 a.m. The run lasted approximately $7 \mathrm{hrs}$. Liquid pressure let-downs and condensate products were taken every 10 minutes.

The feed rate was maintained at $15 \mathrm{lb} / \mathrm{hr}$. Feedstock fed as a function of time of the day was quite constant as shown in Figure D2.1. Mcre details on feeding and output data are as follows: Feed in data: $100 \mathrm{lb}$. of 50/50 Wt. \% wood flour - TR-9, $17 \mathrm{lb}$. asphalt, $11.7 \mathrm{lb} . \mathrm{H}_{2} \mathrm{O}$, and $7.0 \mathrm{lb}$. CO. Output data: $295.9 \mathrm{ft}^{3}$ of gas,(accounting ior $0.73 \mathrm{lb} . \mathrm{H}_{2} \mathrm{O}$ ), 5,909 ml. of $\mathrm{H}_{2} \mathrm{O}$ $\left(13 \mathrm{lb} . \mathrm{H}_{2} \mathrm{O}\right), 4,571 \mathrm{ml}$. oil, $56.9 \mathrm{lb}$. let-down product and $82 \mathrm{lbs}$. of product containing asphalt. Product collection was started at 11:15 a.m. Details about the CO supply conditions are given in Table D2.2. A detailed profile of the accumulation of condensate and its composition is given in Table D2.3.

\section{D2.2 Temperatures and Pressures during the Run}

Pressures were successfully controlled at $500 \mathrm{psi}, 700 \mathrm{psi}$ and 1,000 psi, at various stages of the run. The operations were made at these lower press 'res, since $\mathrm{CO}$ was being fed from cylinders that had various pressures of gas with a inaximum pressure of about 1,800 psi. All temperature controllers were working and the operating temperatures were set as follows: Extruder-feeder: $175^{\circ} \mathrm{C}$, Lower Rerctor: $370^{\circ} \mathrm{C}$, Upper Reactor: $420^{\circ} \mathrm{C}$, Let-down Vessel: $230^{\circ} \mathrm{C}$. Detailed data on the temperatures as controlled during the experiment are given in Table D2.1. A diagrammatic representation of the controlled temperature data for the extruder-feeder, 
lower and upper reactor and for the pressure let-down vessel is given in Figure D2.1. Similarly, the temperatures at the top flange (reactor outlet) and the middle steel spool (between the lower and upper reactor sections) are shown in Figure D2.3.

\section{D2.3 Material Balance for Steady State of Run M2}

The material balances in this experimental run were calculated on the overall basis and for a period of time with steady state operational conditions.

\section{D2.3.1 Overall Material Balance}

The materials fed into the reactor during the whole run between 9:07 a.m. and 5:30 p.m. (between 4:10 and 5:30 an asphalt mixture was fed) were:

$$
\begin{aligned}
& 100.0 \text { lbs. of feedstock } \\
& 17.0 \text { lbs. of asphalt mixture } \\
& 11.7 \text { lbs. of water } \\
& 7.0 \text { lbs. of carbon monoxide } \\
& \hline 135.7 \text { lbs. total input of material }
\end{aligned}
$$

The material leaving the system was:

$$
\begin{aligned}
& 56.9 \text { lbs. of pure product } \\
& 8.2 \text { lbs. of product contaminated with asphalt } \\
& 23.9 \text { lbs. of gas }\left(295.9 \mathrm{ft}^{3} \text { at } 100^{\circ} \mathrm{F}, \mathrm{M}_{\mathrm{av}}=32\right) \\
& 5.0 \text { lbs. of gases flashed } \\
& 24.2 \text { lbs. of condensate }(10480 \mathrm{ml} \text { at } 1.05 \mathrm{sp} \text {. } \mathrm{gr} .) \\
& \hline 117.5 \text { lbs. total output of material }
\end{aligned}
$$

Note that the material left in the reactor at the end of the run was not included in the total output since we started with a full reactor. A total of $18.2 \mathrm{lbs}$. are unaccounted, representing $13 \%$ of the material.

\section{D2.3.2 Material balance for steady state period}

For experimental Run M2, good steady state conditions occurred between 1:00 p.m. and 4:00 p.m. for a period of three hours. The material balance during this period of time is as follows:

\section{Input Material}

$\begin{array}{lr}\text { Feedstock } & 46.0 \mathrm{lbs} . \\ \text { CO supplied } & 3.0 \mathrm{lbs} . \\ \mathrm{H}_{2} \mathrm{O} & 5.0 \mathrm{lbs} . \\ \text { Total } & 54.0 \mathrm{lbs} .\end{array}$




\section{Qutput Material}

\begin{tabular}{lr} 
Liquid Product & $32.0 \mathrm{lbs}$. \\
Condensates & $7.3 \mathrm{lbs}$. \\
Gases released & $7.0 \mathrm{lbs}$. \\
Gases flashed & $2.7 \mathrm{lbs}$ \\
\hline Total & $49.0 \mathrm{lbs}$.
\end{tabular}

The material balance at the steady state condition closed to $9 \%$ compared to $13 \%$ of the overall material balance.

\section{D2.4 Analytical Data}

Elemental analysis of the distillate of the product of Run M2 gave the following results:

$$
\begin{array}{lccc}
\text { Wt.8 } & \frac{W t .8 \mathrm{H}_{2}}{W t .8 \mathrm{O}_{2}} & \text { Wt } / 8 \mathrm{~N}_{2} \\
82.91 & 8.76 & 6.74 & 0.35
\end{array}
$$

The heating value of the same sample was found to be $16250 \mathrm{BTU} / 16$.

The feedstock of Run M2 was checked for insolubles by THF and it was found to be 51 wt. \%. This unusually high THF insolubles may have been due to the high reactor temperature, long residence time and reactor channeling of the carbon monoxide. Vacuum distillation of the let-down product produced $28 \mathrm{wt} \%$ at $2-3 \mathrm{mmHg}$ and $500^{\circ} \mathrm{F}$.

Elemental analysis of the let-down product gave:

$\begin{array}{lcccc}\text { Wt.8C } & \text { Wt.8H } & \text { Wt. } 80 & \text { Wt.8N } & \text { Ash } \\ 81.96 & 6.74 & 8.84 & 0.17 & 3.96\end{array}$

The elemental analysis of the distillate was:

$\begin{array}{lrrr}\text { Wt. } 8 \mathrm{C} & \text { Wt. } 8 \mathrm{H} & \text { Wt.8 } & \text { Wt. } 8 \mathrm{~N} \\ 82.91 & 8.76 & 6.74 & 0.35\end{array}$

More details on this experiment are found in the August-July 1987 Quarterly report. 


\section{D3.0 EXPERIMENTAL RUN M3}

\section{D3.1 General Description of the Experimental Run}

Experimental Run M3 was conducted on July 23, 1987 and ran approximately $4 \mathrm{hrs}$. Some 61 pounds of feedstock of 50:50 WF to TR-9 wt. ratio were processed. Complete process data were recorded by computer acquisition, and certain key data are given here in Tables D3.1 through D3.3 and Figure D3.1.

Experimental Run M3 was planned to have the same operating conditions as the M1 and M2 runs, these being: (1) Feedstock, 50/50 wt. ratio WF to TR-9, (2) Feed rate of 15-20 $\mathrm{lb} / \mathrm{hr}$., (3) a total of $60 \mathrm{lbs}$. of feedstock followed by an asphalt/wood flour purge, (4) Feed CO at a rate of $1 \mathrm{lb} / \mathrm{hr}$., (5) Feed $\mathrm{H}_{2} \mathrm{O}$ (6) pressure let-down the liquid product while maintaining the pressure in the reactor.

The feedstock composed of a 50:50 wt. ratio mixture of Albany TR-9 crude wood oil and WF treated with sodium carbonate was fed into the experimental extruder-feeder-reactor at an average feed temperature of $133^{\circ} \mathrm{C}$. A mixture of asphalt and WF of a 70:30 wt. ratio was used to purge the system at the end of the run to replace the feedstock which had been in the reactor. For this run, a total of $60.6 \mathrm{lbs}$. of feedstock were fed, followed by $16.8 \mathrm{lbs}$. of asphalt/WF. The average temperature of the feed was kept around $-7^{\circ} \mathrm{C}$ since at this temperature, Albany TR-9 crude wood (i! is a brittle solid. It could be easily crushed for feed preparation and fed to the extruder-feeder with no sticking problems. A feed profile for this run is given in Figure D3.1. Pressure let-downs for liquid product were conducted every 10 minutes. Water was injected every 5 minutes. The carbon monoxide was fed from cylinders and the details in the feeding conditions of this gas are given in Table D3.2. The off-gas valve was open most of the time during the experiment and a total of $138 \mathrm{ft}^{3}$ of gas were measured by the flow meter. The condensate from these gases was a total of $5,236 \mathrm{ml}$. of a mixture of water and oil. Details on these mixtures are given in Table D3.3 for cil and water separately. Some more details on the feeding and outlet data are as follows: Feed in data: $60.6 \mathrm{lb}$. 50/50 wt. ratio of WF and TR-9, $6.2 \mathrm{lb}$. of $\mathrm{H}_{2} \mathrm{O}, 3.1 \mathrm{lb}$. of CO, $16.8 \mathrm{lb}$. of asphalt; WF of 70:30 wt. ratio; Output data: $138 \mathrm{ft}^{3}$ of gas, $3,957 \mathrm{ml}$. $\mathrm{H}_{2} \mathrm{O}\left(8.5 \mathrm{lb} . \mathrm{H}_{2} \mathrm{O}\right) ; 1,279 \mathrm{ml}$. of oil, $33.8 \mathrm{lb}$. of product, $5.8 \mathrm{lb}$. of product and asphalt.

This experiment ran smoothly with a feed rate close to $18 \mathrm{lb} / \mathrm{hr}$. The pressures were kept between 500 and 700 psi during this run and temperatures were $350^{\circ} \mathrm{C}$ and $400^{\circ} \mathrm{C}$ in the lower reactor and upper reactor sections, respectively.

\section{D3.2 Temperature and Pressure Data}

Temperature and pressure data for the reactor, extruder-feeder and pressure let-down vessel were recorded with readings taken every 15 minutes. Temperature ranges for important points in the system are as follows: The extruder-feeder feed point varied from $76^{\circ} \mathrm{C}$ to $135^{\circ} \mathrm{C}$ (with intermittent extra cooling) with an average temperature of $112^{\circ} \mathrm{C}$. Temperature range at the extruder-feeder exit was $147^{\circ} \mathrm{C}$ to $214^{\circ} \mathrm{C}$. The extruder-feeder controller was heating the 
unit but was not controlling the temperature, so that it was necessary to control manually for the remainder of the run. The average extruder-feeder outlet temperature was $168^{\circ} \mathrm{C}$. The temperature range at the cross varied from $189^{\circ} \mathrm{C}$ to $290^{\circ} \mathrm{C}$ with an average temperature of $269^{\circ} \mathrm{C}$. At the reactor pressure let-down line the temperature range was from $309^{\circ} \mathrm{C}$ to $348^{\circ} \mathrm{C}$. The pressure let-down valve temperatures varied from $87^{\circ} \mathrm{C}$ to $321^{\circ} \mathrm{C}$ with an average running temperature of $296^{\circ} \mathrm{C}$.

Pressures were purposely controlled at lower levels in order to feed $\mathrm{CO}$ from cylinders on a batch basis. Highest pressure at the extruder-feeder outlet cross was 700 psig. The average pressure while running was 650 psig. Highest pressure at the let-down was 600 psig. The average let-down pressure was 490 psig. The temperatures at various locations on the system are given in Table D3.1.

\section{D3.3 Material Balance Status}

The material balances in this experimental run were made on an overall basis and for a period of steady operational conditions.

\section{D3.3.1 Overall Material Balance}

The materials fed into the reactor between 2:02 p.m. and 5:21 p.m. were:

$$
\begin{aligned}
& 60.6 \text { lbs. of feedstock } \\
& 16.8 \text { lbs. of asphalt mixture } \\
& 6.2 \text { lbs. of water } \\
& 3.1 \text { lbs. of carbon monoxide } \\
& \hline 86.7 \text { lbs. total input of material }
\end{aligned}
$$

The material leaving the system were:

$$
\begin{aligned}
& 33.8 \text { lbs. of pure product } \\
& 5.8 \text { lbs. of product contaminated with asphalt } \\
& 10.1 \text { lbs. of gas }\left(138 \mathrm{ft}^{3} \text { at } 100^{\circ} \mathrm{F}, 32 \mathrm{Mav}-32\right) \\
& 2.7 \text { lbs. of gases flashed } \\
& 12.1 \text { lbs. of condensate }(5236 \mathrm{ml} \text {. at } 1.05 \mathrm{sg}) \\
& \frac{16.0 \text { lbs. of material left in the reactor }}{80.5 \text { lbs. total output of material }}
\end{aligned}
$$

A total of 6.2 lbs. are unaccounted for which is $7 \%$ losses of material.

\section{D3.3.2 Material balance for steady state period}

For experimental Run M3 a good steady state occurred for a period of two hours between 3:00 p.m. and 5:00 p.m. The material balance during this period of time is as follows: 


\section{Input Material}

$\begin{array}{lr}\text { Feedstock supply } & 38.7 \text { lbs } \\ \text { CO supplied } & 2.1 \text { lbs } \\ \mathrm{H}_{2} \mathrm{O} \text { added } & 3.0 \text { lbs } \\ \text { Total } & 43.8 \mathrm{lbs} .\end{array}$

\section{Qutput Material}

\begin{tabular}{lrl} 
Liquid product & 32.0 lbs. \\
Condensates & 6.5 lbs. \\
Gases released & 5.0 lbs. \\
Gases flashed & 1.8 lbs. \\
\hline Total & 43.3 lbs.
\end{tabular}

The material balance for the steady state condition closed to $1 \%$ compared with $7 \%$ closure obtained with the overall material balance.

\section{D3.4 Analytical Data}

Elemental analysis of the distillate of the product of Run M3 gave the following results:

$$
\begin{array}{cccc}
\frac{W t .8 \mathrm{C}}{W t .8 \mathrm{H}_{2}} & \frac{\mathrm{Wt} .8 \mathrm{O}_{2}}{\mathrm{Wt} .8 \mathrm{~N}_{2}} \\
82.10 & 8.87 & 6.47 & 0.11
\end{array}
$$

The heating value of the same sample was found to be $16,160 \mathrm{BTU} / \mathrm{lb}$.

Vacuum distillation of the pressure let-down liquid product gave $22 \mathrm{wt} . \%$ of distillate. More details about this experiment are found in the May-Iuly 1987 Quarterly Report. 


\section{D4.0 EXPERIMENTAL RUN N1}

\section{D4.1 General Description of the Experimental Run}

Experimental Run N1 was made on August 20th, 1987. Some 190 pounds of feedstock were processed. Complete process data were recorded by computer acquisition, and certain key data are given here in Tables D4.1 and D4.2, and Figures D4.1 through D4.5.

New feedstock material was prepared using virgin Albany TR-9 oil and WF. This new feedstock was a mixture of 60/40 wt. ratio of Albany TR-9 oil to WF (WF on a dry basis). The pressures on these runs were between $500-1,000$ psi. No steam $\left(\mathrm{H}_{2} \mathrm{O}\right)$ was fed, as it was assumed that the water in the wood flour itself would be enough for the water gas shift reaction to take place. $\mathrm{CO}$ was fed at rates in the range of $0.5-1.0 \mathrm{lbs} / \mathrm{hr}$. As usual Gas $\left(\mathrm{N}_{2}\right)$ was purged through the system before the start of the experiment and also at the end of it, so as to insure that all the overhead and reactor let-down lines were clear.

Liquid product pressure let-downs and condensate samples were taken every 20 minutes and 10 minutes, respectively. The wood flour used in this run was pretreated with water and $\mathrm{Na}_{2} \mathrm{CO}_{3}$, was heated in an oven for overnight at $60^{\circ} \mathrm{C}$ and was then partially dried in the sun. For this run most of the dried WF had 21 wt. \% moisture and a small amount of WF had 25 wt. \% moisture.

A feed rate of $20 \mathrm{lbs} . / \mathrm{hr}$. was plarned and indeed was maintained throughout the nine hour run. The cumulative feed as a function of time for Run N1 is shown in Figure D4.1. A total of 190 lbs. of feedstock was fed.

Carbon monoxide was fed continuously into the system, totaling $10.1 \mathrm{lbs}$ over nine hours. For the calculation of the amount of $\mathrm{CO}$ by the equation of state, a value of $\mathrm{z}$ (compressibility factor) of 1.1 was used as compared to the higher value of 1.2 used in previous run calculations. This change in value of $z$ is a compromise between the previous value and the different values one obtains by different methods of calculations, such as using virial equations or the generalized diagram for compressibility factor. The flow rates of $\mathrm{CO}$ as a function of time of day are given in Figure D4.2.

The products obtained were as follows: liquid product from the pressure let-down vessel: $99.4 \mathrm{lbs}$; ; water condensate: $26.3 \mathrm{lbs}$.; secondary water condensed from the off-gas: $0.8 \mathrm{lbs}$; oil condensate: $16.2 \mathrm{lbs}$; ; and off-gases in the amount of $355.5 \mathrm{ft}^{3}$ at atmospheric pressure. Product collection from the pressure let-down vessel started at 10:20 a.m. The condensate of oil and water as a function of time are given in Figure D4.5.

\section{D4.2 Temperature and Pressure Data}

The operational temperatures and pressures for Run N1 were lower than in previous runs. The lower temperatures were in order to avoid possible coking problems and the lower pressures were because of some leaks that developed above 1,000 psi. For Run N1, the lower and upper 
reactor temperatures were set at $320^{\circ} \mathrm{C}$ and $340^{\circ} \mathrm{C}$, respectively as opposed to the $375^{\circ} \mathrm{C}$ $400^{\circ} \mathrm{C}$ that was used before. The pressure let-down vessel temperature was about $200^{\circ} \mathrm{C}$. The extruder-feeder temperature (at the outlet) was initially set to $150^{\circ} \mathrm{C}$ but was constantly reduced to avoid feeding problems and was finally held below $95^{\circ} \mathrm{C}$ to insure proper feeding. The temperature of the material in the reactor was $320^{\circ} \mathrm{C}$ at the middle spool and $340^{\circ} \mathrm{C}$ at the reactor exit.

Also monitored during this run was the change in pressure during a liquid product pressure let-down. This process involved closing the off-gas control valve, recording the pressure, opening the liquid let-down valve, closing the liquid let-down valve when all the material had been collected, recording the pressure, and finally returning the off-gas control valve to its controlling mode. The let-down vessel pressure dropped about 100 psi on the average, but yery quickly returned to the desired, controlled pressure. Initial running conditions were to be at a pressure of $1,000 \mathrm{psi}$, but after reaching this pressure, a leak developed at the top flange and, the pressure was decreased to around 500 psi. The temperatures at various location on the system are given in table D4.1 and are shown diagrammatically in Figure D4.3. A graph of the melt temperatures for the middle spool and the upper reactor is given in Figure D4.4.

\section{D4.3 Analytical Data}

The liquid product from the pressure let-down vessel for Run N1 was analyzed by solvent extraction with THF and two samples showed a solid residue of $22.2 \mathrm{wt} . \%$ and $21.0 \mathrm{wt}$.\% thus an average solid content of $21.6 \mathrm{wt} . \%$. It should be noted that Albany TR-9 oil had insoluble solids in the range of 5-7 wt.\%. There may have been incomplete conversion of the phenolic lignin fraction of the wood at these much lower reactor temperatures. The moisture content of this liquid product was found to be $2.4 \mathrm{wt} . \%$ when analyzed by the Karl-Fisher method.

The gas composition of the off-gas samples taken at various times during the experimental run was obtained by the gas chromatographic analysis and the results are summarized in Table D4.2. It should be noted that very little air was allowed during sampling for the first four samples, but air was found in the last four samples due to the inexperience of a different student taking these samples.

A density test made by the picnometric method showed a density for the condensate of $0.97 \mathrm{~g} / \mathrm{cm}^{3}$.

Elemental analysis for the reactor product was:

$$
\begin{array}{lrrrr}
\text { Wt. } 8 \mathrm{C} & \text { Wt. } 8 \mathrm{H} & \text { Wt. } 80 & \text { Wt. } 8 \mathrm{~N} & \text { Wt. } 8 \text { Ash } \\
81.81 & 6.98 & 9.46 & 0.06 & 2.35
\end{array}
$$

The heating value obtained by a Paar 1391 plain pocket bomb colorimeter for the reactor product was $15,700 \mathrm{BTU} / \mathrm{lb}$. More details on this experimental run are found in the AugustOctober 1987 Quarterly Report. 


\section{D5.0 EXPERIMENTAL RUN N2}

\section{D5.1 General Description of the Experimental Run}

Experimental Run N2 was made on August 21, 1987. Some 130 pounds of feedstock were processed. Complete process data were recorded by computer acquisition, and certain key data are given here in Tables D5.1 through D5.3 and Figures D5.1 through D5.6.

This run was a continuation of Run N1 with one slight difference, having a higher moisture content of the WF in the feedstock. It was about $32 \mathrm{wt} . \%$ moisture compared with about $21 \mathrm{wt}$.\% in Run N1. This higher moisture content appeared to affect the operability with respect to the feed rate which was lower than that of Run N1 averaging $16 \mathrm{lbs} / \mathrm{hr}$ compared with $20 \mathrm{lb} / \mathrm{hr}$ in Run N1. A total of $130 \mathrm{lbs}$. were fed and the cumulative feed as a function of time is shown in Figure D5.1. A solvent extraction analysis with THF made on this feedstock gave a solids content of $41.5 \mathrm{wt} . \%$.

No water was added to this run as was the case with Run N1, while CO was added continuously to the system with a total supply of $8.5 \mathrm{lbs}$. The flow rates of $\mathrm{CO}$ as a function of time are given in Figure D5.2 and the pressures in the cylinder as a function of time for the three cylinders used are given in Figure D5.3.

The product obtained are as follows: Liquid product from the let-down vessel: $72.6 \mathrm{lbs}$; water condensate: $13.5 \mathrm{lbs}$.; secondary water condensate from the off-gas: $0.6 \mathrm{lbs}$.; oil condensate: $6.8 \mathrm{lbs}$.; and off-gases in the amount of $260.5 \mathrm{ft}^{3}$.

\section{D5.2 Temperature and Pressure}

The operational data for Run N2 were basically the same as for Run N1. Run N2 was a continuation of Run $\mathrm{N} 1$ and was made one day apart. In fact, the reactor at start-up was full with material left after Run N1 was voluntarily terminated and no problems were encountered at restarting the unit. As soon as temperatures were at operational conditions the feeding was started and the run was smooth and uneventful for the whole day.

The controller temperatures at various locations of the system are given in Table D5.1. A diagrammatic representation of the controlled temperature as a function of time of day is given in Figure D5.4 and a diagram of the temperatures in the reactor mid-spool and top of reactor as a function of time of day is given in Figure D5.5. A graph of the reactor and pressure let-down vessel pressures vs. time of day is given in Figure D5.6 and the change in pressures when liquid product let-downs were taken is given in Table D5.2.

\section{D5.3 Analytical Data}

The liquid product from the pressure let-down vessel for Run $\mathbf{N} 2$ was analyzed by solvent extraction with THF and two samples showed a solid residue of $25.8 \mathrm{wt} . \%$ and $30.0 \mathrm{wt} . \%$, thus an average solid content of $27.8 \mathrm{wt} . \%$. It is believed that these insolubles came from the long 
residence times encountered by the recycled TR-9 wood oil. The moisture content of this liquid product measured by the Karl Fisher method was found to be $2.3 \mathrm{wt}$.\%. The gas computation of the off-gas samples taken during the run were analyzed by the gas chromatograph and the results are summarized in Table D5.3.

The elemental analysis for the reactor product was:

$\begin{array}{llll}\text { Wt. } 8 \mathrm{C} & \text { Wt. } 8 \mathrm{H} & \text { Wt. } 80 & \text { Wt. } 8 \mathrm{~N} \\ 80.40 & 6.88 & 11.13 & 11.13\end{array}$

The elemental analysis for a distillate from a mixture of product of Run N1 and N2 was:

$\begin{array}{lccc}W t .8 C & \frac{W t .8 \mathrm{H}}{W t .80} & \frac{W t .8 \mathrm{~N}}{80.79} \\ 8.89 & 8.49 & 0.17\end{array}$

The heating value of the reactor product was $15,250 \mathrm{BTU} / \mathrm{lb}$ and the heating value of the distillate of a mixture of product from Run N1 and N2 was found to be 15,957 BTU/lb. More details on this experimental run are found in the August-October 1987 Quarterly Report. 


\section{D6.0 EXPERIMENTAL RUN O1}

\section{D6.1 General Description of the Experimental Run}

Experimental Run O1 was made on September 10, 1987. Some 148 pounds of feedstock were processed. Complete process data were recorded by computer acquisition and certain key data are given here in Table D6.1 through D6.3 and Figures D6.1 through D6.3.

This was the first attempt to use the recycle from the Runs N1 and N2 as the wood flour carrier. Temperatures were purposely held on the low side at about $320^{\circ} \mathrm{C}$.

\section{D6.1.1 Preparation of Feedstock with Product Recycle}

The product of Runs N1 and N2 were crushed, analyzed and prepared to be used as the carrier for the wood flour in the next (second) cycle Run O1. A total amount of $170 \mathrm{lbs}$. of crushed product was then mixed with 80 lbs. of pretreated WF with water (but not with $\mathrm{Na}_{2} \mathrm{CO}_{3}$ ). It was assumed that the original sodium carbonate would still be active, regardless of what form it might be (probably some as acetate). This amount of $250 \mathrm{lbs}$. of feedstock was used for the second cycle in this attempt to make an All-Arizona oil. The product from Runs $\mathrm{N} 1$ and N2 had about $25 \mathrm{wt}$.\% solids and the WF was added so as to maintain about $40 \mathrm{wt}$.\% of solids as in the case in the first cycle. The WF had $27 \mathrm{wt} . \%$ moisture and the added WF was on a dry basis. A total of $148 \mathrm{lbs}$. of this mixture was fed at an average rate of $15 \mathrm{lbs}$. $/ \mathrm{hr}$. The product accumulated during the run was $122.1 \mathrm{lbs}$., the condensate was $8.6 \mathrm{lbs}$. and the off-gas was $155.4 \mathrm{ft}^{3}$ at atmospheric pressure.

\section{D6.1.2 Temperature and Pressure Data}

As in previous runs, the extruder-feeder temperatures were closely monitored and kept below $95^{\circ} \mathrm{C}$ during normal feeding conditions.

The temperatures at various locations of the experimental unit are given in Table D6.1. A graphical presentation of the controllers temperatures and in the melt at the mid-spool and top flange of the reactor are given in Figures D6.1 and D6.2 respectively. It should be noted that both reactor sections were held very closely to the same temperature, namely, $320^{\circ} \mathrm{C}$. The pressures in the pressure let-down vessel before and after the liquid let-down products were taken are given in Table D6.2.

\section{D6.1.3 CO Supply}

A constant $C O$ flow rate was maintained from 4:10 p.m. to 7:05 p.m. when the $\mathrm{CO}$ was shut off to change cylinders. A quite constant flow rate of CO was maintained being $1.47 \mathrm{ft}^{3} / \mathrm{hr}$. The flow rates of $\mathrm{CO}$ as a function of time of day are given in Figure D6.3. The total amount of $\mathrm{CO}$ fed during the experiment was $3.68 \mathrm{lbs}$. 


\section{D6.2 Analytical Results}

The reactor feedstock from the Run $\mathrm{Ol}$ was measured for the percentage of solids using THF as a solvent. It was found that the insolubles were in the feedstock, $28.4 \mathrm{wt} . \%$, again believed due to excessive recyciing conditions. The elemental analysis for the liquid distillate of the let-down product were:

$\begin{array}{llll}W t .8 C & W t .8 H & \text { Wt. } 80 & \text { Wt. } 8 \mathrm{~N} \\ 78.83 & 6.81 & 11.42 & 0.29\end{array}$

Heating values for the pressure let-down product were $19,509 \mathrm{BTU} / \mathrm{lb}$. However, this analytical result is probably high and no duplicate sample was available for further testing. Analytical results of samples taken from the off-gas of this experiment and analyzed by a gas chromatograph are given in Table D6.3.

Table D6.3

Gas Chromatographic Analysis Data for the Off-gas of Experimental Run O1, Vol. \%

\begin{tabular}{lllrlllll} 
Time & $\mathrm{H}_{2}$ & $\mathrm{O}_{2}$ & \multicolumn{1}{c}{$\mathrm{N}_{2}$} & $\mathrm{CH}_{4}$ & $\mathrm{CO}$ & $\mathrm{CO}_{2}$ & $\mathrm{C}_{2} \mathrm{H}_{2}$ & $\mathrm{C}_{2} \mathrm{H}_{4}$ \\
$2: 40 \mathrm{pm}$ & 4.16 & 2.93 & 10.86 & 0.69 & 30.67 & 50.34 & 0.03 & 0.31 \\
$4: 20$ & 5.66 & 1.34 & 4.96 & 0.53 & 50.00 & 37.21 & 0.02 & 0.19 \\
$7: 04$ & 7.14 & 0.69 & 2.49 & 0.85 & 61.11 & 27.39 & 0.03 & 0.32
\end{tabular}

More details on this experimental run are found in the August-October 1987 Quarterly Report. 


\section{D7.0 EXPERIMENTAL RUN 02}

\section{D7.1 General Description of the Experimental Run}

Experimental Run $O 2$ was made on September 11th, 1987. Some 83 pounds of feedstock were processed. Complete process data were recorded by computer acquisition, and certain key data are given here in Tables D7.1 throughd D7.3 and Figures D7.1 through D7.3.

The purpose of this run was to continue Run $\mathrm{O} 1$ and use all the feedstock with the first recycle material as the carrier and also to check some additional parameters of operating conditions. No start-up problems occurred and when all of the feedstock was used up the run was terminated. A total of $83 \mathrm{lbs}$. was fed at an average rate of $15.1 \mathrm{lbs} . / \mathrm{hr}$.

The product collection started around 10:00 a.m. and we obtained from the pressure letdown vessel $69.7 \mathrm{lbs}$., the condensate was $1.95 \mathrm{lbs}$. and the off-gas was $52.9 \mathrm{ft}^{3}$ at atmospheric pressure.

\section{D7.2 Temperature and Pressure Data}

Experimental Run $\mathrm{O} 2$ was a continuation of the Run $\mathrm{O} 1$ of the previous day of September the 10th. The reactor heaters were turned off at 8:20 p.m. on September 10, 1987 and turned back on at 7:00 a.m. on September 11, 1987. The temperatures cooled down during the night as follows:

\begin{tabular}{|c|c|c|c|c|}
\hline & $\begin{array}{l}\text { Extruder } \\
\text { Feeder }\end{array}$ & $\begin{array}{l}\text { Upper } \\
\text { Reactor }\end{array}$ & $\begin{array}{l}\text { Lower } \\
\text { Reactor }\end{array}$ & $\begin{array}{l}\text { Let-down } \\
\text { Vessel } \\
\end{array}$ \\
\hline $\begin{array}{l}: 20 \text { p.m., } 9 / 10 / 87 \\
: 00 \text { a.m., } 9 / 11 / 87\end{array}$ & $\begin{array}{r}124^{\circ} \mathrm{C} \\
31^{\circ} \mathrm{C}\end{array}$ & $\begin{array}{l}335^{\circ} \mathrm{C} \\
242^{\circ} \mathrm{C}\end{array}$ & $\begin{array}{l}313^{\circ} \mathrm{C} \\
115^{\circ} \mathrm{C}\end{array}$ & $\begin{array}{r}201^{\circ} \mathrm{C} \\
75^{\circ} \mathrm{C}\end{array}$ \\
\hline
\end{tabular}

The heating next morning on November 11 , proceeded smoothly and operating temperatures were reached at 9:30 a.m. Feeding started at 9:47 a.m. and the feedstock was the same as that for Run 01 . The extruder-feeder temperature was kept below $95^{\circ} \mathrm{C}$.

The temperatures at various locations of the experimental unit are given in Table D7.1. A graphical presentation of the controller temperature and in the melt at the mid-spool and top flange of reactor are given in Figures D7.2 and D7.3 respectively. Excellent control of the reactor temperature (both lower and upper sections) at $340^{\circ} \mathrm{C}$ was achieved at steady state operations for the last five hours of the run. The pressures in the pressure let-down vessel before and after the liquid let-down product were taken, are given in Table D7.2.

\section{D7.3 Co Supply}

The total amount of CO supplied was 1.03 lbs over the first three hours of the run. The flow rates as a function of time of day are given on Figures D7.3. No carbon monoxide was utilized during the last two hours of the run. 


\section{D7.4 Analytical Results}

The reactor feedstock for Run $\mathrm{O} 2$ was tested for solubility in THF and was found to have some $29 \mathrm{wt}$. \% insolubles. Tine heating value for the let-down product was found to be 14,770 BTU/lb.

The elemental analysis for the distillate from the let-down product was:

$\begin{array}{llrl}W t .8 \mathrm{C} & \text { Wt.8H } & \text { Wt. } 80 & \text { Wt. } 8 \mathrm{~N} \\ 80.67 & 0.56 & 12.52 & 0.28\end{array}$

Analytical results of samples taken from the off-gases and analyzed by a gas chromatograph are given in Table D7.3.

\section{Table D7.3}

Gas Chromatographic Analysis Data for the Off-Gas of Experimental Run O2, Vol. \%

\begin{tabular}{|c|c|c|c|c|c|c|c|c|}
\hline Time & $\mathrm{H}_{2}$ & $\mathrm{O}_{2}$ & $\mathrm{~N}_{2}$ & $\mathrm{CH}_{4}$ & CO & $\mathrm{CO}_{2}$ & $\mathrm{C}_{2} \mathrm{H}_{2}$ & $\mathrm{C}_{2} \mathrm{H}_{4}$ \\
\hline $11: 35$ & 5.21 & 18.80 & 54.05 & 0.68 & 14.28 & 6.89 & 0.08 & 0.00 \\
\hline $12: 50$ & 1.41 & 21.76 & 54.17 & 0.27 & 17.04 & 0.32 & 0.003 & 0.00 \\
\hline $1: 10$ & 1.91 & 19.19 & 61.16 & 0.38 & 16.16 & 1.17 & 0.022 & 0.00 \\
\hline $2: 35$ & 7.76 & 20.93 & 49.20 & 1.57 & 12.78 & 7.59 & 0.013 & 0.16 \\
\hline
\end{tabular}

More details on this experiment run are found in the August-October 1987 Quarterly Report. 


\section{D8.0 EXPERIMENTAL RUN P1}

\section{D8.1 General Description of the Experimental Run}

Experimental Run P1 was made on Septrmber 17, 1987 and ran 11 hours. Some 180 pounds of feedstock were processed. Complete process data were recorded by computer acquisition, and some key data are given here in Tables D8.1 and D8.2, and Figures D8.1 through D8.4.

The goal of this run was to ase the second stage recycle product obtained from Runs $\mathrm{O} 1$ and O2. as the carrier for fresh WF. Three concentrations of CO were used. At the initial start up no $\mathrm{CO}$ war fed. This lasted $31 / 2$ hours. A high concentration of $\mathrm{CO}$ was then fed for about 2 hours and tien normal amounts of $\mathrm{CO}$ was fed for the remainder of the run.

The feed mixture for this run consisted of recycled blend of Runs $\mathrm{O1}, \mathrm{O} 1$ and WF treated only with water (approximately $22 \mathrm{wt}$. \% moisture on a wet basis). The liquid products of the Runs $\mathrm{O} 1$ and $\mathrm{O} 2$ were mixed, crushed, and this served as the oil carrier for the WF in this run. A mixture of WF to regrind product of $40 \mathrm{wt} . \%$ solids were prepared ising pretreated WF with water only and heated at $60^{\circ} \mathrm{C}$ for 24 hours in sealed plastic bags in an oven. This run had a second round recycle of the product of Runs $\mathrm{O} 1$ and $\mathrm{O} 2$ which were the first round recycle of product of Runs N1 and N2. A total of approximately $180 \mathrm{lbs}$. of mix was fed at an average feed rate of $16.4 \mathrm{lbs} . / \mathrm{hr}$. The feed rate as a function of time of day is shown in Figure D8.1.

The total product obtained was $148.3 \mathrm{lbs}$. of which $46.75 \mathrm{lbs}$. were obtained when no CO was used, $33.25 \mathrm{lbs}$. were accumulated while a high flow rate of $\mathrm{CO}$ was used and $68.25 \mathrm{lbs}$. were obtained when a regular flow rate of $\mathrm{CO}$ was kept. The total condensate was $4.2 \mathrm{lbs}$.

\section{D8.2 Temperature and Pressure Data}

The operational conditions for Run'P1 were the same as for Runs N1, N2, O1 and O2 and the operation went smoothly for the entire run. In fact, the startup of the unit, which had material left from the previous Run $\mathrm{O} 2$, was also smooth as soon as normal operational conditions were achieved. Feed inlet temperature was kept below $95^{\circ} \mathrm{C}$ in the extruder-feeder. It should be mentioned that during normal operation the heaters on the extruder-feeder were off and all the heat was coming from viscous dissipation. Pressures throughout the system were maintained at approximately 1,000 psi. Pressure drops at liquid let-down times averaged 100 psi.

The temperatures at various locations of the extruder-feeder are shown in Table D8.1. A graphical presentation of the controller temperatures and in the melt at the mid-spool and top flange of the reactor are given in Figures D8.2 and D8.3, respectively. The reactor temperature was held on the low side at about $300-310^{\circ} \mathrm{C}$ during the last six hours of steady state operation. 


\section{D8.3 Co Supply}

Unlike in the case of Runs $\mathrm{O} 1$ and $\mathrm{O} 2$, during experimental Run P1 a high flow rate of $\mathrm{CO}$ was used since an adequate supply of $\mathrm{CO}$ was available at higher pressures. The total $\mathrm{CO}$ supply was $8.37 \mathrm{lbs}$. The flow rate as a function of time of day is given in Figure D8.4.

\section{D8.4 Analytical Results} $\mathrm{g} / \mathrm{cm}^{3}$.

A density test by the picometric method showed a density of the condensate of 1.06

A sample of the overhead condensate light wood oil had a heating value of $14,650 \mathrm{Btu} / \mathrm{lb}$.

The reactor products were measured for the percentage of solids using THF as a solvent and the solid contents were $43.5 \mathrm{wt} . \%, 43.5 \mathrm{wt} . \%$ and $46.8 \mathrm{wt} . \%$ for no CO in feed, for regular $\mathrm{CO}$ feed rate and for high $\mathrm{CO}$ feed rate respectively.

The elemental analysis for the distillates of the pressure let-down liquid product for the same three samples were:

\begin{tabular}{|c|c|c|c|c|}
\hline & Wt. $8 \mathrm{C}$ & Wt, $8 \mathrm{H}$ & Wt. 80 & $W t, z \mathrm{~N}$ \\
\hline $\begin{array}{l}\text { No Co } \\
\text { Regular flow rate co } \\
\text { High flow rate } C O\end{array}$ & $\begin{array}{l}80.62 \\
80.45 \\
80.39\end{array}$ & $\begin{array}{l}6.62 \\
6.00 \\
6.64\end{array}$ & $\begin{array}{l}10.87 \\
11.45 \\
10.82\end{array}$ & $\begin{array}{l}0.27 \\
0.26 \\
0.26\end{array}$ \\
\hline
\end{tabular}

\section{D8.5 Vacuum Distillation for Experimental Run P1}

Liquid let-down products of experimental Run P1 were vacuum distilled in order to determine the amount of liquid distillate in these products. The three different conditions of $\mathrm{CO}$ supply were tested. The amounts of distillate obtained were $13 \mathrm{wt} . \%, 10 \mathrm{wt} . \%$, and $20 \mathrm{wt} . \%$ for low, regular, and high flow rates of $\mathrm{CO}$, respectively. The material balance closures for these vacuum distillations were $100 \%, 94 \%$, and $97 \%$. More details on this experimental run are found in the August-October 1987 Quarterly Report. 


\section{D9.0 EXPERIMENTAL RUN Q1}

\section{D9.1 General Description of the Experimental Run}

Experimental Run Q1 (made on March 7, 1988) was the first experimental run using the new FIX software program. Data acquisition is one important feature of the FIX, and from here on much data was reported as tables and graphs directly from the FIX data base of various experimental data. A total of $125 \mathrm{lb}$. of feedstock of $60 / 40 \mathrm{wt}$. ratio of wood oil TR-9 to treated wood flour was fed during this experiment.

The temperatures at various locations of the unit are given in Tables D9.1 and D9.2. One can see that the temperatures are quite constant except for a short drop in the cross temperature which was easily fixed. Details about this experiment are found in the February-April 1988 Quarterly Report.

\section{D10.0 EXPERIMENTAL RUN Q2}

\section{D10.1 General Description of the Experimental Run}

Run Q2 was made on March 11th, 1988 and lasted 6 hours. The temperatures as a function of time are given in Tables D10.1 and D10.2. The temperatures in the reactor at steady state was held at about $370^{\circ} \mathrm{C}$ (see temperature lines B and E on Figure D10.1).

\section{D10.2 Analytical Results}

Samples of the pressure let-down liquid product were taken for analysis of heating values and it was found to be $15,220 \mathrm{BTU} / \mathrm{lb}$. By extracting the samples with THF solvent $30 \mathrm{wt}$.\% of insolubles were obtained. The elemental analysis for the product was:

$$
\begin{array}{lccc}
\text { Wt. } 8 \mathrm{C} & \text { Wt. } 8 \mathrm{H} & \text { Wt. } 80 & \text { Wt. } 8 \mathrm{~N} \\
83.1 & 6.3 & 9.2 & 0.2
\end{array}
$$

Details on this experimental run can be found in the February-April 1988 Quarterly Report. 


\section{D11.0 EXPERIMENTAL RUN Q3}

\section{D11.1 General Description of the Experimental Run}

A good run was made on March 14, 1988 (Run Q3) which lasted 8.5 hours. The feedstock was $98 \mathrm{lb}$. of a 50/50 weight ratio of TR9 to wood flour and was later $10 \mathrm{lb}$. of a 60/40 wt. ratio of Q1-and-Q2 product to wood flour when the 50/50 wt. ratio was depleted. Complete process data were recorded by using the FIX software, and a few key data are given here as in Tables D11.1 and D11.2 and Figures D11.1 and D11.2.

There were 33 liquid product pressure let-downs, each one 20-25 minutes apart. CO was fed into the unit via the $\mathrm{CO}$ compressor. No problems were encountered as long as the inlet pressure to the first stage was kept at around 100 psi. This was controlled by a metering valve between the gas cylinder and the first stage of the compressor. The weight of the product was $66.6 \mathrm{lb}$. The extruder-feeder was run at $100 \mathrm{rpm}$. Total gas through the system was $111.3 \mathrm{ft}^{3}$ at atmospheric pressure. Liquid condensate was $825 \mathrm{ml}$ of a mixture of oil and water. The pressure in the reactor was controlled above 2000 psi, as seen on Figure D11.1, except during the liquid product let-down periods when it decreased slightly below this level.

The temperatures as a function of time are given in Tables D11.1 and D11.2. All temperatures were quite constant (as seen as B and E on Figure D11.2), holding the reactor temperature at almost $400-410^{\circ} \mathrm{C}$.

\section{D11.2 Analytical Results}

Samples were taken from the pressure let-down liquid products of experimental Run Q3, and analyzed for their heating values, solid content and elemental analysis.

The heating value obtained for the product was $14,000 \mathrm{BTU} / \mathrm{lb}$.

By extracting the product sample by THF solvent, the insoluble solid content was found to be 17 wt. \%.

The elemental analysis was:

$\begin{array}{llll}\text { Wt. } 8 \mathrm{C} & \text { Wt. } 8 \mathrm{H} & \text { Wt. } 8 \mathrm{O} & \text { Wt. } 8 \mathrm{~N} \\ 78.30 & 6.40 & 15.30 & 0.20\end{array}$

Details about this experiment are found in the February-April 1988 Quarterly Report. 


\section{D12.0 EXPERIMENTAL RUN R1}

\section{D12.1 General Description of the Experimental Run}

Experimental Run R1 was made on June 3rd, 1988 and lasted 7 hours. One unique feature of this run was operating above the critical temperature of water $\left(387^{\circ} \mathrm{C}\right)$. A temperature of nearly $500^{\circ} \mathrm{C}$ existed in the upper reactor, but the pressure was controlled at about $2,000 \mathrm{psi}$, such a larger amount of oil product was probably carried overhead. During this run $54 \mathrm{lbs}$. of feedstock was fed into the reactor. The feedstock was 50/50 wt. ratio of TR9/WF. The feeding was at an average feed rate of about $10 \mathrm{lb} / \mathrm{hr}$ and the feeding as a function of time is shown on Figure D12.1. The run was terminated by a plug in the reactor outlet line and was attributed to a faulty heater on that line. However, the plug may have been caused by operating in the critical region.

The first part of the extruder-feeder was maintained at a temperature less than $100^{\circ} \mathrm{C}$ by using dry ice and water with the aid of a cooling coil added to the feeding part of the extruderfeeder. Liquid product pressure let-down were performed every 20 minutes, and the product was admitted into the product surge tank. Approximately 200 psi pressure was released each time a pressure let-down was performed. The inlet CO was monitored and kept between 100-150 psi at the compressor inlet. Connections were made at the $\mathrm{CO}$ tanks located in the rear of the complex. A total of $54 \mathrm{lbs}$. of feedstock was fed to the reactor and $32 \mathrm{lb}$. product was obtained. Also $9.2 \mathrm{ft}^{3}$ of gases were released and $470 \mathrm{~g}$ of condensate were obtained. The difference can be accounted for largely by the hold-up inside the reactor. A UA Risk Management representative also attended this run and took air samples in order to check the CO emission from the process. A maximum CO level of $12 \mathrm{ppm}$ was measured in the process area, which is a reasonable concentration and within the permissible range.

\section{D12.2 Pressure and Temperature Data}

The computer system using the FIX software system performed the data acquisition and process control. The temperatures as a function of time are given in Tables D12.1 and D12.2. The temperatures were quite constant as seen on Figure D12.2 except for the thermocouple on the upper reactor which fluctuated wildly throughout the run but did not affect the other temperatures.

The pressures as a function of time for the liquid product pressure let-downs are given in Tables D12.3. Some pressure profiles for the extruder-feeder are shown in Table 12.4.

\section{D12.3 Carbon Monoxide Feeding}

Feeding of $\mathrm{CO}$ proceeded smoothly during the entire run. About $20 \mathrm{lb}$. of $\mathrm{CO}$ was fed instead of the normal rate of $12 \mathrm{lb}$. The cumulative amount of $\mathrm{CO}$ fed into the system as a function of time is shown in Figure D12.4. Report.

More details about this experimental run are found in the May-July 1988 Quarterly 


\section{D13.0 EXPERIMENTAL RUN R4}

\section{D13.1 General Description of the Experimental Run}

Experimental Run R4 was made on June 16 and continued uninterrupted to June 17, 1988, over a total of 17-1/2 hours. The initial feed was a mixture of $50 \mathrm{wt} . \%$ wood flour and $50 \mathrm{wt} . \%$ TR9. However, since we had some problems with the feeding, another feedstock of $60 \mathrm{wt} . \% / 40$ wt. \% of TR9/wood flour was used.

This feedstock fed with good operability. Around $25 \mathrm{lb}$. were fed in two hours of operation at 3000 psi reactor pressure. Some of the $60 / 40$ wt. ratio to TR9 to WF mixture was then blended with new 50/50 wt. ratio of TR9 to WF thus yielding around $50 \mathrm{lb}$. of feedstock of the composition of 55/45 wt. ratio of TR9/WF. This 55/45 wt. ratio feed mixture was fed for 4 hours at pressures of 2500 psi-3000 psi with good results, with low extruder-feeder amperage and with no plugs. Due to the long run, this feedstock was exhausted and the run was continued by feeding $30 \mathrm{lb}$. of 70/30 wt. ratio of TR9/WF for the final 2 hours. Three shifts were used, and $100 \mathrm{lb}$. of material was fed during the seventeen and one-half hour run. During the run some $70 \mathrm{lb}$. of pressure let-down liquid product was obtained, as well as some $750 \mathrm{ml}$ of overhead liquid condensate which appeared to be mostly water. The feeding as a function of time is shown on Figure D13.1. The product was then distilled and 10\% was topped off. The vacuum bottoms were used as carrier to experimental Runs S1 and S2 to follow.

\section{D13,2 Carbon Monoxide Feeding}

Although the CO feeding seemed to go smoothly, analysis of the data showed that only small amounts of $\mathrm{CO}$ were fed during the run totalling approximately $8 \mathrm{lb}$. On dismantling the $\mathrm{CO}$ system after the run, a partial plug in the $\mathrm{CO}$ line was found, which had prevented smooth CO feeding.

\section{D13.3 Temperature and Pressure Data}

The goal of this run was to operate at $375^{\circ} \mathrm{C}$ and 3000 psi. The extruder-feeder, lower reactor, upper reactor, and liquid product pressure let-down vessel were set at their usual temperatures of $125^{\circ} \mathrm{C}, 375^{\circ} \mathrm{C}$, and $200^{\circ} \mathrm{C}$, respectively. The extruder-feeder operated at a slightly higher temperature because of its self-generating heat. As usual, the feed end of the extruder-feeder needed to be cooled in order to ensure proper feeding. A new water spray coil which was installed at this feed end of the extruder-feeder was used, and was operated semiautomatically from the control room. Complete data on temperatures as a function of time at various locations on the unit is given in Table D13.1 and is shown diagrammatically on Figure D13.2. On Figure D13.3 temperature profiles for a relatively steady state period of time are shown. Pressures as a function of time are shown on Figure D13.4 and D13.5. The relatively steady state period between 8:00 p.m. July 16 and 2:00 a.m. on July 17 is shown on Figure D13.5.

More details on this experimental run are found in the May-July 1988 Quarterly Report. 


\section{D14.0 EXPERIMENTAL RUN S1}

\section{D14.1 General Description of the Experimental Run}

Run S1 was made on July 13,1988, when a new overhead line elbow was installed with a temperature/pressure port in it. Another major improvement for this run was the use of a screw-feeder hopper to feed the extruder-feeder at a constant rate of $13 \mathrm{lbs} / \mathrm{hr}$. Before this modification feeding was batchwise to the extruder-feeder, which then provided a continuous output. It should be noted that project improvements were being made rapidly from several points of view. Several process equipment changes combined with the FIX software program greatly increased operability. Feedstock preparation including pretreatments resulted in having much larger inventories of feedstocks, which in turn permitted much longer runs. The installation of a large batch vacuum distillation unit allowed experimental operations in a more realistic recycle mode. The real-time computer control of the CO compression allowed optimum use of this $\mathrm{CO}$ reactant.

The feedstock for this run was a mixture of 50:50 wt.\% of wood flour pretreated with sodium carbonate and the reactor effluent that had been passed through the reactor three times (product from Run P1), plus vacuum bottoms from the vacuum distillation of the previous Run R4 effluent. Two vacuum distillation runs were made with the reactor effluent product from Run $S 1$. In each case, $10 \mathrm{lbs}$. of material were processed. In the first case temperatures up to $425^{\circ} \mathrm{C}$ and a vacuum of up to $100 \mathrm{mmHg}$ abs. were utilized, which yielded $1,200 \mathrm{~cm}^{3}$ of wood oil distillate. In the second case where only $260^{\circ} \mathrm{C}$ was set and a vacuum of $10 \mathrm{~mm} / \mathrm{Hg}$ abs. were utilized, the yield was $750 \mathrm{ml}$ wood oil distillate. The reactor effluents of Run S1 and Run S2, to follow, were vacuum distilled in order to produce a large quantity of an All-Arizona crude wood oil.

The feeding started at around 13:00 p.m., and the pressure steadily increased, except for the periods of liquid product pressure let-downs, to over $2000 \mathrm{psi}$. At these pressures, a leak developed in the top of the liquid product pressure let-down vessel preventing it from reaching higher pressure.

\section{D14.2 Pressure and Temperature Data}

When the liquid product valve froze in the open position, the pressure was released through the vent line, and the unit was shut down. Data on temperatures are given in Tables D14.1 and D14.2 and data on pressures are given in Table D14.3. Diagrammatic representation of temperatures and pressures at various locations in the unit are given in Figures D14.1 D14.5.

\section{D14.3 Carbon Monoxide Feeding}

The carbon monoxide feeding system was working poorly due to a plug of the line into the reactor. During this run, an estimated total of $4 \mathrm{lbs}$. of $\mathrm{CO}$ was fed.

Details on this experimental run are found in the May-July 1988 Quarterly Report. 


\section{D15.0 EXPERIMENTAL RUN S2}

\section{D15.1 General Description of the Experimental Run}

The last experimental Run S2 for this project was made on July 20, 1988 and lasted for 11 hours. This was a very good run with minor trouble-shooting type of problems. The experimental unit was not moth-balled, because plans at that time were to transfer project management to SERI effective October 1, 1988, to complete the project in two to three years.

Before starting Run S2, the entire system was cleaned and checked. Also, several additions were made, such as five new channels of data acquisition, three thermocouples on the extruder-feeder, a new pressure transducer on the middle spool, and a pressure transducer which reads the $\mathrm{CO}$ compressor inlet pressure. Feeding of $\mathrm{CO}$ was started approximately after $3 \mathrm{lbs}$. of feedstock material was fed into the system, thus eliminating the possibility of CO flowback through the extruder-feeder.

Feeding proceeded smoothly throughout the run, and a total of $200 \mathrm{lbs}$. were fed during the run. The pressure then increased to around 2900 psi with some fluctuations around an average pressure of 2650 psi. The pressures as a function of time at different locations in the unit are given in Table D15.1 and are shown schematically on Figure D15.1.

The temperatures for this run generally started high and finished lower, due to a heavy heat load on the reactor. When feeding started the upper reactor was at $428^{\circ} \mathrm{C}$ and the lower reactor was at $454^{\circ} \mathrm{C}$. By the end of the run the lower reactor had dropped to just below $300^{\circ} \mathrm{C}$. The extruder-feeder was controlled at $170^{\circ} \mathrm{C}$ at the outlet while the inlet temperature was kept below $80^{\circ} \mathrm{C}$ by spraying water on the barrel. The temperature as a function of time at various locations of the unit are given in Table D15.2, D15.3, and D15.4 and are shown diagrammatically for several locations in Figure D15.2 and D15.3.

\section{D15.2 Carbon Monoxide Feeding}

The special design for the low flow rate carbon monoxide injection system worked perfectly during the entire run. A total of $28 \mathrm{lbs}$. of $\mathrm{CO}$ was fed during this run.

\section{D15.3 Power Input to the Extruder-Feeder}

Except for the initial preheating of the extruder-feeder the power of the heater bands of the extruder-feeder were off much of the time and the heat was obtained from viscous dissipation. In fact many times water was sprayed over the barrel of the extruder-feeder in order to keep the temperature down to the level that would provide the proper viscosity to the melt thus enabling proper pumpability of the extruder-feeder. However, due to overcooling and other transient effects the controller would activate the heater as shown on Figure D15.4.

Details on this experimental run are found in the May-July 1988 Quarterly Report. 


\section{DISTRIBUTION}

No. of

No. of

Copies

Copies

\section{OFFSITE}

12 DOE/Office of Scientific and Technical Information

\section{R. Annan \\ Office of Solar Energy Conversion}

U.S. Department of Energy

Forrestal Building (CE-13)

1000 Independence Avenue

Washington, D.C. 20585

\section{J. Allsup \\ Office of Alternative Fuels U.S. Department of Energy Forrestal Building (CE-33) 1000 Independence Avenue Washington, D.C. 20585}

\author{
W. Ayres \\ Pyrotech, Inc. \\ 8016 Stateline \\ Suite 101 \\ Leawood, KS 66208 \\ S. Babu \\ Institute of Gas Technology \\ IIT Center \\ 3424 South State Street \\ Chicago, IL 60616 \\ P. Badger \\ Southeastern Regional Biomass \\ Energy Program \\ Tennessee Valley Authority \\ CEB 4W 436A-M \\ Muscle Shoals, AL 35660 \\ N. Banns \\ Onsite*0fsite, Inc. \\ 2500 East Foothill Blvd. \\ Suite 201 \\ Pasadena, CA 91107
}

K. Birkinshaw

California Energy Commission 1516 - 9th Street, MS-43

Sacramento, CA 95814

H. Clark

American Society of Mechanical

Engineers

1825 K Street N.W., Suite 216

Washington, D.C. 20006-1202

R. Costello

Biofuels Systems Division

U.S. Department of Energy

Forrestal Building (CE-331)

1000 Independence Avenue

Washington, D.C. 20585

J. Diebold

Solar Energy Research Inst.

1617 Cole Bivd.

Golden, CO 80401

K. Durai-Swamy

Manufacturing and Technology

Conversion International, Inc.

13080 Park Street

Santa Fe Springs, CA 90670

V. Flanigan

223 Engineering Research Lab. University of Missouri-Rolla

Rolla, MO 65401

G. Fleischman

Bureau of Energy

Idaho Department of Water

Resources

1301 N. Orchard St.

Boise, ID 83706 
P. Fox

Pacific Northwest and Alaska

Regional Biomass Energy Program

Bonneville Power

Administration

P.0. Box 3621

Portland, OR 97208

S. Friedrich

Waste Material Management

Division

U.S. Department of Energy

Forrestal Building (CE-222)

1000 Independence Avenue

Washington, D.C. 20585

B. Goodman

Solar Energy Research

Institute

1617 Cole Blvd.

Golden, CO 80401

S. Gronich

Solar Thermal \& Biomass Power

Division

U.S. Department of Energy

Forrestal Building (CE-132)

1000 Independence Avenue

Washington, D.C. 20585

J. Hamrick

Aerospace Research Corporation

5454 Jae Valley Rd., S.E.

Roanoke, VA 24014

W. Densmore Hunter

Manager, Energy Technology

Department

Weyerhaeuser Company

WTC-1B-30

Tacoma, WA 98477

J. Kadyszewski

Winrock International

611 Kent St. Suite 600

Arlington, VA 22209-2134
J. Kerstetter

Washington State Energy Office

State of Washington

809 Legion Way S.E., ER-11

Olympia, WA 98504-1211

D. Kirchgessner

Global Warming Control Branch

U.S. Environmental Protection Agency

Research Triangle Park, NC 27711

D. Klass

Institute of Gas Technology

IIT Center

3424 South State Street

Chicago, IL 60616

F. Kuzel

Council of Great Lakes

Governors

310 South Michigan Ave.

Chicago, IL 60604

E. Larson

Center for Energy and Environmental Studies

Engineering Quadrangle

Princeton University

Princeton, NJ 08544-5263

M. Mansour

Manufacturing \& Technology Conversion International, Inc.

P.0. Box 21

Columbia, MD 21044

P. Mathusa

Program Director

New York State Energy Research and Development Authority

2 Rockefeller Plaza

Albany, NY 12223 
T. Miles

Consulting Engineer

5475 S.W. Arrowwood Lane

Portland, OR 97225

\section{T. Milne \\ Solar Energy Research \\ Institute \\ 1617 Cole Bivd. \\ Golden, CO 80401}

\section{R. Moorer \\ Biofuels Systems Division \\ U.S. Department of Energy \\ Forrestal Building (CE-331) \\ 1000 Independence Avenue \\ Washington, D.C. 20585}

R. O'Connell

CONEG Policy Research Center, Inc.

400 N. Capital Street, NW

Washington, DC 20001

D. O'Neil

Georgia Tech Research Institute

Georgia Institute of

Technology

Atlanta, GA 30332-0420

R. Overend

Solar Energy Research

Institute

1617 Cole Blvd.

Golden, CO 80401

M. Paisley

Battelle-Columbus Division

$505 \mathrm{King}$ Avenue

Columbus, $\mathrm{OH} 43201$

J. Roethell

Office of Critical Materials

U.S. Department of Agriculture

342 Aerospace Building

Washington, DC 20250-2200
R. San Martin

Deputy Assistant Secretary

Office of Utility Technology

Forrestal Building

1000 Independence Avenue, SW

Washington D.C. 20585

M. Scheve

Solar Thermal \& Biomass Power Division

U.S. Department of Energy

Forrestal Building (CE-132)

1000 Independence Avenue

Washington, DC 20585

G. Simons

California Energy Commission

1516 - 9th Street, MS-43

Sacramento, CA 9581

S. Sobczynski

Division of Improved Energy Productivity

U.S. Department of Energy

Forrestal Building CE-231

1000 Independence Avenue

Washington, DC 20585

D. Stevens

Cascade Research, Inc. 2952 George Washington Way

Richland, WA 99352

C. Sullivan

Electric Power Research Institute

P. 0. Box 10412

Palo Alto, CA 94303

D. Swanson

Western Regional Biomass Energy Program

Western Area Power Administration

P.0. Box 3402

Golden, CO 80401 
E. Taylor

Corporate Manager,

Energy \& Environmental Affairs

Louisiana-Pacific Corporation

P.0. Box 158

Samoa, CA 95564

C. Wallace

Solar Energy Research

Institute

409 12th St. S.W., Suite 710

Washington, DC 20024

D. Walter

Waste Material Management

Division

U.S. Department of Energy

Forrestal Building (CE-222)

1000 Independence Avenue

Washington, D.C. 20585

E. Wan

Science Applications

International Corporation

1710 Goodridge Drive

McLean, VA 22102

25

D. White

Department of Chemical

Engineering

University of Arizona

Geology Building

Tucson, AZ 85721

R. Williams

Center for Energy and

Environmental Studies

Princeton University

Princeton, NJ 08544

\section{FOREIGN}

D. Asplund

Valtion Teknillinen

Tutkimuseskus

Statens Tekniska

Forskningscentral

Technical Research Centre of Finl and

P.0. Box 221 ..

SF-40101 Jyvaskyla 10

FINLAND

T. Bridgwater

The University of Aston in Birmingham

Dept. of Chemical Engineering

Gosta Green

Birmingham

ENGLAND B4 7ET

J. Fredriksson

Department of Thermal Engineering

The Royal Institute of Technology

S-100 44 Stockholm,

SWEDEN

E. Rensfelt

Department of Fuel Technology Studsvik Energiteknik $A B$

S-611 82 Nykoping,

SWEDEN

\section{ONSITE}

DOE Field office, Richlaid

E. Norman A5-10

10 Pacific Northwest Laboratory

D. Elliott K2-40

M. Gerber P8-38

G. Schiefelbein (2) P8-38

Publishing Coordination

Technical Report Files 

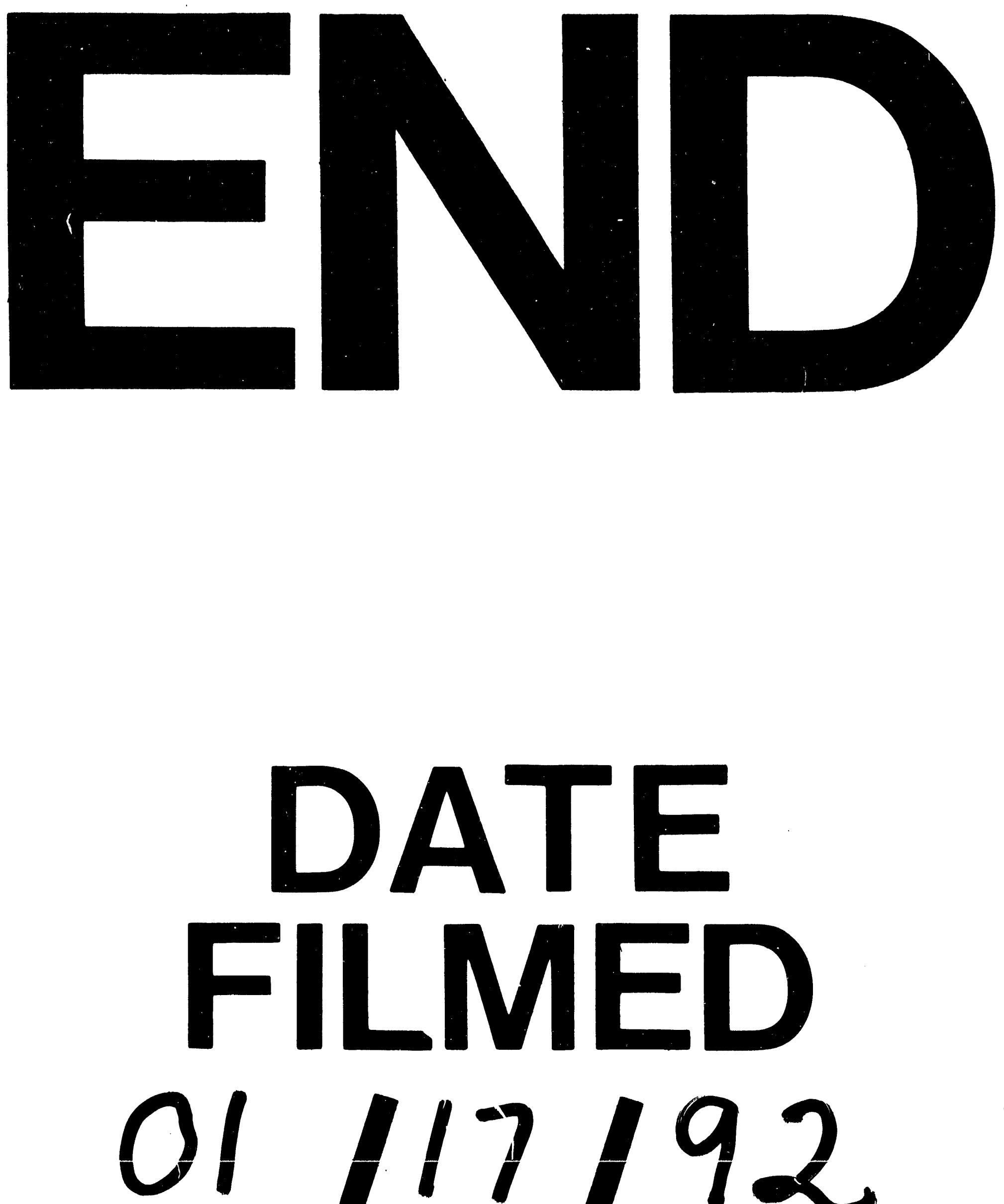

1

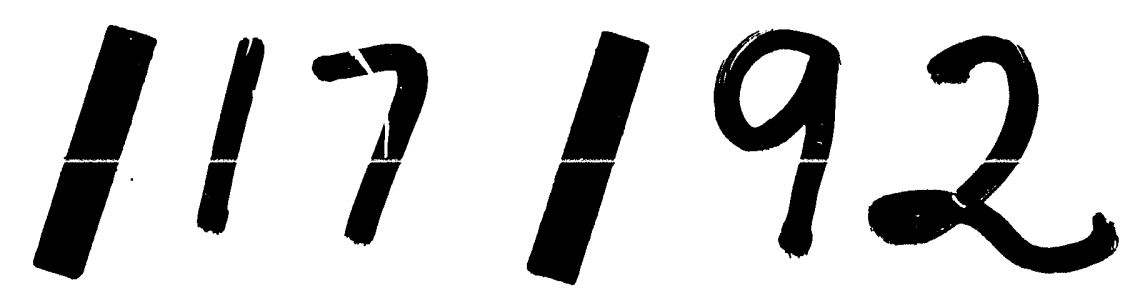


